\title{
Effects of plant sterol and stanol esters on oxyphytosterol concentrations and postprandial metabolism
}

Citation for published version (APA):

Baumgartner, S. (2015). Effects of plant sterol and stanol esters on oxyphytosterol concentrations and postprandial metabolism. [Doctoral Thesis, Maastricht University]. Uitgeverij BOXPress.

https://doi.org/10.26481/dis.20150211sb

Document status and date:

Published: 01/01/2015

DOI:

10.26481/dis.20150211sb

Document Version:

Publisher's PDF, also known as Version of record

Please check the document version of this publication:

- A submitted manuscript is the version of the article upon submission and before peer-review. There can be important differences between the submitted version and the official published version of record.

People interested in the research are advised to contact the author for the final version of the publication, or visit the DOI to the publisher's website.

- The final author version and the galley proof are versions of the publication after peer review.

- The final published version features the final layout of the paper including the volume, issue and page numbers.

Link to publication

\footnotetext{
General rights rights.

- You may freely distribute the URL identifying the publication in the public portal. please follow below link for the End User Agreement:

www.umlib.nl/taverne-license

Take down policy

If you believe that this document breaches copyright please contact us at:

repository@maastrichtuniversity.nl

providing details and we will investigate your claim.
}

Copyright and moral rights for the publications made accessible in the public portal are retained by the authors and/or other copyright owners and it is a condition of accessing publications that users recognise and abide by the legal requirements associated with these

- Users may download and print one copy of any publication from the public portal for the purpose of private study or research.

- You may not further distribute the material or use it for any profit-making activity or commercial gain

If the publication is distributed under the terms of Article $25 \mathrm{fa}$ of the Dutch Copyright Act, indicated by the "Taverne" license above, 
Effects of plant sterol and stanol esters on oxyphytosterol concentrations and postprandial metabolism 


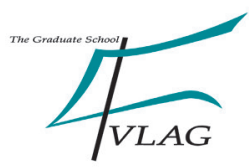

The studies presented in this thesis were performed within NUTRIM School for Nutrition, Toxicology \& Metabolism, which participates in the Graduate School VLAG (Food Technology, Agrobiotechnology, Nutrition and Health Sciences), accredited by the Royal Netherlands Academy of Arts and Sciences.

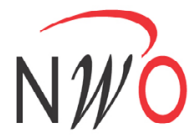

Netherlands Organisation for Scientific Research

The studies described in this thesis were supported by a grant from the Netherlands Organisation for Scientific Research (NWO) (TOP grant no. 912-08-006).

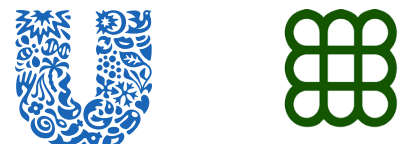 \\ Unilever RAISIO Agilent Technologies}

Financial support by Unilever, RAISIO and Agilent Technologies for the publication of this thesis is gratefully acknowledged.

Cover design: Paul Voncken - Founder/Designer at noos design

Layout: Proefschriftmaken.nl || Uitgeverij BOXPress

Printed by: Proefschriftmaken.nl || Uitgeverij BOXPress

(C) Sabine Baumgartner, Maastricht 2015

ISBN 978-94-6295-074-0 


\title{
Effects of plant sterol and stanol esters on oxyphytosterol concentrations and postprandial metabolism
}

\author{
PROEFSCHRIFT \\ Ter verkrijging van de graad van doctor \\ aan de Universiteit Maastricht \\ op gezag van de Rector Magnificus Prof. dr. L.L.G. Soete, \\ volgens het besluit van het College van Decanen, \\ in het openbaar te verdedigen \\ op woensdag 11 februari 2015 om 14.00 uur
}

door

Sabine Baumgartner

geboren te Heerlen op 25 december 1985 


\section{Promotores}

Prof. dr. J. Plat

Prof. dr. ir. R.P. Mensink

\section{Beoordelingscommissie}

Prof. dr. A.A.M. Masclee (voorzitter)

Prof. dr. E.E. Blaak

Prof. dr. F-J. van Schooten

Prof. dr. E.A. Trautwein (Unilever Food and Health Research Institute, Vlaardingen, the Netherlands)

Dr. O. Weingärtner (Abteilung für Kardiologie, Klinikum Oldenburg, European-Medical School OldenburgGroningen, Carl von Ossietzky Universität, Oldenburg, Germany) 


\section{Content}

Chapter $1 \quad$ General introduction 7

Chapter 2 Plant sterols and stanols in the treatment of dyslipidaemia:

new insights into targets and mechanisms related to cardiovascular risk 19

Chapter 3 Effects of plant sterol or stanol enriched margarine on fasting

plasma oxyphytosterol concentrations in healthy subjects

Chapter 4 Oxyphytosterol formation in humans:

identification of high vs. low oxidizers

Chapter 5 Postprandial plasma oxyphytosterol concentrations after consumption

of plant sterol or stanol enriched mixed meals in healthy subjects

Chapter 6 Effects of a plant sterol or stanol enriched mixed meal on postprandial lipid and glucose metabolism in healthy subjects

Chapter 7 Effects of vitamin E or lipoic acid supplementation on fasting oxyphytosterol concentrations in subjects with impaired glucose tolerance or type II diabetes

Chapter 8 General Discussion

Summary

Samenvatting

Appendix Dankwoord

Curriculum Vitae

List of publications 



\section{CHAPTER 1}

General Introduction 


\section{Introduction}

Cardiovascular disease (CVD) is a collective term to describe disorders of the heart and blood vessels such as angina pectoris, myocardial infarction, stroke and transient ischemic attack. One of the underlying cause of CVD is atherosclerosis, which is a slow, chronic and continuing process that starts with the formation of fatty streaks at an early age and eventually results in plaque formation within the vessel walls [1]. Endothelial dysfunction and inflammatory responses play a central role in the development of atherosclerosis, resulting in an increased permeability of the endothelial layer. This allows atherogenic lowdensity lipoprotein (LDL) particles to migrate into the underlying intima layer, where they subsequently can be oxidized. Accumulated oxidized LDL particles in the endothelial wall will stimulate the expression of adhesion molecules, attracting monocytes that can migrate into the intima layer and can transformed into macrophages. Oxidized LDL particles are taken up by macrophages and will form lipid-loaded foam cells, creating a viscous cycle of inflammatory responses with secretion of cytokines and growth factors. Ultimately, an advanced complicated lesion is formed, covered by a fibrous cap consisting of fibrous tissue, smooth muscle cells, platelets and macrophages, which can obstruct arterial blood flow. When an atherosclerotic lesion ruptures, it can form a thrombus and cause a myocardial or cerebrovascular infarction [2, 3].

The risk to develop atherosclerotic lesions is influenced via many factors, such as cigarette smoking, high blood pressure, diabetes mellitus and obesity. Another important CVD risk factor is an unfavourable lipoprotein profile, which is characterized by increased LDL-cholesterol (LDL-C) concentrations, increased triacylglycerol (TAG) concentrations and/or decreased high-density lipoprotein cholesterol (HDL-C) concentrations. For this reason, reducing LDL-C concentrations is the major target in CVD prevention [4]. Elevated serum LDL-C concentrations can be lowered via lifestyle changes and if necessary via pharmacological treatment. The most widely prescribed drugs are statins, which are able to lower LDL-C concentrations up to $50 \%$. More dramatic decreases in LDL-C concentrations can be achieved by targeting PCSK9, which is a protein secreted by hepatocytes and regulates LDL receptor breakdown. Antibodies to PCSK9 are in clinical trial development and LDL-C reductions of $60 \%$ were seen in hypercholesterolemic patients, while reductions up to $70 \%$ were achieved in statin-treated patients $[5,6]$.

Subjects suffering from mild hypercholesterolemia do not qualify for pharmacological treatment and are able to achieve more modest LDL-C reductions through dietary changes. In addition, subjects on statins not meeting their LDL-C goals or subjects suffering from statin intolerance might also benefit from dietary changes to lower LDL-C concentrations [7]. Changing the composition of the diet and adding specific foods or food components (so-called functional foods) to the daily diet improves an unfavourable lipoprotein profile. Nowadays, functional foods are widely incorporated with a variety of health-promoting activities. 


\section{Plant sterols and plant stanols as cholesterol-lowering functional foods}

The enrichment of foods with plant sterol and plant stanol esters is one of the first examples of functional foods that demonstrated a clear health benefit, i.e. lowering serum total and LDL cholesterol concentrations. Plant sterols and plant stanols share structural similarities with cholesterol. They consist of a steroid nucleus with a double bond present at C5-C6 while only the side-chain configuration differs. Plant stanols are the saturated derivative of plant sterols (Figure 1.1). Plant sterols and plant stanols are naturally occurring constituents of plants and are present in our daily diet. They are found in vegetable oils, such as corn oil, soybean oil, and rapeseed oil and they are also present in cereals, nuts, fruit and vegetables. The average intake of plant sterols and plant stanols in Western countries is approximately $300 \mathrm{mg} /$ day, but can be as high as $600 \mathrm{mg} /$ day in vegetarians. The most abundant plant sterols in the human diet are $\beta$-sitosterol, campesterol and stigmasterol, while plant stanols are less abundant and consist mainly of sitostanol and campestanol [8]. Serum plant sterol and plant stanol concentrations are the result of intestinal absorption and biliary secretion, since humans cannot synthesize plant sterols and plant stanols. Their fractional absorption rate is very low $(0.5-2.0 \%$ for plant sterols and $0.04-0.2 \%$ for plant stanols) and biliary secretion is high, which results in serum concentrations of plant sterols and plant stanols that are less than $1 \%$ of that of serum cholesterol. On average, plasma sitosterol concentrations range from 0.16 to $0.67 \mathrm{mg} / \mathrm{dL}$ and campesterol concentrations from 0.28 to $1.12 \mathrm{mg} / \mathrm{dL}$ [9], while plasma plant stanol concentrations are approximately 100 times lower and vary between 2 and $12 \mathrm{ug} / \mathrm{dL}$ in the normal population [10].<smiles>CC(C)CCC[C@H](C)[C@H]1CCC2C3CC=C4C[C@@H](O)CC[C@]4(C)[C@H]3CC[C@]21C</smiles><smiles>CCC(C)CCC(C)[C@H]1CCC2C3CC=C4C[C@@H](O)CC[C@]4(C)[C@H]3CC[C@]21C</smiles><smiles>CCC(C)CC[C@H](C)[C@H]1CCC2C3CC[C@@H]4C[C@@H](O)CC[C@]4(C)C3CC[C@]21C</smiles><smiles>CC(C)CCC(C)[C@H]1CCC2C3CC=C4C[C@@H](O)CC[C@]4(C)C3CC[C@]21C</smiles><smiles>CC(C)CCC(C)[C@H]1CCC2C3CCC4C[C@@H](O)CC[C@]4(C)C3CC[C@]21C</smiles>

Figure 1.1 Chemical structures of cholesterol, plant sterols and plant stanols. 
The LDL-C lowering effect of plant sterols and plants stanols has been demonstrated in numerous studies and has resulted in the recommendations to consume plant sterol and plant stanol enriched products in current dietary guidelines [11]. Plant sterols or plant stanols are able to reduce serum LDL-C concentrations by decreasing intestinal cholesterol absorption, which results in an increased endogenous cholesterol synthesis rate and an upregulation of LDL receptor expression. Large meta-analyses have shown that consuming approximately $2.5 \mathrm{~g} /$ day of plant sterols or plant stanols lowers serum LDL-C concentrations up to $10 \%$. At doses up to $3.0 \mathrm{~g} /$ day, plant sterols and plant stanols have been shown to have a comparable LDL-C lowering efficacy, while there are discrepancies between the efficacy of plant sterols and plant stanols at higher intakes. However, studies specifically designed to answer this question are lacking and therefore conclusions regarding relative efficacy of plant sterols and plant stanols at higher intakes cannot be drawn. Plant sterol and plant stanol enriched products have been shown to lower LDL-C concentration in different populations and incorporated into different matrices as extensively reviewed $[11,12]$. While reduced LDL-C concentrations after plant sterol and plant stanol consumption have been unequivocally proven, there is a lack of hard endpoint studies evaluating the clinical benefit from the consumption of plant sterol and plant stanol enriched products.

\section{Potential atherogenicity of plant sterol and plant stanol consumption}

Consuming plant sterol enriched products will increase serum plant sterol concentrations, while the consumption of plant stanols will decrease plant sterol concentrations. A recent meta-analysis reported average increases in sitosterol concentrations of $31 \%$ ( $\mathrm{Cl}: 26-37 \%)$ and increases in campesterol concentrations of $37 \%$ (Cl: 29-45) after consumption of plant sterol enriched products [13]. Phytosterolemia is a rare genetic sterol storage disease that is characterized by dramatic increases in serum plant sterol concentrations, ranging from 10-65 mg/dL, while serum cholesterol concentrations are normal or only slightly increased. Patients suffering from this disease often develop tendon and tuberous xanthomas and some patients develop premature atherosclerosis, while other patients do not show any signs of CVD, complicating the association between increased plant sterol concentrations and CVD risk [14]. The disease is caused by a mutation in the ABCG5/8 half transporters, resulting in a decreased secretion of absorbed sterols from the enterocytes back into the lumen, as well as a reduction from the liver into bile. In healthy subjects, increases after plant sterol consumption remain within the normal range $(<1.0 \mathrm{mg} / \mathrm{dL})$ and are only marginal as compared to plant sterol concentrations observed in phytosterolemic subjects. However, the potential impact of these elevated circulating plant sterol concentrations on cardiovascular risk is currently hotly debated. Several prospective and cross-sectional epidemiological studies evaluated the potential relationship between circulating plant sterol concentrations and CVD risk with contradictive results. Genser et al. performed a systematic review based upon 17 epidemiological studies $(n=11.182)$ and did not find an 
association between serum concentrations of plant sterols and elevated risk of CVD [15]. Serum plant sterol concentrations are surrogate markers for intestinal absorption and might underlie the potential association between increased plant sterol concentrations and CVD risk as shown by Silbernagel et al. in a recent study [16]. They identified an atherogenic role for high intestinal cholesterol absorption rather than for increased circulating plant sterol concentrations, based on the cholestanol-to-cholesterol ratio. Cholestanol is a derivative of cholesterol and produced by the liver and often used as a surrogate marker for cholesterol absorption. However, the validity of this marker has recently been questioned since cholestanol is also present in diet (less than $2 \mathrm{mg} /$ day) and it does not reflect cholesterol absorption under certain conditions such as impaired biliary secretion [17, 18]. Although cholestanol concentrations correlated with fraction cholesterol absorption in a recent overview of plant stanol studies, individual studies do not always show this correlation. Silbernagel et al. implied that increased plant sterol concentrations are merely a marker for high cholesterol absorption rates without being atherogenic themselves. However, since this assumption heavily relies on serum cholestanol concentrations as a surrogate marker for cholesterol absorption, verification in future research is desirable.

\section{Oxidation of cholesterol, plant sterols and oxysterol concentrations}

Besides plant sterols acting as a surrogate marker, another possibility to explain the potential association between plant sterol concentrations and CVD risk might be increases in plasma oxyphytosterol concentrations. Plant sterols are - analogue to cholesterol - susceptible to oxidation and can result in the formation of oxyphytosterols, while plant stanols do not have a double bond in their ring structure and can therefore not be oxidized.

Oxycholesterol and oxyphytosterol concentrations can result from dietary absorption or from endogenous oxidation from non-oxidized sterols. Plant sterols most likely can only be oxidized at the 7-position of the sterol ring, while cholesterol can be oxidized both at the sterol ring and on their side-chain [19]. Figure 1.2 shows the most important oxycholesterol and oxyphytosterol structures present in most tissues. In general, ring-oxidation products are formed non-enzymatically, e.g. through reactive oxidative species (ROS)-mediated oxidation while side-chain oxidation products are formed enzymatically. Exceptions to this are $7 \alpha-\mathrm{OH}$-sterols and $25-\mathrm{OH}$-cholesterol, which both can be formed enzymatically and non-enzymatically. ROS-mediated oxidation of a cholesterol or a plant sterol molecule starts with the abstraction of an allylic hydrogen atom at carbon-7 of the sterol ring. The generated radical can further react with oxygen to form a cholesterol or plant sterol peroxyl radical and after further abstraction of hydrogen, the relatively stable $7 \alpha$ - and/ or $7 \beta$-hydroxyperoxides are formed. These hydroxyperoxides products can be reduced to form $7 \alpha$ - and or $7 \beta-\mathrm{OH}$ products or be dehydrated to form 7-keto-products, which are the major non-enzymatic oxycholesterols and oxyphytosterols present in the human body [20]. For cholesterol, 24-, 25- and 27-OH-cholesterols are generated by enzymatic oxidation of 
the side-chain. 27-OH-cholesterol is produced by sterol 27-hydroxylase (CYP27A1), a P450 enzyme mostly expressed in the liver and macrophages that is involved in many processes, including the breakdown of cholesterol to bile acids. Cholesterol 24-hydroxylase (CYP46A1) is also a P450 enzyme, located in neural cells of the brain and retina and is able to produce 24-OH-cholesterol. 25-OH-cholesterol is a regulator of the sterol regulatory element binding protein (SREBP) pathway for cholesterol synthesis and is produced both non-enzymatically as well as enzymatically by cholesterol 25-hydroxylase [21]. Oxycholesterols formed through P450-oxidation are involved in functional processes in the body, such as sterol synthesis/ breakdown and the metabolism of potential harmful compounds. On the other hand, ROSmediated oxycholesterols mainly reflect oxidation status of the body and will often be accompanied by many other, potentially toxic, oxidized compounds [22]. Regarding plant sterols, oxidation only occurs at the 7-position of the ring structure, indicating that the majority of oxidized plant sterols will result from radical oxidation by ROS and not through enzymatic oxidation. However, information regarding oxyphytosterol metabolism is very scarce and enzymes responsible for plant sterol oxidation might be identified in future research.

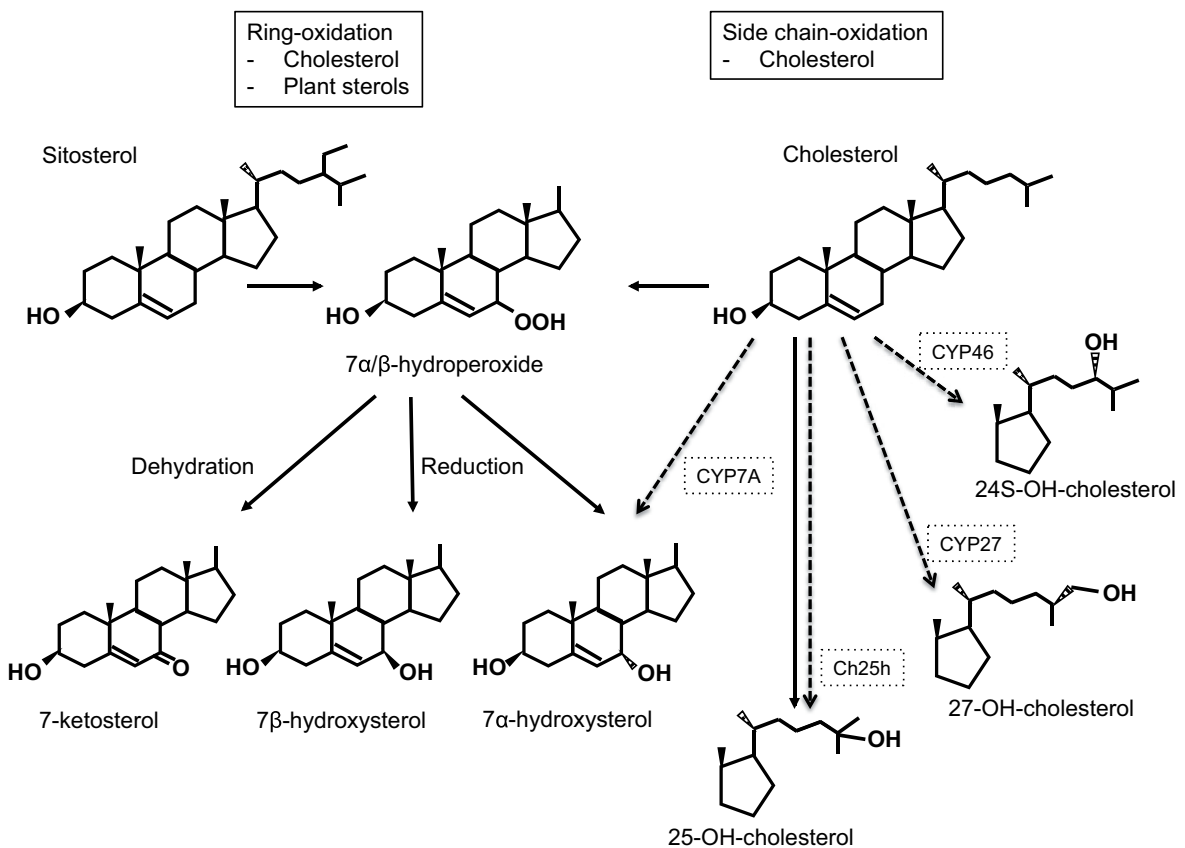

Figure 1.2. Plant sterol and cholesterol oxidation products. In general, cholesterol and plant sterol oxidation products oxygenated at the sterol ring are produced non-enzymatically, while cholesterol oxidation products oxygenated at the side chain require enzymes. $25-$ and $7 \alpha-\mathrm{OH}$-cholesterols can be produced enzymatically and non-enzymatically.

Besides in vivo formation, oxyphytosterols are also found in food products, such as heated vegetable oils, infant milk formulas, parenteral nutrition, French fries, potato chips 
and coffee beans. However, the main source of dietary oxyphytosterols are plant sterol enriched products, where one serving can provide up to $1.7 \mathrm{mg}$ oxyphytosterols per day if a recommended daily intake of 20-25 gram of spread is consumed. This exceeds the intake of other oxyphytosterol-containing products, such as heated vegetable oils, where oxyphytosterol intake was estimated to be $0.7 \mathrm{mg}$ per day or less [23-26]. Circulating oxyphytosterols have been identified in phytosterolemic subjects [27], in healthy subjects $[28,29]$ and in aortic tissue of CVD patients [30]. Concentrations in healthy subjects are very low, i.e. a range of 0.3-4.5 ng/mL, which is 10-100 times lower than plasma oxycholesterol concentrations. Whether circulating oxyphytosterols originate from dietary absorption, endogenous oxidation from non-oxidized plant sterols or a combination of both remains to be determined. Since there is hardly anything known regarding oxyphytosterols (i.e. absorption, endogenous oxidation of plant sterols and dietary influence), we carried out two intervention studies to increase our basic knowledge on oxyphytosterol metabolism. In a large randomised cross-over trial, we examined the effects of consuming plant sterol or stanol ester enriched margarines on fasting and postprandial plasma oxyphytosterol concentrations in healthy subjects (chapter 3 and 5). We also investigated the difference between subjects with low and high plasma oxyphytosterol concentrations to increase our understanding of potential determinants of circulating oxyphytosterol concentrations (chapter 4). In a subsequent study, we also evaluated whether plasma oxyphytosterol concentrations are influenced by antioxidant supplementation in a population characterized by increased oxidative stress (chapter 7 ).

\section{Effects of plant sterol and plant stanol consumption on postprandial metabolism and sequential meal consumption}

Atherosclerosis has been suggested to be a postprandial disease, where remnant lipoproteins play a large role and evidence is accumulating towards non-fasting TAG as another important CVD risk factor [31, 32]. Except for a couple of hours in the early morning, humans are in a non-fasting state for most part of the day. The (postprandial) transport of lipoproteins is shown in Figure 1.3. After consumption of a (fatty) meal, dietary triglycerides are hydrolysed via enzymatic lipases to free fatty acids and monoglycerides (MAGs) and, together with other lipophilic substances such as bile salts and cholesterol, are formed into mixed micelles. Fatty acids and MAGs are absorbed in the enterocytes and resynthesized to form TAGs in the endoplasmatic reticulum. They are then packed with apolipoprotein (apo) B48 particles, A-1 and A-IV into chylomicrons, secreted into lymph and pass into the blood via the thoracic duct. In the circulation, chylomicrons acquire apoCII and apoE from HDL particles. Chylomicron-TAGs are hydrolysed by lipoprotein lipase (LPL) present on endothelial cells which uses apoCII as a co-factor, and the released FAs are absorbed by adipose or skeletal muscle and used for energy generation or storage as TAGs. Phospholipids, cholesterol and apolipoproteins are transferred to HDL particles and the remaining cholesterol-rich chylomicron is transferred into a remnant particle. Chylomicron remnants are taken up by 
the liver via surface cell receptors (LDL-receptor via apoB and LDL-receptor related protein (LRP) via apoE), which completes the exogenous lipoprotein transport. On the other hand, the endogenous lipoprotein transport involves the production of TAG-rich VLDL particles by the liver. VLDLs contain predominantly TAGs, smaller amounts of cholesterol and apoB100, $\mathrm{CI}$ and E. Similar to chylomicrons, they undergo lipolysis via LPL, which results in the formation of intermediate-density lipoproteins (IDL) that can be taken up by the liver or be converted into LDL particles. VLDL and LDL particles are removed from the circulation via LDL-receptor and LRP-mediated clearance [33]. LDL-receptor mediated uptake is no longer possible when apoB100 is modified (for example through oxidative stress) and LDL is then taken up by scavenger receptors present on macrophages, contributing to the development of atherosclerosis [34]. HDL particles are responsible for reverse cholesterol transport (RCT). For this, nascent HDL particles acquire cholesterol from non-hepatic cells by interacting with $A B C A 1$ and ABCG1, after which cholesterol is esterified by lecithin:cholesterol acyltransferase (LCAT) and mature HDL particles are formed. Cholesterol ester transfer protein (CETP) can transfer cholesterol esters from HDL to VLDL, LDL and chylomicron particles in exchange for

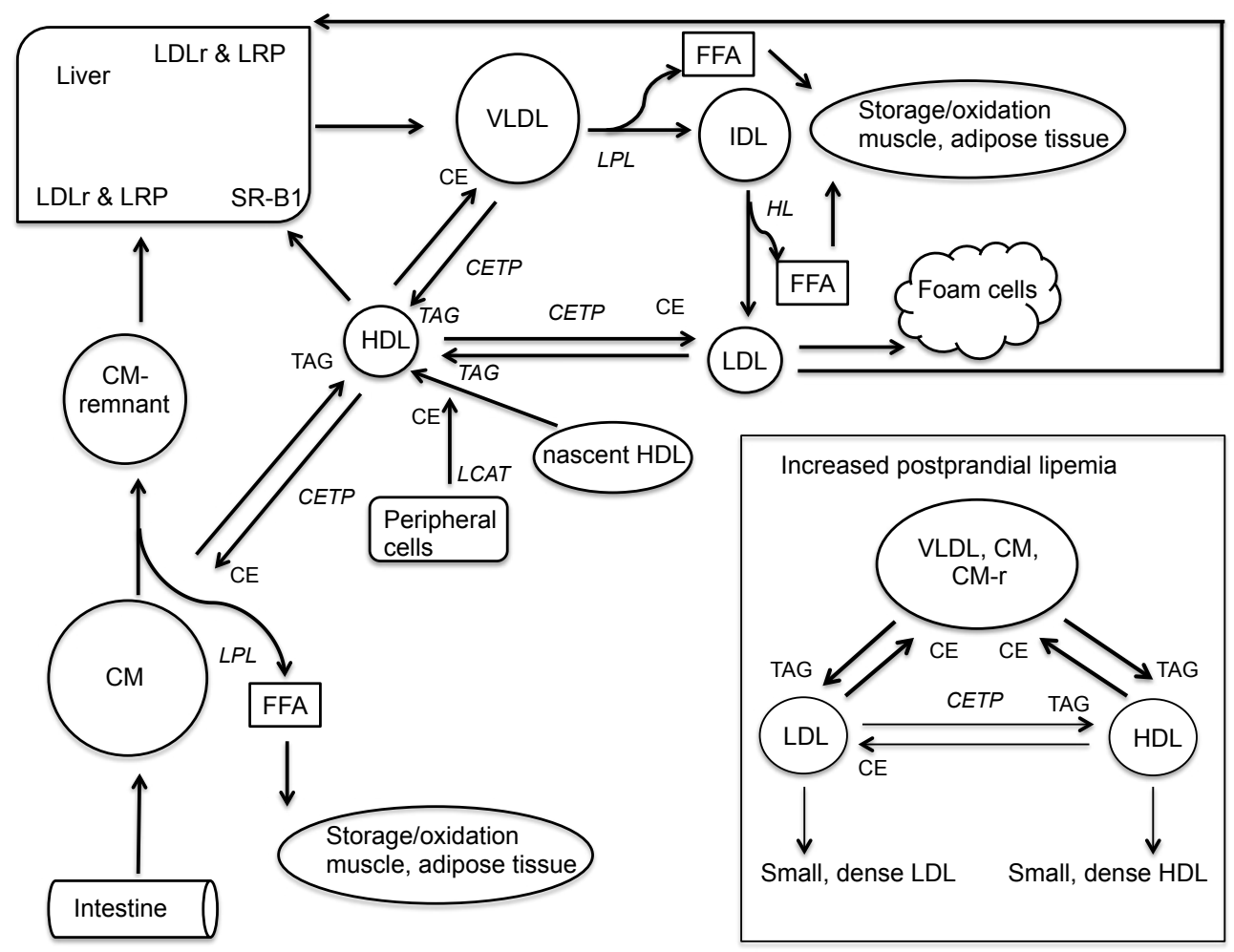

Figure 1.3. Schematic overview of the lipoprotein metabolism. LDLr: low-density lipoprotein receptor, LRP: lipoprotein receptor-related protein, SR-B1: scavenger receptor class B member 1, CM: chylomicron, VLDL: very low-density lipoprotein, IDL: intermediate low-density lipoprotein, LDL: low-density lipoprotein, HDL: high-density lipoprotein, LPL: lipoprotein lipase, CE: cholesterol ester, TAG: triglycerides, FFA: free fatty acids, CETP: cholesterol ester transfer protein, LCAT: lecithin-cholesterol acyltransferase. 
TAG. The transfer of cholesterol from HDL-C to LDL-C predominates, with minor transfer to VLDLs and chylomicrons [35].

Postprandial lipemia is a normal response of the human body, which is determined by intestinal and hepatic TAG secretion (into chylomicron and VLDL particles), TAG clearance by specific lipases and remnant-receptor driven removal of particles from the circulation. This response is transitory, but can become pathological when the extent of the TAG response is increased after meal consumption, which will then result in an accumulation of TAG-rich lipoproteins (TRLs) and their remnants. An accumulation of TRLs in the circulation will result in smaller chylomicron and VLDL remnant particles with a higher density that are more atherogenic than their larger counterparts. Smaller high dense remnants can more easily infiltrate into the arterial wall, are more prone to oxidation and are cleared more slowly. In addition, postprandial accumulation of TAG-rich lipoproteins enhances the exchange of TAGs for cholesterol esters from LDL-C and HDL-C, leading to a TAG enrichment of both HDL-C and LDL-C, giving rise to the formation of smaller and denser HDL-C and LDL-C particles (see insert Figure 1.3) [36]. Recent guidelines state that increased non-fasting TAG concentrations are markers for CVD, but cut-off values are lacking. In addition, there is no consensus with respect to the optimal study design to assess postprandial lipemia. Dietary and lifestyle changes remain the first line of approach to reduce (non-fasting) TAG concentrations, but studies addressing postprandial lipid and lipoprotein responses after plant sterol and stanol ester intake are scarce. Since there is a need for more detailed knowledge regarding postprandial effects of plant sterol and stanol ester consumption on lipoprotein metabolism, we assessed the effects of plant sterol and stanol ester consumption on postprandial lipoprotein metabolism (chapter 6).

\section{Outline thesis}

This thesis describes the results of two human intervention studies, investigating the effects of plant sterol and plant stanol consumption in the fasting and postprandial state and evaluating the effect of antioxidant supplementation on plasma plant sterol oxidation products. In chapter 2, an overview of the available literature is provided on the use of plant sterols and plant stanols in the treatment of dyslipidaemia. Chapter 3 describes the effects of plant sterol and plant stanol consumption on fasting plasma oxyphytosterol concentrations in healthy human subjects. Potential factors that might explain interindividual difference in plasma oxyphytosterol concentrations are investigated in chapter 4. In the postprandial study described in chapter 5, plasma oxyphytosterol concentrations are evaluated after consumption of a plant sterol or stanol enriched mixed meal in healthy subjects. In chapter 6 , the effects of plant sterol or stanol consumption on postprandial metabolism are evaluated. In chapter 7 , the results are described of a human intervention study, carried out in subjects with type 2 diabetes or impaired glucose tolerance, in which the effects of antioxidant supplementation on plasma oxyphytosterol concentrations were 
studied. In chapter 8 , the main results and conclusion are described and discussed and future directions within this field are addressed.

\section{References}

1. Frostegard J. Immunity, atherosclerosis and cardiovascular disease. BMC Med. 2013;11:117.

2. Maiolino G, Rossitto G, Caielli P, Bisogni V, Rossi GP, Calo LA. The role of oxidized low-density lipoproteins in atherosclerosis: the myths and the facts. Mediators Inflamm. 2013;2013:714653.

3. Ross R. Atherosclerosis--an inflammatory disease. N Engl J Med. 1999 Jan 14;340:115-26.

4. Baigent C, Blackwell L, Emberson J, Holland LE, Reith C, Bhala N, et al. Efficacy and safety of more intensive lowering of LDL cholesterol: a meta-analysis of data from 170,000 participants in 26 randomised trials. Lancet. 2010 Nov 13;376:1670-81.

5. Davidson $\mathrm{MH}$. Emerging low-density lipoprotein therapies: Targeting PCSK9 for low-density lipoprotein reduction. J Clin Lipidol. 2013 May-Jun;7:S11-5.

6. Stein EA, Giugliano RP, Koren MJ, Raal FJ, Roth EM, Weiss R, et al. Efficacy and safety of evolocumab (AMG 145), a fully human monoclonal antibody to PCSK9, in hyperlipidaemic patients on various background lipid therapies: pooled analysis of 1359 patients in four phase 2 trials. Eur Heart J. 2014 Sep 1;35:2249-59.

7. Gylling H, Plat J, Turley S, Ginsberg HN, Ellegard L, Jessup W, et al. Plant sterols and plant stanols in the management of dyslipidaemia and prevention of cardiovascular disease. Atherosclerosis. 2014 Feb;232:34660 .

8. Ostlund RE, Jr. Phytosterols in human nutrition. Annu Rev Nutr. 2002;22:533-49.

9. Chan YM, Varady KA, Lin Y, Trautwein E, Mensink RP, Plat J, et al. Plasma concentrations of plant sterols: physiology and relationship with coronary heart disease. Nutr Rev. 2006 Sep;64:385-402.

10. Gylling H, Miettinen TA. The effects of plant stanol ester in different subject groups. Eur Cardiol. 2010;6:18-21.

11. Plat J, Mackay D, Baumgartner S, Clifton PM, Gylling H, Jones PJ. Progress and prospective of plant sterol and plant stanol research: report of the Maastricht meeting. Atherosclerosis. 2012 Dec;225:521-33.

12. Demonty I, Ras RT, van der Knaap HC, Duchateau GS, Meijer L, Zock PL, et al. Continuous dose-response relationship of the LDL-cholesterol-lowering effect of phytosterol intake. J Nutr. 2009 Feb;139:271-84.

13. Ras RT, Hiemstra H, Lin Y, Vermeer MA, Duchateau GS, Trautwein EA. Consumption of plant sterol-enriched foods and effects on plasma plant sterol concentrations--a meta-analysis of randomized controlled studies. Atherosclerosis. 2013 Oct;230:336-46.

14. Hansel B, Carrie A, Brun-Druc N, Leclert G, Chantepie S, Coiffard AS, et al. Premature atherosclerosis is not systematic in phytosterolemic patients: severe hypercholesterolemia as a confounding factor in five subjects. Atherosclerosis. 2014 May;234:162-8.

15. Genser B, Silbernagel G, De Backer G, Bruckert E, Carmena R, Chapman MJ, et al. Plant sterols and cardiovascular disease: a systematic review and meta-analysis. Eur Heart J. 2012 Feb;33:444-51.

16. Silbernagel G, Fauler G, Hoffmann MM, Lutjohann D, Winkelmann BR, Boehm BO, et al. The associations of cholesterol metabolism and plasma plant sterols with all-cause and cardiovascular mortality. J Lipid Res. 2010 Aug;51:2384-93.

17. Gylling H, Vuoristo M, Farkkila M, Miettinen TA. The metabolism of cholestanol in primary biliary cirrhosis. J Hepatol. 1996 Apr;24:444-51.

18. Miettinen TA, Tilvis RS, Kesaniemi YA. Serum cholestanol and plant sterol levels in relation to cholesterol metabolism in middle-aged men. Metabolism. 1989 Feb;38:136-40. 
19. Vanmierlo T, Husche C, Schott HF, Pettersson H, Lutjohann D. Plant sterol oxidation products--analogs to cholesterol oxidation products from plant origin? Biochimie. 2013 Mar;95:464-72.

20. Brown AJ, Jessup W. Oxysterols and atherosclerosis. Atherosclerosis. 1999 Jan;142:1-28.

21. Russell DW. Oxysterol biosynthetic enzymes. Biochim Biophys Acta. 2000 Dec 15;1529:126-35.

22. Brown AJ, Jessup W. Oxysterols: Sources, cellular storage and metabolism, and new insights into their roles in cholesterol homeostasis. Mol Aspects Med. 2009 Jun;30:111-22.

23. Dutta P. Studies on phytosterol oxides. II: Content in come vegetable oild and in French Fires prepared in these oils. JAOCS. 1997; 74:647-66.

24. Dutta P. Studies on phytosterol oxides. I: Effect of storage on the content in potato chips prepared in different vegetable oils. JAOCS. 1997;74:647-57.

25. Turchetto E, Lercker G, Bortolomeazzi R. Oxisterol determination in selected coffees. Toxicol Ind Health. 1993 May-Jun;9:519-27.

26. Zunin P, Calcagno C, Evangelisti F. Sterol oxidation in infant milk formulas and milk cereals. J Dairy Res. 1998 Nov;65:591-8.

27. Plat J, Brzezinka H, Lutjohann D, Mensink RP, von Bergmann K. Oxidized plant sterols in human serum and lipid infusions as measured by combined gas-liquid chromatography-mass spectrometry. J Lipid Res. 2001 Dec;42:2030-8.

28. Husche $\mathrm{C}$, Weingartner $\mathrm{O}$, Pettersson $\mathrm{H}$, Vanmierlo $\mathrm{T}$, Bohm M, Laufs $\mathrm{U}$, et al. Validation of an isotope dilution gas chromatography-mass spectrometry method for analysis of 7-oxygenated campesterol and sitosterol in human serum. Chem Phys Lipids. 2011 Sep;164:425-31.

29. Baumgartner S, Mensink RP, Husche C, Lutjohann D, Plat J. Effects of plant sterol- or stanol-enriched margarine on fasting plasma oxyphytosterol concentrations in healthy subjects. Atherosclerosis. 2013 Apr;227:414-9.

30. Schott HF, Luister A, Husche C, Schafers HJ, Bohm M, Plat J, et al. The relationships of phytosterols and oxyphytosterols in plasma and aortic valve cusps in patients with severe aortic stenosis. Biochem Biophys Res Commun. 2014 Apr 11;446:805-10.

31. Bansal S, Buring JE, Rifai N, Mora S, Sacks FM, Ridker PM. Fasting compared with nonfasting triglycerides and risk of cardiovascular events in women. Jama. 2007 Jul 18;298:309-16.

32. Nordestgaard BG, Benn M, Schnohr P, Tybjaerg-Hansen A. Nonfasting triglycerides and risk of myocardial infarction, ischemic heart disease, and death in men and women. Jama. 2007 Jul 18;298:299-308.

33. Brown MS, Goldstein JL. A receptor-mediated pathway for cholesterol homeostasis. Science. 1986 Apr 4;232:34-47.

34. Gleissner CA, Leitinger N, Ley K. Effects of native and modified low-density lipoproteins on monocyte recruitment in atherosclerosis. Hypertension. 2007 Aug;50:276-83.

35. Rosenson RS, Brewer HB, Jr., Davidson WS, Fayad ZA, Fuster V, Goldstein J, et al. Cholesterol efflux and atheroprotection: advancing the concept of reverse cholesterol transport. Circulation. 2012 Apr 17;125:190519.

36. Klop B, Elte JW, Cabezas MC. Dyslipidemia in obesity: mechanisms and potential targets. Nutrients. 2013 Apr;5:1218-40. 



\section{Chapter 2}

Plant sterols and stanols in the treatment of dyslipidaemia: new insights into targets and mechanisms related to cardiovascular risk

Sabine Baumgartner, Ronald P. Mensink, Jogchum Plat

Current Pharmaceutical Design 2011; 17: $922-932$ 


\begin{abstract}
Plant sterols and stanols are naturally occurring constituents of plants and as such normal components of our daily diet. The consumption of foods enriched in plant sterols and stanols may help to reduce low-density (LDL) cholesterol concentrations. Meta-analyses have shown that consuming approximately 2.5 gram plant sterols or stanols per day lowers serum LDL-cholesterol concentrations up to $10 \%$, with little additional benefit achieved at higher intakes. However, recent studies evaluating plant stanol intakes up to $9 \mathrm{~g} / \mathrm{d}$ have indicated that LDL-cholesterol concentrations can be reduced up to $17 \%$, which suggests that more pronounced reductions can be achieved at higher intakes. Studies describing effects of high plant sterol intakes on serum LDL-cholesterol concentrations are not consistent. Besides the effects of higher than advocated intakes on serum LDL-cholesterol concentrations several topics will be discussed in this review. First, besides the well-characterized effect of plant sterols and stanols on serum LDL-cholesterol concentrations, evidence is now emerging of their effects on triacylglycerol metabolism, which makes them highly attractive for interventions in metabolic syndrome-like populations. Secondly, there is an ongoing debate whether increased plant sterol concentrations are associated with an increased cardiovascular disease risk or not. For this there are at least two possible explanations. First, the potential atherogenicity of increased plant sterol concentrations might be ascribed to the formation of plant sterol oxidation products (so-called oxyphytosterols) or secondly elevated serum plant sterol concentrations should only be seen as surrogate markers for characterizing subjects with a high intestinal cholesterol absorption. Finally, we will discuss recent studies, which suggest that plant sterols and stanols are able to improve endothelial dysfunction in subjects at risk, although evidence is limited and more research is needed.
\end{abstract}

\title{
Plant sterols and stanols
}

Dyslipidaemia is a major risk factor for developing cardiovascular disease (CVD), which includes hypercholesterolemia as well as hypertriglyceridemia. By lowering low-density lipoprotein (LDL) cholesterol concentrations, CVD risk is considerably reduced. It has been estimated that each percentage reduction in LDL-cholesterol can reduce CVD risk by $2 \%$ [1]. The impact of lowering circulating LDL-cholesterol concentrations on CVD risk can also be deduced from genetic studies. Carriers of the PCSK9 SNP (PCSK9 ${ }^{142 x}$ or PCSK9 ${ }^{679 x}$ ), for example, have lifelong on average $28 \%$ lower serum LDL-cholesterol concentrations and an $88 \%$ lower CVD risk [2]. PCSK9 is involved in the degradation of the LDL receptor and the above-mentioned loss of function mutation consequently results in lower serum cholesterol concentrations [3]. The consumption of food products enriched with plant sterols and stanols may help to reduce increased LDL-cholesterol concentrations and as such the risk of CVD. Evidence for this LDL-cholesterol lowering effect has evolved so strongly over the past decade that plant sterols and stanols are now part of the NCEP guidelines, which encourages the daily incorporation of $2 \mathrm{~g}$ of plant sterols into a healthy diet low in saturated 
fatty acids to reduce CVD risk for subjects with elevated LDL-cholesterol concentrations [4]. Plant sterols are naturally occurring constituents of plants and are common components of our daily diet. They are structurally related to cholesterol and the cellular functions of plant sterols in plants are analogous to those of cholesterol in animals. Both cholesterol and plant sterols consist of a steroid nucleus with a double bond present at C5-C6 and only the side-chain configuration differs. The average intake of plant sterols in Western countries is approximately $250 \mathrm{mg} /$ day, mainly derived from vegetable oils, cereals, nuts, seeds, fruits and vegetables [5]. The most abundant plant sterols in the human diet are $\beta$-sitosterol, campesterol, and stigmasterol. Plant stanols are the saturated derivatives of plant sterols. The major plant stanols are sitostanol and campestanol, which are considerably less abundant in nature than plant sterols are [6]. Since humans are unable to synthesize plant sterols and stanols, their serum concentrations are the results of intestinal absorption and biliary secretion. In contrast to the absorption rate of cholesterol, which is around $50 \%$, the absorption rate of plant sterols is much lower; i.e. about $10-15 \%$ for campesterol and campestanol, $4-7 \%$ for sitosterol and $1 \%$ for sitostanol [7]. Once present in the circulation, plant sterols and stanols are taken up by the liver and rapidly secreted into bile by hepatic $A B C G 5 / G 8$ transporters. Although cholesterol is also secreted into bile, the rate of plant sterol and stanol secretion into bile is much faster [8]. Due to their low absorption and high biliary secretion serum concentrations of plant sterols and stanols are less than $1 \%$ of that of serum cholesterol [9]. On average, plasma sitosterol concentrations range from 0.12 to 0.62 $\mathrm{mg} / \mathrm{dL}$ and campesterol concentrations from 0.27 to $1.08 \mathrm{mg} / \mathrm{dL}$ [10].

While the effect of plant sterols and stanols on serum LDL-cholesterol is well characterized and has been reviewed extensively $[6,7,11,12]$, evidence is emerging of effects beyond LDL-cholesterol lowering. Plant sterols have been studied in relation to immune modulation $[13,14]$, triacylglycerol metabolism [15] and cancer prevention [16]. In this review we will therefore only briefly discuss the effects of plant sterols and stanols on serum LDLcholesterol concentrations and cholesterol metabolism. The focus will be on the effects of plant sterols and stanols on triacylglycerol metabolism. Furthermore, we will address recent studies suggesting that plant stanol esters have larger effects on serum LDL-cholesterol concentrations when provided in amounts higher than currently advocated. The issue of promoting higher daily plant sterol and / or stanol intakes is especially relevant regarding the ongoing debate whether elevated serum plant sterol concentrations are associated with cardiovascular risk or not. Two explanations for this possible relationship will be discussed. First, we will discuss the possible atherogenicity of plant sterols as a result from plant sterol oxidation, i.e. formation of the so-called oxyphytosterols. Secondly, we will consider the possibility that serum plant sterols should only be considered as markers for cholesterol absorption, which means that subjects with elevated serum plant sterol concentrations absorb also more (dietary) cholesterol. Finally, we will briefly discuss the evidence whether plant sterol and stanol consumption influences endothelial function and characteristics of the microcirculation. 


\section{LDL-cholesterol lowering effect}

Several meta-analyses have clearly indicated the LDL-cholesterol lowering effect of plant sterols and stanols. Here, we will provide a short overview of the main conclusions from these meta-analyses. The very first meta-analysis by Law [6], already published in 2000, summarized the results of 10 studies, in which plant sterols and stanols were mainly consumed when added to fat spreads. It was found that at doses of $>2 \mathrm{~g} / \mathrm{d}$, the average reduction in LDL-cholesterol ranged from $0.43-0.54 \mathrm{mmol} / \mathrm{L}$, or $9-14 \%$. Three larger metaanalyses have been performed thereafter, which unanimously concluded that a non-linear dose-response relationship existed between the intake of functional foods enriched with plant sterols and stanols and decreases in serum LDL-cholesterol concentrations [7, 11, 12]. The meta-analysis by Katan et al. [7] identified 41 trials, with mainly fat-based foods such as spreads, mayonnaise and salad dressings. At an intake of $2 \mathrm{~g} / \mathrm{d}$, it was estimated that serum LDL-cholesterol was reduced by $10 \%$, with little additional benefit at intakes higher than 2.5 $\mathrm{g} / \mathrm{d}$. An updated meta-analysis by Abumweis et al. [11] identified 59 studies that consisted of 95 relevant strata. Evidence was found for a dose-response effect with LDL-cholesterol reductions of respectively $0.29 \mathrm{mmol} / \mathrm{L}, 0.32 \mathrm{mmol} / \mathrm{L}$ and $0.42 \mathrm{mmol} / \mathrm{L}$ for plant sterol or stanol intakes of $1.5-2.0 \mathrm{~g} / \mathrm{d}, 2.1-2.5 \mathrm{~g} / \mathrm{d}$ and $2.5 \mathrm{~g} / \mathrm{d}$. This meta-analysis also highlighted the importance of the food matrix. Finally, Demonty et al. [12] aimed to quantify the doseresponse relationship between LDL-cholesterol reductions and plant sterol or stanol intake, and the impact of different intervention characteristics such as plant sterol type (sterol vs. stanol) and food format. Eighty-four eligible trials with 141 strata were identified. The mean plant sterol / stanol intake was $2.15 \mathrm{~g} / \mathrm{d}$ (range 0.45-9.00 g/d), which was consumed for 21 to 182 days. In 74 strata plant sterols were used while in 53 strata the experiments were conducted with plant stanols. The dose-response equation predicted a serum LDLcholesterol lowering effect of $9 \%$ at the recommended daily intake of $2 \mathrm{~g} / \mathrm{d}$. In agreement with the estimation made by Katan et al. [7], the LDL-cholesterol lowering effect levelled off at an intake of $3 \mathrm{~g} / \mathrm{d}$ and was $10.7 \%$. Thus, also this meta-analysis indicated that intakes of plant sterols and stanols higher than $2.5 \mathrm{~g} / \mathrm{d}$ offered little additional benefit. The results of these three large meta-analyses are in contrast with the outcomes of two recently published placebo-controlled intervention studies. Mensink et al. [17] showed a linear dose-response relationship between plant stanol intake and the reduction in LDL-cholesterol. Plant stanol intakes were $0,3,6$ or $9 \mathrm{~g} / \mathrm{d}$ and LDL-cholesterol decreased linearly up to $17.0 \%$ at the highest intake. This observation completely agreed with a study by Gylling et al., [18] who found a reduction of $17.4 \%$ after an intake of $8.8 \mathrm{~g} / \mathrm{d}$ of plant stanols. Results from studies with high plant sterol intakes, are less consistent, Ayesh et al. [19] found an LDL-cholesterol reduction of $23 \%$ at an intake of $8.6 \mathrm{~g} / \mathrm{d}$ of plant sterols. This effect may however been slightly overestimated, as the cholesterol content of the control and experiment margarines were not comparable. Clifton et al. [20] provided $6.6 \mathrm{~g} / \mathrm{d}$ of plant sterols to 35 subjects and reported an LDL-cholesterol reduction of $12.4 \%$. In contrast, Davidson et al. [21] found no additional effect on LDL-cholesterol when an intake of $9 \mathrm{~g} / \mathrm{d}$ of plant sterols was compared 
with that of $3 \mathrm{~g} / \mathrm{d}$. The characteristics of the described studies performed with a high dose plant sterol or stanol intake are given in table 2.1.

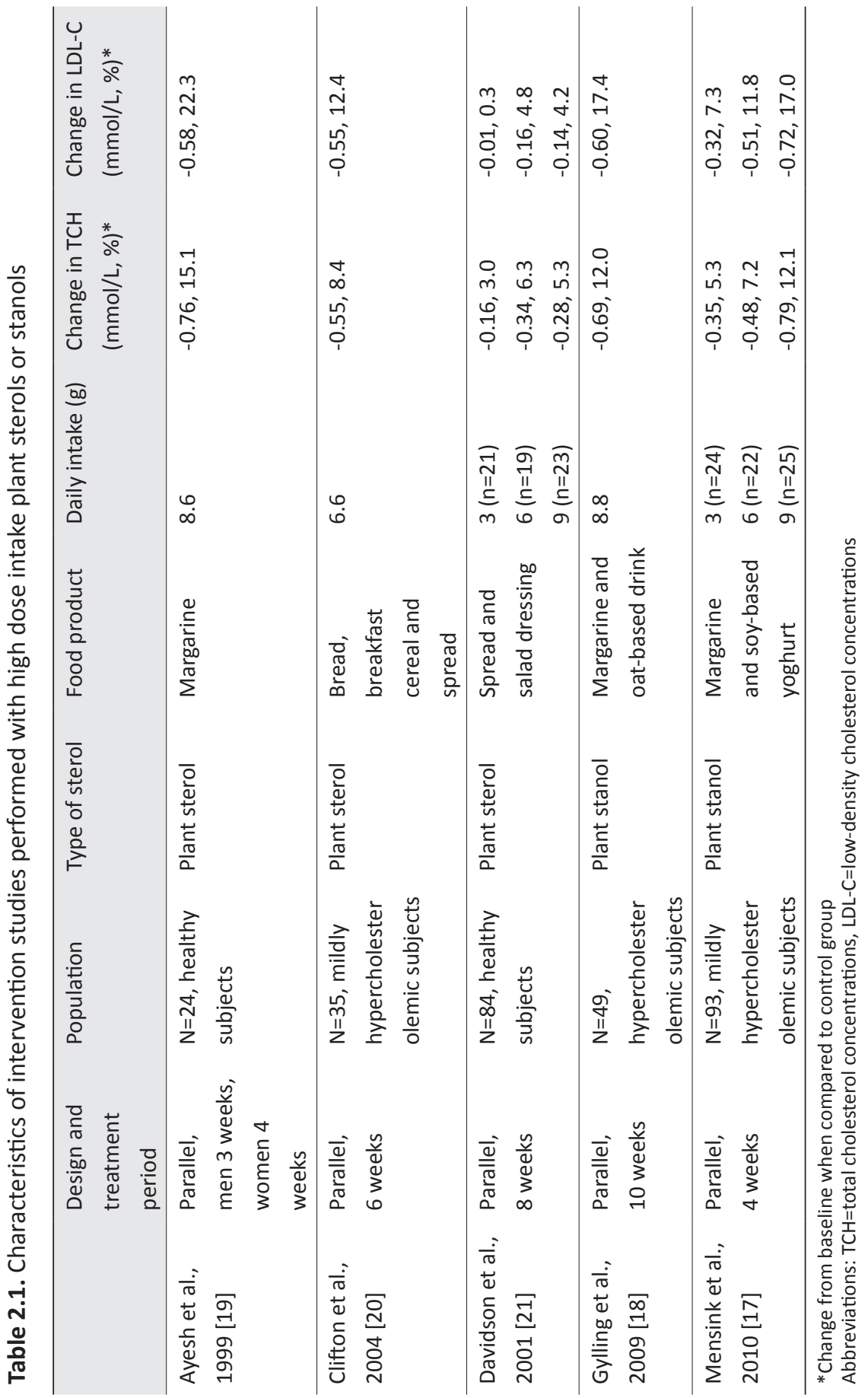


Up till now, 5 studies have provided far more plant sterols or stanols than currently advocated and it is important to monitor the effects of these high intakes on fat-soluble antioxidant concentrations. Several studies have found reduced concentrations of especially the lipophylic hydrocarbon carotenoids, like $\beta$-carotene and lycopene after plant sterol and stanol intake [22]. However, most high-dose studies did not show larger reduction in antioxidant concentrations than found at recommended intakes. Moreover, several parameters reflecting liver and kidney function were unchanged during the intervention periods. More studies for a longer duration and in other population groups are however warranted before advocating higher intakes than currently recommended. The high intake studies carried out so far should be regarded as proof-of-principle experiments, in which it is shown that LDL-cholesterol lowering can be extended over the currently advocated intakes, although evidence regarding is still contradictive.

Plant sterols and stanols are currently incorporated into a wide variety of food products. There is an ongoing discussion concerning the types of food that yields the most efficient LDL-cholesterol reduction. Abumweis et al. reported a larger reduction in LDL-cholesterol when plant sterols and stanols were incorporated into food products like fat spreads, mayonnaise and salad dressing or milk and yoghurt as compared with food products, such as cereal and chocolate bars, orange juice, non-fat beverages and bread [11]. On the other hand, the meta-analysis by Demonty et al. indicated that the food characteristics (fat-based vs. non fat-based formats, dairy vs. non-dairy formats, free plant sterol/stanols vs. esterified forms, and plant sterols vs. stanols) did not influence its LDL-cholesterol lowering efficacy [12]. The frequency of intake may also be important. Plat et al. compared the effects of once per day compared to a 3-times/d intake of plant stanols and reported no difference in LDL-cholesterol lowering between the treatments [23]. Demonty et al., however, concluded that most evidence pointed towards a larger efficacy of plants sterols and stanols when consumed at multiple time points [12]. In this respect, when consumed once a day, the time of consumption may be essential. Abumweis et al. showed that consumption of a single dose of plant sterols in the morning failed to lower LDL-cholesterol concentrations [24]. It seems that plant sterols or stanols should be consumed during or after a meal, preferably a larger meal like lunch or dinner [11].

\section{Effects beyond LDL-cholesterol lowering}

Besides the well-characterized LDL-cholesterol lowering effects, studies are emerging showing that plant sterols and stanols can also affect other lipid parameters. Until recently, almost all studies reported that plant sterol or stanol intake did not change serum highdensity (HDL) cholesterol or triacylglycerol (TAG) concentrations. In some studies, slight changes were found, but these changes were most likely due to other dietary changes and not to plant sterol or stanol intake per se [25]. However in a recent meta-analysis, Naumann and co-workers analysed data from five well-controlled intervention studies with 
plant stanols performed at their department and reported that changes in HDL cholesterol depended on baseline concentrations. In subjects with low concentrations at the start of the study, slight increases were observed, while decreases were seen in subjects with high baseline concentrations. Without this differentiation, the mean change in HDL cholesterol in the intervention groups was zero. Results of this meta-analysis also suggested that plant stanols lowered fasting TAG concentrations, especially in individuals with elevated baseline TAG concentrations [26]. A reason why this effect was not observed in earlier studies could have been due to a lack of statistical power, as most participants in the trials had normal to low baseline TAG concentrations. Therefore, Theuwissen et al. [15] designed a study to specifically evaluate the effect of plant stanol supplementation on serum TAG changes in a population with elevated fasting serum TAG concentrations. Figure $\mathbf{2 . 1}$ indeed shows that serum TAG concentrations hardly changed in subjects with baseline TAG concentrations $<2.3$ $\mathrm{mmol} / \mathrm{L}$ (change of $0.09 \mathrm{mmol} / \mathrm{L}$ compared to controls), while a significant TAG reduction was observed in subjects with higher baseline TAG concentrations (change of $-0.53 \mathrm{mmol} / \mathrm{L}$ compared to controls).

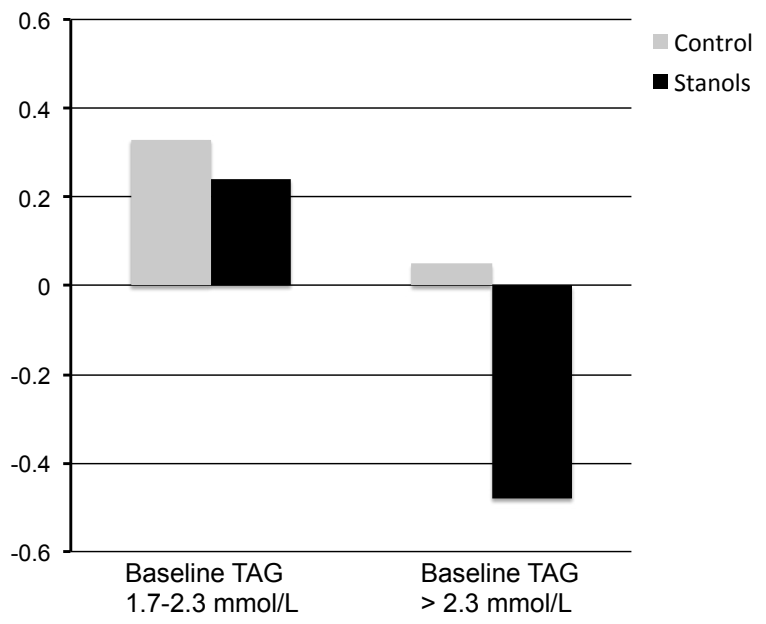

Figure 2.1. Changes in TAG concentrations ( $\mathrm{mmol} / \mathrm{L})$ for subjects with moderate $(1.7-2.3 \mathrm{mmol} / \mathrm{L})$ and high baseline (>2.3 mmol/L) concentrations.

Also in a study performed with metabolic syndrome patients, who are characterized by increased serum TAG concentrations, a significant reduction of $32 \%$ in fasting serum TAG concentrations was found after consumption for 9 weeks of $2 \mathrm{~g} / \mathrm{d}$ of plant stanols provided via a yoghurt drink [27]. These findings show that functional foods enriched with plant stanols are not only useful to lower serum LDL-cholesterol concentrations, but may also be beneficial to lower serum TAG concentrations in specific population groups. These effects may not be exclusive for plant stanol esters. A daily intake of $1.6 \mathrm{~g}$ of plant sterols provided via a low-fat drinkable yoghurt reduced serum TAG concentrations with $12.9 \%$ in 
hypercholesterolemic subjects with normal TAG concentrations [28]. In addition, Judd et al. showed that $3.6 \mathrm{~g} / \mathrm{d}$ of plant sterols reduced not only serum LDL-cholesterol, but also serum TAG concentrations in healthy volunteers [29]. Thus, these two studies indicate that plant sterols may reduce serum TAG concentrations when provided in a low-fat format. More interestingly, these effects were found in populations without elevated baseline serum TAG concentrations, which contrasts the findings of Naumann et al., [26] suggesting that effects were hardly present in subjects with normal serum TAG concentrations. It should, however, be taken into account that at least 50 other studies with plant sterol esters in normotriglyceridemic subjects did not show these effects. Table $\mathbf{2} . \mathbf{2}$ shows an overview of the described studies that showed an effect of plant sterol or stanol ester consumption on serum TAG concentrations. A meta-analysis with all published studies that measured serum TAG concentrations after plant sterol or stanol consumption is lacking. It would be valuable to carry out such a meta-analysis according to the same principles as has been used to examine effects on LDL-cholesterol concentrations [11], also focusing on factors like the food matrix and intake frequency.

The most widely accepted mechanism via which plant sterols and stanols reduce LDLcholesterol is through the displacement of cholesterol from mixed micelles, since plant sterols and stanols are more hydrophobic than cholesterol [30]. This replacement reduces micellar cholesterol concentrations and consequently cholesterol absorption. It has also been shown in Caco- 2 cells that plant stanols were able to up-regulate the expression of ABC-transporters, which could lead to an increased excretion of cholesterol by the enterocyte back into the lumen [31]. Each of these two proposed mechanisms will result in a reduced intestinal cholesterol absorption and thus in a reduced cholesterol flux through the chylomicrons to the liver. A reduced flux to the liver will lead to a compensatory increase in hepatic endogenous cholesterol synthesis and an up-regulated hepatic LDL receptor expression, ultimately resulting in reduced serum LDL-cholesterol concentrations. A possible mechanism via which plant sterols and stanols might lower serum TAG concentrations is by reducing hepatic production of large TAG-rich VLDL-1 particles. This hypothesis was evaluated by Plat et al. [32], who showed in two independent studies that plant stanol esters significantly lowered serum VLDL-1 particle concentrations. One study was carried out in normocholesterolemic subjects, and the other study in subjects with the metabolic syndrome subjects. Obviously, effects were much more pronounced in the metabolic syndrome subjects, who had higher circulating VLDL-1 particle concentrations [32]. Although supportive, these data do not prove that the postulated hypothesis that the serum TAG-lowering effect of plant stanols is caused by a reduction in the hepatic production of large TAG-rich VLDL-particles. It is also possible that serum VLDL-1 particle concentrations are reduced via an increased clearance rate of VLDL-1. This, however, demands further study. The mechanism by which ezetimibe, like plant sterols and stanols a potent intestinal cholesterol absorption inhibitor, lowers serum TAG concentrations in humans involves a reduced production of VLDL particles, thereby lowering VLDL pool size $[33,34]$ with a concomitant reduction in hepatic lipid 


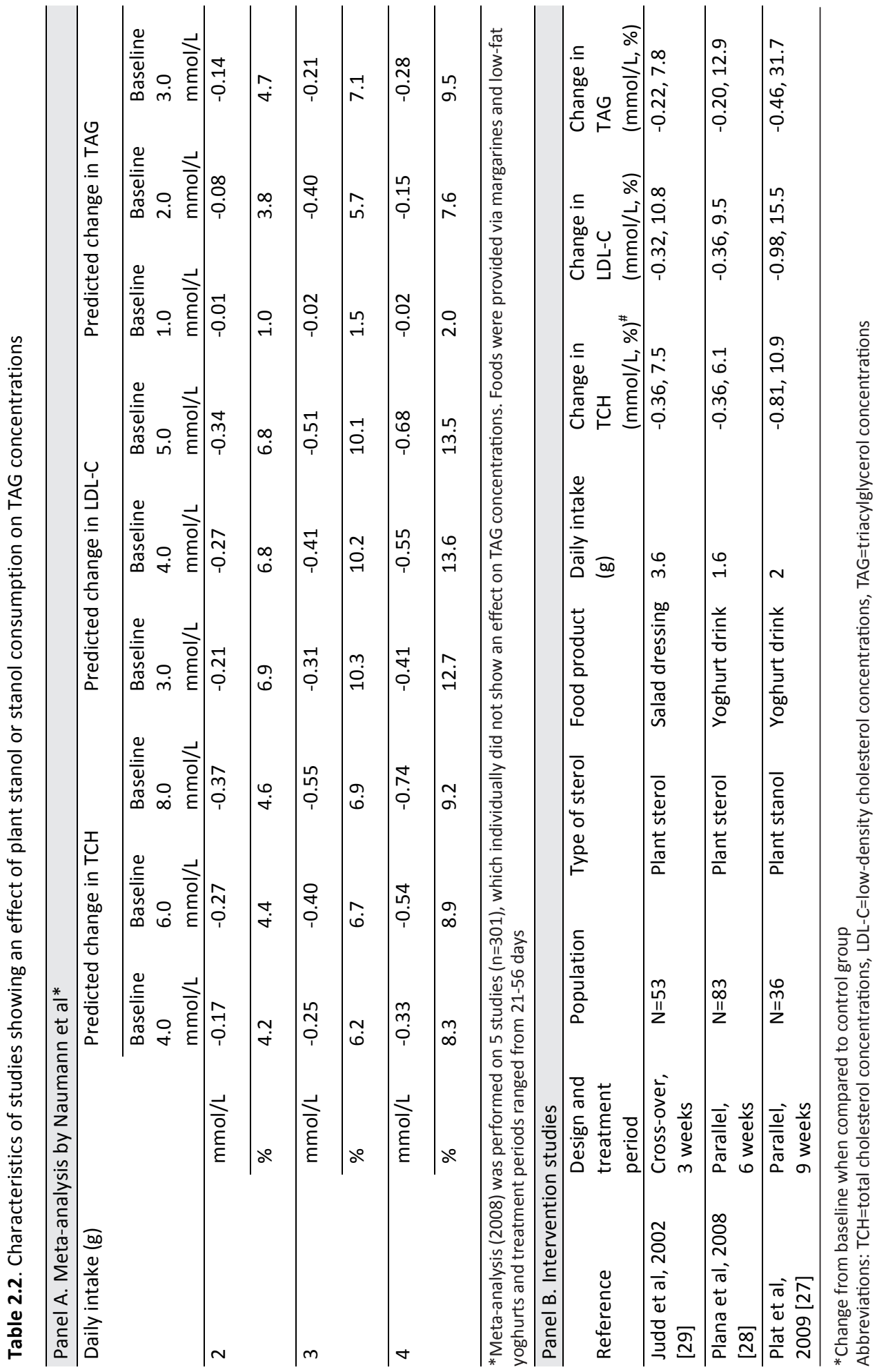


content [35]. Whether plant sterols and stanols also affect intra-hepatic fat accumulation warrants further research.

A reduction of $32 \%$ in serum TAG concentrations, as seen in the study by Plat et al., [27] is in the same magnitude as described for fish oils [36, 37]. Fish oils are nowadays one of the very few nutritional strategies to lower serum TAG concentrations. An interesting question is whether effects of plant sterols and stanols on serum TAG concentrations are additional to the effects of fish oils. Demonty et al. performed a study in which they compared a diet rich in plant sterols esterified with sunflower oil, a diet rich in plant sterols esterified with fish-oil and a diet rich in regular fish oil supplementation. No change in TAG concentration was seen after the diet enriched with plant sterols esterified with sunflower oil, while a marked decrease was seen after the fish-oil supplementation and an even more pronounced decrease was seen after the diet enriched with fish-oil esters of plant sterols. The authors attribute this stronger TAG decrease of the combination therapy to the plant sterol content of the intervention. However, it is difficult to make this conclusion, as the design of the study does not allow making these assumptions. The composition of the fishoil supplementation was not the same for both interventions; the combination therapy contained, next to plant sterols, also a much higher content of fish oils. Therefore, it is not possible to determine whether the additional TAG reducing effect in the combination therapy stems from the additional plant sterol or higher fish oil content of the intervention. More studies are warranted to provide evidence that even larger effects in serum TAG concentrations can be achieved by combination strategies and to help find mechanistic explanations underlying the observed effects. Finally, Ford et al. [38] estimated that about one-third of the population is characterized by elevated fasting serum TAG concentrations. Moreover, Sarwar et al. [39] identified in 29 prospective studies that elevated fasting TAG concentrations are an independent risk factor for CVD. The high prevalence and increased risk of elevated TAG concentrations indicates the need and potential clinical benefit for TAG lowering interventions.

\section{Potential atherogenicity}

Among others, Naumann et al. have shown that the increase in serum plant sterol concentrations is positively related to plant sterol intake, while plant stanol ester consumption lowers serum plant sterol concentrations [40]. The implication of increased serum plant sterol concentrations is not clear, but speculations about a potential undesirable effect were first brought up after the identification of the disease phytosterolemia. Phytosterolemia is a rare autosomal-recessively inheritable sterol storage disease that has only been identified in \pm 200 patients worldwide (personal communication D. Lütjohann). The disease is characterized by very high plant sterol concentrations ranging from $10-65 \mathrm{mg} /$ $\mathrm{dL}$ while the reference range in non-affected subjects is below $1 \mathrm{mg} / \mathrm{dL}$. Despite high serum plant sterol concentrations, serum cholesterol concentrations are normal or only slightly 
increased. Patients with this disease exhibit tendon and tuberous xanthomas and have a strong predisposition to develop premature coronary atherosclerosis [41]. The cause of this disease is a mutation in the $A B C G 5 / 8$ half transporters, which results in a decreased secretion of absorbed sterols from the enterocytes back into the lumen, as well as a reduced plant sterol excretion from the liver into bile [42]. The fact that these patients are confronted with severe vascular diseases at a relatively young age, despite normal cholesterol concentrations, raised the issue about the atherogenicity of increased plant sterol concentrations. Although many clinical trials have unequivocally shown that plant sterols and stanols lower serum LDL-cholesterol concentrations, effects on clinical endpoints related to CVD are not clear. Of course, the reduction in LDL-cholesterol is a strong indication that CVD risk will be lowered. However, the potential association between elevated plant sterol concentrations and CVD risk might influence the outcome.

The potential association between circulating plant sterol concentrations and CVD risk has been investigated in several prospective and cross-sectional epidemiological studies with contradictive results. Some large prospective cohort studies have shown that elevated concentrations of plant sterols are associated with an increased risk of CVD [43, 44]. Elevated plant sterol concentrations have also been associated with a family history of premature CVD in hypercholesterolemic subjects $[45,46]$. More recent studies have also related increased serum plant sterol concentrations with an increased mortality risk. For example, Silbernagel et al. [47] have shown that serum campesterol concentrations were associated with increased all cause and cardiovascular mortality in a large cohort of subjects who were referred to the hospital for an angiogram. In addition, Teupser et al. [48] have observed that single nucleotide polymorphisms (SNPs) in the gene encoding for ABCG8 were not only associated with increased serum campesterol concentrations, but also with a risk for coronary artery disease. This indicates that genetic variants affecting plant sterol metabolism may also be related to the susceptibility to develop coronary artery disease. However, despite this list of studies suggesting possible atherogenic effects of plant sterols, a number of other prospective studies did not find an association between serum plant sterol concentrations and CVD risk $[49,50]$, while two studies even indicated that elevated plant sterol concentrations were associated with a decreased CVD risk [51, 52]. In Table 2.3 and 2.4, an overview is provided in which characteristics are given of the studies that have examined the potential association between increased plant sterol concentrations and CVD risk.

It has been postulated that the ongoing controversy about the potential atherogenicity of plant sterols may be due to the formation of oxyphytosterols, the oxidized forms of plant sterols. Oxyphytosterols can be formed during physical processes, such as heating and radiation, by non-enzymatic processes, such as reactions with reactive oxygen species (ROS) or enzymatically by specific cytochrome P450 mono-oxygenases. The side-chain of cholesterol can be oxidized enzymatically and the nucleus non-enzymatically, the latter probably being a radical driven process. For plant sterols, only the nucleus can be oxidized 


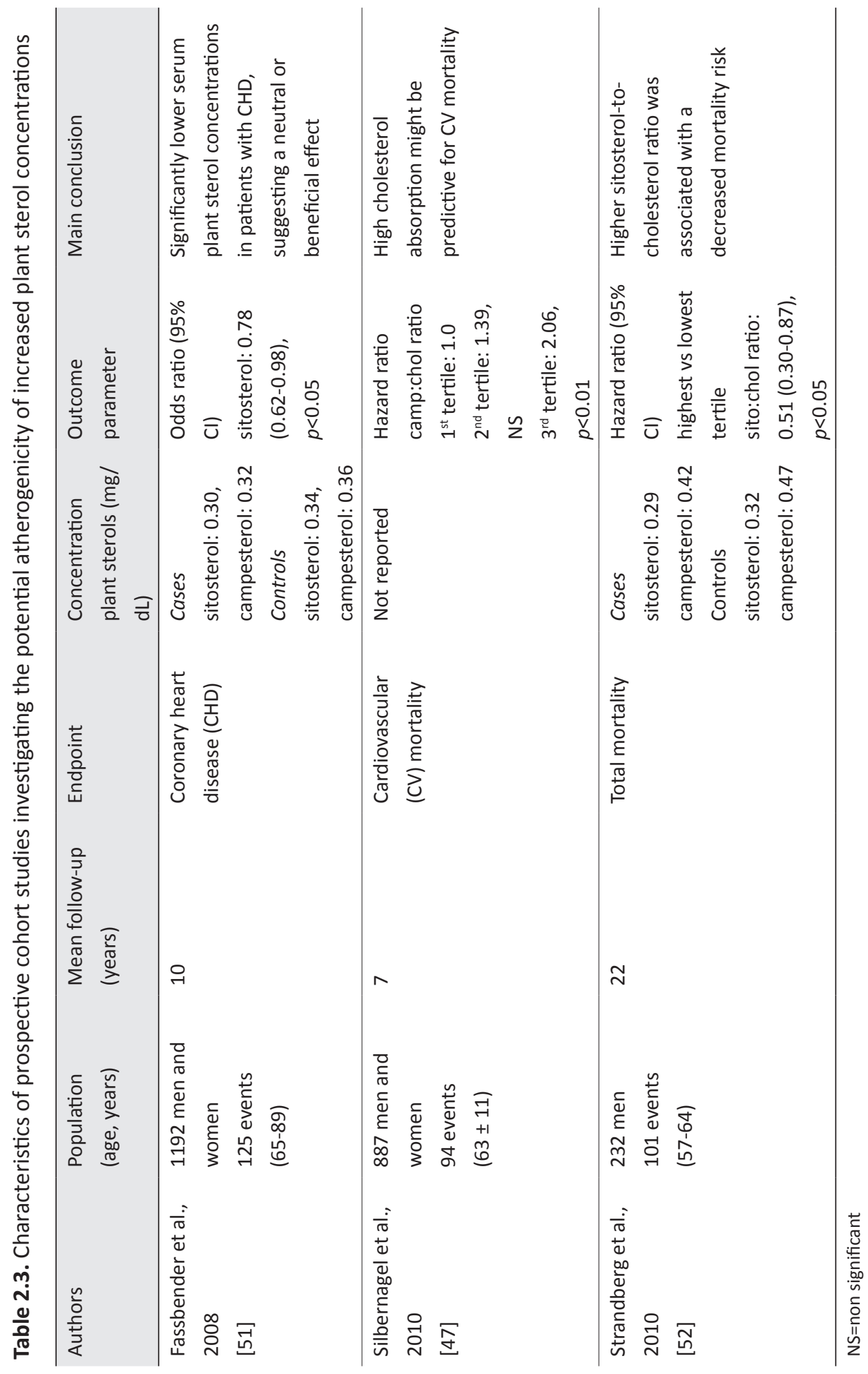




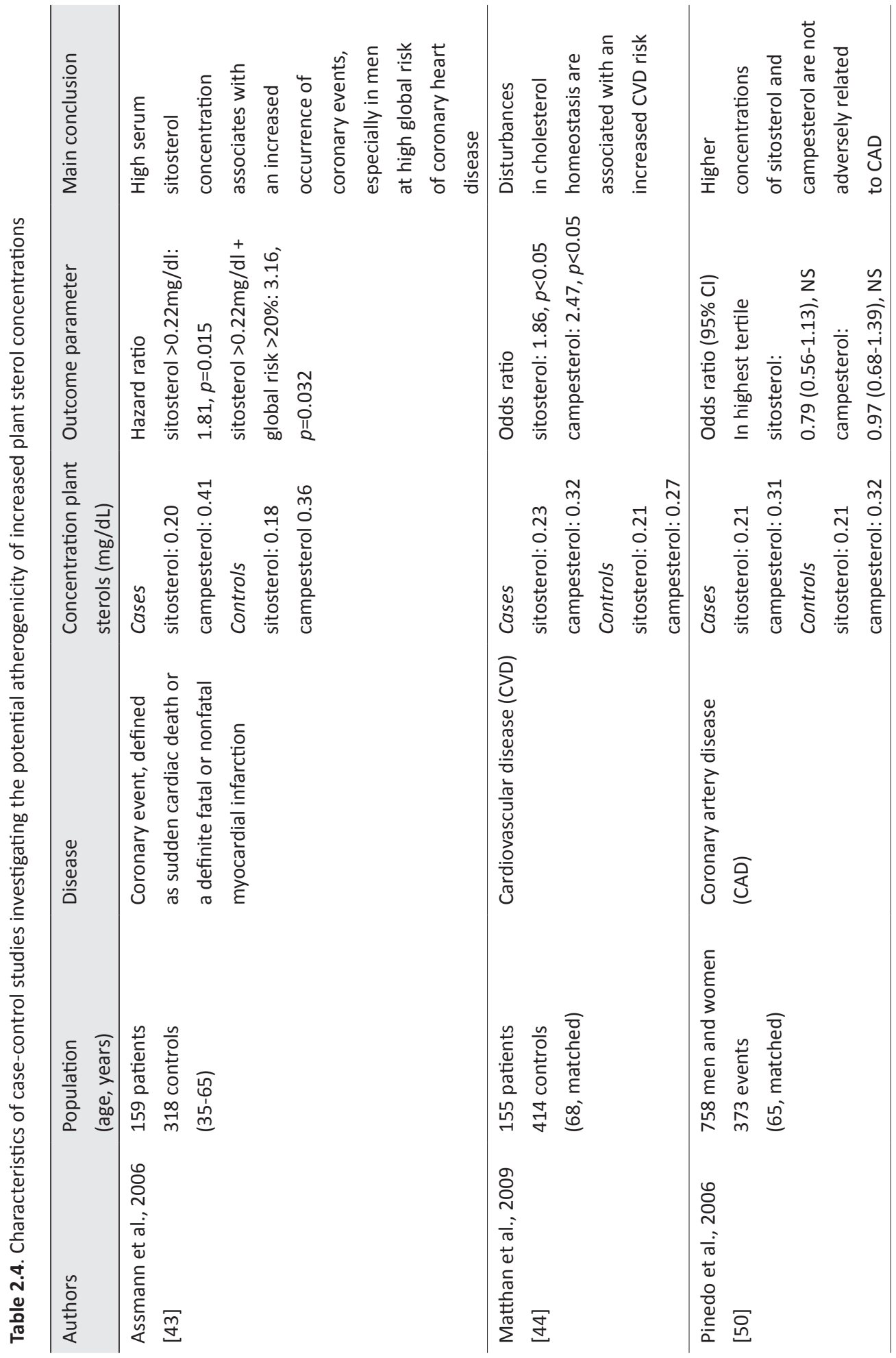




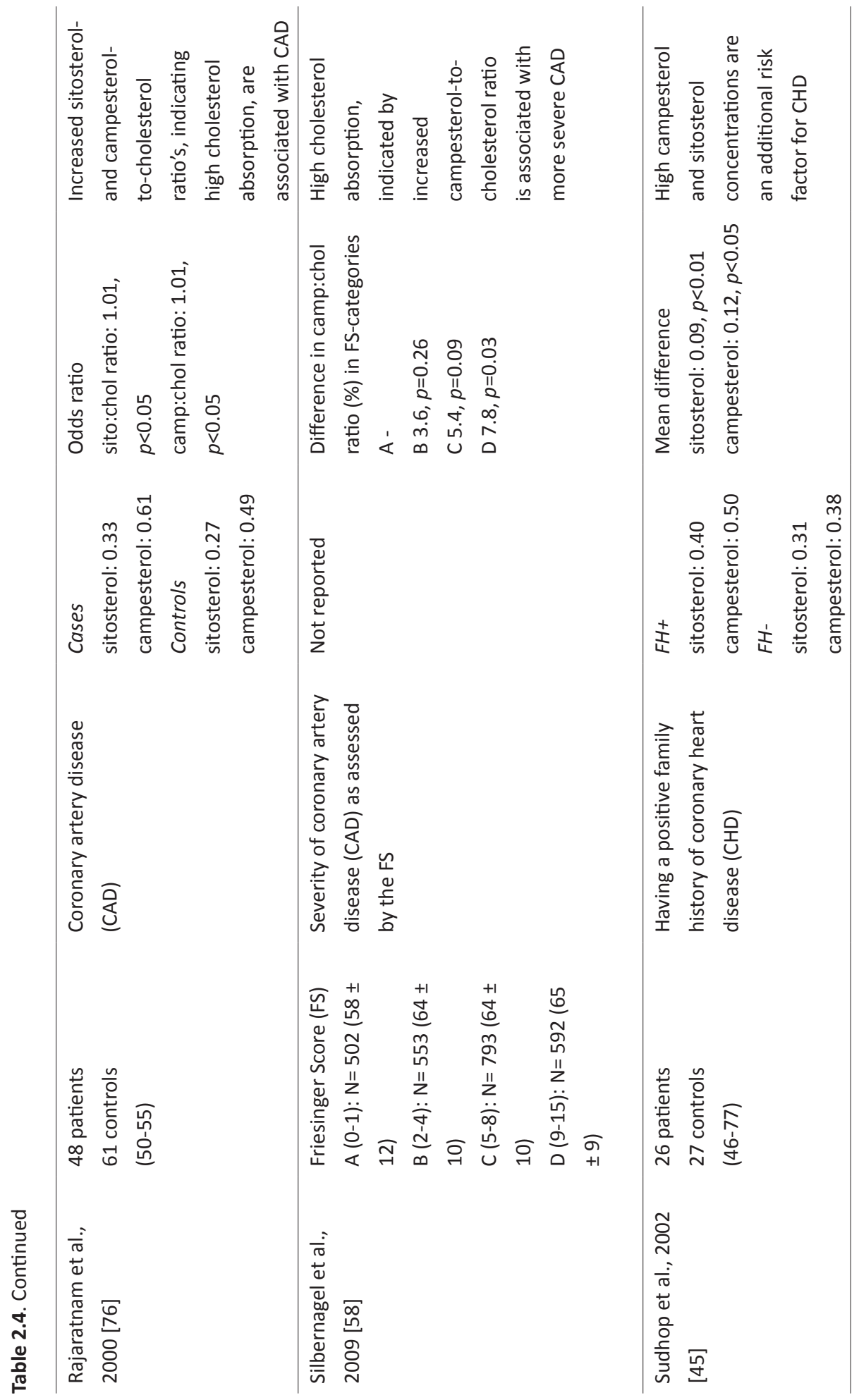




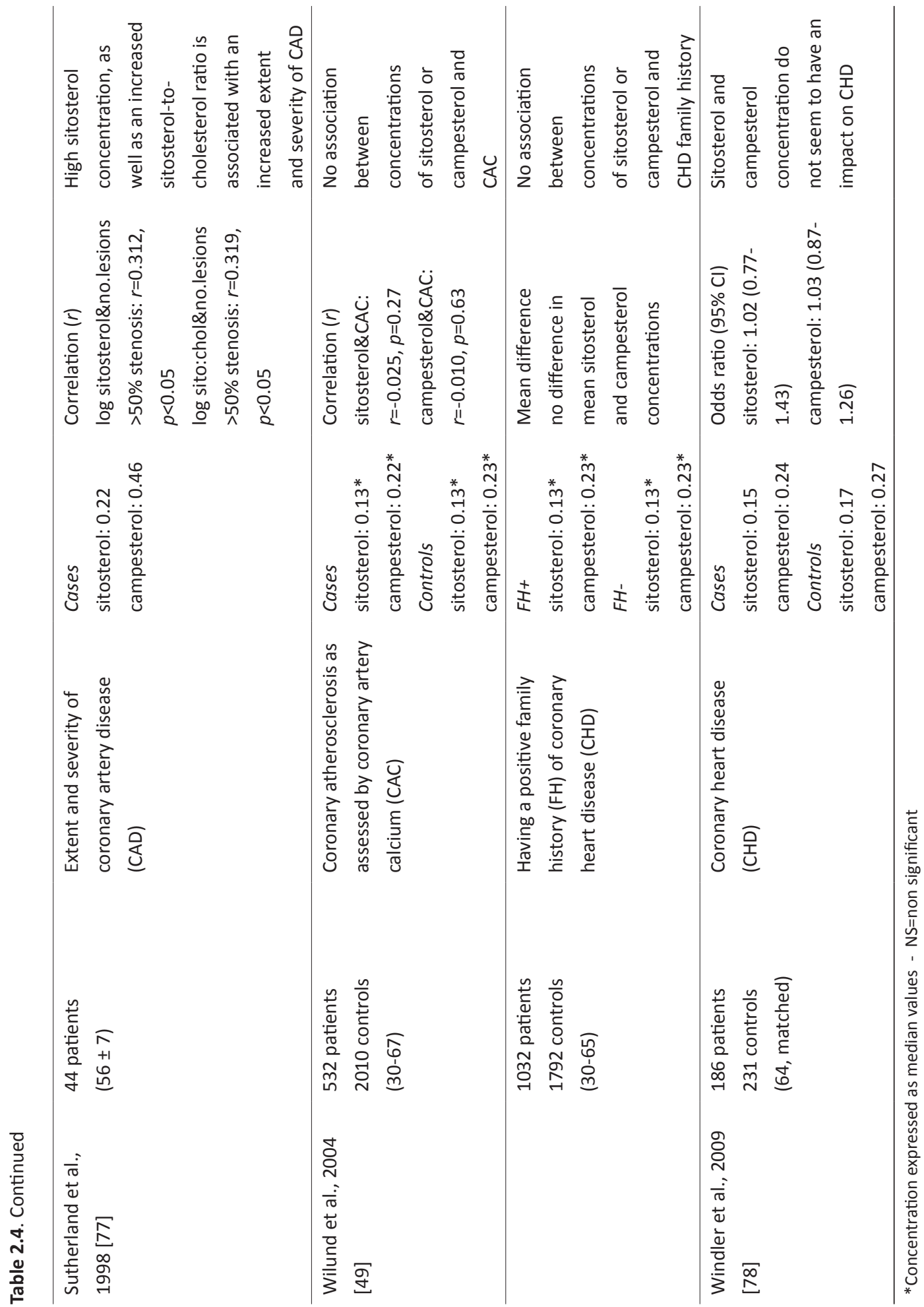


at the double bond at the C5-C6 position [53]. Due to sterical hindrance because of different structures, the side-chains of plant sterols is - unlike the side chain of cholesterol - not accessible for oxidizing enzymes and can, as far as known yet, not be oxidized [54]. The ring-oxidation products of cholesterol are potentially atherogenic, as indicated by animal studies [55]. Plant stanols do not have a double bond in the steroid nucleus and can therefore not be oxidized [53]. Interest in oxyphytosterol concentrations as mediators of CVD risk originates from the presence of elevated oxyphytosterol concentrations in serum of phytosterolemic patients [56]. In this study, it was shown that about $1.4 \%$ of sitosterol was present in its oxidized form. No oxyphytosterols could be identified in serum of healthy volunteers, which was probably due to a lack of sensitivity of the method. In a later study, Grandgirard et al. used a quantification method with a lower detection limit and was able to identify oxyphytosterols in plasma from healthy volunteers as well [57]. The question now is whether oxyphytosterols are atherogenic as has been suggested for oxysterols, or not. In vitro experiments from our group using human coronary arterial endothelial cells (HCAECs) have indicated that especially oxyphytosterols increased MCP-1 expression (unpublished results). Therefore the question whether the existing discrepancy in associations between elevated plant sterol concentrations and CVD risk is related to differences in oxyphytosterol concentrations, certainly deserves attention.

A second possible explanation for the association between elevated serum plant sterol concentrations and CVD risk relates to the finding that increased serum plant sterol concentrations are a marker for increased intestinal cholesterol absorption. Recently, Silbernagel et al. have determined concentrations of cholesterol absorption and synthesis markers in a large cohort of subjects undergoing angiography [58]. In this cohort, increased concentrations of both campesterol and cholestanol (markers of fractional cholesterol absorption) were associated with an increased severity of coronary artery disease (CAD), while a negative association was found for the cholesterol synthesis marker lathosterol. As this association was also evident for cholestanol, also a marker for fractional cholesterol absorption, a specific atherogenic role of (oxidized) plant sterols may be not likely, whereas it is more likely that the higher fractional intestinal cholesterol absorption may be the underlying reason for this association. This study also identified a positive association between an increased campesterol-to-lathosterol ratio and the severity of CAD. Since the campesterollathosterol ratio combines cholesterol absorption and synthesis, the question remains what the merit is of this ratio? Weingärtner et al. [59] found that the ratio campesterol-tolathosterol was associated with CAD severity in patients with severe aortic valve stenosis. However, in this particular study the increase in the ratio was driven by a continuous lower lathosterol concentration, instead of higher cholesterol absorption markers, for which no differences were found. This means that a one-directional change of this ratio can thus result from two different processes. Since these two studies indicated a positive association between this ratio and CAD severity, by means of two different underlying and causative metabolic changes, no real value can be ascribed to this ratio. To our opinion, changes in 
the absolute markers are favourable over using the described ratio. This implies that the finding by Silbernagel et al., [58] in which the so-called 'absorbers' display an increased severity of CAD, still holds true. Weingärtner and co-workers also isolated aortic valve cusps via elective aortic valve replacement and found a positive correlation between plant sterol concentrations in aortic valve cusps and the degree of aortic valve stenosis [59]. In an earlier study, this group also observed a positive association between the intake of plant sterols with sitosterol and campesterol concentrations in both serum and in aortic valve cusps [60]. Although these associations do not prove causality, they may suggest some role or another for plant sterols in the pathogenesis of aortic valve disease. However, in another study Weingärtner et al. [61] found no correlation between cholesterol absorption markers and carotid intima-media thickness (cIMT), while they did find a significant correlation between cholesterol synthesis markers and cIMT. This contrasts the suggestion that (sterol) absorbers as identified by elevated plant sterol concentrations are at risk. Thus, the question remains what causes the apparent inconsistency between studies examining the association between serum plant sterols and CVD risk. It has been suggested that age could play a role. Strandberg et al. have suggested that higher plant sterol concentrations may increase CVD risk at a younger age, but could be protective in older subjects [52]. In that prospective study in middle-aged men with an average of 61 years, higher plant sterol concentrations at baseline were associated with a decreased CVD risk 22 years later. Also the LASA study showed a reduced CVD risk associated with increased plant sterol concentrations at an older age [51]. In LASA, the average age of the subjects was 75 years, which is higher than in most other studies. The suggestion that increased plant sterol concentrations may protect at an older age should however be considered carefully, since it can also be argued that subjects with a low cholesterol absorption (low plant sterol concentrations) and a high cholesterol synthesis may have died before inclusion in these studies. Therefore, Strandberg et al. [52] concluded that the relationship between non-cholesterol sterols and CVD risk might be an example of 'reverse epidemiology'. This paradox states that factors which are harmful at younger age, such as overweight and high LDL-cholesterol concentrations, might look beneficial at older age [62]. Although other studies in which a negative association between serum plant sterols with CVD risk was observed were performed in younger populations [61], this concept is still very interesting to explore into more detail.

\section{Endothelial function}

Recent evidence suggests that consumption of plant sterols or stanols might affect endothelial function. This effects might either be caused by the plant sterols directly or indirectly as a consequence of the reduced serum LDL-cholesterol concentrations. Unfortunately, the number of studies that have investigated these effects is limited. Endothelial dysfunction is a reflection of an early, but still reversible phase in the development of atherosclerosis and studies have indicated that the presence of endothelial dysfunction is predictive for future 
cardiovascular events. In other words, preservation or improvement of endothelial function in response to treatment may decrease the risk for future cardiovascular events. Endothelial function can be determined via a wide variety of available techniques and flow-mediated dilatation (FMD) is probably the most commonly used and validated technique to measure endothelial function [63]. It is well known that statin therapy reduces LDL-cholesterol, which is associated with normalization of endothelial function [64]. It is however also possible, that effects are due to the pleiotropic effects of statins [65]. Effects of plant sterols and stanols on endothelial function have been examined in several studies. Results, however, are not conclusive. De Jongh et al. [66] performed a study in 41 children (5-12 years old), which were diagnosed with heterozygous familial hypercholesterolemia and had already impaired endothelial function. Although the consumption of $2.3 \mathrm{~g} / \mathrm{d}$ of plant sterols for 4 weeks decreased serum LDL-cholesterol concentrations by $14 \%$, this decrease was not associated with an improvement in endothelial function. Jakulj et al. [67] evaluated the effect of plant stanol supplementation on endothelial function in 42 children (7-12 years old) with heterozygous familial hypercholesterolemia. Serum LDL-cholesterol concentrations decreased with $9.2 \%$ after a 4 week intervention in which the children consumed $2.0 \mathrm{~g} / \mathrm{d}$ of plant stanols. Again, despite a significant reduction in serum LDL-cholesterol, endothelial function did not improve. Although these two studies do suggest that plant sterol and stanol consumption is an effective strategy to lower serum LDL-cholesterol in children with familial hypercholesterolemia, both studies did not provide any evidence for an effect on endothelial function. In line with these two studies in children, Hallikainen et al. [68] investigated the effects of consuming $2.0 \mathrm{~g} / \mathrm{d}$ of plant stanol and sterol esters for 10 weeks on endothelial function in hypercholesterolemic adult subjects. The intervention reduced LDL-cholesterol by $9-12 \%$ as compared to controls, but there was no change in endothelial function as measured by FMD. Brachial artery diameter was also determined, which did not change after the control treatment or the plant stanol treatment. The brachial artery diameter was however diminished after the plant sterol treatment, but the clinical relevance of such a reduction remains unclear. Also Raitakari et al. [69] assessed in hypercholesterolemic subjects FMD and carotid arterial compliance to determine the effect of consuming $2 \mathrm{~g} / \mathrm{d}$ of plant stanols for a period of 12 weeks on endothelial function and arterial elasticity. The intervention reduced the serum LDL-cholesterol by $9 \%$, but FMD and arterial elasticity did not change. However, subgroup analyses showed that endothelial function and arterial elasticity were improved in subjects who were characterized with below average values for these parameters at the start of the study. Similar results were found by De Jong et al., [70] who investigated long-term (85 weeks) plant sterol or stanol ester consumption on endothelial function and arterial stiffness in patients on statin treatment. They did not find an effect on vascular function in the whole study population, but in a subgroup of patients with more pronounced CVD, as indicated by high baseline levels of matrix metalloproteinase- 9 , an improvement in endothelial function and arterial stiffness was observed. These results seem promising for a possible role of plant sterols and stanols in improving vascular 
function for subjects with suboptimal vascular function. The possible effects of plant sterols and stanols on endothelial function are only minor in comparison to the effects of statins, which have a strong ability of improving endothelial function. Plausible explanations for this discrepancy in improving endothelial function between statins and plant sterols and stanols could be ascribed to the more potent LDL-cholesterol lowering effects of statins as compared to those of plant sterols and stanols [66]. Another possibility is that statins exert pleiotropic effects on the vasculature [71]. Since these pleiotropic effects have not been found for plant sterols and stanols, this latter option could be a likely explanation for the difference in potency between statins and plant sterols and stanols regarding their ability to improve endothelial function.

Besides effects on the larger vessels as measured via techniques like FMD, plant sterol and stanol consumption might change the microcirculation. Cardiovascular disease is known to be a disease of the large vessels, but evidence is accumulating that disturbances in the microcirculation also predict future CVD risk [72]. Studies have shown that a larger retinal venular diameter is associated with several established atherosclerotic risk factors [73]. Until now, only one study has investigated the long-term effects of plant sterol and stanol consumption on the retinal vasculature. Kelly et al. [74] performed a study in which subjects were asked to consume $2.5 \mathrm{~g} / \mathrm{d}$ of plant sterols or plant stanols for a period of 85 weeks. They identified a non-significant increase in venular diameter after consumption of plant sterols, when compared to the changes in the plant stanol and control group. Linear regression analysis however showed a significant positive association between increases in cholesterol-standardized serum campesterol concentrations and increases in venular diameter. The functional consequences of the findings in terms of CVD risk are however unknown. Kelly et al. observed an increase in venular diameter of $2.3 \mu \mathrm{m}$ in the sterol group when compared to the change in both the stanol and control group. Kawasaki et al. [75] showed that subjects suffering from the metabolic syndrome had on average an increase of $4.69 \mu \mathrm{m}$ in their venular diameter, when compared to healthy subjects. Ikram et al. estimated that an increase in venular diameter of $0.4 \mu \mathrm{m}$ was associated with a one point increase in carotid plaque-score and that current smokers had on average a $10 \mu \mathrm{m}$ larger venular diameter than non-smokers [73]. Therefore, these findings warrant further investigation in terms of the functional consequences of diet-induced changes in venular diameter.

To summarize, the role of plant sterols and stanols as cholesterol lowering agents is well characterized. Several meta-analyses have shown that consumption of $2.5 \mathrm{~g} / \mathrm{d}$ of plant sterols and stanols can lower serum LDL-cholesterol concentrations up to $\sim 10 \%$, while recent studies have shown that additional benefit can be achieved at higher intakes. Besides their cholesterol lowering effect, evidence is now emerging that plant sterols and stanols are also able to exert beneficial effects on triacylglycerol metabolism, which makes them more attractive for metabolic syndrome-like populations. On the other hand, there is an 
ongoing debate whether increased serum plant sterol concentrations are associated with an increased CVD risk. Finally. Some studies suggested that plant sterols and stanols might improve endothelial dysfunction in those at risk, although evidence is still limited and more research is needed.

\section{References}

1. Law MR, Wald NJ, Thompson SG. By how much and how quickly does reduction in serum cholesterol concentration lower risk of ischaemic heart disease? BMJ 1994; 308: 367-72.

2. Cohen JC, Boerwinkle E, Mosley TH, Jr., Hobbs HH. Sequence variations in PCSK9, low LDL, and protection against coronary heart disease. N Engl J Med 2006; 354: 1264-72.

3. Duff CJ, Hooper NM. PCSK9: an emerging target for treatment of hypercholesterolemia. Expert Opin Ther Targets 2011; 15: 157-68.

4. Executive Summary of The Third Report of The National Cholesterol Education Program (NCEP) Expert Panel on Detection, Evaluation, And Treatment of High Blood Cholesterol In Adults (Adult Treatment Panel III). JAMA 2001; 285: 2486-97.

5. Ostlund RE, Jr. Phytosterols in human nutrition. Annu Rev Nutr 2002; 22: 533-49.

6. Law M. Plant sterol and stanol margarines and health. BMJ 2000; 320: 861-4.

7. Katan MB, Grundy SM, Jones P, Law M, Miettinen T, Paoletti R. Efficacy and safety of plant stanols and sterols in the management of blood cholesterol levels. Mayo Clin Proc 2003; 78: 965-78.

8. Sudhop T, Sahin Y, Lindenthal B, Hahn C, Luers C, Berthold HK, et al. Comparison of the hepatic clearances of campesterol, sitosterol, and cholesterol in healthy subjects suggests that efflux transporters controlling intestinal sterol absorption also regulate biliary secretion. Gut 2002; 51: 860-3.

9. Miettinen TA, Tilvis RS, Kesaniemi YA. Serum plant sterols and cholesterol precursors reflect cholesterol absorption and synthesis in volunteers of a randomly selected male population. Am J Epidemiol 1990; 131: 20-31.

10. Chan YM, Varady KA, Lin Y, Trautwein E, Mensink RP, Plat J, et al. Plasma concentrations of plant sterols: physiology and relationship with coronary heart disease. Nutr Rev 2006; 64: 385-402.

11. Abumweis SS, Barake R, Jones PJ. Plant sterols/stanols as cholesterol lowering agents: A meta-analysis of randomized controlled trials. Food Nutr Res 2008; 52.

12. Demonty I, Ras RT, van der Knaap HC, Duchateau GS, Meijer L, Zock PL, et al. Continuous dose-response relationship of the LDL-cholesterol-lowering effect of phytosterol intake. J Nutr 2009; 139: 271-84.

13. Brull F, Mensink RP, van den Hurk K, Duijvestijn A, Plat J. TLR2 activation is essential to induce a Th1 shift in human peripheral blood mononuclear cells by plant stanols and plant sterols. J Biol Chem 2010; 285: 2951-8.

14. Brull FM, RP. Plat, J. Plant sterols: functional lipids in immune function and inflammation? Clin Lipidol 2009; 4: 355-65.

15. Theuwissen E, Plat J, van der Kallen CJ, van Greevenbroek MM, Mensink RP. Plant stanol supplementation decreases serum triacylglycerols in subjects with overt hypertriglyceridemia. Lipids 2009; 44: 1131-40.

16. Jones PJ, AbuMweis SS. Phytosterols as functional food ingredients: linkages to cardiovascular disease and cancer. Curr Opin Clin Nutr Metab Care 2009; 12: 147-51.

17. Mensink RP, de Jong A, Lutjohann D, Haenen GR, Plat J. Plant stanols dose-dependently decrease LDLcholesterol concentrations, but not cholesterol-standardized fat-soluble antioxidant concentrations, at intakes up to $9 \mathrm{~g} / \mathrm{d}$. Am J Clin Nutr 2010; 92: 24-33.

18. Gylling $\mathrm{H}$, Hallikainen $\mathrm{M}$, Nissinen MJ, Simonen $\mathrm{P}$, Miettinen TA. Very high plant stanol intake and serum plant stanols and non-cholesterol sterols. Eur J Nutr 2009; 49: 111-7. 
19. Ayesh R, Weststrate JA, Drewitt PN, Hepburn PA. Safety evaluation of phytosterol esters. Part 5. Faecal shortchain fatty acid and microflora content, faecal bacterial enzyme activity and serum female sex hormones in healthy normolipidaemic volunteers consuming a controlled diet either with or without a phytosterol esterenriched margarine. Food Chem Toxicol 1999; 37: 1127-38.

20. Clifton PM, Noakes M, Ross D, Fassoulakis A, Cehun M, Nestel P. High dietary intake of phytosterol esters decreases carotenoids and increases plasma plant sterol levels with no additional cholesterol lowering. J Lipid Res 2004; 45: 1493-9.

21. Davidson MH, Maki KC, Umporowicz DM, Ingram KA, Dicklin MR, Schaefer E, et al. Safety and tolerability of esterified phytosterols administered in reduced-fat spread and salad dressing to healthy adult men and women. J Am Coll Nutr 2001; 20: 307-19.

22. Plat J, Mensink RP. Plant stanol and sterol esters in the control of blood cholesterol levels: mechanism and safety aspects. Am J Cardiol 2005; 96: 15D-22D.

23. Plat J, van Onselen EN, van Heugten MM, Mensink RP. Effects on serum lipids, lipoproteins and fat soluble antioxidant concentrations of consumption frequency of margarines and shortenings enriched with plant stanol esters. Eur J Clin Nutr 2000; 54: 671-7.

24. AbuMweis SS, Vanstone CA, Ebine N, Kassis A, Ausman LM, Jones PJ, Lichtenstein AH. Intake of a single morning dose of standard and novel plant sterol preparations for 4 weeks does not dramatically affect plasma lipid concentrations in humans. J Nutr 2006; 136: 1012-6.

25. Derdemezis CS, Filippatos TD, Mikhailidis DP, Elisaf MS. Review article: effects of plant sterols and stanols beyond low-density lipoprotein cholesterol lowering. J Cardiovasc Pharmacol Ther 2010; 15: 120-34.

26. Naumann E, Plat J, Kester AD, Mensink RP. The baseline serum lipoprotein profile is related to plant stanol induced changes in serum lipoprotein cholesterol and triacylglycerol concentrations. J Am Coll Nutr 2008; 27: 117-26.

27. Plat J, Brufau G, Dallinga-Thie GM, Dasselaar M, Mensink RP. A plant stanol yogurt drink alone or combined with a low-dose statin lowers serum triacylglycerol and non-HDL cholesterol in metabolic syndrome patients. J Nutr 2009; 139: 1143-9.

28. Plana N, Nicolle C, Ferre R, Camps J, Cos R, Villoria J, et al. Plant sterol-enriched fermented milk enhances the attainment of LDL-cholesterol goal in hypercholesterolemic subjects. Eur J Nutr 2008; 47: 32-9.

29. Judd JT, Baer DJ, Chen SC, Clevidence BA, Muesing RA, Kramer M, et al. Plant sterol esters lower plasma lipids and most carotenoids in mildly hypercholesterolemic adults. Lipids 2002; 37: 33-42.

30. Child P, Kuksis A. Investigation of the role of micellar phospholipid in the preferential uptake of cholesterol over sitosterol by dispersed rat jejunal villus cells. Biochem Cell Biol 1986; 64: 847-53.

31. Plat J, Mensink RP. Increased intestinal ABCA1 expression contributes to the decrease in cholesterol absorption after plant stanol consumption. FASEB J 2002; 16: 1248-53.

32. Plat J, Mensink RP. Plant stanol esters lower serum triacylglycerol concentrations via a reduced hepatic VLDL-1 production. Lipids 2009; 44: 1149-53.

33. Tremblay AJ, Lamarche B, Hogue JC, Couture P. Effects of ezetimibe and simvastatin on apolipoprotein B metabolism in males with mixed hyperlipidemia. J Lipid Res 2009; 50: 1463-71.

34. Chan DC, Watts GF. Dyslipidaemia in the metabolic syndrome and type 2 diabetes: pathogenesis, priorities, pharmacotherapies. Expert Opin Pharmacother 2011; 12: 13-30.

35. Chan DC, Watts GF, Gan SK, Ooi EM, Barrett PH. Effect of ezetimibe on hepatic fat, inflammatory markers, and apolipoprotein B-100 kinetics in insulin-resistant obese subjects on a weight loss diet. Diabetes Care 2010; 33: 1134-9.

36. Balk EM, Lichtenstein AH, Chung M, Kupelnick B, Chew P, Lau J. Effects of omega-3 fatty acids on serum markers of cardiovascular disease risk: a systematic review. Atherosclerosis 2006; 189: 19-30. 
37. Skulas-Ray AC, Kris-Etherton PM, Harris WS, Vanden Heuvel JP, Wagner PR, West SG. Dose-response effects of omega-3 fatty acids on triglycerides, inflammation, and endothelial function in healthy persons with moderate hypertriglyceridemia. Am J Clin Nutr 2011; 93: 243-52.

38. Ford ES, Li C, Zhao G, Pearson WS, Mokdad AH. Hypertriglyceridemia and its pharmacologic treatment among US adults. Arch Intern Med 2009; 169: 572-8.

39. Sarwar N, Danesh J, Eiriksdottir G, Sigurdsson G, Wareham N, Bingham S, et al. Triglycerides and the risk of coronary heart disease: 10,158 incident cases among 262,525 participants in 29 Western prospective studies. Circulation 2007; 115: 450-8.

40. Naumann E, Plat J, Mensink RP. Changes in serum concentrations of noncholesterol sterols and lipoproteins in healthy subjects do not depend on the ratio of plant sterols to stanols in the diet. J Nutr 2003; 133: 2741-7.

41. Salen G, Horak I, Rothkopf M, Cohen JL, Speck J, Tint GS, et al. Lethal atherosclerosis associated with abnormal plasma and tissue sterol composition in sitosterolemia with xanthomatosis. J Lipid Res 1985; 26: 1126-33.

42. Berge KE, Tian H, Graf GA, Yu L, Grishin NV, Schultz J, et al. Accumulation of dietary cholesterol in sitosterolemia caused by mutations in adjacent ABC transporters. Science 2000; 290: 1771-5.

43. Assmann G, Cullen P, Erbey J, Ramey DR, Kannenberg F, Schulte H. Plasma sitosterol elevations are associated with an increased incidence of coronary events in men: results of a nested case-control analysis of the Prospective Cardiovascular Munster (PROCAM) study. Nutr Metab Cardiovasc Dis 2006; 16: 13-21.

44. Matthan NR, Pencina M, LaRocque JM, Jacques PF, D'Agostino RB, Schaefer EJ, et al. Alterations in cholesterol absorption/synthesis markers characterize Framingham offspring study participants with CHD. J Lipid Res 2009; 50: 1927-35.

45. Sudhop T, Gottwald BM, von Bergmann K. Serum plant sterols as a potential risk factor for coronary heart disease. Metabolism 2002; 51: 1519-21.

46. Glueck CJ, Speirs J, Tracy T, Streicher P, Illig E, Vandegrift J. Relationships of serum plant sterols (phytosterols) and cholesterol in 595 hypercholesterolemic subjects, and familial aggregation of phytosterols, cholesterol, and premature coronary heart disease in hyperphytosterolemic probands and their first-degree relatives. Metabolism 1991; 40: 842-8.

47. Silbernagel G, Fauler G, Hoffmann MM, Lutjohann D, Winkelmann BR, Boehm BO, et al. The associations of cholesterol metabolism and plasma plant sterols with all-cause and cardiovascular mortality. J Lipid Res 2010; 51: 2384-93.

48. Teupser D, Baber R, Ceglarek U, Scholz M, Illig T, Gieger C, et al. Genetic regulation of serum phytosterol levels and risk of coronary artery disease. Circ Cardiovasc Genet 2010; 3: 331-9.

49. Wilund KR, Yu L, Xu F, Vega GL, Grundy SM, Cohen JC, et al. No association between plasma levels of plant sterols and atherosclerosis in mice and men. Arterioscler Thromb Vasc Biol 2004; 24: 2326-32.

50. Pinedo S, Vissers MN, von Bergmann K, Elharchaoui K, Lutjohann D, Luben R, et al. Plasma levels of plant sterols and the risk of coronary artery disease: the prospective EPIC-Norfolk Population Study. J Lipid Res 2007; 48: 139-44.

51. Fassbender K, Lutjohann D, Dik MG, Bremmer M, Konig J, Walter S, et al. Moderately elevated plant sterol levels are associated with reduced cardiovascular risk--the LASA study. Atherosclerosis 2008; 196: 283-8.

52. Strandberg TE, Gylling H, Tilvis RS, Miettinen TA. Serum plant and other noncholesterol sterols, cholesterol metabolism and 22-year mortality among middle-aged men. Atherosclerosis; 210: 282-7.

53. Hovenkamp E, Demonty I, Plat J, Lutjohann D, Mensink RP, Trautwein EA. Biological effects of oxidized phytosterols: a review of the current knowledge. Prog Lipid Res 2008; 47: 37-49.

54. Lutjohann D. Sterol autoxidation: from phytosterols to oxyphytosterols. Br J Nutr 2004; 91 : -4.

55. Bjorkhem I, Meaney S, Diczfalusy U. Oxysterols in human circulation: which role do they have? Curr Opin Lipidol 2002; 13: 247-53. 
56. Plat J, Brzezinka H, Lutjohann D, Mensink RP, von Bergmann K. Oxidized plant sterols in human serum and lipid infusions as measured by combined gas-liquid chromatography-mass spectrometry. J Lipid Res 2001; 42: 2030-8.

57. Grandgirard A, Martine L, Demaison L, Cordelet C, Joffre C, Berdeaux O, et al. Oxyphytosterols are present in plasma of healthy human subjects. Br J Nutr 2004; 91: 101-6.

58. Silbernagel G, Fauler G, Renner W, Landl EM, Hoffmann MM, Winkelmann BR, et al. The relationships of cholesterol metabolism and plasma plant sterols with the severity of coronary artery disease. J Lipid Res 2009; 50: 334-41.

59. Weingartner O, Weingartner N, Scheller B, Lutjohann D, Graber S, Schafers HJ, et al. Alterations in cholesterol homeostasis are associated with coronary heart disease in patients with aortic stenosis. Coron Artery Dis 2009; 20: 376-82.

60. Weingartner O, Lutjohann D, Ji S, Weisshoff N, List F, Sudhop T, et al. Vascular effects of diet supplementation with plant sterols. J Am Coll Cardiol 2008; 51: 1553-61.

61. Weingartner O, Pinsdorf T, Rogacev KS, Blomer L, Grenner Y, Graber S, et al. The relationships of markers of cholesterol homeostasis with carotid intima-media thickness. PLoS One 2010; 5: e13467.

62. Kalantar-Zadeh K, Horwich TB, Oreopoulos A, Kovesdy CP, Younessi H, Anker SD, et al. Risk factor paradox in wasting diseases. Curr Opin Clin Nutr Metab Care 2007; 10: 433-42.

63. Corretti MC, Anderson TJ, Benjamin EJ, Celermajer D, Charbonneau F, Creager MA, et al. Guidelines for the ultrasound assessment of endothelial-dependent flow-mediated vasodilation of the brachial artery: a report of the International Brachial Artery Reactivity Task Force. J Am Coll Cardiol 2002; 39: 257-65.

64. Davignon J. Beneficial cardiovascular pleiotropic effects of statins. Circulation 2004; 109: III39-43.

65. Masumoto A, Hirooka Y, Hironaga K, Eshima K, Setoguchi S, Egashira K, et al. Effect of pravastatin on endothelial function in patients with coronary artery disease (cholesterol-independent effect of pravastatin). Am J Cardiol 2001; 88: 1291-4.

66. de Jongh S, Vissers MN, Rol P, Bakker HD, Kastelein JJ, Stroes ES. Plant sterols lower LDL cholesterol without improving endothelial function in prepubertal children with familial hypercholesterolaemia. J Inherit Metab Dis 2003; 26: 343-51.

67. Jakulj L, Vissers MN, Rodenburg J, Wiegman A, Trip MD, Kastelein JJ. Plant stanols do not restore endothelial function in pre-pubertal children with familial hypercholesterolemia despite reduction of low-density lipoprotein cholesterol levels. J Pediatr 2006; 148: 495-500.

68. Hallikainen M, Lyyra-Laitinen T, Laitinen T, Agren JJ, Pihlajamaki J, Rauramaa R, et al. Endothelial function in hypercholesterolemic subjects: Effects of plant stanol and sterol esters. Atherosclerosis 2006; 188: 425-32.

69. Raitakari OT, Salo P, Gylling H, Miettinen TA. Plant stanol ester consumption and arterial elasticity and endothelial function. Br J Nutr 2008; 100: 603-8.

70. De Jong A, Plat J, Bast A, Godschalk RW, Basu S, Mensink RP. Effects of plant sterol and stanol ester consumption on lipid metabolism, antioxidant status and markers of oxidative stress, endothelial function and low-grade inflammation in patients on current statin treatment. Eur J Clin Nutr 2008; 62: 263-73.

71. Landmesser U, Bahlmann F, Mueller M, Spiekermann S, Kirchhoff N, Schulz S, et al. Simvastatin versus ezetimibe: pleiotropic and lipid-lowering effects on endothelial function in humans. Circulation 2005; 111: 2356-63.

72. Wong TY, Klein R, Nieto FJ, Klein BE, Sharrett AR, Meuer SM, et al. Retinal microvascular abnormalities and 10-year cardiovascular mortality: a population-based case-control study. Ophthalmology 2003; 110: 933-40.

73. Ikram MK, de Jong FJ, Vingerling JR, Witteman JC, Hofman A, Breteler MM, et al. Are retinal arteriolar or venular diameters associated with markers for cardiovascular disorders? The Rotterdam Study. Invest Ophthalmol Vis Sci 2004; 45: 2129-34.

74. Kelly ER, Plat J, Mensink RP, Berendschot TT. Effects of long term plant sterol and -stanol consumption on the retinal vasculature: A randomized controlled trial in statin users. Atherosclerosis 2011;214(1)225-30. 


\section{CHAPTER 2}

75. Kawasaki R, Tielsch JM, Wang JJ, Wong TY, Mitchell P, Tano Y, et al. The metabolic syndrome and retinal microvascular signs in a Japanese population: the Funagata study. Br J Ophthalmol 2008; 92: 161-6.

76. Rajaratnam RA, Gylling H, Miettinen TA. Independent association of serum squalene and noncholesterol sterols with coronary artery disease in postmenopausal women. J Am Coll Cardiol 2000; 35: 1185-91.

77. Sutherland WHF, Williams MJA, Nye ER, Resticaux NJ, de Jong SA, Walker HL. Associations of plasma noncholesterol sterol levels with severity of coronary artery disease. Nutr Metab Cardiovasc Dis 1998; 8: 38691.

78. Windler A, Zyriax B-C, Kuipers F, Linseisen J, Boeing H. Association of plasma phytosterol concentrations with incident coronary heart disease: Data from the CORA study, a case-control study of coronary artery disease in women. Atherosclerosis 2009; 203: 284-90. 


\section{Chapter 3}

\section{Effects of plant sterol or stanol enriched margarine on fasting plasma oxyphytosterol concentrations in healthy subjects}

Sabine Baumgartner, Ronald P. Mensink, Constanze Husche, Dieter Lütjohann, Jogchum Plat 


\begin{abstract}
Consumption of plant sterols and plant stanols reduces low-density lipoprotein cholesterol (LDL-C) concentrations. At the same time, plasma plant sterol concentrations will increase after plant sterol consumption, but decrease after plant stanol consumption. In contrast to plant stanols, plant sterols can undergo oxidation and form oxyphytosterols. Findings from in vitro and animal studies suggest that oxyphytosterols might be atherogenic. The objective was to examine whether plant sterol and stanol consumption changes fasting plasma oxyphytosterol concentrations. A randomised, double blind, cross-over study was performed in which 43 healthy subjects (18-70 years) consumed for 4 weeks a plant sterol enriched ( $3.0 \mathrm{~g} / \mathrm{d}$ of plant sterols), a plant stanol enriched ( $3.0 \mathrm{~g} / \mathrm{d}$ of plant stanols), and a control margarine separated by wash-out periods of 4 weeks. Oxyphytosterol concentrations were determined in BHT-enriched plasma via GC-MS. Compared to control, serum LDL-C concentrations were reduced after plant sterol $(-8.1 \% ; p<0.001)$ and plant stanol consumption $(-7.8 \% ; p<0.001)$. Plant sterol consumption did not change plasma oxyphytosterol concentrations. On the other hand, intake of the plant stanol margarine reduced $7 \beta-\mathrm{OH}$-campesterol by $0.07 \mathrm{ng} / \mathrm{mL}(\sim 14 \% ; p<0.01)$ and by $0.07 \mathrm{ng} / \mathrm{mL}(\sim 15 \%$; $p<0.01)$ compared with the control and sterol margarines, respectively. When standardized for serum cholesterol, effects on these oxyphytosterols were comparable. In addition, plant stanol intake reduced cholesterol-standardized 7-keto-campesterol levels compared with plant sterol intake $(p<0.05)$. Daily consumption of a plant sterol enriched margarine does not increase oxyphytosterol concentrations, while plant stanol consumption may reduce the concentrations of the oxidative plant sterol metabolites $7 \beta-\mathrm{OH}$-campesterol and 7-ketocampesterol. This trial is registered at clinicaltrials.gov as NCT01559428.
\end{abstract}




\section{Introduction}

Plant sterols are structurally related to cholesterol and only the side-chain configuration at the C24 position differs. Thus, both components consist of a steroid nucleus with a double bond present at $\mathrm{C} 5-\mathrm{C} 6$. This double bond is missing in plant stanols, the hydrogenated form of plant sterols. Humans are unable to synthesize plant sterols and stanols, which mean that serum plant sterols are by definition diet-derived. On average, serum sitosterol concentrations range from 0.12 to $0.62 \mathrm{mg} / \mathrm{dL}$ and campesterol concentrations from 0.27 to $1.08 \mathrm{mg} / \mathrm{dL}$ [1]. Serum plant stanol concentrations are approximately 100 times lower and vary between 2 and $10 \mu \mathrm{g} / \mathrm{dL}$ in the normal population [2].

Although plant sterol and plant stanol ester enriched products lower serum (low-density lipoprotein cholesterol (LDL-C) concentrations to the same extent at the recommended intake of approximately $2.5 \mathrm{~g} /$ day, they have a different effect on serum plant sterol concentrations; i.e. increased plant sterol consumption will elevate serum plant sterol concentrations, while an increased plant stanol consumption will lower serum plant sterol concentrations [3]. The relevance of increased serum plant sterol concentrations relates in great detail to the ongoing debate whether plant sterol concentrations are positively associated with cardiovascular disease (CVD) risk or not. The atherogenicity of increased plant sterol concentrations was first suggested after the identification of the rare autosomal-recessively inheritable sterol storage disease phytosterolemia. These patients are characterized by extremely high plant sterol concentrations ranging from 10-65 mg/dL and a strong predisposition for premature coronary atherosclerosis [4, 5]. Moreover, some epidemiological studies have suggested that also in the general population plasma plant sterol concentrations are positively associated with an increased risk to develop CVD [6-8]. Results are however far from conclusive, since there are also numerous studies that did not show this association [9]. How these inconsistencies between study outcomes can be explained is not known. One possibility is that the potential association between circulating plant sterols and CVD risk may not relate to plant sterols per se, but to the fact that serum plant sterols are a marker for intestinal cholesterol absorption [10]. In other words, it is possible that an increased absorption of cholesterol associates with CVD risk [11]. Alternatively, it is possible that oxidation of plant sterols - i.e. the formation of oxyphytosterols - is important to explain the potential association between plant sterol concentrations and CVD risk. Like cholesterol, plant sterols can undergo oxidation, as they possess a double bond between C5-C6 in the steroid nucleus (Figure 3.1). 


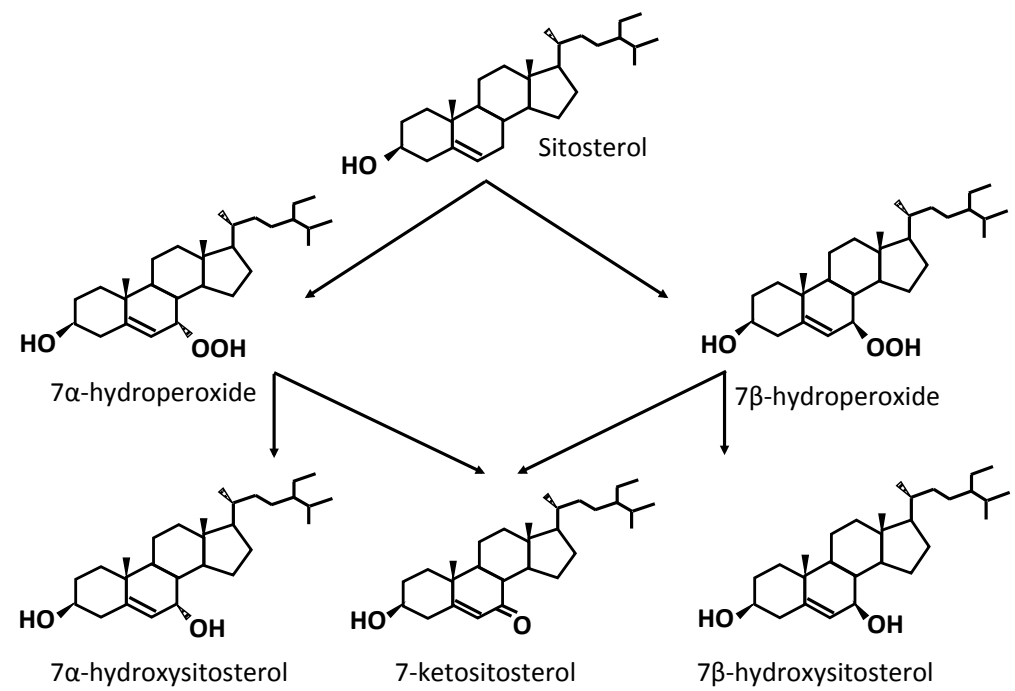

Figure 3.1. Non-enzymatically formed oxysitosterol structures. Similar structures are also formed for campesterol and other plant sterols.

Ring-oxidation products of cholesterol may be atherogenic [12-14], while not much is known about the biological effects of ring-oxyphytosterols. Oxyphytosterols first received attention as potential mediators of CVD risk after it was shown that about $1.4 \%$ of circulating sitosterol in serum of phytosterolemic patients was present in its oxidized form [15]. Plant stanols do not have a double bond in the steroid nucleus and can therefore not oxidize [16]. In light of the widespread use of plant sterol enriched products, it is important to identify whether an increased intake of plant sterols will result in increased plasma oxyphytosterol concentrations. Another interesting question is whether an increased plant stanol intake will not only decrease serum plant sterol concentrations, but will also change those of the oxyphytosterols. Therefore, the objective of this study was to examine the effects of consuming plant sterol or stanol ester enriched margarines on fasting serum oxyphytosterol concentrations in healthy volunteers.

\section{Subjects and Methods}

\section{Subjects}

Subjects were recruited through announcements in local newspapers and university buildings in Maastricht, the Netherlands, between February and April 2010. They were invited for two screening visits if they met the following criteria: aged between 18 and 70 years, BMI between 20 and $30 \mathrm{~kg} / \mathrm{m}^{2}$, no active cardiovascular disease or severe medical condition that might interfere with the study, no use of lipid-lowering medication or a medically prescribed 
diet, stable body weight during the last three months, and no consumption of plant sterolor plant stanol enriched products in the previous month. During the screening visits, weight and height were measured and two fasting blood samples were drawn to determine plasma glucose and serum lipid and lipoprotein concentrations. Forty-seven subjects (18 male and 29 female) were enrolled in the study. Two subjects did not complete the study due to time constraints and difficulties performing the venipuncture. In addition, two subjects were excluded before the analyses of the results: one male subject was not fasted during one blood sampling day and one female subject did not comply with margarine consumption. Baseline characteristics are shown in Table 3.1. All participants gave written informed consent before entering the study. The protocol was approved by the medical ethical committee of the Maastricht University Medical Centre+ (MUMC+). This trial is registered at clinicaltrials.gov as NCT01559428.

Table 3.1. Baseline characteristics of the subjects $(n=43)$

\begin{tabular}{ll}
\hline Age (years) & $41 \pm 18$ \\
\hline Male / Female $(\mathrm{n})$ & $17 / 26$ \\
\hline BMI $\left(\mathrm{kg} / \mathrm{m}^{2}\right)$ & $24.8 \pm 2.8$ \\
\hline Weight $(\mathrm{kg})$ & $73.2 \pm 11.0$ \\
\hline Height $(\mathrm{m})$ & $1.72 \pm 0.1$ \\
\hline Glucose (mmol/L) & $5.25 \pm 0.54$ \\
\hline Total cholesterol (mmol/L) & $5.72 \pm 1.12$ \\
\hline LDL cholesterol (mmol/L) & $3.53 \pm 1.06$ \\
\hline HDL cholesterol (mmol/L) & $1.69 \pm 0.37$ \\
\hline Triacylglycerol (mmol/L) & $1.14 \pm 0.46$ \\
\hline Values arem
\end{tabular}

Values are means \pm SD

\section{Diet and design}

Subjects participated in a randomised placebo-controlled crossover trial, which consisted of three intervention periods of 4 weeks, separated by washout periods of 4 weeks. They were allocated to the intervention periods in a randomised order, based upon a computergenerated table with random numbers. During each period, subjects were asked to replace their own spread with the test margarine (70\% fat) of which 20 gram had to be consumed on a daily basis. The daily intake of 20 gram of margarine provided no, or $3.0 \mathrm{~g}$ of plant 
sterols or stanols per day, referred to as the control, sterol or stanol period. The margarines were packed in tubs of 140 grams each, providing margarine for 7 days. The margarines were similar in colour and taste and the tubs were colour coded to blind both subjects and investigators. All volunteers received instructions to consume the margarines divided over two meals, i.e. at lunch and diner. The margarines were all rapeseed oil based with (saturated) soy sterols as source of the plant sterols / stanols. Plant sterols and stanols were provided as fatty acid esters by transesterification of free plant sterols and stanols with rapeseed oil fatty acids. The plant sterol ester mixtures contained mainly sitosterol ester (43\%), campesterol ester (25\%) and stigmasterol ester (20\%). Plant stanol mixtures were obtained by saturation of these sterols, resulting in sitostanol ester (76\%) and campestanol ester (22\%) (Raisio group, Raisio, Finland). Plant sterol, plant stanol and oxyphytosterol content of the margarines are shown in Table 3.2.

Table 3.2. Plant sterol, plant stanol and oxyphytosterol content of the margarines ${ }^{1}$

\begin{tabular}{|c|c|c|c|}
\hline & Control margarine & Plant sterol margarine & Plant stanol margarine \\
\hline Sitosterol & 0 & 64.8 & 1.4 \\
\hline Campesterol & 0 & 38.1 & 2.4 \\
\hline Stigmasterol & 0 & 29.6 & 0 \\
\hline Sitostanol & 0 & 3.8 & 114.3 \\
\hline Campestanol & 0 & 1.7 & 33.0 \\
\hline $7 \alpha$-OH-sitosterol & 0.35 & 6.15 & 0.19 \\
\hline $7 \alpha$-OH-campesterol & 0.09 & 2.48 & 0.08 \\
\hline $7 \beta$-OH-sitosterol & 0.80 & 11.39 & 0.51 \\
\hline $7 \beta$-OH-campesterol & 0.30 & 2.77 & 0.09 \\
\hline 7-keto-sitosterol & 1.67 & 5.41 & 2.31 \\
\hline 7-keto-campesterol & 1.67 & 5.54 & 2.23 \\
\hline
\end{tabular}

${ }^{1}$ Plant sterol and stanol content in $\mu \mathrm{g} / \mathrm{mg}$ and oxyphytosterol content in $\mathrm{ng} / \mathrm{mg}$

Subjects visited the university at the start of each period, and after 3 and 4 weeks of intervention. They received 4 tubs of margarine at the start of each period, the amount needed for 4 weeks. At the end of each week, the used margarine tubs had to be set aside and returned to the department to be weighed to determine compliance. Subjects completed a validated food frequency questionnaire (FFQ) at the end of all three intervention periods [17], and a dietician checked these questionnaires to calculate energy and nutrient intakes using the Dutch food composition table. Subjects were asked not to change their habitual 
diet, level of physical exercise or use of alcohol throughout the three intervention periods in the study.

\section{Blood sampling}

Blood was sampled after an overnight fast. The same person performed all venipuncture at approximately the same time of the day. Blood was sampled at the start of each period and after 3 and 4 weeks of intervention. A clotting tube (Becton, Dickinson and Company, Franklin Lakes, NY, USA) was sampled at each occasion and serum was obtained by lowspeed centrifugation at 1300x g for $15 \mathrm{~min}$ at room temperature, at least half an hour after venipuncture. Serum was stored at $-80^{\circ} \mathrm{C}$ and used for analysis of lipid and (apo)lipoprotein concentrations, and for plant sterol and plant stanol concentrations. An EDTA tube (Becton, Dickinson and Company, Franklin Lakes, NY, USA) was sampled at the start of each period and after 4 weeks and plasma was obtained by low-speed centrifugation at $1300 \mathrm{x}$ g for 15 min at $4{ }^{\circ} \mathrm{C}$, and then stored at $-80^{\circ} \mathrm{C}$. To avoid auto-oxidation, oxyphytosterol concentrations were determined in butylated hydroxytoluene (BHT)-enriched plasma; for this $10 \mu \mathrm{BHT}$ ( $25 \mathrm{mg} / \mathrm{mL}$ ethanol) was added per $1 \mathrm{~mL}$ of EDTA plasma, immediately after centrifugation.

\section{Analyses}

Total cholesterol (CHOD-PAP method; Roche Diagnostics, Mannheim, Germany), highdensity lipoprotein cholesterol (HDL-C) (CHOD-PAP method; Roche Diagnostics, Mannheim, Germany) after precipitation of apoB-containing lipoproteins with phosphotungstic acid and magnesium ions, and triacylglycerol (TAG) concentrations, with correction for free glycerol, were analysed in serum enzymatically (GPO-Trinder; Sigma-Aldrich Corp., St. Louis, MO, USA). All samples from one subject were analysed within one run the end of the study. LDL-C concentrations were calculated according to the Friedewald equation [18]. Apolipoprotein concentrations (apoA-1 and apoB100) were analysed using highly sensitive immunoturbidimetric assays (Horiba ABX, Montpellier, France). Lipid and (apo) lipoprotein concentrations from weeks 3 and 4 were averaged for data analysis. Plant sterol (sitosterol, campesterol), plant stanol (sitostanol, campestanol), cholesterol precursor (lathosterol), cholestanol and oxyphytosterol concentrations from week 4 were analysed by gas-liquid chromatography-mass spectroscopy (GC-MS) as described previously [19, 20]. Plant sterol, plant stanol and lathosterol concentrations were expressed as $10^{2} \mathrm{x} \mu \mathrm{mol} /$ $\mathrm{mmol}$ total cholesterol. The measured oxyphytosterols were $7 \alpha$-hydroxy $(\mathrm{OH})$-sitosterol, $7 \alpha-\mathrm{OH}$-campesterol, $7 \beta-\mathrm{OH}$-sitosterol, $7 \beta-\mathrm{OH}$-campesterol, 7-keto-sitosterol, and 7-ketocampesterol according the procedure as described by Husche et al. (20) and expressed as $\mathrm{ng} / \mathrm{mL}$. Oxyphytosterol concentrations were standardized for cholesterol concentrations and expressed as $\mathrm{nmol} / \mathrm{mmol}$ cholesterol. 


\section{Statistics}

To detect a change of $17 \mathrm{ng} / \mathrm{mL}$ in plasma oxyphytosterol concentrations with a power of $80 \%$ and a known within-subject variation on the response of $34 \mathrm{ng} / \mathrm{mL}$ (20), a sample size of 47 subjects was necessary, given an anticipated dropout rate of $10 \%$. All data are presented as means \pm standard deviations (SD). Effects of the experimental products were evaluated by a univariate analysis of variance (ANOVA) followed by Bonferroni's correction for multiple comparisons. Results were considered to be statistically significant if $p<0.05$. Results were analysed to assess whether gender effects or carryover effects existed, and both effects were not present in the data. All statistical analyses were performed using SPSS 18.0 for Mac Os X (SPSS Inc., Chicago, IL, USA).

\section{Results}

\section{Dietary intakes}

As shown in Table 3.3, the average daily intakes of total energy (MJ/day), protein (energy\%), carbohydrates (CHO, energy\%), total fat (energy\%), fatty acids (saturated fatty acids (SAFA), monounsaturated fatty acids (MUFA), and polyunsaturated fatty acids (PUFA), energy\%), fibre (g/day), cholesterol ( $\mathrm{mg} /$ day) and vitamin $\mathrm{E}(\mathrm{mg} /$ day) did not differ between the three intervention periods.

\section{Serum lipids and lipoproteins}

Serum lipid and lipoprotein concentrations are shown in Table 3.4. Compared with the control period, serum total cholesterol concentrations decreased by $0.30 \pm 0.51 \mathrm{mmol} / \mathrm{L}$ $(-5.3 \% ; p<0.001)$ in the sterol period and by $0.29 \pm 0.42 \mathrm{mmol} / \mathrm{L}(-5.3 \% ; p<0.001)$ in the stanol period. These reductions could almost completely be ascribed to decreases in serum LDL-C concentrations. In the sterol period, serum LDL-C concentrations decreased by 0.29 $\pm 0.43 \mathrm{mmol} / \mathrm{L}(-8.1 \%)$ and in the stanol period by $0.26 \pm 0.41 \mathrm{mmol} / \mathrm{L}(-7.8 \% ; p<0.001$ for both periods). Serum HDL-C concentrations were not different between the three periods. This shift towards a more beneficial partitioning of cholesterol was also reflected in the total cholesterol/HDL cholesterol ratio, which decreased in the sterol period by $0.14 \pm 0.36$ (-3.1\%; $p<0.05)$ and in the stanol period by $0.18 \pm 0.35(-4.9 \% ; p<0.01)$. Serum apolipoprotein B100 concentrations were reduced in the sterol period by $0.05 \pm 0.09 \mathrm{~g} / \mathrm{L}(-4.4 \%)$ and in the stanol period by $0.05 \pm 0.08 \mathrm{~g} / \mathrm{L}$ (-5.1\%; $p<0.01$ for both periods). No differences were found in serum TAG and apolipoprotein A1 concentrations between the three periods. 
Table 3.3. Daily dietary intake during the study

\begin{tabular}{lccc}
\hline & Control period & Plant sterol period & Plant stanol period \\
\hline Energy (MJ) & $10.6 \pm 3.4$ & $10.6 \pm 3.2$ & $10.5 \pm 3.2$ \\
\hline Fat (energy\%) & $37.5 \pm 7.2$ & $37.4 \pm 6.5$ & $37.4 \pm 6.6$ \\
SAFA $^{1}$ & $12.1 \pm 3.1$ & $12.2 \pm 3.0$ & $11.9 \pm 3.0$ \\
MUFA & $14.4 \pm 3.2$ & $14.6 \pm 2.7$ & $14.6 \pm 3.0$ \\
PUFA & $7.9 \pm 2.4$ & $8.2 \pm 2.0$ & $8.0 \pm 1.8$ \\
\hline Protein (energy\%) & $15.5 \pm 3.6$ & $15.4 \pm 3.4$ & $15.4 \pm 3.2$ \\
\hline CHO (energy\%) & $45.3 \pm 9.5$ & $44.4 \pm 7.5$ & $44.6 \pm 8.1$ \\
\hline Alcohol (energy\%) & $2.9 \pm 2.9$ & $2.6 \pm 2.6$ & $2.8 \pm 3.2$ \\
\hline Fibre (g/day) & $23.5 \pm 7.8$ & $24.0 \pm 7.5$ & $23.3 \pm 7.6$ \\
\hline Cholesterol (mg/day) & $221 \pm 111$ & $209 \pm 92$ & $205 \pm 77$ \\
\hline Vitamin E (mg/day) & $13.1 \pm 5.3$ & $13.6 \pm 5.8$ & $13.3 \pm 5.7$ \\
\hline Vales & & 2.0 & \\
\hline
\end{tabular}

Values are means $\pm S D$. All subjects $(n=43)$ received the three dietary periods in random order.

${ }^{1}$ SAFA: saturated fatty acids, MUFA: monounsaturated fatty acids, PUFA: polyunsaturated fatty acids, CHO: carbohydrates

\section{Serum plant sterols, plant stanols, lathosterol and cholestanol}

Cholesterol-standardized serum plant sterol, plant stanol, lathosterol and cholestanol levels are shown in Table 3.4. Sitosterol levels increased in the sterol period by $86.6 \pm 19910^{2} \times \mu \mathrm{mol} /$ $\mathrm{mmol}$ cholesterol $(49 \% ; \mathrm{p}<0.01)$ compared with the control period and by $138 \pm 24810^{2} \mathrm{x}$ $\mu \mathrm{mol} / \mathrm{mmol}$ cholesterol $(167 \%$; $\mathrm{p}<0.001)$ compared with the stanol period. For campesterol, these values were $132 \pm 13710^{2} \times \mu \mathrm{mol} / \mathrm{mmol}$ cholesterol (66\%; $\left.\mathrm{p}<0.001\right)$ and $214 \pm 138$ $10^{2} \times \mu \mathrm{mol} / \mathrm{mmol}$ cholesterol (179\%; $\left.\mathrm{p}<0.001\right)$. In addition, campesterol levels decreased in the stanol period by $82.3 \pm 53.310^{2} \times \mu \mathrm{mol} / \mathrm{mmol}$ cholesterol (37.3\%) compared with the control period $(p<0.001)$.

Sitostanol levels increased in the stanol period by $182 \pm 11410^{2} \times \mu \mathrm{mol} / \mathrm{mmol}$ cholesterol

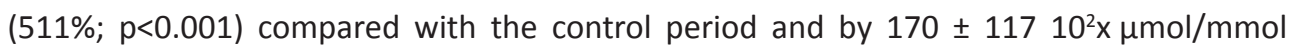
cholesterol $(404 \% ; \mathrm{p}<0.001)$ compared with the sterol period. For campestanol, these values were $103 \pm 7010^{2} \times \mu \mathrm{mol} / \mathrm{mmol}$ cholesterol (398\%; $\left.\mathrm{p}<0.001\right)$ and $96 \pm 6610^{2} \times \mu \mathrm{mol} /$ mmol cholesterol (295\%; $p<0.001$ ). Lathosterol levels, a marker for cholesterol synthesis, increased in the sterol period by $189 \pm 45410^{2} \times \mu \mathrm{mol} / \mathrm{mmol}$ cholesterol $(24.1 \% ; p<0.01)$ and in the stanol period by $147 \pm 32210^{2} \times \mu \mathrm{mol} / \mathrm{mmol}$ cholesterol $(17.5 \%$; $p<0.05)$ compared with the control period. Cholestanol levels, a marker for cholesterol absorption, decreased 
Table 3.4. Effect of consumption of plant sterol and plant stanol enriched margarines on serum lipid and lipoprotein concentrations, and on serum plant sterol, plant stanol and lathosterol levels

\begin{tabular}{|c|c|c|c|}
\hline & Control period & Plant sterol period & Plant stanol period \\
\hline Total cholesterol (mmol/L) & $5.56 \pm 1.07$ & $5.26 \pm 1.08^{1}$ & $5.27 \pm 1.11^{1}$ \\
\hline LDL cholesterol (mmol/L) & $3.36 \pm 1.06$ & $3.08 \pm 1.00^{1}$ & $3.10 \pm 1.05^{1}$ \\
\hline HDL cholesterol (mmol/L) & $1.69 \pm 0.39$ & $1.65 \pm 0.39$ & $1.68 \pm 0.39$ \\
\hline Total cholesterol/HDL & $3.46 \pm 1.00$ & $3.32 \pm 0.93^{2}$ & $3.28 \pm 0.96^{3}$ \\
\hline Triacylglycerol (mmol/L) & $1.14 \pm 0.40$ & $1.18 \pm 0.44$ & $1.08 \pm 0.41$ \\
\hline ApoB100 (g/L) & $0.97 \pm 0.25$ & $0.93 \pm 0.24^{3}$ & $0.92 \pm 0.26^{3}$ \\
\hline ApoA1 (g/L) & $1.57 \pm 0.31$ & $1.55 \pm 0.31$ & $1.55 \pm 0.27$ \\
\hline Sitosterol* & $140 \pm 69$ & $226 \pm 255^{3}$ & $88 \pm 35^{4}$ \\
\hline Campesterol & $214 \pm 83$ & $346 \pm 172^{1}$ & $131 \pm 59^{1,4}$ \\
\hline Sitostanol & $4.3 \pm 3.3$ & $5.5 \pm 5.7$ & $22.4 \pm 11.7^{1,4}$ \\
\hline Campestanol & $2.8 \pm 1.6$ & $3.5 \pm 2.0$ & $13.1 \pm 7.7^{1,4}$ \\
\hline Lathosterol & $115 \pm 57$ & $134 \pm 56^{3}$ & $130 \pm 55^{2}$ \\
\hline Cholestanol & $165 \pm 0.33$ & $153 \pm 32^{2}$ & $155 \pm 32^{2}$ \\
\hline
\end{tabular}

Values are means \pm SD and *sterols are expressed as $10^{2} \mathrm{x} \mu \mathrm{mol} / \mathrm{mmol}$ cholesterol. All subjects $(n=43)$ received the three dietary periods in random order.

Significantly different compared with control period: ${ }^{1}(p<0.001),{ }^{2}(p<0.05),{ }^{3}(p<0.01)$

Significantly different compared with sterol period ${ }^{4}(p<0.001)$

in the sterol period by $112 \pm 29210^{2} \times \mu \mathrm{mol} / \mathrm{mmol}$ cholesterol $(5.2 \% ; p<0.05)$ and in the stanol period by $96 \pm 20510^{2} \times \mu \mathrm{mol} / \mathrm{mmol}$ cholesterol $(4.9 \%$; $p<0.05)$ compared with the control period.

\section{Plasma oxyphytosterols}

Absolute oxyphytosterol concentrations $(\mathrm{ng} / \mathrm{mL})$ in BHT-enriched EDTA plasma are shown in Table 3.5. $7 \beta-\mathrm{OH}$-campesterol concentrations were decreased in the stanol period by $0.07 \pm 0.17 \mathrm{ng} / \mathrm{mL}(13.6 \%)$ compared with the control period $(p<0.01)$ and by $0.07 \pm 0.14$ 
$\mathrm{ng} / \mathrm{mL}(15.0 \%)$ compared with the sterol period $(p<0.01)$. Concentrations of the other oxyphytosterol were comparable between the three periods.

Cholesterol-standardized oxyphytosterol levels ( $\mathrm{nmol} / \mathrm{mmol}$ cholesterol) showed comparable results, i.e. a decreased $7 \beta-\mathrm{OH}$-campesterol level in the stanol period compared with the control and sterol period ( $p<0.01$ and $p<0.05$, respectively). In addition, 7-ketocampesterol levels were reduced in the stanol period compared with the sterol period $(p<0.05)$.

Table 3.5. Effect of consumption of plant sterol and plant stanol enriched margarines on plasma oxyphytosterol concentrations

\begin{tabular}{|c|c|c|c|}
\hline A & Control period & Plant sterol period & Plant stanol period \\
\hline $7 \alpha$-OH-sitosterol & $0.21 \pm 0.09$ & $0.22 \pm 0.11$ & $0.26 \pm 0.35$ \\
\hline $7 \alpha$-OH-campesterol & $0.09 \pm 0.05$ & $0.09 \pm 0.06$ & $0.08 \pm 0.05$ \\
\hline $7 \beta-\mathrm{OH}$-sitosterol & $1.17 \pm 0.35$ & $1.09 \pm 0.52$ & $1.09 \pm 0.58$ \\
\hline 7ß-OH-campesterol & $0.32 \pm 0.16$ & $0.32 \pm 0.15$ & $0.25 \pm 0.11^{1,2}$ \\
\hline 7-keto-sitosterol & $2.49 \pm 0.58$ & $2.35 \pm 0.78$ & $2.35 \pm 0.60$ \\
\hline 7-keto-campesterol & $0.48 \pm 0.19$ & $0.49 \pm 0.28$ & $0.44 \pm 0.22$ \\
\hline \multicolumn{4}{|l|}{ B } \\
\hline $7 \alpha-\mathrm{OH}$-sitosterol & $0.10 \pm 0.05$ & $0.11 \pm 0.06$ & $0.12 \pm 0.16$ \\
\hline $7 \alpha$-OH-campesterol & $0.04 \pm 0.03$ & $0.05 \pm 0.03$ & $0.04 \pm 0.02$ \\
\hline $7 \beta$-OH-sitosterol & $0.54 \pm 0.17$ & $0.56 \pm 0.26$ & $0.50 \pm 0.26$ \\
\hline 7ß-OH-campesterol & $0.15 \pm 0.08$ & $0.17 \pm 0.08$ & $0.12 \pm 0.05^{1,3}$ \\
\hline 7-keto-sitosterol & $1.18 \pm 0.34$ & $1.22 \pm 0.45$ & $1.10 \pm 0.30$ \\
\hline 7-keto-campesterol & $0.23 \pm 0.10$ & $0.26 \pm 0.15$ & $0.21 \pm 0.10^{4}$ \\
\hline
\end{tabular}

Panel A: Values are means \pm SD and are expressed as $\mathrm{ng} / \mathrm{mL}$. Panel $\mathrm{B}$ : Values are means $\pm \mathrm{SD}$ and are expressed as $\mathrm{nmol} / \mathrm{mmol}$ cholesterol. All subjects $(n=43)$ received the three dietary periods in random order.

Significantly different compared with sterol period ${ }^{1}(p<0.01),{ }^{4}(p<0.05)$

Significantly different compared with control period ${ }^{2}(p<0.01),{ }^{3}(p<0.05)$ 


\section{Discussion}

There is an ongoing debate whether there is a relation between circulating serum plant sterol concentrations and cardiovascular risk. Based on findings from animal studies [2123], we hypothesized that plant sterols themselves are not, but become atherogenic, when oxidized. We here show that in healthy volunteers, despite the increase in non-oxidized plant sterols concentrations, absolute concentrations of oxyphytosterols do not increase after consumption of plant sterol enriched margarines. However, plant stanol consumption reduced $7 \beta-\mathrm{OH}$-campesterol concentrations and - when standardized for cholesterol also 7-keto-campesterol levels - compared with the control as well as with the plant sterol enriched margarine.

Oxyphytosterol concentrations in humans have only been determined in a few - merely crosssectional - studies. In 2001, Plat et al. identified oxyphytosterols in serum of phytosterolemic patients, but not in serum of healthy subjects [15]. A few years later, Grandgirard et al. used a method with a lower detection limit and detected $\alpha$ - and $\beta$-epoxysitosterol, 7-ketositosterol and sitostanetriol in plasma of healthy subjects in a range of 5-57 ng/mL [24]. We found oxyphytosterol concentrations in a range of $0.08-2.49 \mathrm{ng} / \mathrm{mL}$, but measured different oxyphytosterols. 7-keto-sitosterol, however, was measured in both studies and while we measured a mean concentration of $2.5 \mathrm{ng} / \mathrm{mL}$, Grandgirard et al. found a mean concentration of $6.1 \mathrm{ng} / \mathrm{mL}$. The amount BHT added to the samples differed between our and Grandgirard's study (1\% vs. $0.05 \%$ ), which might explain the discrepancies in oxyphytosterol concentrations. Menéndez-Carreño measured the same oxyphytosterols as we did, but found somewhat higher oxyphytosterol concentrations in serum of healthy volunteers $(0.25-4.48 \mathrm{ng} / \mathrm{mL})$ [25]. This difference between our results with Menéndez-Carreño's data is probably due to the use of different methods, emphasizing the need for standardization of oxyphytosterol analyses. Recently, Husche et al. determined oxyphytosterol concentrations in plasma from 16 volunteers, who were given plant sterol enriched margarine for 4 weeks, providing 3.0 gram of plant sterols per day. Oxyphytosterol concentrations did not change after plant sterol consumption, except for an $85 \%$ increase in $7 \beta-O H$-sitosterol concentrations [20]. In our study $7 \beta-\mathrm{OH}$-sitosterol concentrations did not change after consumption of a plant sterol enriched margarine, despite the fact that baseline $7 \beta-\mathrm{OH}$-sitosterol concentrations were comparable between the two studies $(1.20 \pm 0.54 \mathrm{ng} / \mathrm{mL}$ vs. $1.17 \pm 0.35 \mathrm{ng} / \mathrm{mL})$. The study of Husche et al., however, was not placebo-controlled, which might have influenced the results. The range of the different oxyphytosterol concentrations in Husche's study and our study was comparable $(0.07-3.01 \mathrm{ng} / \mathrm{mL}$ vs. $0.08-2.49 \mathrm{ng} / \mathrm{mL}$ ) and this consistency in baseline oxyphytosterol concentrations may help to define normal serum values.

So far oxyphytosterol concentrations have been reported as absolute values in literature. The question arises whether concentrations, as for non-oxidized plant sterols, should be standardized for cholesterol concentrations or not. Plant sterols concentrations are standardized for cholesterol, as plant sterols are transported by lipoproteins. This may be 
true for oxyphytosterols as well. When oxyphytosterols are standardized for cholesterol concentrations, conclusions were very comparable to those of the absolute changes, i.e. there was a significant decrease in $7 \beta-\mathrm{OH}$-campesterol concentrations in the stanol period compared to the sterol and control period. In addition, 7-keto-campesterol was significantly decreased in the stanol compared with the sterol period. Alternatively, oxyphytosterols levels can also be expressed as the proportion of circulating plant sterol concentrations, which more or less indicates the percentage of substrate that is oxidized. The percentage oxidized plant sterols of total plant sterols is the highest in the stanol period and the lowest in the sterol period, but this is mostly due to a change in plant sterol concentrations and not in oxyphytosterol concentrations. For this reason, it was chosen to only express oxyphytosterols in absolute and cholesterol-standardized levels (Table 5).

Theoretically, oxyphytosterols can be derived from absorption of oxidized plant sterols present in food, as well as from endogenous synthesis (either from enzymatic or non-enzymatic ringoxidation processes). Since this study cannot distinguish between endogenously formed and diet-derived oxyphytosterols, we can only speculate about the origin of the measured circulating oxyphytosterols. Although phytosterolemic patients follow a strict plant sterolpoor (and consequently also oxyphytosterol poor) diet, they still have elevated plasma (oxy) phytosterol concentrations [4]. This could indicate that plasma oxyphytosterols originate from in vivo oxidation of the high circulating non-oxidized serum plant sterol concentrations. A second potential indication for the in vivo formation of oxyphytosterols might be found in the oxyphytosterol content of the margarines. Oxyphytosterols in the diet are mainly derived from plant sterol enriched products [16]. Our plant sterol enriched margarine contained 34 ng oxyphytosterols per milligram margarine, while the oxyphytosterol content of the other two margarines was $\sim 5 \mathrm{ng} / \mathrm{mg}$ margarine (Table 2). However, this higher oxyphytosterol content did not translate into increased serum concentrations, which might suggest that serum concentrations are not related to absorption of oxyphytosterols from the diet. On the other hand, while non-oxidized plant sterol concentrations increased, oxyphytosterol concentrations did not increase, which could imply that oxyphytosterols are not formed in vivo but origin from intestinal absorption. In this respect, the relative absorption of different oxyphytosterols might give more insight into the origin of circulating oxyphytosterols. The sterol enriched margarines contained twice as much sitosterol oxidation products as campesterol oxidation products, while concentrations of sitosterol oxidation products in plasma were four to five times as high as campesterol concentration products. This may suggest that sitosterol oxidation products are preferentially absorbed or formed in vivo. However, in humans, non-oxidized campesterol is better absorbed than non-oxidized sitosterol and serum concentrations are also higher [26]. Human data is lacking, but animal studies have consistently shown that - analogue to the non-oxidized sterols - campesterol oxidation products are better absorbed than sitosterol oxidation products $[27,28]$. This may suggest that in vivo formation of plant sterol oxidation products is more likely than intestinal absorption, or perhaps that excretion of sitosterol oxidation products is low. To definitively 
answer the question whether plasma oxyphytosterols result from absorption or from in vivo formation, future studies should be performed in which for example labeled non-oxidized plant sterols are consumed and subsequent enrichment in labeled plasma oxyphytosterols is measured. In addition, little is known about tissue distribution of oxyphytosterols and whether serum oxyphytosterol concentrations relate to tissue concentrations. These questions should be addressed in future studies to elucidate the physiological role of circulating oxyphytosterols in humans.

We observed a decrease in absolute $7 \beta-\mathrm{OH}$-campesterol concentrations or cholesterol standardized $7 \beta-\mathrm{OH}$-campesterol and 7-keto-campesterol after plant stanol enriched margarine consumption. Again, it is not known whether this is due to effects on in vivo formation or on absorption. Also, it may be a chance finding. However, if true, it is interesting that $7 \beta-\mathrm{OH}$-cholesterol (cholesterol oxidation product) is regarded as the most atherogenic oxysterol and has been identified as the strongest predictor of a rapid progression of carotid atherosclerosis in humans [29]. Whether $7 \beta-\mathrm{OH}$-campesterol might also be regarded as an atherogenic compound remains to be determined.

Potential differences in dietary oxyphytosterol intake between treatments cannot be eliminated as the study is performed in a free-living setting, but due to the crossover design and low oxyphytosterol content in daily diet this is not very likely.

In conclusion, we have shown that a daily consumption of a plant sterol enriched margarine for a period of 4 weeks does not increase plasma oxyphytosterol levels. We further found that plant

stanol consumption reduced the absolute and cholesterol-standardized $7 \beta-\mathrm{OH}$-campesterol levels and the cholesterol-standardized 7-keto-campesterol level. The reproducibility and possible clinical implication of these reductions remain to be determined and deserve further investigation.

The project was funded by the Netherlands Organisation for Scientific Research (TOP grant No. 91208006). The authors' responsibilities were as follows-SB, RPM and JP: designed the research and wrote the manuscript; SB: conducted the research; $\mathrm{CH}$ and $\mathrm{DL}$; performed the sterol analyses; JP had primary responsibility for the final content. All authors read and approved the final manuscript and none of the authors had a conflict of interest.

\section{References}

1. Chan YM, Varady KA, Lin Y, et al. Plasma concentrations of plant sterols: physiology and relationship with coronary heart disease. Nutr Rev 2006;64:385-402.

2. Gylling H, Miettinen TA. The effects of plant stanol ester in different subject groups. Euro Cardiol 2010;6:1821.

3. Naumann E, Plat J, Mensink RP. Changes in serum concentrations of noncholesterol sterols and lipoproteins in healthy subjects do not depend on the ratio of plant sterols to stanols in the diet. J Nutr 2003;133:2741-7. 
4. Salen G, Horak I, Rothkopf M, et al. Lethal atherosclerosis associated with abnormal plasma and tissue sterol composition in sitosterolemia with xanthomatosis. J Lipid Res 1985;26:1126-33.

5. Sudhop T, von Bergmann K. Sitosterolemia--a rare disease. Are elevated plant sterols an additional risk factor? Z Kardiol 2004;93:921-8.

6. Assmann G, Cullen P, Erbey J, Ramey DR, Kannenberg F, Schulte H. Plasma sitosterol elevations are associated with an increased incidence of coronary events in men: results of a nested case-control analysis of the Prospective Cardiovascular Munster (PROCAM) study. Nutr Metab Cardiovas 2006;16:13-21.

7. Matthan NR, Pencina M, LaRocque JM, et al. Alterations in cholesterol absorption/synthesis markers characterize Framingham offspring study participants with CHD. J Lipid Res 2009;50:1927-35.

8. Silbernagel G, Fauler G, Hoffmann MM, et al. The associations of cholesterol metabolism and plasma plant sterols with all-cause and cardiovascular mortality. J Lipid Res 2010;51:2384-93.

9. Baumgartner S, Mensink RP, Plat J. Plant sterols and stanols in the treatment of dyslipidemia: new insights into targets and mechanisms related to cardiovascular risk. Curr Pharm Design 2011;17:922-32.

10. Tilvis RS, Miettinen TA. Serum plant sterols and their relation to cholesterol absorption. Am J Clin Nutr 1986;43:92-7.

11. Plat J, Lutjohann D, Mensink RP. What is the real meaning of increased serum plant sterol concentrations? $\mathrm{Br}$ J Nutr 2012;108:943-5.

12. Bjorkhem I, Meaney S, Diczfalusy U. Oxysterols in human circulation: which role do they have? Curr Opin Lipidol 2002;13:247-53.

13. Poli G, Sottero B, Gargiulo S, Leonarduzzi G. Cholesterol oxidation products in the vascular remodeling due to atherosclerosis. Mol Aspects Med 2009;30:180-9.

14. Vejux A, Malvitte L, Lizard G. Side effects of oxysterols: cytotoxicity, oxidation, inflammation, and phospholipidosis. Braz J Med Biol Res 2008;41:545-56.

15. Plat J, Brzezinka H, Lutjohann D, Mensink RP, von Bergmann K. Oxidized plant sterols in human serum and lipid infusions as measured by combined gas-liquid chromatography-mass spectrometry. J Lipid Res 2001;42:20308.

16. Hovenkamp E, Demonty I, Plat J, Lutjohann D, Mensink RP, Trautwein EA. Biological effects of oxidized phytosterols: a review of the current knowledge. Prog Lipid Res 2008;47:37-49.

17. Plat J, Mensink RP. Vegetable oil based versus wood based stanol ester mixtures: effects on serum lipids and hemostatic factors in non-hypercholesterolemic subjects. Atherosclerosis 2000;148:101-12.

18. Friedewald WT, Levy RI, Fredrickson DS. Estimation of the concentration of low-density lipoprotein cholesterol in plasma, without use of the preparative ultracentrifuge. Clin chem 1972;18:499-502.

19. De Jong A, Plat J, Bast A, Godschalk RW, Basu S, Mensink RP. Effects of plant sterol and stanol ester consumption on lipid metabolism, antioxidant status and markers of oxidative stress, endothelial function and low-grade inflammation in patients on current statin treatment. Eur J Clin Nutr 2008;62:263-73.

20. Husche $\mathrm{C}$, Weingartner $\mathrm{O}$, Pettersson $\mathrm{H}$, et al. Validation of an isotope dilution gas chromatography-mass spectrometry method for analysis of 7-oxygenated campesterol and sitosterol in human serum. Chem Phys Lipids 2011;164:425-31.

21. Plat J, Theuwissen E, Lutjohann D, Mensink RP. Are oxidized plant sterols underlying CHD risk in sitosterolemia? Atherosclerosis suppl 2009;10:Abstract.

22. Liang YT, Wong WT, Guan L, et al. Effect of phytosterols and their oxidation products on lipoprotein profiles and vascular function in hamster fed a high cholesterol diet. Atherosclerosis 2011;219:124-33.

23. Staprans I, Pan XM, Rapp JH, Grunfeld C, Feingold KR. Oxidized cholesterol in the diet accelerates the development of atherosclerosis in LDL receptor- and apolipoprotein E-deficient mice. Arterioscl Throm Vas 2000;20:708-14. 


\section{CHAPTER 3}

24. Grandgirard A, Martine L, Demaison L, et al. Oxyphytosterols are present in plasma of healthy human subjects. Br J Nutr 2004;91:101-6.

25. Menendez-Carreno M, Steenbergen H, Janssen HG. Development and validation of a comprehensive twodimensional gas chromatography-mass spectrometry method for the analysis of phytosterol oxidation products in human plasma. Anal Bioanal Chem 2012;402:2023-32.

26. Lutjohann D, Bjorkhem I, Beil UF, von Bergmann K. Sterol absorption and sterol balance in phytosterolemia evaluated by deuterium-labeled sterols: effect of sitostanol treatment. J Lipid Res 1995;36:1763-73.

27. Grandgirard A, Sergiel JP, Nour M, Demaison-Meloche J, Ginies C. Lymphatic absorption of phytosterol oxides in rats. Lipids 1999;34:563-70.

28. Tomoyori $\mathrm{H}$, Kawata $\mathrm{Y}$, Higuchi $\mathrm{T}$, et al. Phytosterol oxidation products are absorbed in the intestinal lymphatics in rats but do not accelerate atherosclerosis in apolipoprotein E-deficient mice. J Nutr 2004;134:1690-6.

29. Salonen JT, Nyyssonen K, Salonen R, et al. Lipoprotein oxidation and progression of carotid atherosclerosis. Circulation 1997;95:840-5. 


\section{Chapter 4}

\section{Oxyphytosterol formation in humans: identification of high vs. low oxidizers}

Sabine Baumgartner, Ronald P. Mensink, Gertjan den Hartog, Aalt Bast, Otto Bekers, Constanze Husche, Dieter Lütjohann and Jogchum Plat 


\begin{abstract}
Animal studies suggest that oxyphytosterols are atherogenic. However, we have previously shown that plasma oxyphytosterol concentrations did not increase after consuming a diet enriched in plant sterol esters ( $3 \mathrm{~g} /$ day), while minor reductions were seen after consuming a plant stanol ester-enriched diet. Large variations in oxyphytosterol concentrations between individuals however existed. The aim of this study was to identify factors that may explain inter-individual differences in plasma oxyphytosterol concentrations. For this, 43 subjects consumed for 4 weeks in random order a plant sterol, stanol and control margarine. Plasma oxyphytosterol concentrations were determined in butylated hydroxytoluene (BHT)-enriched EDTA plasma via GC-MS and serum oxidized low-density lipoprotein (oxLDL) concentrations were analysed via ELISA. Trolox equivalent antioxidant capacity (TEAC) values, $\alpha$-tocopherol concentrations and iron/copper status were determined to assess plasma oxidative and anti-oxidative capacity. Serum (non-oxidized) sitosterol and campesterol concentrations did not correlate with plasma oxysitosterol and oxycampesterol concentrations during any of the three dietary interventions. Moreover, plasma oxyphytosterol concentrations remained relatively stable over time. Six subjects could be arbitrarily classified as having consistent low or high plasma oxyphytosterol concentrations, which was also reflected in oxLDL concentrations. However, oxidative and anti-oxidative capacity markers, such as iron/copper status, $\alpha$-tocopherol concentrations and TEAC values, could not explain these differences. In conclusion, subjects seem to have consistent plasma oxyphytosterol concentrations, which resulted in the identification of 'low and high oxidizers'. Differences, however, could not be attributed to the oxidative and anti-oxidative capacity markers analysed.
\end{abstract}




\section{Introduction}

Cholesterol oxidation products (oxycholesterols) can be derived from dietary intake and from in vivo oxidation by specific enzymes or by reactive oxygen species (ROS) [1]. Increased oxycholesterol concentrations are found in plasma of patients suffering from cardiovascular disease (CVD) [2] and in atherosclerotic plaques [3]. Further, a positive correlation has been observed between ROS-induced oxycholesterol concentrations in serum and established CVD risk factors, such as obesity and increased triglyceride concentrations [4]. In addition, recent studies have also suggested that oxycholesterols contribute to the development of degenerative diseases such as age-related macular degeneration [5]. Although these findings are suggestive, causal relations between elevated plasma oxycholesterol concentrations and pathological conditions have not been established so far.

Plant sterols are structurally related to cholesterol and can be oxidized to oxyphytosterols [6]. While the biological role of oxycholesterols has been studied into large detail $[1,7]$, studies evaluating the formation, kinetics and (patho)physiological effects of oxyphytosterols are scarce. Oxycholesterols and oxyphytosterols exert cytotoxic and apoptotic effects in vitro, as indicated by an inhibition of cell growth and a reduction of cell viability [8]. Oxycholesterols may be more cytotoxic than oxyphytosterols [9], while pathways underlying the cytotoxicity of oxycholesterols and oxyphytosterols seem to be different, i.e. antioxidants protected against the damaging effects of oxycholesterols, but not against the toxicity of oxyphytosterols [10]. Studies in rodents have demonstrated that oxycholesterols and oxyphytosterols accumulate in tissues, but discrepancies exist regarding their potential atherogenicity [11-14].

What is clearly lacking is a comprehensive understanding of the aetiology behind the formation of oxyphytosterols and their effects in humans. Circulating oxyphytosterol concentrations have only been measured occasionally in human studies [15-18] and large variations in serum oxyphytosterol concentrations are observed when comparing the results of these studies. In a previous study, we have shown that plasma oxyphytosterol concentrations in healthy volunteers did not increase after consuming a diet enriched in plant sterol esters ( $3 \mathrm{~g} /$ day) for 4 weeks, while minor reductions were seen after consuming a plant stanol ester enriched [19]. More importantly, we identified large variations in oxyphytosterol concentrations between healthy human subjects, which remained stable over time. The aim of this study was now to identify factors that relate to these interindividual differences in plasma oxyphytosterol concentrations.

\section{Subjects and Methods}

Subjects, diets and design

The protocol of this placebo-controlled double-blind dietary intervention study has been reported into detail [19]. Briefly, subjects were recruited in Maastricht and surroundings. Subjects met the following criteria: 18-70 years of age; body mass index (BMI) between $20-30 \mathrm{~kg} / \mathrm{m}^{2}$; no active cardiovascular disease or severe medical condition during the past 5 
years that might interfere with the study; no use of lipid-lowering medication or a medically prescribed diet; stable body weight during the last three months; and no consumption of plant sterol or plant stanol enriched products in the previous month. In addition, serum total cholesterol concentrations were $<7.8 \mathrm{mmol} / \mathrm{L}$; serum triglyceride concentrations $<3.0 \mathrm{mmol} / \mathrm{L}$ and plasma glucose concentrations $<6.1 \mathrm{mmol} / \mathrm{L}$, as determined during two screening visits. Baseline characteristics are shown in Table 4.1. All participants gave written informed consent before entering the study. The protocol was approved by the medical ethical committee of the Maastricht University Medical Centre+ (MUMC+), and the study was registered at clinicaltrials.gov as NCT01559428.

Table 4.1. Baseline characteristics

\begin{tabular}{ll}
\hline Age $(\mathrm{y})$ & $41 \pm 18$ \\
\hline Male / female $(\mathrm{n})$ & $17 / 26$ \\
\hline BMI $\left(\mathrm{kg} / \mathrm{m}^{2}\right)$ & $24.8 \pm 2.8$ \\
\hline Total cholesterol $(\mathrm{mmol} / \mathrm{L})$ & $5.72 \pm 1.12$ \\
\hline LDL cholesterol $(\mathrm{mmol} / \mathrm{L})$ & $3.53 \pm 1.06$ \\
\hline HDL cholesterol $(\mathrm{mmol} / \mathrm{L})$ & $1.69 \pm 0.37$ \\
\hline Triacylglycerol $(\mathrm{mmol} / \mathrm{L})$ & $1.14 \pm 0.46$ \\
\hline
\end{tabular}

Values are means \pm SD

The study had a crossover design and consisted of three intervention periods of 4 weeks, separated by washout periods of 4 weeks. Subjects were stratified for gender and allocated to the intervention periods in a randomised order, based upon a computer-generated table with random numbers. During each intervention period, subjects were asked to replace their own spread with the test margarine (70\% fat) of which 20 gram had to be consumed on a daily basis. The daily consumption of 20 gram of margarine provided no, or 3.0 gram of plant sterols or stanols (provided as fatty-acid esters), referred to as control, sterol or stanol period. Margarine composition has previously been described into detail [19].

\section{Blood sampling}

Blood was sampled after an overnight fast after 3 and 4 weeks of intervention. A clotting tube (Becton, Dickinson and Company, Franklin Lakes, NY, USA) was sampled and serum was obtained by low-speed centrifugation at 1300x g for $15 \mathrm{~min}$ at room temperature, at least half an hour after venipuncture. Serum was stored at $-80^{\circ} \mathrm{C}$ and used for analysis of lipid and lipoprotein concentrations, of plant sterol and plant stanol concentrations, of oxidized low-density lipoprotein (oxLDL) concentrations, of $\alpha$-tocopherol (vitamin E) 
concentrations, of iron status parameters, i.e. total iron, ferritin and transferrin and of copper status parameters, i.e. copper and ceruloplasmin. An EDTA and NaF tube (Becton, Dickinson and Company, Franklin Lakes, NY, USA) were sampled. EDTA and NaF plasma was obtained by low-speed centrifugation at $1300 \mathrm{x}$ g for $15 \mathrm{~min}$ at $4 \stackrel{\circ}{\circ}$, and then stored at -80 ${ }^{\circ} \mathrm{C}$. To avoid auto-oxidation, oxyphytosterol concentrations were determined in butylated hydroxytoluene (BHT)-enriched EDTA plasma; for this $10 \mu \mathrm{lBHT}$ (25 mg/mL ethanol) was added per $1 \mathrm{~mL}$ of EDTA plasma, immediately after centrifugation. The trolox equivalent antioxidant capacity (TEAC) assay was performed in de-proteinated NaF plasma; for this $10 \%$ TCA was added to the plasma (1:1) followed by centrifugation ( $13.000 \mathrm{rpm}, 5$ minutes at $\left.4{ }^{\circ} \mathrm{C}\right)$.

\section{Analyses}

All analyses were performed in samples from week 4 of each intervention period, and samples from one subject were always analysed within one run to avoid bias caused by between run variations. Serum total cholesterol, plant sterol (sitosterol, campesterol) and plant stanol (sitostanol, campestanol) concentrations were analysed by gas-liquid chromatography-mass spectroscopy (GC-MS) as described previously [17, 20]. Plant sterol and plant stanol concentrations were expressed as $10^{2} \mathrm{x} \mu \mathrm{mol} / \mathrm{mmol}$ total cholesterol. The measured oxyphytosterols were $7 \alpha$-hydroxy $(\mathrm{OH})$-sitosterol, $7 \alpha-\mathrm{OH}$-campesterol, $7 \beta-\mathrm{OH}$-sitosterol, 7 $\beta$-OH-campesterol, 7-keto-sitosterol, and 7-keto-campesterol by GCMS according the procedure as described by Husche et al. [17] and expressed as $\mathrm{ng} / \mathrm{mL}$. Oxyphytosterol concentrations were also standardized for cholesterol concentrations and expressed as $\mathrm{nmol} / \mathrm{mmol}$ cholesterol. OxLDL concentrations were analysed by a commercially available sandwich ELISA (Mercodia, Uppsala, Sweden) and $\alpha$-tocopherol concentrations by reversed-phase HPLC as described before [21]. The TEAC value is a measurement for the total antioxidant status, relating the free radical scavenging properties of a solution or a compound to that of the synthetic antioxidant trolox. The assay was performed as previously described [22]. Total iron concentrations were determined with a fixed-timed endpoint assay on a Beckman Coulter LX20 PRO Clinical Chemistry analyser (Beckman Coulter, Fullerton, USA). Transferrin and ceruloplasmin concentrations were analysed by particle-enhanced immunonephelometry on the BN Prospect from Siemens Healthcare Diagnostics (Siemens, Munich, Germany). The transferrin saturation (\%) was calculated as Iron $(\mu \mathrm{mol} /)$ / (transferrin $(\mathrm{g} / \mathrm{L}) * 25) * 100 \%$. Ferritin concentrations were determined using an immunoturbidimetric assay on a Cobas 6000 system (Roche Diagnostics, Basel, Switzerland) and copper concentrations using the Thermo Scientific XSERIES 2 ICP-MS (Inductive Coupled Plasma-Mass Spectrometry) (Thermo Fischer Scientific, Florida, US). 


\section{Statistics}

Effects of the experimental products were evaluated by a univariate analysis of variance (ANOVA) followed by Bonferroni's correction for multiple comparisons with subject number as a random factor. Pearson correlation coefficients were used to examine linear relationships between parameters. Results were considered statistically significant if $p<0.05$. All statistical analyses were performed using SPSS 18.0 for Mac Os X (SPSS Inc., Chicago, IL, USA).

\section{Results}

Serum plant sterols and plasma oxyphytosterols

As reported previously [19], cholesterol-standardized serum sitosterol and campesterol levels increased in the sterol period compared with the control period $(49 \% ; p<0.01$ and $66 \% ; p<0.001$, respectively) and the stanol period (167\%; $p<0.001$ and $179 \% ; p<0.001$, respectively). In addition, cholesterol-standardized serum campesterol levels decreased in the stanol period compared with the control period ( $37 \% ; p<0.001)$. Plasma oxyphytosterol levels were not changed after consumption of the plant sterol enriched margarine. On the other hand, plant stanol consumption reduced cholesterol-standardized $7 \beta-\mathrm{OH}$-campesterol levels by $12 \%(p<0.05)$ and $21 \%(p<0.01)$ compared with the control and sterol period respectively, and 7-keto-campesterol levels by $12 \%(p<0.05)$ compared with the sterol period.

Serum (non-oxidized) sitosterol concentrations did not correlate with plasma oxysitosterol (oxidized sitosterol) concentrations $(r=0.08 ; p=0.45)$ during the control period. This was also true for serum campesterol and plasma oxycampesterol concentrations ( $r=0.12 ; p=0.59)$. Differences in serum plant sterol concentrations between the control period and sterol or stanol period $\mathrm{n}$ did not correlate with those in plasma oxyphytosterol concentrations $(r=0.23$; $p=0.13$ and $r=0.01 ; p=0.96$ respectively). Figure 4.1 (Panel $A$ ) shows individual differences in plasma oxyphytosterols (sum of oxysitosterol and oxycampesterol) and serum plant sterols (sum of sitosterol and campesterol) concentrations between the sterol and control periods, while panel B shows these differences between the stanol and control periods.

The individual changes in oxyphytosterol concentrations were ranked from the largest decrease to the highest increase (upper panels) and the accompanying changes in plant sterol concentrations in the same individual are plotted in the lower panels. As expected, the patterns of changing plasma oxyphytosterol concentrations and serum plant sterols concentrations did not correspond, i.e. an increase in serum plant sterol concentrations is not by definition accompanied by an increase in plasma oxyphytosterol concentrations (Figure 4.1, panel A). Similarly, a decrease in serum plant sterol concentrations was not accompanied by a corresponding decrease in plasma oxyphytosterol concentrations in the same individual (Figure 4.1, panel B). 

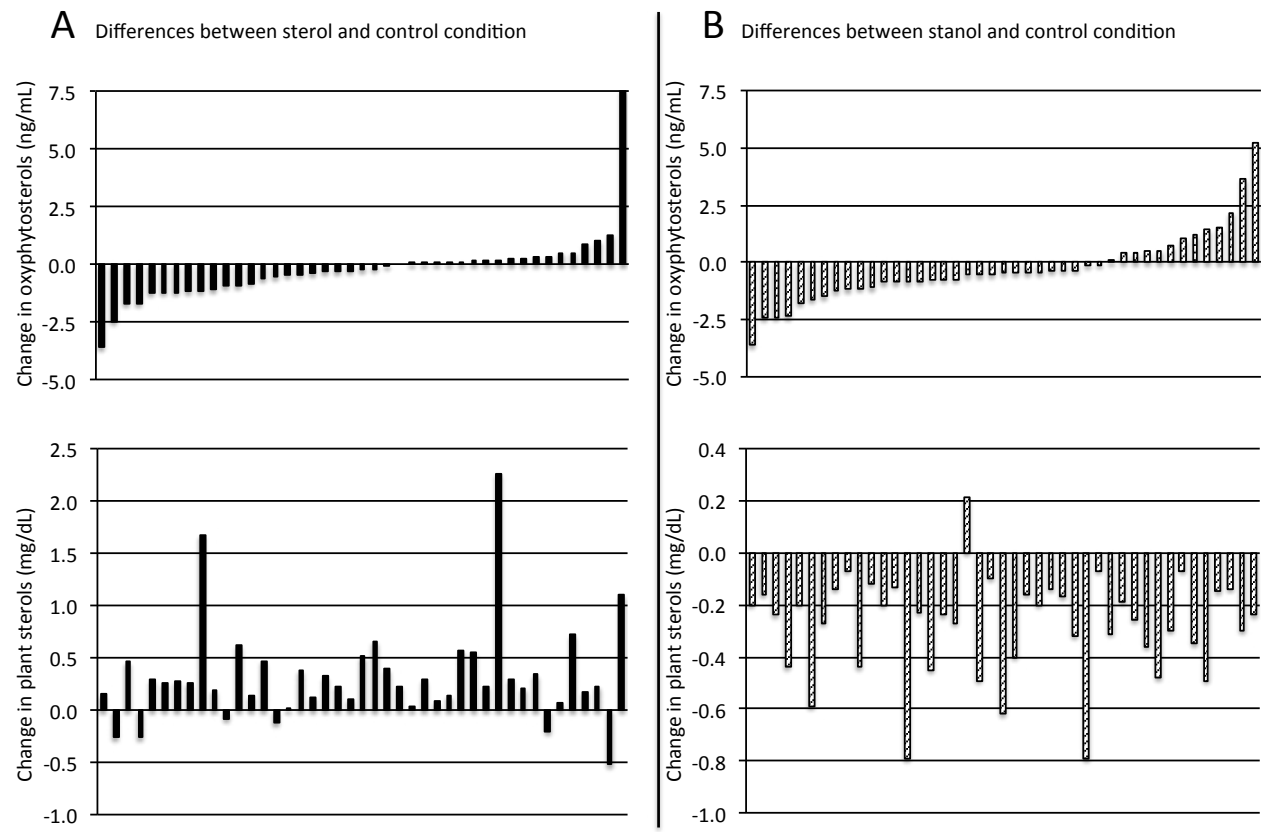

Figure 4.1. Individual differences between sum oxyphytosterol concentrations and sum plant sterol concentrations after plant sterol (panel A) and plant stanol consumption (panel B) when compared to control period $(n=43)$.

Plasma oxysitosterol concentrations at the end of the control and sterol period were significantly correlated (Figure 4.2; panel $A, r=0.51 ; p<0.001$ ), and this was also true for serum oxycampesterol concentrations (panel $B, r=0.45, p<0.01$ ). Significant correlations between dietary periods were also seen for the individual oxidation products $(7 \alpha-\mathrm{OH}, 7 \beta-\mathrm{OH}$ and 7-keto) of sitosterol and campesterol (data not shown). This suggests that differences in plasma oxyphytosterol concentrations between subjects were consistent during the different dietary interventions. By comparing the various oxyphytosterol correlation graphs (of all six individual oxyphytosterols, during all three dietary interventions), three subjects could arbitrarily be classified as having consistent low plasma oxyphytosterol concentrations and three subjects as having consistent high plasma oxyphytosterol concentrations.

To further explore this difference in oxyphytosterol concentrations between these so-called low and high oxidizers, serum oxLDL concentrations were determined. Figure 4.3 shows oxyphytosterol and oxLDL concentrations in the entire group and in the low and high oxidizers in the control period. In line with the findings for plasma oxyphytosterol concentrations, similar differences between low and high oxidizers in oxLDL concentrations were shown. Figure 3 illustrates that differences in oxyphytosterol concentrations are also reflected in oxLDL concentrations, although the groups are somewhat overlapping. The correlation between sum oxyphytosterol and oxLDL concentrations in the control period did not reach significance $(r=0.13, p=N S)$. On the other hand, there was a significant correlation between 
sum oxyphytosterol and oxLDL concentrations in the sterol period $(r=0.36 ; p<0.05)$ and stanol period $(r=0.32 ; p<0.05)$. More specifically, these significant correlations were only present for $7 \beta-\mathrm{OH}$-sitosterol, $7 \beta-\mathrm{OH}$-campesterol, 7-keto-sitosterol and 7-keto-campesterol (ROS-induced oxyphytosterols) and not for $7 \alpha-\mathrm{OH}$-sitosterol and $7 \alpha-\mathrm{OH}$-campesterol, which are in contrast to the other oxyphytosterols not only formed via ROS but also enzymatically produced (data not shown).
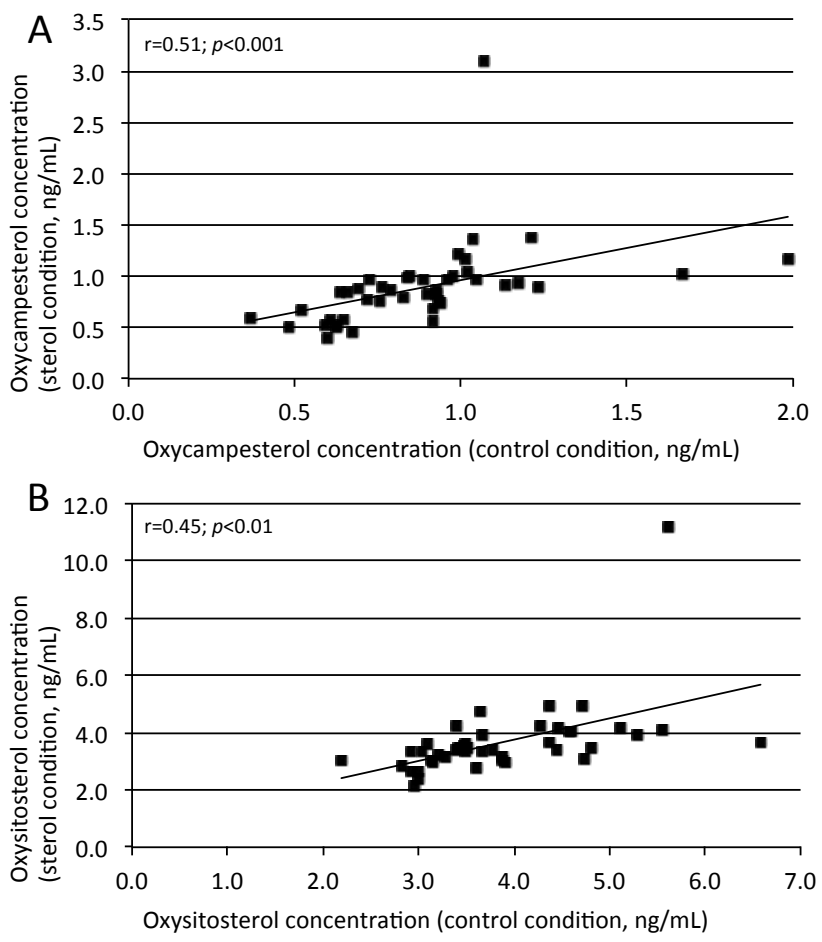

Figure 4.2. Correlations between sum oxycampesterol concentrations (panel $A, r=0.51 ; p<0.001$ ) and between sum oxysitosterol concentrations (panel $B, r=0.45 ; p<0.01$ ) in control and sterol period $(n=43)$.

\section{Anti-oxidative and pro-oxidative markers}

Plasma $\alpha$-tocopherol concentrations, TEAC values and iron and copper status markers were determined to identify factors that could relate to circulating plasma oxyphytosterol concentrations. As shown in Table 4.2, plasma $\alpha$-tocopherol concentrations decreased in the stanol period by $3.73 \pm 10.6 \mu \mathrm{mol} / \mathrm{L}$ compared with the control period $(7.9 \% ; p<0.05)$, while TEAC values and iron and copper status did not differ between the three dietary periods. This implies that a possible correlation between any of these parameters and plasma oxyphytosterol concentrations cannot be attributed to diet-induced changes in these anti-oxidative and pro-oxidative markers. No correlations between plasma oxyphytosterol 
concentrations with $\alpha$-tocopherol concentrations or TEAC values, both accepted markers of anti-oxidative capacity, were observed during any of the three dietary periods.
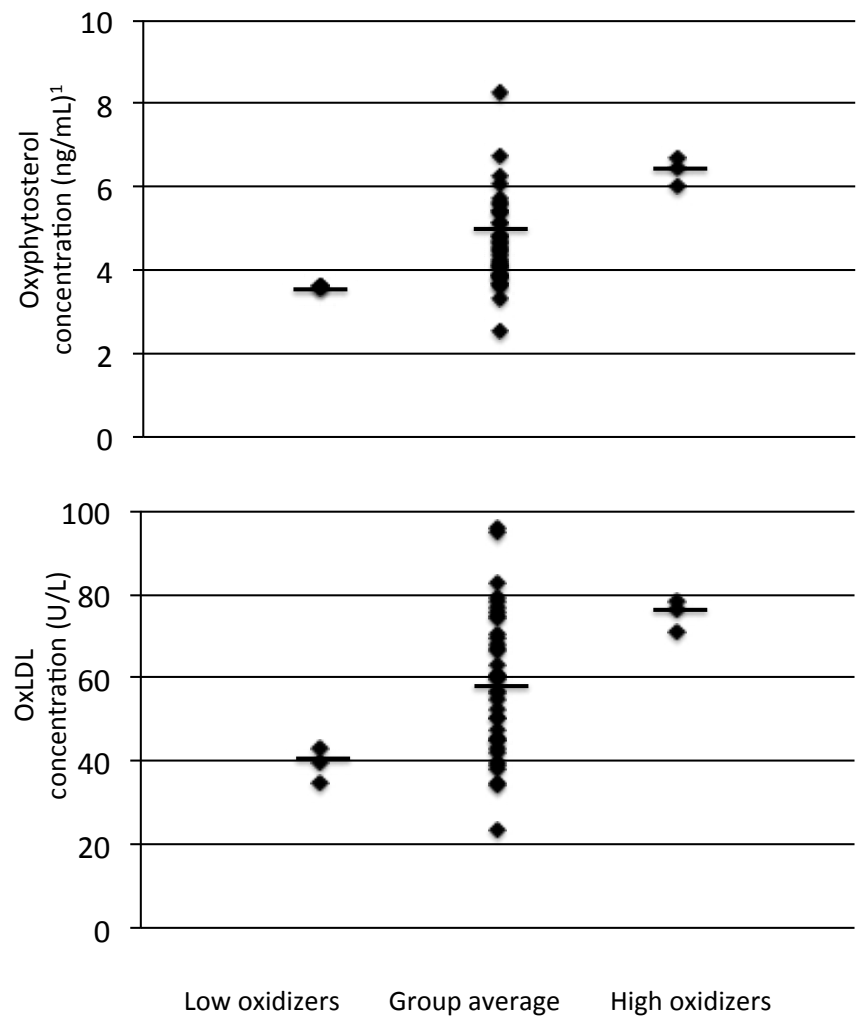

Figure 4.3. Oxidative stress markers in low and high oxidizers vs. group average.

${ }^{1}$ Oxyphytosterol is the sum of $7 \alpha$-sitosterol, $7 \beta-\mathrm{OH}$-sitosterol, 7-keto-sitosterol, $7 \alpha$-campesterol, $7 \beta-\mathrm{OH}-$ campesterol and 7-keto-campesterol concentrations. All analyses have been performed in each individual in the control period.

Next, iron status, a contributor to metal-induced oxidation in vivo, was determined by measuring total iron, ferritin and transferrin saturation. Correlations between all three iron status markers and oxLDL, and between iron status markers and oxyphytosterol concentrations during the control period are shown in Figure 4.4. In line with expectations, there were positive correlations between all three iron status markers and plasma oxLDL concentrations (total iron $r=0.37 ; p<0.05$, ferritin $r=0.37 ; p<0.05$, transferrin saturation $r=0.35 ; p<0.05)$. These correlations were comparable during all three dietary periods, except for oxLDL and ferritin concentration during the sterol period, which showed no statistically significant correlation ( $r=0.15 ; p=0.34)$. In contrast, no correlations were observed between any of the three iron status markers and oxyphytosterol concentrations during each of the three dietary periods. Finally, copper and ceruloplasmin (copper-binding protein) 
concentrations did not correlate with oxLDL concentrations or with plasma oxyphytosterol concentrations during any of the three dietary periods.

Table 4.2. Effect of consumption of plant sterol and plant stanol enriched margarines on plasma $\alpha$-tocopherol concentrations, TEAC values and on iron and copper status markers

\begin{tabular}{lccc}
\hline & $\begin{array}{c}\text { Control } \\
\text { period }\end{array}$ & $\begin{array}{c}\text { Plant sterol } \\
\text { period }\end{array}$ & $\begin{array}{c}\text { Plant stanol } \\
\text { period }\end{array}$ \\
\hline$\alpha$-tocopherol $(\mu \mathrm{mol} / \mathrm{L})$ & $44.5 \pm 12.5$ & $41.9 \pm 13.3$ & $40.8 \pm 15.3^{1}$ \\
TEAC values & $658.5 \pm 101.9$ & $676.0 \pm 118.9$ & $675.7 \pm 102.1$ \\
Total iron $(\mu \mathrm{mol} / \mathrm{L})$ & $17.9 \pm 7.7$ & $17.1 \pm 7.5$ & $16.7 \pm 7.4$ \\
Ferritin $(\mu \mathrm{g} / \mathrm{L})$ & $62.3 \pm 51.8$ & $65.8 \pm 51.7$ & $63.2 \pm 54.1$ \\
Transferrin saturation $(\%)$ & $30.7 \pm 16.7$ & $28.7 \pm 14.2$ & $28.3 \pm 15.1$ \\
Copper $(\mu \mathrm{mol} / \mathrm{L})$ & $18.4 \pm 8.0$ & $19.0 \pm 8.0$ & $18.5 \pm 7.6$ \\
Ceruloplasmin $(\mathrm{g} / \mathrm{L})$ & $0.30 \pm 0.11$ & $0.31 \pm 0.11$ & $0.31 \pm 0.10$ \\
\hline
\end{tabular}

Values are means \pm SD. All subjects $(n=43)$ received the three dietary periods in random order.

${ }^{1}$ Significantly different compared with control period $(p<0.05)$ 

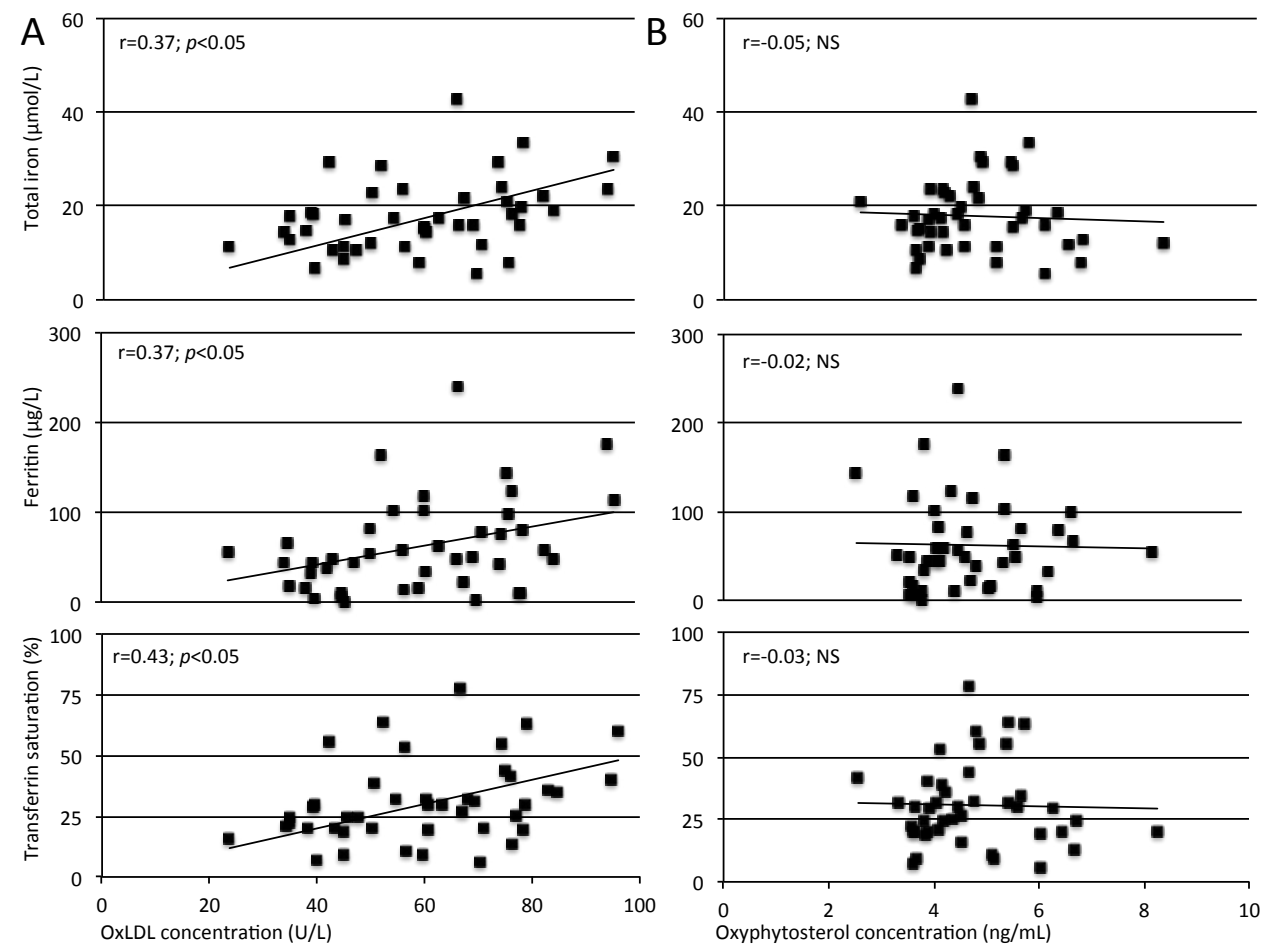

Figure 4.4. Correlations between iron status markers and oxLDL concentrations (panel A) and between iron status makers and sum oxyphytosterol concentrations (panel B) in control period $(n=43)$.

\section{Discussion}

This study demonstrates that in healthy volunteers plasma oxyphytosterol concentrations do not correlate with serum non-oxidized plant sterol concentrations. This lack of correlation was expected, as we have earlier found in the same study that an increased consumption of plant sterols does not increase plasma oxyphytosterol concentrations [19]. However, what we also showed is that plasma oxyphytosterol concentrations remained relatively stable during the 20 week study period. This consistency in low or high plasma oxyphytosterol concentrations was also reflected in serum oxLDL concentrations, a frequently used oxidative stress marker, which suggests a relationship between plasma oxyphytosterol concentrations and oxidative stress. Although the evidence is scarce, it is possible that oxyphytosterols - just like oxycholesterols - are atherogenic components. In animal studies, oxycholesterols and oxyphytosterols have been shown to accumulate in serum and liver, but the implications of this are still under debate [11-14]. What is lacking is a clear insight in the factors that influence formation of oxyphytosterols in humans, as well as the exact locations of oxidation within the human body. To identify factors that relate to these inter- 
individual differences in plasma oxyphytosterol concentrations, we searched for similarities and differences between oxLDL and oxyphytosterol concentrations.

In vivo oxidation is often catalysed by iron ions. Ferrous ions $\left(\mathrm{Fe}^{2+}\right)$ generate highly reactive hydroxyl radicals from hydrogen peroxide. These can oxidize lipids, nucleic acids, and proteins [23]. Increased iron stores are associated with oxidative stress, but associations between iron stores with oxidative stress-related diseases, such as type II diabetes and cardiovascular diseases remain contradictive $[24,25]$. We here show a positive correlation between iron stores and serum oxLDL concentrations. However, plasma oxyphytosterol concentrations were not correlated with iron stores. This suggests that oxidation of plant sterols and oxidation of LDL particles are not - at least not entirely - regulated by the same mechanisms. This might in part be explained by the fact that serum oxLDL concentrations represent essentially a fatty acid oxidation process and the antibody used binds to malondialdehyde (MDA)-modified apolipoprotein B particles. In contrast, oxidation of plant sterols represents sterol oxidation. Sterols are less susceptible to oxidative attack than polyunsaturated fatty acyl moieties, and will therefore be accompanied by other oxidized compounds [1]. Nevertheless, plasma oxycholesterol concentrations were positively associated with serum ferritin concentrations in a large cohort of Finnish men [26]. This is the first study that relates iron stores to plasma oxyphytosterols concentrations and our findings suggest that oxidation of plant sterols - in contrast to oxycholesterol and oxLDL formation - might not be iron-mediated. In contrast to the positive correlations between iron markers and oxLDL concentrations, we did not find this correlation for markers of copper status. As for iron, there was also no correlation between copper markers and oxyphytosterol concentrations. Epidemiological data regarding the role of copper in oxidative processes and CVD risk are not consistent and are still a matter of debate [27]. Copper is part of superoxide dismutase (SOD); an enzymatic antioxidant and copper deficiency (e.g. decreased SOD status) is associated with specific pathologies [28]. On the other hand, not only deficiencies but also copper overload is associated with inflammation and markers of oxidative stress in the body [29]. Ceruloplasmin is the major copper-containing plasma protein and depending on the circumstances can act as an antioxidant or pro-oxidant [27]. The fact that in this study serum copper and ceruloplasmin concentrations did not correlate with serum oxLDL or plasma oxyphytosterol concentrations seems in contrast with in vitro studies in which oxidation tendency of LDL particles is studied by means of copper-ions [30]. However, there is strong evidence that different oxidative products are generated during in vitro copper-induced oxidation of LDL compared with in vivo oxidation of these particles [1]. As described before, the role of copper in in vivo oxidative processes is contradictive and our results suggest that in this population of healthy volunteers, copper does not play a role (anti-oxidative or prooxidative) in the oxidation of LDL or plant sterols.

Both TEAC values and $\alpha$-tocopherol concentrations, markers for anti-oxidative capacity, were not associated with plasma oxyphytosterol concentrations, indicating that a relationship between oxyphytosterols and oxidative stress is not straightforward. On the other hand, 
serum oxLDL concentrations, a validated marker for oxidative stress, also did not correlate with TEAC values. Although these correlations imply that there is no association between anti-oxidative capacity and oxyphytosterol concentrations, it must be kept in mind that these are cross-sectional correlations and it would be interesting to assess oxyphytosterol concentrations after antioxidant supplementation.

Altogether the obtained results imply that for now, we cannot answer the question which factors contribute to the large inter-individual differences in fasting plasma oxyphytosterol concentrations. We have been able to exclude some parameters that seemed most logical to consider. In general, this search is complicated by the fact that information regarding oxy(phyto)sterol metabolism is scarce; not much is known about normal plasma concentrations in healthy subjects and in specific diseases, what the consequences are of increased concentrations, and whether plasma concentrations reflect tissue concentrations. To summarize, this study shows that plasma oxyphytosterol concentrations are linked to oxLDL concentrations, that concentrations remain relatively stable over time and that oxidation of plant sterols - in contrast to oxidation of LDL - might not be iron-mediated. Thus, many questions regarding oxyphytosterol metabolism still remain that deserve to be answered in future studies.

\section{References}

1. Brown AJ, Jessup W. Oxysterols: Sources, cellular storage and metabolism, and new insights into their roles in cholesterol homeostasis. Mol Aspects Med 2009;30:111-22.

2. Rimner A, Al Makdessi S, Sweidan H, Wischhusen J, Rabenstein B, Shatat K, et al. Relevance and mechanism of oxysterol stereospecifity in coronary artery disease. Free Radic Biol Med 2005;38:535-44.

3. Iuliano L, Micheletta F, Natoli S, Ginanni Corradini S, lappelli M, et al. Measurement of oxysterols and alphatocopherol in plasma and tissue samples as indices of oxidant stress status. Anal Biochem 2003;312:217-23.

4. Menendez-Carreno M, Varo N, Mugueta C, Restituto P, Ansorena D, Astiasaran I. Correlation between serum content of the main COPs (cholesterol oxidation products) from autoxidation and cardiovascular risk factors. Nutr Hosp 2011;26:144-51.

5. Malvitte L, Montange T, Joffre C, Vejux A, Maiza C, Bron A, et al. [Analogies between atherosclerosis and agerelated maculopathy: expected roles of oxysterols]. J Fr Ophtalmol 2006;29:570-8.

6. Hovenkamp E, Demonty I, Plat J, Lutjohann D, Mensink RP, Trautwein EA. Biological effects of oxidized phytosterols: a review of the current knowledge. Prog Lipid Res 2008;47:37-49.

7. Vaya J, Szuchman A, Tavori H, Aluf Y. Oxysterols formation as a reflection of biochemical pathways: summary of in vitro and in vivo studies. Chem Phys Lipids 2011;164:438-42.

8. Adcox C, Boyd L, Oehrl L, Allen J, Fenner G. Comparative effects of phytosterol oxides and cholesterol oxides in cultured macrophage-derived cell lines. J Agric Food Chem 2001;49:2090-5.

9. Maguire L, Konoplyannikov M, Ford A, Maguire AR, O’Brien NM. Comparison of the cytotoxic effects of betasitosterol oxides and a cholesterol oxide, 7beta-hydroxycholesterol, in cultured mammalian cells. Br J Nutr. 2003;90:767-75.

10. Ryan E, Chopra J, McCarthy F, Maguire AR, O'Brien NM. Qualitative and quantitative comparison of the cytotoxic and apoptotic potential of phytosterol oxidation products with their corresponding cholesterol oxidation products. Br J Nutr 2005;94:443-51. 
11. Liang $Y T$, Wong $W T$, Guan L, Tian $X Y$, Ma KY, Huang $Y$, et al. Effect of phytosterols and their oxidation products on lipoprotein profiles and vascular function in hamster fed a high cholesterol diet. Atherosclerosis 2011;219:124-33.

12. Tomoyori H, Kawata Y, Higuchi T, Ichi I, Sato H, Sato M, et al. Phytosterol oxidation products are absorbed in the intestinal lymphatics in rats but do not accelerate atherosclerosis in apolipoprotein E-deficient mice. J Nutr 2004;134:1690-6.

13. Ando M, Tomoyori H, Imaizumi K. Dietary cholesterol-oxidation products accumulate in serum and liver in apolipoprotein E-deficient mice, but do not accelerate atherosclerosis. Br J Nutr 2002;88:339-45.

14. Staprans I, Pan XM, Rapp JH, Grunfeld C, Feingold KR. Oxidized cholesterol in the diet accelerates the development of atherosclerosis in LDL receptor- and apolipoprotein E-deficient mice. Arterioscler Thromb Vasc Biol. 2000;20:708-14.

15. Plat J, Brzezinka H, Lutjohann D, Mensink RP, von Bergmann K. Oxidized plant sterols in human serum and lipid infusions as measured by combined gas-liquid chromatography-mass spectrometry. J Lipid Res 2001;42:20308.

16. Grandgirard A, Martine L, Demaison L, Cordelet C, Joffre C, Berdeaux O, et al. Oxyphytosterols are present in plasma of healthy human subjects. Br J Nutr 2004;91:101-6.

17. Husche $\mathrm{C}$, Weingartner $\mathrm{O}$, Pettersson $\mathrm{H}$, Vanmierlo $\mathrm{T}$, Bohm $\mathrm{M}$, Laufs $\mathrm{U}$, et al. Validation of an isotope dilution gas chromatography-mass spectrometry method for analysis of 7-oxygenated campesterol and sitosterol in human serum. Chem Phys Lipids 2011;164:425-31.

18. Menendez-Carreno M, Steenbergen H, Janssen HG. Development and validation of a comprehensive twodimensional gas chromatography-mass spectrometry method for the analysis of phytosterol oxidation products in human plasma. Anal Bioanal Chem 2012;402:2023-32.

19. Baumgartner S, Mensink R. P, Husche C, Lütjohann D, Plat J. Effects of plant sterol-or stanol-enriched margarine on fasting plasma oxyphytosterol concentrations in healthy subjects. Atherosclerosis 2013;227(2):4114-9.

20. De Jong A, Plat J, Bast A, Godschalk RW, Basu S, Mensink RP. Effects of plant sterol and stanol ester consumption on lipid metabolism, antioxidant status and markers of oxidative stress, endothelial function and low-grade inflammation in patients on current statin treatment. Eur J Clin Nutr 2008;62:263-73.

21. Plat J, Mensink RP. Effects of diets enriched with two different plant stanol ester mixtures on plasma ubiquinol-10 and fat-soluble antioxidant concentrations. Metabolism 2001;50:520-9.

22. de Jongh R, Dambros M, Haenen GR, den Hartog GJ, Bast A, van Kerrebroeck PE, et al. Partial bladder outlet obstruction reduces the tissue antioxidant capacity and muscle nerve density of the guinea pig bladder. Neurourol Urodyn 2009;28:461-7.

23. Halliwell B, Gutteridge JM. Biologically relevant metal ion-dependent hydroxyl radical generation. An update. FEBS Lett 1992;307:108-12.

24. Salonen JT, Nyyssonen K, Korpela H, Tuomilehto J, Seppanen R, Salonen R. High stored iron levels are associated with excess risk of myocardial infarction in eastern Finnish men. Circulation 1992;86:803-11.

25. Ascherio A, Willett WC, Rimm EB, Giovannucci EL, Stampfer MJ. Dietary iron intake and risk of coronary disease among men. Circulation 1994;89:969-74.

26. Tuomainen TP, Diczfalusy U, Kaikkonen J, Nyyssonen K, Salonen JT. Serum ferritin concentration is associated with plasma levels of cholesterol oxidation products in man. Free Radic Biol Med 2003;35:922-8.

27. Ferns GA, Lamb DJ, Taylor A. The possible role of copper ions in atherogenesis: the Blue Janus. Atherosclerosis 1997;133:139-52.

28. Johnson F, Giulivi C. Superoxide dismutases and their impact upon human health. Mol Aspects Med 2005;26:340-52.

29. Brewer GJ. Risks of copper and iron toxicity during aging in humans. Chem Res Toxicol 2010;23:319-26.

30. Esterbauer H, Striegl G, Puhl H, Rotheneder M. Continuous monitoring of in vitro oxidation of human low density lipoprotein. Free Radic Res Commun 1989;6:67-75. 


\section{Chapter 5}

\section{Postprandial plasma oxyphytosterol concentrations after consumption of plant sterol or stanol enriched mixed meals in healthy subjects}

Sabine Baumgartner, Ronald P. Mensink, Maurice Konings, Hans-F. Schött, Silvia Friedrichs, Constanze Husche, Dieter Lütjohann and Jogchum Plat 


\begin{abstract}
Epidemiological studies have reported inconsistent results on the relationship between increased plant sterol concentrations with cardiovascular risk, which might be related to the formation of oxyphytosterols (plant sterol oxidation products) from plant sterols. However, determinants of oxyphytosterol formation and metabolism are largely unknown. It is known, however, that serum plant sterol concentrations increase after daily consumption of plant sterol enriched products, while concentrations decrease after plant stanol consumption. Still, we have earlier reported that fasting oxyphytosterol concentrations did not increase after consuming a plant sterol- or a plant stanol enriched margarine $(3.0 \mathrm{~g} / \mathrm{d}$ of plant sterols or stanols) for 4 weeks. Since humans are in a non-fasting state for most part of the day, we have now investigated effects on oxyphytosterol concentrations during the postprandial state. For this, subjects consumed a shake $(50 \mathrm{~g}$ of fat, $12 \mathrm{~g}$ of protein, $67 \mathrm{~g}$ of carbohydrates), containing no, or $3.0 \mathrm{~g}$ of plant sterols or plant stanols. Blood samples were taken up to 8 hours and after 4 hours subjects received a second shake (without plant sterols or plant stanols). Serum oxyphytosterol concentrations were determined in BHT-enriched EDTA plasma via GC-MS/MS. 7 $\beta-O H$-campesterol and $7 \beta-O H$-sitosterol concentrations were significantly higher after consumption of a mixed meal enriched with plant sterol esters compared to the control and plant stanol ester meal. These increases were seen only after consumption of the second shake, illustrative for a second meal effect. Non-oxidized campesterol and sitosterol concentrations also increased after plant sterol consumption, in parallel with $7 \beta-O H$ concentrations and again only after the second meal. Apparently, plant sterols and oxyphytosterols follow the same second meal effect as described for dietary cholesterol. However, the question remains whether the increase in oxyphytosterols in the postprandial phase is due to absorption or endogenous formation.
\end{abstract}




\section{Introduction}

A daily consumption of 2-3 gram plant sterols or plant stanols reduces fasting serum lowdensity lipoprotein cholesterol (LDL-C) concentrations up to $10 \%$ [1]. At the same time, however, serum plant sterol concentrations increase after daily consumption of plant sterol enriched products, while concentrations decrease after consumption of plant stanol enriched products [2]. We have previously reported increases of $36-50 \%$ in serum concentrations of the various plant sterols [3], which is in line with a recent meta-analysis that reported average increases of $31 \%$ (95\% Cl: $26-37 \%$ ) and $37 \%$ (95\% Cl: $29-45 \%)$ in sitosterol and campesterol concentrations after consumption of plant sterol enriched products at an average dose of $1.6 \mathrm{~g} / \mathrm{d}$ [4]. Although these concentrations are only marginal as compared to those observed in phytosterolemic subjects, the potential impact of these elevated circulating plant sterol concentrations on cardiovascular risk is strongly debated, as epidemiological studies have reported inconsistent results regarding the potential association of increased plant sterol concentrations and CVD risk $[5,6]$. The controversy around the potential atherogenicity of plant sterols might relate to the question whether plant sterols are oxidized or not. We and others have previously shown that in transgenic mouse models plant sterol enriched diets lower atherosclerotic lesion development [7-9] while enrichment with oxidized plant sterols (oxyphytosterols) resulted in larger and more severe atherosclerotic lesions [10]. Data regarding origin, metabolism, pathophysiological effects and effects of specific diets on oxyphytosterol metabolism in humans are however scarce. Oxyphytosterols have been identified in serum of healthy and phytosterolemic subjects, and in aortic tissue of patients undergoing elective aortic valve replacement [11]. Previously, we have reported the effect of consuming a plant sterol or a plant stanol enriched margarine $(3.0 \mathrm{~g} / \mathrm{d}$ of plant sterols or stanols) for 4 weeks on fasting oxyphytosterol concentrations. No effects on fasting oxyphytosterol concentrations were observed after plant sterol consumption, while $7 \beta-\mathrm{OH}$-campesterol concentrations - and when standardized for cholesterol also 7-keto-campesterol levels - were reduced after plant stanol consumption. Since humans are in a non-fasting state for the major part of the day, we have now examined the 8-hour postprandial oxyphytosterol response after consuming plant sterol or plant stanol ester enriched margarine as part of a mixed meal.

\section{Materials and Methods}

\section{Subjects}

Samples were derived from a subgroup $(\mathrm{N}=10)$ randomly selected from a, double-blind placebo-controlled cross-over intervention study with 43 healthy subjects. Subject characteristics of the complete study population have previously been reported into detail when effects of plant sterol and plant stanol consumption on fasting lipoprotein and oxyphytosterol concentrations were reported [3]. The 10 healthy subjects (3 males and 
7 females) were $44 \pm 19$ years old, had a body mass index (BMI) of $24.3 \pm 2.8 \mathrm{~kg} / \mathrm{m}^{2}$, a total cholesterol concentration of $5.4 \pm 0.8 \mathrm{mmol} / \mathrm{L}$ and a triglyceride concentration of 1.1 $\pm 0.4 \mathrm{mmol} / \mathrm{L}$. Statistical analyses showed no differences between this subgroup and the remaining 33 subjects regarding baseline characteristics and fasting responses after plant sterol or plant stanol consumption. All participants gave their written informed consent before entering the study. The medical ethical committee of the Maastricht University Medical Centre+ (MUMC+) approved the protocol and the trial is registered at clinicaltrials. gov as NCT01559428.

\section{Diet and Design}

Subjects participated in a 20 weeks intervention study, which consisted of three intervention periods of 4 weeks, separated by washout periods of 4 weeks. Subjects consumed 20 gram of test margarine on a daily basis, which provided no, or 3.0 gram of plant sterols or stanols per day. At the end of each of the three intervention periods, a postprandial test was performed (Figure 5.1). For this, an intravenous cannula was placed and a fasting blood sample was collected. Subjects consumed a shake containing no, or 3.0 gram of plant sterols or plant stanols provided as their fatty acid esters, depending on the preceding 4-week intervention period. Subsequent blood samples were drawn up to 8 hours and subjects received a second shake (without cholesterol, plant sterol esters or plant stanol esters) after 4 hours. The compositions of the shakes are shown in Table 5.1. Subjects were not allowed to eat anything else, but were allowed to drink water $( \pm 500 \mathrm{~mL})$ throughout the entire test day.

First meal response Second meal response

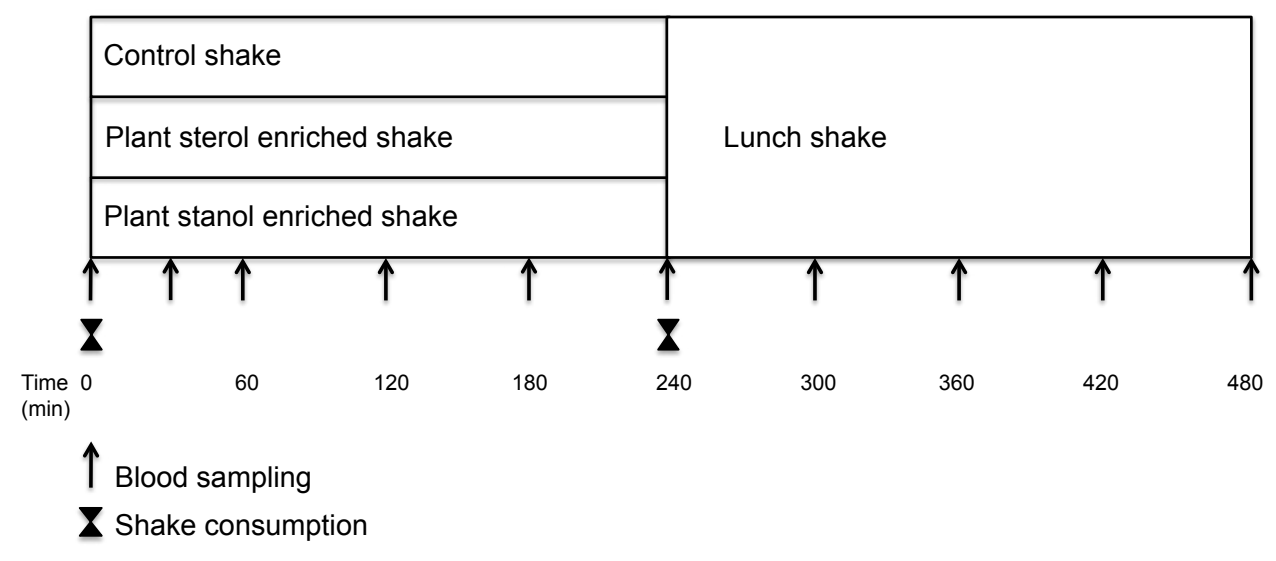

Figure 5.1. Outline of the postprandial meal test 
Table 5.1. Composition of the breakfast shakes enriched with plant sterol or plant stanol esters and the lunch shake

\begin{tabular}{|c|c|c|c|c|}
\hline & $\begin{array}{c}\text { Breakfast shake; } \\
\text { control period }\end{array}$ & $\begin{array}{c}\text { Breakfast } \\
\text { shake; } \\
\text { sterol period }\end{array}$ & $\begin{array}{c}\text { Breakfast } \\
\text { shake; } \\
\text { stanol period }\end{array}$ & $\begin{array}{l}\text { Lunch } \\
\text { shake }\end{array}$ \\
\hline Energy (MJ) & 3.15 & 3.15 & 3.14 & 3.16 \\
\hline Fat (energy\%) & 59.6 & 59.6 & 59.5 & 60.1 \\
\hline SAFA* & 24.7 & 24.7 & 27.8 & 23.4 \\
\hline MUFA & 20.9 & 20.9 & 18.8 & 22.2 \\
\hline PUFA & 10.1 & 10.1 & 9.1 & 12.2 \\
\hline Protein (energy\%) & 6.2 & 6.2 & 6.2 & 4.2 \\
\hline CHO (energy\%) & 35.2 & 35.2 & 35.3 & 36.4 \\
\hline Cholesterol (mg) & 250.2 & 250.2 & 250.2 & 17.3 \\
\hline Plant sterols (g) & - & 3.0 & - & - \\
\hline Plant stanols (g) & - & - & 3.0 & - \\
\hline Oxyphytosterol (mg) & 0.10 & 0.68 & 0.11 & 0.10 \\
\hline$\Sigma$ oxycampesterol (mg) & 0.04 & 0.22 & 0.05 & 0.04 \\
\hline$\Sigma$ oxysitosterol (mg) & 0.06 & 0.46 & 0.06 & 0.06 \\
\hline 7ß-OH-campesterol (mg) & 0.01 & 0.06 & 0.00 & 0.01 \\
\hline 7ß-OH-sitosterol (mg) & 0.02 & 0.23 & 0.01 & 0.02 \\
\hline 7-keto-campesterol (mg) & 0.03 & 0.11 & 0.05 & 0.03 \\
\hline 7-keto-sitosterol (mg) & 0.03 & 0.11 & 0.05 & 0.03 \\
\hline
\end{tabular}

* SAFA: saturated fatty acids, MUFA: monounsaturated fatty acids, PUFA: polyunsaturated fatty acids, CHO: carbohydrates 


\section{Blood sampling and analyses}

A clotting tube and an EDTA tube (Becton, Dickinson and Company, Franklin Lakes, NY, USA) were sampled at each time point. Serum was obtained from the clotting tube by low-speed centrifugation at 1300x g for $15 \mathrm{~min}$ at room temperature, at least half an hour after venipuncture and was used for the analysis of plant sterol concentrations. Plasma was obtained by low-speed centrifugation of the EDTA tube at $1300 \mathrm{x} g$ for $15 \mathrm{~min}$ at 4 o $\mathrm{C}$ and was used for the analysis of plasma oxyphytosterol concentrations. To avoid auto-oxidation, $10 \mu \mathrm{BHT}(25 \mathrm{mg} / \mathrm{mL}$ ethanol) was added per $1 \mathrm{~mL}$ of EDTA plasma, immediately after centrifugation. All serum and plasma samples were snap frozen in liquid nitrogen and stored at $-80^{\circ} \mathrm{C}$ until analysis.

Sitosterol and campesterol concentrations were analysed using gas chromatography - flame ion detection (GC-FID) as described previously [12] and concentrations are expressed as $\mathrm{mg} / \mathrm{dL}$. 7 $\beta$-Hydroxy $(\mathrm{OH})$-campesterol, 7 $\beta-\mathrm{OH}$-sitosterol, 7-keto-campesterol and 7-ketositosterol were analysed by gas chromatography-mass spectroscopy (GC-MS/MS) according to the procedure as described by Husche et al [13] with minor modifications related to the use of a GC-MS triplequad in stead of a GC-MS singlequad and are expressed as $\mathrm{ng} / \mathrm{mL}$.

\section{Statistics}

All data are presented as means \pm standard deviations (SD). Differences in baseline concentrations between the test meals were statistically evaluated using univariate analysis of variance (ANOVA) with diet as fixed factor and subject as random factor. Changes from baseline were analysed using linear mixed models with diet and time as within-subject fixed factors, and with diet-time interaction. If the interaction term was not statistically significant, it was omitted from the model. If the interaction term, factor time or factor diet was significant, Bonferroni's correction for multiple comparisons was used. Results were considered to be statistically significant if $p<0.05$. All statistical analyses were performed using SPSS 20.0 for Mac Os X (SPSS Inc., Chicago, IL, USA).

\section{Results}

Fasting plasma oxyphytosterol concentrations at the start of the postprandial test day (after consuming plant sterol enriched, plant stanol enriched or placebo margarines for 4 weeks) were not different (Table 5.2). The postprandial responses in plasma oxyphytosterol concentrations are presented in Figure 5.2. There was a significant diet*time interaction for $7 \beta-\mathrm{OH}$-campesterol concentrations during the postprandial period $(p<0.05)$. Following Bonferroni's correction for multiple comparisons, concentrations were significantly higher after consumption of a mixed meal enriched with plant sterol esters compared with the control meal at T240 $(p<0.01)$, T360 $(p<0.001)$ and T480 $(p<0.001)$. Moreover, concentrations were higher after the plant sterol enriched meal compared with the plant stanol enriched meal 
at T360 $(p<0.001)$ and T480 $(p<0.01)$. Also for postprandial $7 \beta-O H$-sitosterol concentrations, a significant diet*time interaction $(p<0.05)$ was found. Following Bonferroni's correction, concentrations were higher after consumption of a mixed meal enriched with plant sterol esters compared with the plant stanol meal at T360 $(p<0.01)$ and T480 $(p<0.05)$. These data indicate that $7 \beta-\mathrm{OH}$-campesterol and $7 \beta-\mathrm{OH}$-sitosterol concentrations were only increased after the second meal (i.e. lunch without added plant sterols/stanols and cholesterol). For postprandial 7-keto-campesterol concentrations, there was only a significant time effect. Concentrations were increased at T360 and T480 compared with T0 ( $p<0.05)$, compared with T60 $(p<0.01)$ and compared with T240 $(p<0.001)$. Postprandial 7-keto-sitosterol concentrations were increased at T480 compared with T240 $(p<0.01)$.

Table 5.2. Fasting plant sterol and oxyphytosterol concentrations after consumption of plant sterol enriched, plant stanol enriched or placebo margarines $(n=10)$

\begin{tabular}{llcc}
\hline & $\begin{array}{c}\text { Control } \\
\text { period }\end{array}$ & $\begin{array}{c}\text { Plant sterol } \\
\text { period }\end{array}$ & $\begin{array}{c}\text { Plant stanol } \\
\text { period }\end{array}$ \\
\hline Campesterol $(\mathrm{mg} / \mathrm{dL})$ & $0.56 \pm 0.21$ & $0.89 \pm 0.26^{13}$ & $0.35 \pm 0.11$ \\
\hline Sitosterol $(\mathrm{mg} / \mathrm{dL})$ & $0.32 \pm 0.11$ & $0.41 \pm 0.11^{2,3}$ & $0.22 \pm 0.06$ \\
\hline $7 \beta$-OH-campesterol $(\mathrm{ng} / \mathrm{mL})$ & $0.39 \pm 0.15$ & $0.37 \pm 0.08$ & $0.33 \pm 0.08$ \\
\hline $7 \beta$-OH-sitosterol $(\mathrm{ng} / \mathrm{mL})$ & $0.57 \pm 0.25$ & $0.50 \pm 0.14$ & $0.51 \pm 0.20$ \\
\hline 7-keto-OH-campesterol $(\mathrm{ng} / \mathrm{mL})$ & $0.94 \pm 0.26$ & $0.96 \pm 0.17$ & $0.91 \pm 0.11$ \\
\hline 7-keto-OH-sitosterol $(\mathrm{ng} / \mathrm{mL})$ & $2.35 \pm 0.67$ & $2.76 \pm 0.82$ & $2.87 \pm 0.76$ \\
\hline
\end{tabular}

significantly different compared with control period ${ }^{1}(p<0.001),{ }^{2}(p<0.01)$

significantly different compared with plant stanol period ${ }^{3}(p<0.001)$

Besides oxyphytosterol concentrations, we also quantified non-oxidized plant sterol concentrations since these are the potential substrates to be oxidized. Fasting serum campesterol and sitosterol concentrations were higher after the plant sterol intervention compared with the plant stanol and control intervention (Table 5.2). The postprandial responses in serum campesterol and sitosterol concentrations are presented in Figure 5.3. Serum campesterol concentrations were increased after a mixed meal enriched with plant sterol esters compared with plant stanol esters (diet effect; $p<0.05$ ). Postprandial serum campesterol concentrations were also significant for the factor time; concentrations were higher at T360 and T480 compared with T60 ( $p<0.05$ and $p<0.01$, respectively). Changes in sitosterol concentration were significant for diet (sterol $>$ stanol, $p<0.01$ ) and for time (T480 > T60, $p<0.01$ ). In line with the oxyphytosterol concentrations, serum plant sterol concentrations were particularly increased after the second meal. Postprandial sitosterol and campesterol concentrations were comparable after a mixed meal enriched with plant stanol esters compared with the control intervention. 
A

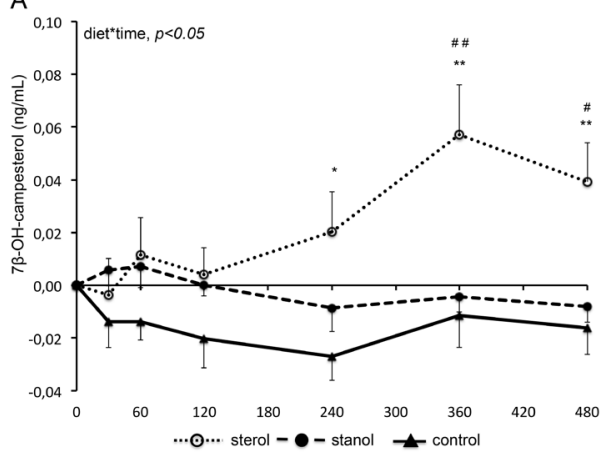

$\mathrm{C}$

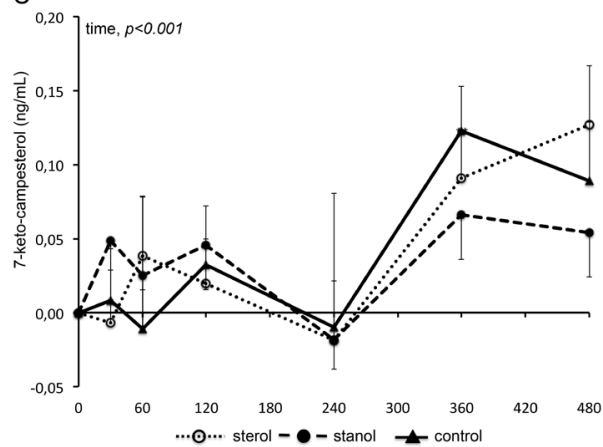

B

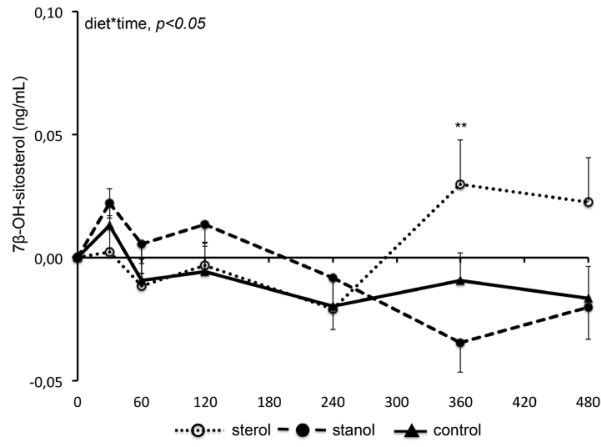

D

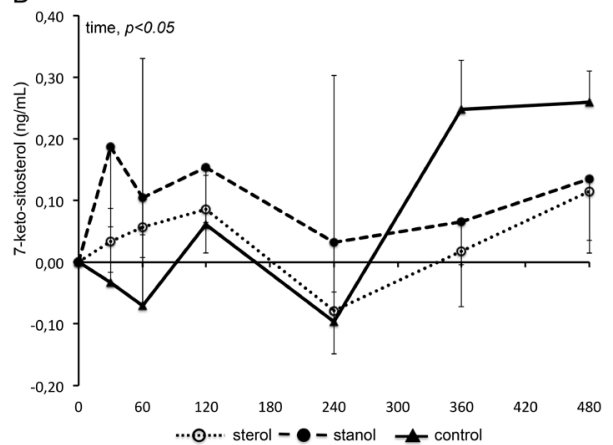

Figure 5.2. Plasma concentrations of (A) 7 $3-\mathrm{OH}$-campesterol, (B), 7 $\mathrm{B}-\mathrm{OH}$-sitosterol, (C), 7-keto-campesterol and (D) 7-keto-sitosterol after consumption of a shake containing no, or 3.0 gram of plant sterols or plant stanols. Data are presented as mean \pm SEM.

A: significantly different from control period $*(p<0.01)$, $* *(p<0.001)$, significantly different from stanol period $\#(p<0.01)$, \# \#(p<0.001)

B: significantly different from stanol period $*(p<0.05), * *(p<0.01)$

C: significant time effect, T360 > T0: and T480 > T0* $(p<0.01)$

D: significant time effect, $\mathrm{T} 480>\mathrm{T} 240 *(\mathrm{p}<0.01)$

A

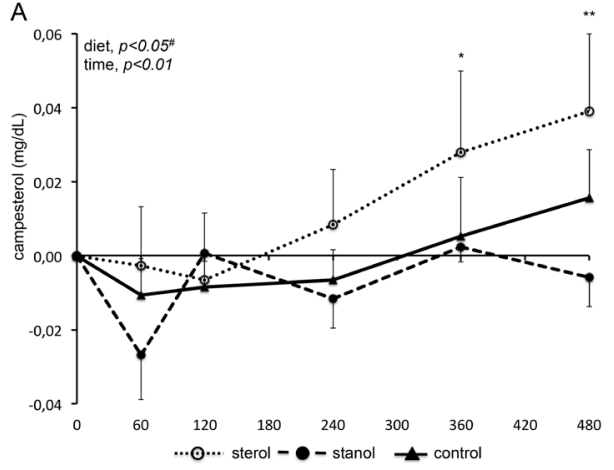

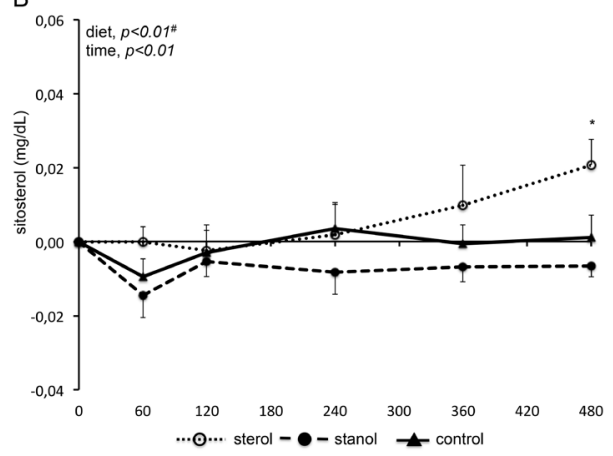

Figure 5.3. Serum concentrations of (A) campesterol and (B) sitosterol after consumption of a shake containing no, or 3.0 gram of plant sterols or plant stanols. Data are presented as mean $\pm \mathrm{SEM}$.

A: Significant diet effect, sterol > stanol \#(p<0.05), significant time effect, T360 > T60* $(p<0.05)$ and T480 > T60 $* *(p<0.01)$

B: Significant diet effect, sterol $>$ stanol \#(p<0.01), significant time effect, T480 $>$ T60* $(p<0.01)$ 


\section{Discussion}

Earlier, we have found that daily consumption of a plant sterol enriched diet increased fasting serum plant sterol concentrations, but did not elevate plasma oxyphytosterol concentrations. Here, we show that consumption of a mixed meal enriched with plant sterol esters increased postprandial serum plant sterol and plasma oxyphytosterol concentrations as compared to a mixed meal or a mixed meal enriched with plant stanol esters. Interestingly, these higher plant sterol and oxyphytosterol concentrations were particularly present after consumption of a second meal.

Plant sterols share structural similarities to cholesterol and also have the typical double bond between $\mathrm{C} 5-\mathrm{C} 6$ in the steroid nucleus. Therefore, plant sterols are - analogue to cholesterol - prone to reactive oxidative species (ROS)-mediated oxidation [14]. Plant stanols lack this double bond and can therefore not be oxidized by ROS. Since plant sterol oxidation products are present in foods $[15,16]$, circulating plant sterol oxidation products can either result from dietary absorption or from endogenous oxidation of non-oxidized plant sterols. Oxyphytosterols have been identified in foods such as heated vegetable oils, infant milk formulas, parenteral nutrition, French fries, potato chips and coffee beans [17-20]. However, the main sources of dietary oxyphytosterols are plant sterol enriched products and a recommended daily consumption of 20-25 gram of spread can provide up to $1.7 \mathrm{mg}$ oxyphytosterols [21]. We here show that postprandial oxyphytosterol concentrations increase after consumption of plant sterol enriched margarine. However, given the experimental design, we cannot distinguish between oxyphytosterols originating from dietary absorption and from endogenous oxidation. Therefore, we can only speculate on their origin.

The postprandial patterns of non-oxidized plant sterol concentrations are suggestive for a second meal response as already reported in 1998 for dietary cholesterol [22-24], which states that cholesterol from the first meal is secreted via intestinally derived chylomicrons during subsequent meal consumptions. This might explain why most studies so far did not report increased postprandial plant sterol concentrations after plant sterol consumption. In two studies, blood sampling may have been too late after consumption of the meals [25, 26 ], while in another 4-hour study a second meal was not included [27]. Plasma $7 \beta-O H-$ phytosterol concentrations demonstrated a comparable second meal response, since peak concentrations were seen two hours after consumption of the second meal. This suggests that oxyphytosterols present in the shake were absorbed in the enterocytes after the first meal (breakfast) and released after the second meal (lunch). Alternatively, one can speculate that plant sterols in the shake were absorbed after the first meal followed by endogenous oxidation and appearance in the circulation. It could also be possible that plant sterols undergo enterohepatic recycling, implying that they are absorbed after the first meal, oxidized in the liver and then secreted back into the intestinal lumen via bile, after which absorption of oxidized plant sterols might take place. 
In the plant sterol enriched margarine, sitosterol concentrations were higher than those of campesterol. Also, concentrations of sitosterol oxidation products were higher than those of campesterol oxidation products. In humans, it has consistently been shown that nonoxidized campesterol is better absorbed than sitosterol, resulting in higher fasting serum concentrations $[4,28]$. This is also reflected in our postprandial data, where postprandial increases in serum campesterol are higher than those of sitosterol after consumption of the plant sterol enriched shake. Postprandial oxycampesterol responses were also larger than oxysitosterol responses (peak change of $0.06 \mathrm{vs} .0 .03 \mathrm{ng} / \mathrm{mL}$ ). This would suggest that - analogue to non-oxidized plant sterols - campesterol oxidation products are better absorbed (or less efficiently excreted) than sitosterol oxidation products. Rodent models have been used to measure lymphatic recovery to estimate oxyphytosterol absorption rates and indeed reported that campesterol oxidation products were better absorbed than sitosterol oxidation products $[29,30]$. However, when fasting plasma oxyphytosterol concentrations are compared, absolute plasma $7 \beta-\mathrm{OH}$-sitosterol concentrations are higher than those of $7 \beta-O H$-campesterol ( 0.57 vs. $0.39 \mathrm{ng} / \mathrm{mL}$, in control period). This is clearly different from the non-oxidized sterols, where campesterol concentrations are higher than sitosterol concentrations ( $0.56 \mathrm{vs} .0 .32 \mathrm{mg} / \mathrm{dL}$, in control period). This might suggest that sitosterol is preferentially oxidized (either in enterocytes or in the circulation) and that (part of) oxyphytosterol concentrations originate from endogenous oxidation of circulating plant sterols. However, we have reported previously that after plant sterol consumption fasting oxyphytosterol concentrations were not increased despite increased plant sterol concentrations (+36-50\%), suggesting that the availability of substrate does not influence oxidation rates of serum plant sterol concentrations. Another argument for endogenous oxidation relates to oxyphytosterol differences between subjects [31], which might be attributed to different absorption rates or differences in endogenous oxidation of circulating plant sterols. The latter is probably more plausible, since other oxidative stress markers were also higher in subjects with increased oxyphytosterol concentrations.

In a previous study, fasting $7 \beta-\mathrm{OH}$-campesterol concentrations and - when standardized for cholesterol - also 7-keto-campesterol levels oxyphytosterols were reduced after plant stanol consumption [3]. We hypothesized that oxyphytosterol absorption - analogue to non-oxidized plant sterol absorption - is inhibited after consumption of plant stanol enriched products. Postprandial oxyphytosterol concentrations were not changed after plant stanol consumption, suggesting that postprandial oxyphytosterol absorption is not inhibited and oxyphytosterol concentrations in the postprandial phase might origin from endogenous formation. However, postprandial non-oxidized plant sterol concentrations were also not changed, while plant stanol consumption inhibits dietary absorption of plant sterols and reduces fasting plant sterol concentrations. However, this does not exclude that postprandial oxyphytosterols could still originate from dietary absorption. Also, levels of plant sterols and oxyphytosterol in the plant stanol enriched margarine may have been too low to observe clear changes. To provide definite answers to the question whether 
plasma oxyphytosterols result from absorption or from endogenous oxidation of circulating plant sterols, studies using labelled non-oxidized plant sterols and subsequent enrichment in labelled plasma oxyphytosterols should be performed. In addition, postprandial plant sterol and oxyphytosterol curves demonstrate that future studies demand longer-term postprandial follow-up periods and inclusion of multiple meals or incorporation of labelled (oxy)phytosterols to assess origin. It would also be interesting to assess whether single or multiple daily intakes of plant sterol enriched products would lead to different changes in circulating oxyphytosterol concentrations.

In conclusion, while we previously reported that four weeks plant sterol enriched margarine consumption did not change fasting oxyphytosterol concentrations, we show here for the first time that postprandial oxyphytosterol concentrations increase after consumption of a mixed meal enriched with plant sterol esters. Data regarding the origin of these oxyphytosterols, i.e. absorption from diet, endogenous formation as well as further oxyphytosterol metabolism in humans is missing and further research is needed to understand the possible relationship between (postprandial) plant sterol and oxyphytosterol concentrations and CVD risk.

\section{Acknowledgements}

The project was funded by the Netherlands Organisation for Scientific Research (TOP grant No. 91208006) and the margarines were kindly provided by RAISIO (Raisio Group, Finland). There are no conflicts of interest to declare.

\section{References}

1. Plat J, Mackay D, Baumgartner S, Clifton PM, Gylling H, Jones PJ. Progress and prospective of plant sterol and plant stanol research: report of the Maastricht meeting. Atherosclerosis. 2012 Dec;225:521-33.

2. Gylling H, Plat J, Turley S, Ginsberg HN, Ellegard L, Jessup W, et al. Plant sterols and plant stanols in the management of dyslipidaemia and prevention of cardiovascular disease. Atherosclerosis. 2014 Feb;232:34660.

3. Baumgartner S, Mensink RP, Husche C, Lutjohann D, Plat J. Effects of plant sterol- or stanol-enriched margarine on fasting plasma oxyphytosterol concentrations in healthy subjects. Atherosclerosis. 2013 Apr;227:414-9.

4. Ras RT, Hiemstra H, Lin Y, Vermeer MA, Duchateau GS, Trautwein EA. Consumption of plant sterol-enriched foods and effects on plasma plant sterol concentrations--a meta-analysis of randomized controlled studies. Atherosclerosis. 2013 Oct;230:336-46.

5. Escurriol V, Cofan M, Moreno-Iribas C, Larranaga N, Martinez C, Navarro C, et al. Phytosterol plasma concentrations and coronary heart disease in the prospective Spanish EPIC cohort. J Lipid Res. 2010 Mar;51:618-24.

6. Matthan NR, Pencina M, LaRocque JM, Jacques PF, D’Agostino RB, Schaefer EJ, et al. Alterations in cholesterol absorption/synthesis markers characterize Framingham offspring study participants with CHD. J Lipid Res. 2009 Sep;50:1927-35. 
7. Moghadasian $\mathrm{MH}$, Godin DV, McManus BM, Frohlich JJ. Lack of regression of atherosclerotic lesions in phytosterol-treated apo E-deficient mice. Life Sci. 1999;64:1029-36.

8. Plat J, Beugels I, Gijbels MJ, de Winther MP, Mensink RP. Plant sterol or stanol esters retard lesion formation in LDL receptor-deficient mice independent of changes in serum plant sterols. J Lipid Res. 2006 Dec;47:2762-71.

9. Volger OL, Mensink RP, Plat J, Hornstra G, Havekes LM, Princen HM. Dietary vegetable oil and wood derived plant stanol esters reduce atherosclerotic lesion size and severity in apoE*3-Leiden transgenic mice. Atherosclerosis. 2001 Aug;157:375-81.

10. Plat J, Theuwissen E, Husche C, Lutjohann D, Gijbels MJ, Jeurissen M, et al. Oxidised plant sterols as well as oxycholesterol increase the proportion of severe atherosclerotic lesions in female LDL receptor+/ - mice. $\mathrm{Br} J$ Nutr. 2014 Jan 14;111:64-70.

11. Schott HF, Luister A, Husche C, Schafers HJ, Bohm M, Plat J, et al. The relationships of phytosterols and oxyphytosterols in plasma and aortic valve cusps in patients with severe aortic stenosis. Biochem Biophys Res Commun. 2014 Apr 11;446:805-10.

12. Thelen KM, Laaksonen R, Paiva H, Lehtimaki T, Lutjohann D. High-dose statin treatment does not alter plasma marker for brain cholesterol metabolism in patients with moderately elevated plasma cholesterol levels. J Clin Pharmacol. 2006 Jul;46:812-6.

13. Husche $\mathrm{C}$, Weingartner $\mathrm{O}$, Pettersson $\mathrm{H}$, Vanmierlo T, Bohm M, Laufs $\mathrm{U}$, et al. Validation of an isotope dilution gas chromatography-mass spectrometry method for analysis of 7-oxygenated campesterol and sitosterol in human serum. Chem Phys Lipids. 2011 Sep;164:425-31.

14. Brown AJ, Jessup W. Oxysterols: Sources, cellular storage and metabolism, and new insights into their roles in cholesterol homeostasis. Mol Aspects Med. 2009 Jun;30:111-22

15. O'Callaghan Y, McCarthy FO, O'Brien NM. Recent advances in Phytosterol Oxidation Products. Biochem Biophys Res Commun. 2014 Apr 11;446:786-91.

16. Otaegui-Arrazola A, Menendez-Carreno M, Ansorena D, Astiasaran I. Oxysterols: A world to explore. Food Chem Toxicol. 2010 Dec;48:3289-303.

17. Dutta P. Studies on phytosterol oxides. II: Content in come vegetable oild and in French Fires prepared in these oils. JAOCS. 1997;74:647-66.

18. Dutta P. Studies on phytosterol oxides. I: Effect of storage on the content in potato chips prepared in different vegetable oils. JAOCS. 1997;74:647-57.

19. Turchetto E, Lercker G, Bortolomeazzi R. Oxisterol determination in selected coffees. Toxicol Ind Health. 1993 May-Jun;9:519-27.

20. Zunin P, Calcagno C, Evangelisti F. Sterol oxidation in infant milk formulas and milk cereals. J Dairy Res. 1998 Nov;65:591-8.

21. Hovenkamp E, Demonty I, Plat J, Lutjohann D, Mensink RP, Trautwein EA. Biological effects of oxidized phytosterols: a review of the current knowledge. Prog Lipid Res. 2008 Jan;47:37-49.

22. Fielding B. Tracing the fate of dietary fatty acids: metabolic studies of postprandial lipaemia in human subjects. Proc Nutr Soc. 2011 Aug;70:342-50.

23. Beaumier-Gallon G, Dubois C, Portugal H, Lairon D. Postprandial studies on dietary cholesterol in human subjects using stable isotopes and gas chromatography-mass spectrometry analysis. Atherosclerosis. 1998 Dec;141 Suppl 1:S81-5.

24. Silva KD, Wright JW, Williams CM, Lovegrove JA. Meal ingestion provokes entry of lipoproteins containing fat from the previous meal: possible metabolic implications. Eur J Nutr. 2005 Sep;44:377-83.

25. Relas H, Gylling H, Miettinen TA. Effect of stanol ester on postabsorptive squalene and retinyl palmitate. Metabolism. 2000 Apr;49:473-8.

26. Relas H, Gylling H, Miettinen TA. Acute effect of dietary stanyl ester dose on post-absorptive alpha-tocopherol, beta-carotene, retinol and retinyl palmitate concentrations. Br J Nutr. 2001 Feb;85:141-7. 
27. Gylling H, Hallikainen M, Simonen P, Miettinen HE, Nissinen MJ, Miettinen TA. Serum and lipoprotein sitostanol and non-cholesterol sterols after an acute dose of plant stanol ester on its long-term consumption. Eur J Nutr. 2012 Aug;51:615-22.

28. Ostlund RE, Jr., McGill JB, Zeng CM, Covey DF, Stearns J, Stenson WF, et al. Gastrointestinal absorption and plasma kinetics of soy Delta(5)-phytosterols and phytostanols in humans. Am J Physiol Endocrinol Metab. 2002 Apr;282:E911-6.

29. Grandgirard A, Sergiel JP, Nour M, Demaison-Meloche J, Ginies C. Lymphatic absorption of phytosterol oxides in rats. Lipids. 1999 Jun;34:563-70.

30. Tomoyori H, Kawata Y, Higuchi T, Ichi I, Sato H, Sato M, et al. Phytosterol oxidation products are absorbed in the intestinal lymphatics in rats but do not accelerate atherosclerosis in apolipoprotein E-deficient mice. J Nutr. 2004 Jul;134:1690-6.

31. Baumgartner S, Mensink RP, den Hartog G, Bast A, Bekers O, Husche C, et al. Oxyphytosterol formation in humans: identification of high vs. low oxidizers. Biochem Pharmacol. 2013 Jul 1;86:19-25. 



\section{Chapter 6}

\section{Effects of a plant sterol or stanol enriched mixed meal on postprandial lipid and glucose metabolism in healthy subjects}

Sabine Baumgartner, Ronald P. Mensink and Jogchum Plat 


\section{Abstract}

The low-density lipoprotein cholesterol (LDL-C) lowering effect of plant sterols and stanols has unequivocally been established in numerous studies whereas more recently, a possible triacylglycerol (TAG) lowering effect also received attention. A potential TAG lowering effect of plant sterol and plant stanol consumption is interesting not only in a fasting state, but particularly when present in a postprandial state, since elevated postprandial TAG concentrations are emerging as an important cardiovascular disease (CVD) risk factor. The objective of this study was to examine the 8-hour postprandial response after consuming plant sterol or plant stanol ester enriched margarine as part of a mixed meal.

This postprandial study was part of a randomised, double-blind, cross-over study in which 42 healthy subjects (18-70 years) consumed for 4 weeks a plant sterol enriched ( $3 \mathrm{~g} / \mathrm{d}$ of plant sterols), a plant stanol enriched ( $3 \mathrm{~g} / \mathrm{d}$ of plant stanols), and a control margarine separated by wash-out periods of 4 weeks. At the end of each intervention period, subjects underwent a meal test in which they consumed a shake enriched with either $3 \mathrm{~g}$ of plant sterol esters (sterol period), 3g of plant stanol esters (stanol period) or no addition (control period). Blood sampling was performed up to 8-hours and subjects received a second shake without plant sterols or stanols after 4 hours. This prolonged protocol enabled us to evaluate effects on the $2^{\text {nd }}$ meal response as well. To evaluate postprandial responses, incremental areas under the curves (iAUC) were calculated. The TAG and apoB48 iAUC of the total (0-8 hours) and $1^{\text {st }}$ meal (0-4 hours) responses were comparable between the three test meals. However, the TAG and apoB48 iAUC after the second meal responses (4-8 hours) were higher in the stanol period compared to the sterol period. This $2^{\text {nd }}$ meal response after plant stanol consumption was more pronounced with increasing age and might be related to a change in intestinal TAG absorption or a delay in lipoprotein clearance. This study demonstrates an age-dependent increase in postprandial TAG and apoB48 responses after plant stanol ester consumption. Further validation of these results is warranted, particularly since the effect was most pronounced at a higher age, i.e. the target population of plant sterol and plant stanol consumption. 


\section{Introduction}

It has unequivocally been established that a daily consumption of plant sterol- and plant stanol enriched products reduces fasting serum low-density lipoprotein cholesterol (LDL-C) concentrations [1]. Functional foods enriched with plant sterols and plant stanols, as part of a healthy diet, have therefore been advocated in the management of mild hypercholesterolemia [2, 3]. Except for LDL-C, more recent studies have also suggested that plant sterols and plant stanols lower serum triacylglycerol (TAG) concentrations [4, 5]. Prospective and case-control studies have identified high fasting serum TAG concentrations as an independent risk marker for CVD, which are routinely measured to assess CVD risk [6]. However, most people are in a non-fasting state for most part of the day and nonfasting serum TAG concentrations are an emerging marker contributing to CVD risk due to the postprandial atherogenicity of TAG-rich (remnant) lipoprotein particles [6, 7]. Indeed, independent of other risk markers, non-fasting TAG concentrations estimated CVD risk more precisely than fasting TAG concentrations did [8, 9]. Besides non-fasting TAG concentrations, remnant cholesterol (cholesterol present in TAG-rich particles during the fasting and non-fasting state) may be an important CVD risk marker $[3,10]$, illustrating the importance of including postprandial lipoprotein metabolism to assess CVD risk. Therefore, evaluation of the effects of plant sterol and plant stanol consumption on postprandial lipid metabolism is warranted. So far, only three studies have addressed postprandial lipid and lipoprotein responses after plant stanol ester intake [11-13], while there are no reports on postprandial responses after plant sterol ester intake. Although these three studies have their limitations with respect to assessing postprandial responses, they do suggest that chronic or acute consumption of plant stanol esters does not affect postprandial lipid and lipoprotein concentrations. This is remarkable, since it is generally acknowledged that lipoprotein metabolism is affected by plant stanol and sterol ester consumption in fasting state through inhibition of intestinal cholesterol absorption [14]. The mechanism underlying the reduction in fasting serum TAGs is not known, but was suggested to be due to a reduced intestinal fatty acid absorption, at least in mice [15]. This illustrates that there is a need for a more detailed knowledge regarding postprandial effects of plant sterol and stanol ester consumption on lipoprotein metabolism. Therefore, the objective of the present study was to examine the 8-hour postprandial response after consuming plant sterol or plant stanol ester enriched margarines as part of a shake. Since the appearance of dietary cholesterol in the circulation is delayed [16-18], we decided to provide a second mixed meal after 4 hours. This postprandial meal test was performed after completing a 4-week intervention period during which subjects consumed plant sterol or plant stanol ester enriched margarine on a daily basis. 


\section{Subjects and Methods}

\section{Subjects}

Details of the study have been described previously, when the effects of the intervention on fasting lipoprotein and oxyphytosterol concentrations were reported [19]. Briefly, subjects were recruited in Maastricht and met the following criteria: 18-70 years of age; body mass index (BMI) between $20-30 \mathrm{~kg} / \mathrm{m}^{2}$; no active cardiovascular disease or severe medical period during the past 5 years that might interfere with the study and no use of lipid-lowering medication or a medically prescribed diet. In addition, serum total cholesterol concentrations were $<7.8 \mathrm{mmol} / \mathrm{L}$; serum TAG concentrations $<3.0 \mathrm{mmol} / \mathrm{L}$ and plasma glucose concentrations $<6.1 \mathrm{mmol} / \mathrm{L}$, as determined during two screening visits. All participants gave their written informed consent before entering the study. The medical ethical committee of the Maastricht University Medical Centre+ (MUMC+) had approved the protocol and the trial is registered at clinicaltrials.gov as NCT01559428.

\section{Diet and Design}

The complete 20 weeks intervention study was a randomised placebo-controlled crossover trial, which consisted of three intervention periods of 4 weeks, separated by washout periods of 4 weeks [19]. Subjects replaced their own spread with the test margarine of which 20 gram had to be consumed on a daily basis. The margarines provided no, or 3.0 gram of plant sterols or stanols per day. At the end of each of the three intervention periods a postprandial test was carried out. Subjects were asked not to perform any strenuous exercise, not to consume alcohol, and to refrain from high-fat foods on the day prior to the postprandial test days. Subjects arrived at the university by public transport or by car after a 12-hour overnight fast. An intravenous cannula was placed in an antecubital vein and a fasting blood sample was collected ( $T=0 \mathrm{~min}$ ). Subjects were then asked to consume the test meal within 10 minutes. The test meal was provided as a shake and contained no, or 3.0 gram of plant sterols or stanols provided as their fatty acid esters, similar to the intervention of the preceding 4-week intervention period. This breakfast shake contained $250 \mathrm{mg}$ cholesterol and in addition $100.000 \mathrm{IU}$ oil-soluble vitamin A (retinyl palmitate). Subsequent blood samples were drawn after 15, 30, 45, 60, 90, 120, 180, 240, 300, 360, 420 and 480 minutes. Following the blood sample after 240 minutes (approximately around lunch time), subjects received a second meal, which consisted again of a shake. This lunch shake contained no cholesterol, no plant sterols or stanols and no vitamin A. The composition of the two shakes is shown in Table 6.1. Subjects were not allowed to eat anything else, but were allowed to drink water $( \pm 500 \mathrm{~mL})$ throughout the entire test day. 
Table 6.1. Composition of the breakfast shakes enriched with plant sterol or stanol esters and the lunch shake

\begin{tabular}{lccc}
\hline & $\begin{array}{c}\text { Breakfast shake; } \\
\text { sterol/stanol period }\end{array}$ & $\begin{array}{c}\text { Breakfast shake; } \\
\text { control period }\end{array}$ & Lunch shake \\
\hline Energy (MJ) & 3.15 & 3.14 & 3.16 \\
\hline Fat (en\%) & 59.6 & 59.5 & 60.1 \\
\hline SAFA (en\%) & 24.7 & 27.8 & 23.4 \\
\hline MUFA (en\%) & 20.9 & 18.8 & 22.2 \\
\hline PUFA (en\%) & 10.1 & 9.1 & 12.2 \\
\hline Protein (en\%) & 6.2 & 6.2 & 4.2 \\
\hline Carbohydrate (en\%) & 35.2 & 35.3 & 36.4 \\
\hline Cholesterol (mg) & 250.2 & 250.2 & 17.3 \\
\hline Plant sterol or stanol & 3.0 & - & - \\
esters (g) & 100.000 & 100.000 & - \\
\hline Retinyl palmitate (IU) & & & \\
\hline
\end{tabular}

Values are means $\pm S D$. All subjects $(n=43)$ received the three breakfast shakes in random order. ${ }^{1}$ SAFA: saturated fatty acids, MUFA: monounsaturated fatty acids, PUFA: polyunsaturated fatty acids, CHO: carbohydrates

\section{Blood sampling and analyses}

A clotting tube and a sodium fluoride (NaF) tube (Becton, Dickinson and Company, Franklin Lakes, NY, USA) were sampled at each time point. Serum was obtained from the clotting tube by low-speed centrifugation at $1300 \times \mathrm{g}$ for $15 \mathrm{~min}$ at room temperature, at least half an hour after venipuncture and was used for the analysis of TAG, apolipoprotein (apo) B48 and insulin concentrations. Plasma was obtained by low-speed centrifugation of the NaF tube at $1300 \mathrm{x}$ g for $15 \mathrm{~min}$ at $4 \stackrel{\circ}{\circ}$ and was used for the analysis of plasma glucose and retinyl palmitate (RP) concentrations. All serum and plasma samples were snap frozen in liquid nitrogen and stored at $-80^{\circ} \mathrm{C}$ until analysis.

Plasma glucose concentrations (Roche Diagnostic Systems, Hoffmann-La Roche) and serum TAG concentrations (GPO Trinder; Sigma-Aldrich) with correction for free glycerol were measured at baseline and after 15, 30, 45, 60 and 90 minutes, and at hourly intervals up to 8 hours. Serum insulin concentrations were measured at baseline and after $30,45,60$ and 90 minutes and at hourly intervals up to 8 hours with a human insulin-specific RIA kit (Linco Research). Serum apoB48 concentrations were measured at baseline and after 30 minutes and at hourly intervals up to 8 hours with an ELISA kit (Shibayagi). Retinyl palmitate concentrations were measured at baseline and after 15, 30, 45, 60 and 90 minutes and at hourly intervals up to 8 hours with high-performance liquid chromatography in a randomly selected subgroup of 13 subjects ( 4 men, 9 women). All samples from one subject were analysed within one run at the end of the study. 


\section{Statistics}

All data are presented as means \pm standard deviations (SD). To evaluate the overall postprandial responses, the incremental areas under the curve (iAUC) were calculated using the trapezoidal rule. We assessed the total postprandial response (0-8 hours), as well as the first meal response (0-4 hours) and second meal response (4-8 hours). Maximal changes were calculated by subtracting fasting concentrations $(T=0)$ from the maximal concentrations. Differences in fasting concentrations, iAUC and maximal changes between the test meals were statistically evaluated by repeated-measures analysis of variance (ANOVA) with diet as within subject factor. We also evaluated whether the observed postprandial changes were dependent on gender, body mass index (BMI) or age. There were, however, no gender or BMI effects present. The interaction term diet*age was significant for TAG iAUC (total and $2^{\text {nd }}$ meal responses), for glucose iAUC (total response), but not for apoB48 iAUC. This indicated that dietary effects were influenced by age and diet effects were therefore further evaluated per age category (category I: $18-35 y(n=17)$, category II: 36-52y $(n=11)$ and category III: 53$69 y(n=14))$. Results were considered to be statistically significant if $p<0.05$. All statistical analyses were performed using SPSS 18.0 for Mac Os X and adjusted for Bonferroni's correction for multiple comparisons when appropriate (SPSS Inc., Chicago, IL, USA).

\section{Results}

The study was completed by 43 subjects [19]. However, for one woman it was not possible to insert the cannula and results of the present postprandial study therefore refer to 42 subjects (Table 6.2).

Table 6.2. Characteristics of the subjects

\begin{tabular}{|c|c|c|c|c|}
\hline & $\begin{array}{c}\text { All subjects } \\
18-69 y(n=42)\end{array}$ & $\begin{array}{l}\text { Age category I } \\
18-35 y(n=17)\end{array}$ & $\begin{array}{l}\text { Age category II } \\
36-52 y(n=11)\end{array}$ & $\begin{array}{l}\text { Age category III } \\
53-69 y(n=14)\end{array}$ \\
\hline Age (y) & $42 \pm 18$ & $23 \pm 4$ & $46 \pm 4$ & $62 \pm 4$ \\
\hline Male / female (n) & $17 / 25$ & $5 / 12$ & $4 / 7$ & $8 / 6$ \\
\hline Weight (kg) & $73.5 \pm 11.3$ & $73.0 \pm 11.4$ & $68.5 \pm 12.6$ & $78.2 \pm 8.8$ \\
\hline Height (m) & $1.72 \pm 0.09$ & $1.74 \pm 0.10$ & $1.69 \pm 0.11$ & $1.73 \pm 0.06$ \\
\hline BMI $\left(\mathrm{kg} / \mathrm{m}^{2}\right)$ & $24.7 \pm 2.8$ & $24.1 \pm 2.3$ & $23.9 \pm 3.1$ & $26.1 \pm 2.7$ \\
\hline Glucose (mmol/L) & $5.26 \pm 0.55$ & $4.82 \pm 0.23$ & $5.42 \pm 0.36^{1}$ & $5.66 \pm 0.58^{1}$ \\
\hline $\mathrm{TCH}(\mathrm{mmol} / \mathrm{L})$ & $5.73 \pm 1.13$ & $5.09 \pm 0.95$ & $5.62 \pm 1.15$ & $6.60 \pm 0.74^{1,3}$ \\
\hline $\mathrm{HDL}-\mathrm{C}(\mathrm{mmol} / \mathrm{L})$ & $1.69 \pm 0.38$ & $1.64 \pm 0.36$ & $1.81 \pm 0.39$ & $1.66 \pm 0.39$ \\
\hline $\mathrm{TC} / \mathrm{HDL}$ ratio & $3.52 \pm 1.03$ & $3.22 \pm 0.90$ & $3.16 \pm 0.70$ & $4.19 \pm 1.11^{2,3}$ \\
\hline TAG (mmol/L) & $1.13 \pm 0.46$ & $1.15 \pm 0.50$ & $1.13 \pm 0.49$ & $1.09 \pm 0.41$ \\
\hline
\end{tabular}

Values are means \pm SD

Significantly different compared with age category $I^{1}(p<0.01),{ }^{2}(p<0.05)$

Significantly different compared with age category $1{ }^{3}(p<0.05)$ 


\section{Postprandial lipemia}

Fasting serum TAG and apoB48 concentrations were not different after the three intervention periods. The postprandial responses in serum TAG concentrations are presented in Figure 6.1 and Table 6.3. Serum TAG concentrations gradually increased after consumption of the first meal to peak at 3-4 hours. A second peak was observed already one hour after consumption of the second meal (after 5 hours). The TAG iAUC of the total TAG response $\left(\mathrm{i} A \cup C^{\top}\right)$ and after the $1^{\text {st }}$ meal ( $\left(\mathrm{A} A \mathrm{C}^{1}\right)$ and $2^{\text {nd }}$ meal (iAUC ${ }^{2}$ ) were comparable between the test meals in the first age category (18-35 y). In the second age category (36-52 y), iAUC ${ }^{\top}$ and iAUC ${ }^{1}$ were comparable between the test meals, but there was a trend for a higher iAUC ${ }^{2}$ in the stanol period as compared with the sterol period (difference of $46.8 \pm 58.8 \mathrm{mmol} / \mathrm{L}$ / min; $p=0.07$ ). In the third age category (53-69 y), iAUC ${ }^{\top}$ and $\mathrm{i} \mathrm{UUC}^{1}$ were again comparable between the test meals, but there was a significantly higher iAUC ${ }^{2}$ in the stanol period as compared with the sterol period $(63.1 \pm 53.0 \mathrm{mmol} / \mathrm{L} / \mathrm{min} ; p<0.01)$ and the control period (43.2 $\pm 52.4 \mathrm{mmol} / \mathrm{L} / \mathrm{min} ; p<0.05)$.

Age was positively correlated with $\mathrm{iAUC}^{\top}$ in all three intervention periods (control: $r=0.47$; $p<0.01$, sterol: $r=0.44 ; p<0.01$, stanol: $r=0.56 ; p<0.01)$, while the correlation between age and iAUC ${ }^{2}$ was only significant in the stanol period $(r=0.57 ; p<0.01)$. The maximal TAG (maxTAG) concentration increased with age in all three periods (control: $r=0.49 ; p<0.01$, sterol: $r=0.36$; $p<0.05$, stanol: $r=0.45 ; p<0.01)$. In addition, there was a trend towards a higher maxTAG after stanol consumption compared with sterol consumption in age category II $(0.60 \pm 0.74$; $\mathrm{mmol} / \mathrm{L} ; p=0.07)$.

The postprandial responses in serum apoB48 concentrations are presented in Figure 2 and Table 4. Interestingly, serum apoB48 concentrations displayed a much earlier peak (60 minutes-3 hours) after the first meal as compared with the TAG response (3-4 hours). Another clear difference is that the time-to-peak after the second meal was delayed from the younger to the older age categories (i.e. from 5 hours to 6 hours after meal ingestion), which was not seen in the postprandial TAG response. ApoB48 $\mathrm{IAUC}^{\top}$ and $\mathrm{IAUC}^{1}$ were comparable between the three test meals in all age categories. The apoB48 $\mathrm{iAUC}^{2}$ was comparable in the first two age categories, but in age category III the iAUC ${ }^{2}$ after stanol consumption was increased as compared with the sterol period $(67.1 \pm 77.0 \mathrm{mg} / \mathrm{L} / \mathrm{min} ; p<0.05)$ and tended to be higher iAUC ${ }^{2}$ after stanol consumption compared with the control period $(43.1 \pm 64.5$ $\mathrm{mg} / \mathrm{L} / \mathrm{min} ; p=0.08$ ).

Age was positively correlated with iAUC $C^{\top}$ in the stanol period $(r=0.47 ; p<0.01)$ and with iAUC $^{2}$ in the control and stanol period ( $r=0.32 ; p<0.05$ and $r=0.43 ; p<0.01$, respectively). The maximal apoB48 (maxApoB48) concentration correlated with age in the stanol period $(r=0.43 ; p<0.01)$, but not in the sterol and control period. In addition, there was a trend towards a higher maxApoB48 after stanol consumption compared with the control period in age category III ( $2.9 \pm 4.2 \mathrm{mg} / \mathrm{L} ; p=0.07)$.

Retinyl palmitate was incorporated only in the breakfast shake and appearance in the circulation provides information about the lipid content of the chylomicron fraction, 
whereas apoB48 provides information about the number of particles [20, 21]. Postprandial plasma retinyl palmitate concentrations (shown in Figure 6.3, panel A) were determined in 13 subjects and the curve closely resembled the serum TAG curve, showing a first meal peak between 3-4 hours and a second meal peak one hour after consuming the lunch shake. Due to the smaller sample size ( $n=13$ instead of $n=42)$, no statistical analyses in age subgroups were performed on the retinyl palmitate data. Changes in postprandial TAG concentrations always consist of a combined effect of changes in chylomicron and very low-density lipoprotein (VLDL) particle numbers and composition.
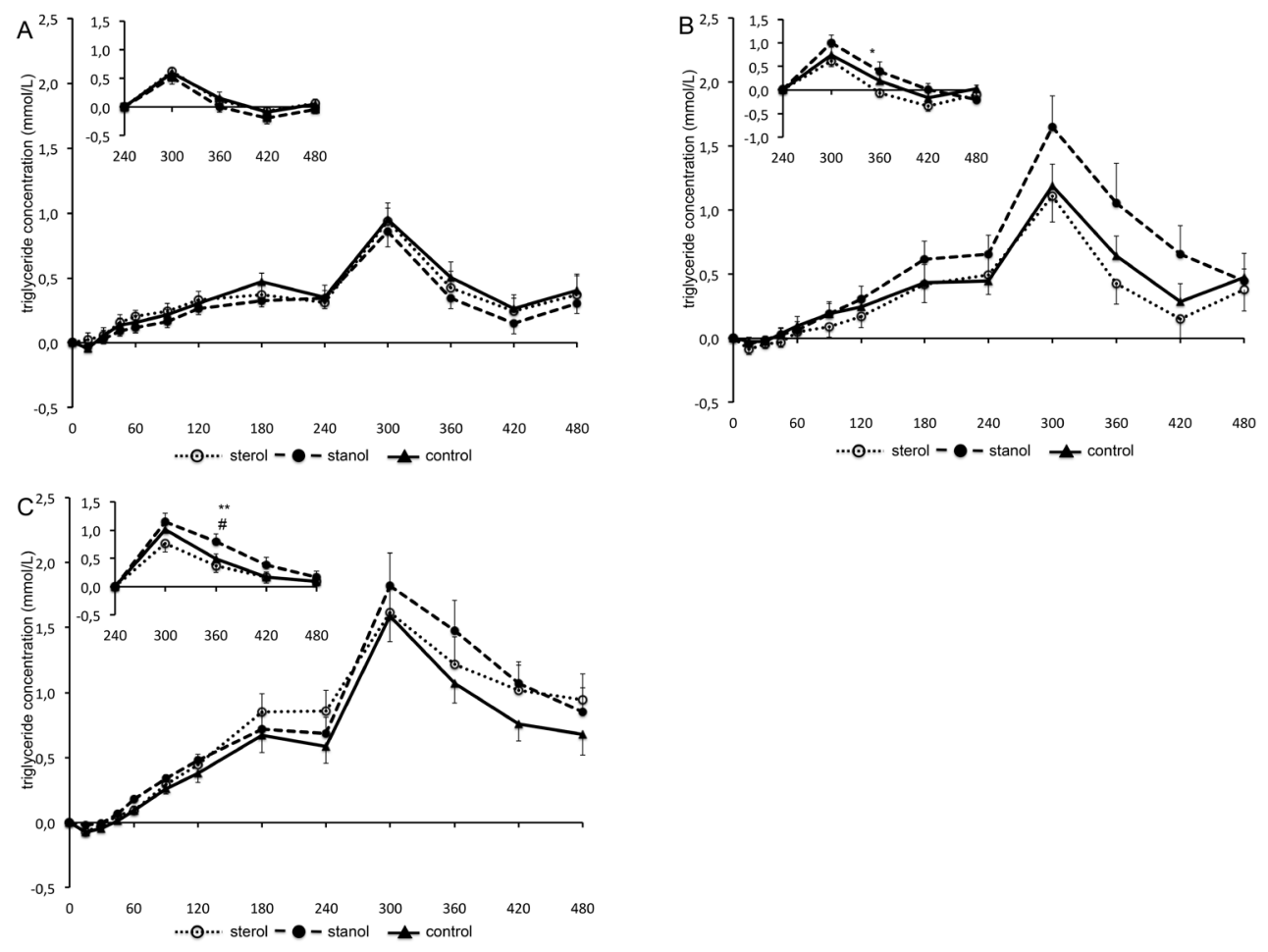

Figure 6.1. Serum triglyceride concentrations in (A) age category I: 18-35 years, (B) age category II: 36-52 years, (C) age category III: 53-69 years after consumption of a mixed meal containing no, or 3.0 gram of plant sterols or plant stanols. Inserts show second meal response (4-8 hours). Data are presented as mean \pm SEM.

B: trend different iAUC ${ }^{2}$ between stanol and sterol period * $(p=0.07)$

C: significantly different iAUC $C^{2}$ between stanol and control period ${ }^{\#}(p<0.05)$ and stanol and sterol period ${ }^{* *}(p<0.01)$

To visualize the postprandial lipid response of the first 4 hours, we plotted retinyl palmitate concentrations as ratio over serum apoB48 concentrations (Figure 6.3, panel B), which gives information about the amount of TAG derived from the diet as compared to chylomicron particles in the circulation and specifically provides information about the lipid content of chylomicrons, e.g. their size [22]. Figures $2 \mathrm{~A}-\mathrm{C}$ show increases in apoB48 concentrations up to 60 minutes, after which concentrations remain relatively stable up to 4 hours, indicating that production rate of chylomicrons equals their clearance rate. 


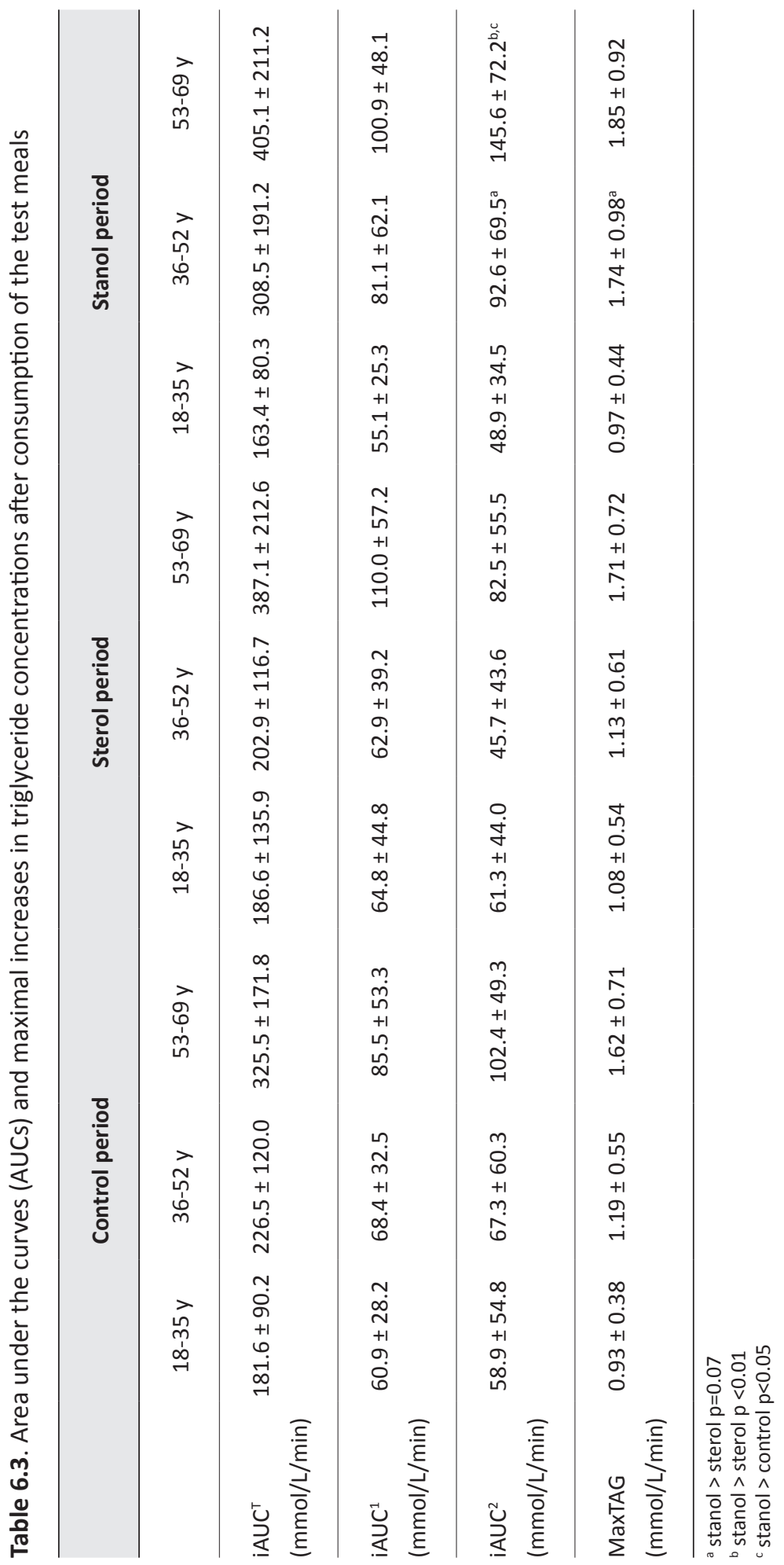



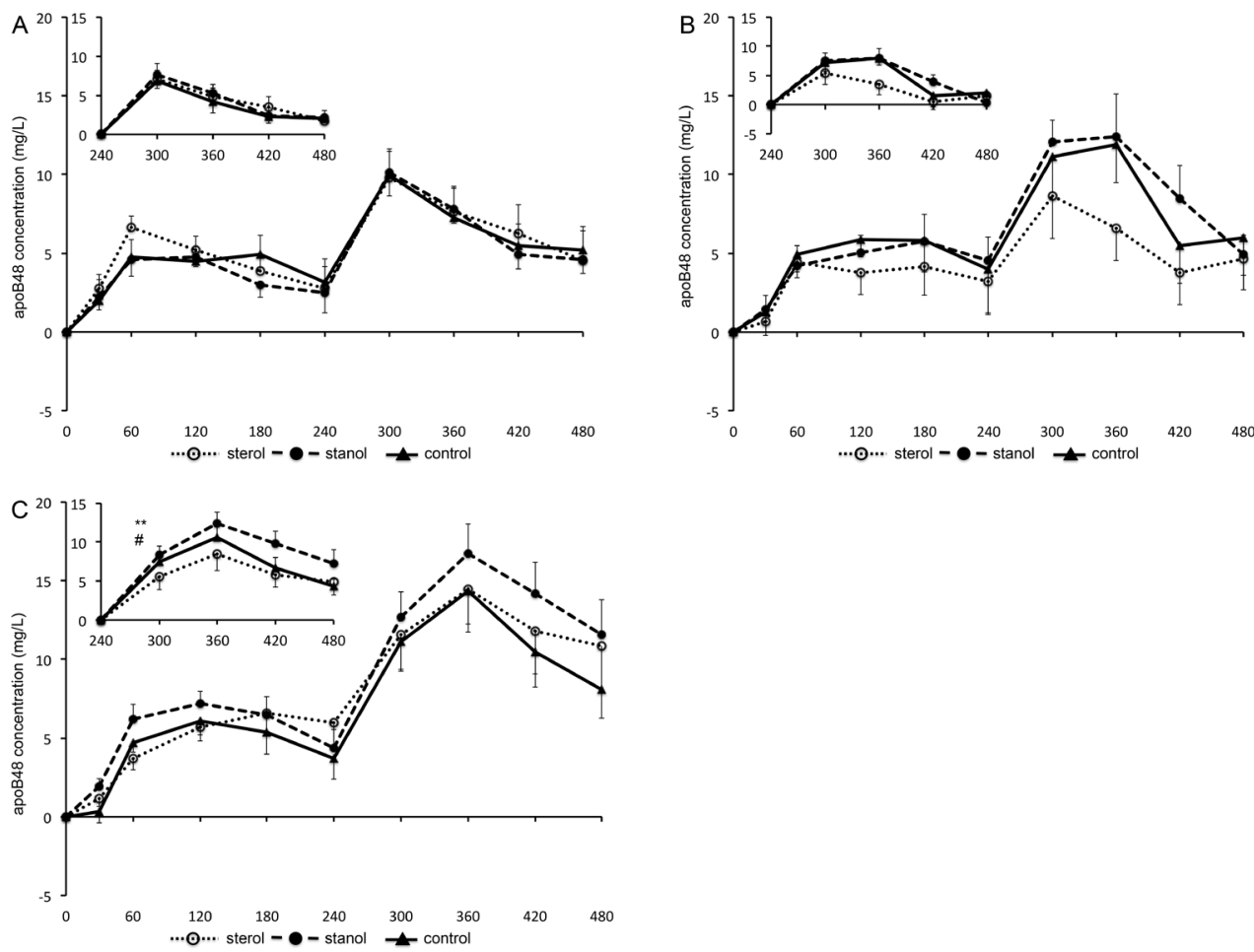

Figure 6.2. Serum apoB48 concentrations in (A) age category I: 18-35 years, (B) age category II: $36-52$ years, (C) age category III: 53-69 years after consumption of a mixed meal containing no, or 3.0 gram of plant sterols or plant stanols. Inserts show second meal response (4-8 hours). Data are presented as mean \pm SEM.

C: significantly different iAUC ${ }^{2}$ between stanol and sterol period $*(p<0.05)$ and trend different iAUC ${ }^{2}$ between stanol and control period ${ }^{\#}(\mathrm{p}=0.08)$

This observation combined with Figure 3B, shows that TAG-poor chylomicrons are produced during the first hour, after which the dietary TAG content of chylomicrons (e.g. size) increases up to 4 hours. No diet effects were observed for RP/ApoB48 ratios. Due to the smaller sample size, no statistical analyses in age subgroups were performed. 


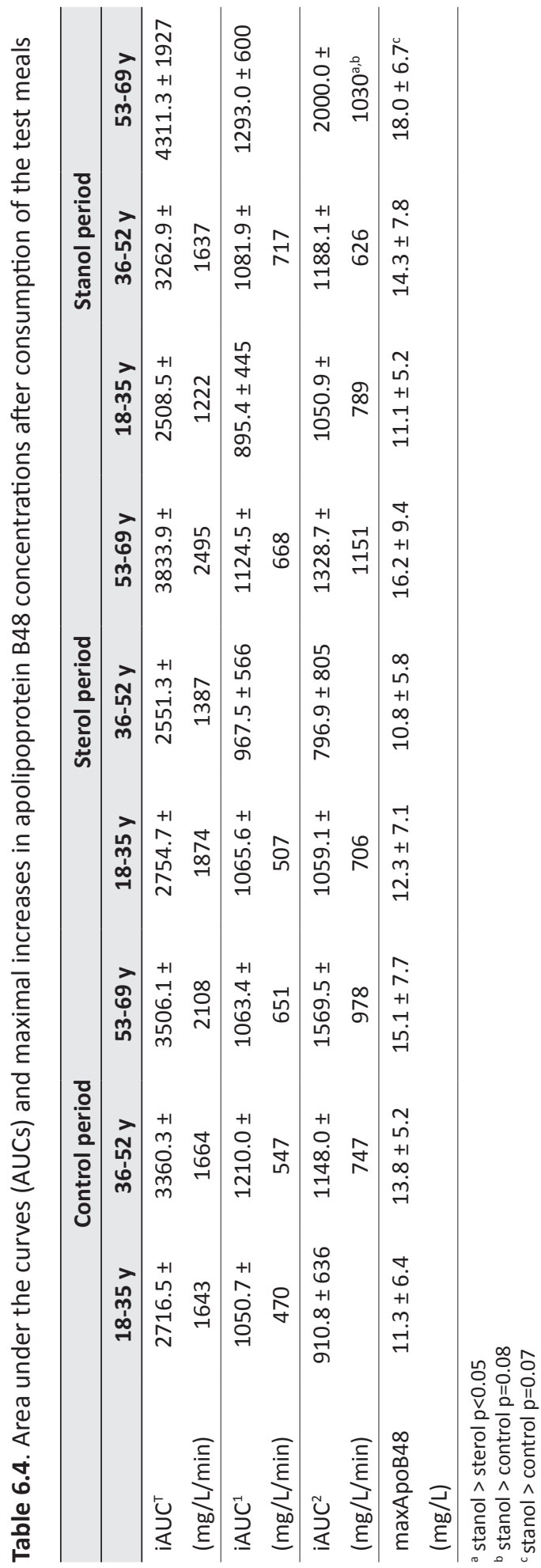




\section{Postprandial glycaemia}

Fasting glucose and insulin concentrations were comparable between the three test days. Postprandial plasma glucose concentrations increased during the first $30 \mathrm{~min}$ after consumption of the first meal, returned to baseline after $60 \mathrm{~min}$ and remained below baseline till consumption of the second meal (Figure 6.4). Plasma glucose concentrations were maximally increased one hour after consumption of the second meal. Glucose iAUC was higher in the stanol period compared with the sterol period in age category I (229.4 \pm 108.1 vs. $168.5 \pm 106.4 \mathrm{mmol} / \mathrm{L} / \mathrm{min}$; $p<0.05$; data not shown). Postprandial glucose responses did not differ between the test meals in age category II and III. Serum insulin concentrations were maximally increased $30 \mathrm{~min}$ after first meal consumption and returned to baseline concentrations after $180 \mathrm{~min}$. A second (smaller) peak was observed after
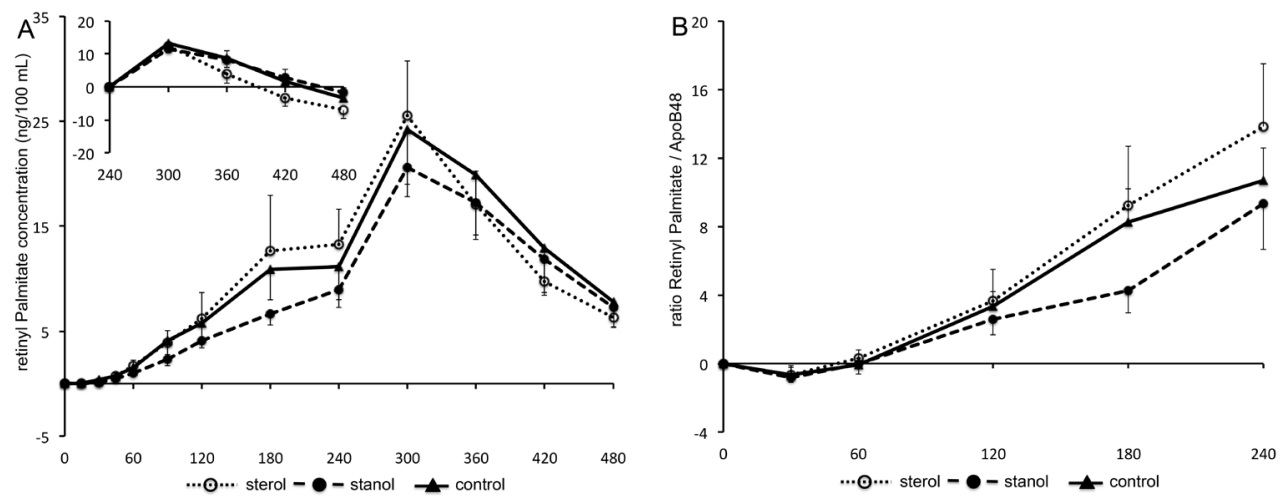

Figure 6.3. (A) Plasma retinyl palmitate concentrations and (B) ratio retinyl palmitate/apoB48 ( $n=13)$ after consumption of a mixed meal containing no, or 3.0 gram of plant sterols or plant stanols. Insert shows second meal response (4-8 hours). Data are presented as mean \pm SEM.

consumption of the second meal. No diet effects were observed for postprandial insulin responses in all subjects or in the different age categories.
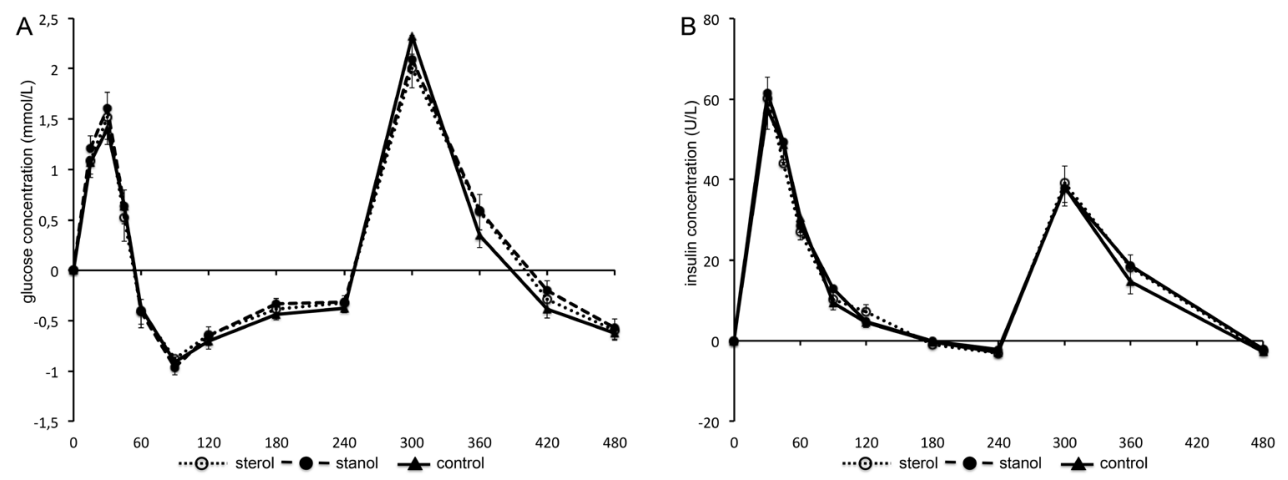

Figure 6.4. (A) Plasma glucose and (B) insulin concentrations $(n=42)$ after consumption of a mixed meal containing no, or 3.0 gram of plant sterols or plant stanols. Data are presented as mean \pm SEM. 


\section{Discussion}

In this randomised controlled trial, we found an increased TAG and apoB48 second meal response in subjects aged between 53 and 69 years after consuming a mixed meal enriched with plant stanol esters as compared to a mixed meal with or without plant sterol esters. The LDL-C lowering effect of plant sterol and plant stanols is well known, but recent studies have suggested that plant sterol and plant stanol esters also reduce fasting TAG concentrations $[1,5]$ by a so far unknown mechanism. Although fasting and postprandial TAG concentrations are positively associated with CVD risk [7-9], only three studies so far have addressed the postprandial effects of foods enriched with plant stanol esters on lipid and lipoprotein metabolism. Relas et al. performed two postprandial mixed meal studies enriched with plant stanol esters: a 24-hour study with $3.0 \mathrm{~g}$ of plant stanol esters after a 2-week intervention period and an acute study with 1.0g of plant stanol esters [12, 13]. In both studies, the addition of plant stanol esters to a high-fat breakfast did not affect postprandial cholesterol and TAG concentrations in serum or in lipoprotein fractions. Gylling et al. provided a low-fat breakfast containing 4.5g of plant stanol esters after a 10 -week intervention period (daily intake 8.8g of plant stanol esters) [11]. Unfortunately, changes in serum TAG and apoB48 concentrations were not determined in that study. The different postprandial study designs complicates the comparison to our study, especially because we found that plant stanol esters affect the second meal TAG and apoB48 response by using a sequential meal protocol with regular blood sampling. We demonstrated that the iAUC for TAG and apoB48 responses were similar after the first meal, while these responses were increased after consumption of the second meal in the plant stanol period. This effect was stronger with increasing age and more evident compared to the sterol period than to the control period. The second meal response predominantly addresses a potential change in TAG clearance $[23,24]$ and suggests that postprandial TAG and chylomicron particle clearance are less efficient after plant stanol consumption. LPL may play a crucial role in this respect. After plant stanol consumption, plasma plant sterol concentrations decrease [25], which may offer an explanation for the delay in TAG clearance. Theoretically, LPL activity might be decreased by reduced plant sterol concentrations through several mechanisms. LPL activity is regulated at the level of gene transcription by peroxisome proliferator activated receptor (PPAR)- $\alpha$ and $-\gamma$. Although studies on the effects of plant sterols and stanols on PPAR is scarce, a study performed in mice reported reduced plasma and hepatic TAG concentrations in response to plant sterol consumption with an unexpected reduction in intestinal PPAR $\alpha$ mRNA expression and no change in hepatic PPAR $\alpha$ mRNA expression [15]. Plat et al. found in peripheral mononuclear blood cells from metabolic syndrome patients after plant stanol consumption, no change in PPAR $\alpha$ or liver $X$ receptor (LXR) expression, although serum TAG concentrations were reduced [26]. Future studies are needed to elucidate whether changes in local PPAR expression in for example adipose and/or skeletal muscle might play a role in LPL modulation after plant sterol or stanol consumption. Also, other modulators of LPL activity, such as apoCII and apoCIII could have been affected by a change in plant sterol 
concentrations and would definitely be interesting for future research. Another explanation for the second meal effect after plant stanol ester consumption might be found in changed oxyphytosterol concentrations (oxidized plant sterols). We have already reported that plant stanol consumption reduced fasting oxyphytosterol concentrations [19]. Oxysterols (oxidized cholesterol) are natural ligands of LXR, which in turn induce LPL expression. There are some suggestions that oxyphytosterols also activate LXR, which could lead to an induction of LPL expression. If so, a positive effect of oxyphytosterols on LPL activity might be lost after plant stanol consumption, which could have resulted in decreased TAG clearance.

The increase in TAG concentrations after consumption of a second meal seems to contradict recent findings of reduced fasting TAGs concentrations after plant stanol consumption [4, 5]. However, reductions in fasting TAG concentrations were only observed in subjects with elevated fasting TAG concentrations and there is no data describing the effect of plant sterol and plant stanol consumption on postprandial responses in these populations. In the present study in apparently healthy, slightly hypercholesterolemic, normotriglyceridemic subjects, no effects of plant sterol and stanol esters on fasting TAGs were found [19], while postprandial TAG and apoB48 responses were increased in the plant stanol ester group. For now, it remains speculative whether the same observation on postprandial TAGs would have been found in a population with elevated fasting TAGs. It should however be noted that the observed plant stanol effect after consumption of a second meal was only present in older subjects, which may form a relatively large part of the target population for the consumption of plant sterol and plant stanol enriched products i.e. subjects with mild hypercholesterolemia (consensus paper). As reported before, non-fasting TAG concentrations are an emerging CVD risk marker and these findings need to be confirmed and evaluated into more detail.

This study also addresses the difference in conclusions that could be made after single meal consumption or after including a second meal, which highlights the metabolic consequences of sequential meal consumption in general. Unfortunately, different postprandial lipoprotein fractions were not collected in this study, but the addition of RP to the first breakfast meal gives us some opportunity to speculate concerning the postprandial lipemic response. After absorption, RP associates with chylomicrons and their remnants until taken up without being re-secreted - by the liver, providing information regarding the lipid content of chylomicrons [21, 27]. In contrast, apoB48 concentrations provide information regarding the number of chylomicron particles [20]. Even though RP has several drawbacks, i.e. mainly accurate in early postprandial period (0-9h) [21], it provides clear evidence for a second meal effect. The fact that a RP peak is seen one hour after consumption of the lunch shake (while no RP was present in the lunch shake), indicates that this second meal induced chylomicron appearance containing fat from the previous breakfast shake. This illustrates the importance of choosing the appropriate study design to address a certain research question, especially when investigating nutritional effects on postprandial lipid responses. The postprandial response after the first meal shows a discrepancy between TAG and apoB48 concentrations, 
i.e. an earlier rise and decrease to baseline in apoB48 concentrations as compared to TAG concentrations. By calculating ratios of dietary TAG concentrations to apoB48 concentrations, we have proposed that TAG-enrichment of chylomicrons continues to increase up to 4 hours without a concomitant increase in apoB48 concentrations after the first hour. This suggests that more TAG-rich chylomicrons are produced and our proposed ratios are in line with literature, which states that dietary lipid transport following a meal is mainly through increased chylomicron particle size with a relatively lesser increase in particle numbers, i.e. an increase in lipid content per chylomicron [28].

In conclusion, this study demonstrates an age-dependent increase in the postprandial TAG and apoB48 response after plant stanol ester consumption as part of a mixed meal, compared to a control meal and to a meal enriched in plant sterol esters. Further research is warranted to validate these results. Also, the mechanism by which plant sterols and plant stanols exert different effects on postprandial lipemic responses needs to be investigated, whether this observation maintains in subjects with elevated fasting TAGs, and if these effects have health consequences. In addition, our findings highlight the impact of sequential meal consumption as it provides more detailed information on postprandial lipid and lipoprotein responses.

\section{Acknowledgements}

The project was funded by the Netherlands Organisation for Scientific Research (TOP grant No. 91208006) and the margarines were kindly provided by RAISIO (Raisio Group, Finland). We would like to thank M. Beckers and Y. Verhulst for their technical and dietary assistance throughout the study. There are no conflicts of interest to declare.

\section{References}

1. Plat J, Mackay D, Baumgartner S, Clifton PM, Gylling H, Jones PJ. Progress and prospective of plant sterol and plant stanol research: report of the Maastricht meeting. Atherosclerosis. 2012 Dec;225:521-33.

2. Gylling H, Plat J, Turley S, Ginsberg HN, Ellegard L, Jessup W, et al. Plant sterols and plant stanols in the management of dyslipidaemia and prevention of cardiovascular disease. Atherosclerosis. 2014 Feb;232:34660.

3. An International Atherosclerosis Society Position Paper: global recommendations for the management of dyslipidemia--full report. J Clin Lipidol. 2014 Jan-Feb;8:29-60.

4. Naumann E, Plat J, Kester AD, Mensink RP. The baseline serum lipoprotein profile is related to plant stanol induced changes in serum lipoprotein cholesterol and triacylglycerol concentrations. J Am Coll Nutr. 2008 Feb;27:117-26.

5. Demonty I, Ras RT, van der Knaap HC, Meijer L, Zock PL, Geleijnse JM, et al. The effect of plant sterols on serum triglyceride concentrations is dependent on baseline concentrations: a pooled analysis of 12 randomised controlled trials. Eur J Nutr. 2013 Feb;52:153-60. 
6. Hegele RA, Ginsberg HN, Chapman MJ, Nordestgaard BG, Kuivenhoven JA, Averna M, et al. The polygenic nature of hypertriglyceridaemia: implications for definition, diagnosis, and management. Lancet Diabetes Endocrinol. 2014 Aug;2:655-66.

7. Sarwar N, Sattar N. Triglycerides and coronary heart disease: have recent insights yielded conclusive answers? Curr Opin Lipidol. 2009 Aug;20:275-81.

8. Bansal S, Buring JE, Rifai N, Mora S, Sacks FM, Ridker PM. Fasting compared with nonfasting triglycerides and risk of cardiovascular events in women. Jama. 2007 Jul 18;298:309-16.

9. Nordestgaard BG, Benn M, Schnohr P, Tybjaerg-Hansen A. Nonfasting triglycerides and risk of myocardial infarction, ischemic heart disease, and death in men and women. Jama. 2007 Jul 18;298:299-308.

10. Varbo A, Benn M, Tybjaerg-Hansen A, Jorgensen AB, Frikke-Schmidt R, Nordestgaard BG. Remnant cholesterol as a causal risk factor for ischemic heart disease. J Am Coll Cardiol. 2013 Jan 29;61:427-36.

11. Gylling $\mathrm{H}$, Hallikainen M, Simonen P, Miettinen HE, Nissinen MJ, Miettinen TA. Serum and lipoprotein sitostanol and non-cholesterol sterols after an acute dose of plant stanol ester on its long-term consumption. Eur J Nutr. 2012 Aug;51:615-22.

12. Relas H, Gylling H, Miettinen TA. Effect of stanol ester on postabsorptive squalene and retinyl palmitate. Metabolism. 2000 Apr;49:473-8.

13. Relas H, Gylling H, Miettinen TA. Acute effect of dietary stanyl ester dose on post-absorptive alpha-tocopherol, beta-carotene, retinol and retinyl palmitate concentrations. Br J Nutr. 2001 Feb;85:141-7.

14. De Smet E, Mensink RP, Plat J. Effects of plant sterols and stanols on intestinal cholesterol metabolism: suggested mechanisms from past to present. Mol Nutr Food Res. 2012 Jul;56:1058-72.

15. Rideout TC, Harding SV, Jones PJ. Consumption of plant sterols reduces plasma and hepatic triglycerides and modulates the expression of lipid regulatory genes and de novo lipogenesis in C57BL/6J mice. Mol Nutr Food Res. 2010 May;54 Suppl 1:S7-13.

16. Beaumier-Gallon G, Dubois C, Portugal H, Lairon D. Postprandial studies on dietary cholesterol in human subjects using stable isotopes and gas chromatography-mass spectrometry analysis. Atherosclerosis. 1998 Dec;141 Suppl 1:S81-5.

17. Fielding B. Tracing the fate of dietary fatty acids: metabolic studies of postprandial lipaemia in human subjects. Proc Nutr Soc. 2011 Aug;70:342-50.

18. Silva KD, Wright JW, Williams CM, Lovegrove JA. Meal ingestion provokes entry of lipoproteins containing fat from the previous meal: possible metabolic implications. Eur J Nutr. 2005 Sep;44:377-83.

19. Baumgartner S, Mensink RP, Husche C, Lutjohann D, Plat J. Effects of plant sterol- or stanol-enriched margarine on fasting plasma oxyphytosterol concentrations in healthy subjects. Atherosclerosis. 2013 Apr;227:414-9.

20. Xiao C, Lewis GF. Regulation of chylomicron production in humans. Biochim Biophys Acta. 2012 May;1821:73646.

21. Cohn JS. Postprandial lipemia and remnant lipoproteins. Clin Lab Med. 2006 Dec;26:773-86.

22. Naissides M, Mamo JC, James AP, Pal S. The effect of acute red wine polyphenol consumption on postprandial lipaemia in postmenopausal women. Atherosclerosis. 2004 Dec;177:401-8.

23. Jackson KG, Abraham EC, Smith AM, Murray P, O'Malley B, Williams CM, et al. Impact of age and menopausal status on the postprandial triacylglycerol response in healthy women. Atherosclerosis. $2010 \mathrm{Jan} ; 208: 246-52$.

24. Jackson KG, Walden CM, Murray P, Smith AM, Lovegrove JA, Minihane AM, et al. A sequential two meal challenge reveals abnormalities in postprandial TAG but not glucose in men with increasing numbers of metabolic syndrome components. Atherosclerosis. 2012 Jan;220:237-43.

25. Fransen HP, de Jong $\mathrm{N}$, Wolfs $\mathrm{M}$, Verhagen $\mathrm{H}$, Verschuren $\mathrm{WM}$, Lutjohann $\mathrm{D}$, et al. Customary use of plant sterol and plant stanol enriched margarine is associated with changes in serum plant sterol and stanol concentrations in humans. J Nutr. 2007 May;137:1301-6. 
26. Plat J, Brufau G, Dallinga-Thie GM, Dasselaar M, Mensink RP. A plant stanol yogurt drink alone or combined with a low-dose statin lowers serum triacylglycerol and non-HDL cholesterol in metabolic syndrome patients. J Nutr. 2009 Jun;139:1143-9.

27. Wilson DE, Chan IF, Ball M. Plasma lipoprotein retinoids after vitamin A feeding in normal man: minimal appearance of retinyl esters among low-density lipoproteins. Metabolism. 1983 May;32:514-7.

28. Cohn JS, Johnson EJ, Millar JS, Cohn SD, Milne RW, Marcel YL, et al. Contribution of apoB-48 and apoB-100 triglyceride-rich lipoproteins (TRL) to postprandial increases in the plasma concentration of TRL triglycerides and retinyl esters. J Lipid Res. 1993 Dec;34:2033-40. 



\section{Chapter 7}

Effects of vitamin E or lipoic acid supplementation on fasting oxyphytosterol concentrations in subjects with impaired glucose tolerance or type II diabetes

Sabine Baumgartner, Ronald P. Mensink, Guido Haenen, Aalt Bast, Christoph J. Binder, Otto Bekers, Constanze Husche, Dieter Lütjohann and Jogchum Plat 


\begin{abstract}
Consumption of plant sterol enriched products increases serum plant sterol concentrations. Plant sterols can be oxidized and form oxyphytosterols (plant sterol oxidation products). We have previously shown that fasting oxyphytosterol concentrations are not increased when healthy subjects consumed a plant sterol or a plant stanol enriched margarine $(3.0 \mathrm{~g} / \mathrm{d}$ of plant sterols or stanols) for 4 weeks. Now we have examined the effects of 4 weeks vitamin $E$ or lipoic acid supplementation on fasting plasma oxyphytosterol concentrations in subjects with impaired glucose tolerance (IGT) or type II diabetes. For this, 20 subjects with IGT or type II diabetes consumed for 4 weeks in a random order placebo capsules, vitamin E capsules (804 mg/d) or lipoic acid capsules $(600 \mathrm{mg} / \mathrm{d})$. Plasma oxyphytosterol and oxycholesterol concentrations were determined in butylated hydroxytoluene (BHT)-enriched EDTA plasma via GC-MS. In addition, markers reflecting oxidative stress (oxidized LDL levels and MDA concentrations) and antioxidant capacity (TEAC assay, uric acid concentrations and GSH/ GSSG) were also measured.

Oxyphytosterol concentrations were higher in subjects with IGT or type II diabetes as compared to concentrations in healthy subjects. Despite these higher values, plasma oxyphytosterol and oxycholesterol were not reduced after consumption of vitamin $E$ or lipoic acid for 4 weeks. In addition, none of the other markers reflecting oxidative stress and anti-oxidative capacity were changed after consuming high-doses of these two antioxidants for 4 weeks. In conclusion, we demonstrated that the higher oxyphytosterol concentrations in subjects with impaired glucose tolerance or type II diabetes are not reduced by vitamin $\mathrm{E}$ and lipoic acid supplementation.
\end{abstract}




\section{Introduction}

Consumption of plant sterol enriched products reduces fasting serum low-density lipoprotein cholesterol (LDL-C) concentrations. However, as shown by a recent meta-analysis, at the same time serum concentrations of sitosterol increases by $31 \%$ [Cl: $26-37 \%]$ and those of campesterol by $37 \%$ [Cl: 29-45] at recommended intakes of $1.6 \mathrm{~g} / \mathrm{d}$ [1]. Whether these increased plant sterol concentrations have an impact on CVD risk has been subject of debate for many years now, as epidemiological studies have reported contradictive findings $[2,3]$. Previously, we have postulated that this controversy might relate to the fact whether plant sterols are oxidized or not [4]. Cholesterol and plant sterols share structural similarities and can therefore both be oxidized to form either oxycholesterols (cholesterol oxidation products) or oxyphytosterols (plant sterol oxidation products) [5]. While oxycholesterol concentrations have been characterised as an oxidative stress marker [6], information regarding oxyphytosterol metabolism and their health effects in humans is scarce. In fact, there is a clear lack of knowledge regarding absorption, endogenous formation via (ROSmediated) oxidation of circulating plant sterols, and potential effects of other dietary components on circulating serum oxyphytosterol concentrations. We have previously shown that increased dietary plant sterol consumption did not change fasting oxyphytosterol concentrations, despite elevated fasting plant sterol concentrations. However, postprandial oxyphytosterol concentrations increased after consumption of a high-fat meal enriched with plant sterol esters [7]. Information of dietary antioxidant supplementation on circulating oxyphytosterol concentrations in metabolically stressed subjects would expand our knowledge on oxyphytosterol metabolism in humans. Therefore, the objective of this study was to examine changes in plasma oxyphytosterol concentrations after 4 weeks vitamin E or lipoic acid supplementation in subjects with impaired glucose tolerance or diabetes type II (DMII), who are characterized by increased oxidative stress. These two antioxidants were chosen since vitamin $\mathrm{E}$ is a typical fat-soluble antioxidant, while lipoic acid is a fat- and water-soluble antioxidant and both vitamin $\mathrm{E}$ and lipoic have been show to reduce oxidative markers in type II diabetics.

\section{Subjects and Methods}

\section{Subjects}

The study population consisted of 20 men and women with impaired glucose tolerance (IGT) or type II diabetes. They were recruited via announcements in local newspapers in Maastricht and surroundings between October 2012 and March 2013. Subjects were invited for two screening visits if they met the following criteria: aged between 18 and 75 years, BMI between 20 and $35 \mathrm{~kg} / \mathrm{m}^{2}$, no active cardiovascular disease or severe medical condition that might interfere with the study and no use of insulin or lipid-lowering medication. During screening visits, weight and height were measured and a fasting blood sample was 
drawn to determine lipid and lipoprotein concentrations. The diagnosis of type II diabetes or IGT was based on the use of oral hypoglycemic agents or an oral glucose tolerance test. Only subjects without diagnosed diabetes underwent an oral glucose tolerance test to verify potential presence of impaired glucose tolerance. For this, subject consumed 82.5 gram of dextrose monohydrate dissolved in $250 \mathrm{~mL}$ of tap water and plasma glucose concentrations were measured after 2 hours with an value between $7.8-11.1 \mathrm{mmol} / \mathrm{L}$ defined as having IGT [8]. Twenty subjects of which 8 subjects with type II diabetes and 12 subjects with IGT were enrolled and completed the study. Baseline characteristics are shown in Table 7.1. All participants gave written informed consent before entering the study. The protocol was approved by the medical ethical committee of the Maastricht University Medical Centre+ (MUMC+) and the trial is registered at clinicaltrials.gov as NCT01984567.

Table 7.1. Baseline characteristics

\begin{tabular}{ll}
\hline Age (years) & $63.1 \pm 5.8$ \\
\hline Male / Female $(\mathrm{n})$ & $16 / 4$ \\
\hline Weight $(\mathrm{kg})$ & $90.1 \pm 13.6$ \\
\hline Height $(\mathrm{m})$ & $1.75 \pm 0.1$ \\
\hline BMI $(\mathrm{kg} / \mathrm{m} 2)$ & $29.5 \pm 3.7$ \\
\hline Total cholesterol (mmol/L) & $5.3 \pm 0.9$ \\
\hline
\end{tabular}

\section{Diets and design}

The study had a randomised placebo-controlled cross-over design and consisted of three intervention periods of 4 weeks, separated by washout periods of 4 weeks. Subjects were allocated to the intervention periods in a randomised order, based upon a computergenerated table with random numbers. During each period, subjects were asked to consume daily either three placebo capsules, three capsules containing R-vitamin E (268 mg three times; $804 \mathrm{mg}$ a day) or three capsules containing R-lipoic acid (200 mg three times; $600 \mathrm{mg}$ a day). They were instructed to consume one capsule during each meal with a glass of water. Subjects visited the university at the start of each period, and again after 3 and 4 weeks of intervention. They were provided with at least the amount of capsules needed for 4 weeks and excess capsules were returned at the end of each intervention period. Subjects completed a validated food frequency questionnaire (FFQ) at the end of each intervention periods and a dietician checked these questionnaires to calculate energy and nutrient intakes over the previous 4 weeks using the Dutch food composition table. Subjects were asked not to change their habitual diet, level of physical exercise or use of alcohol throughout the three intervention periods in the study. 


\section{Blood sampling}

Blood was sampled after an overnight fast at the start of each intervention period and after 3 and 4 weeks of intervention. The same person performed all venipunctures at approximately the same time of the day at the same day of the week.

A clotting tube (Becton, Dickinson and Company, Franklin Lakes, NY, USA) was sampled at each occasion and serum was obtained by low-speed centrifugation at $1300 \mathrm{~g}$ for $15 \mathrm{~min}$

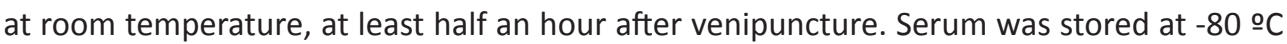
and used for analysis of lipid and (apo)lipoprotein concentrations, hsCRP concentrations, iron status parameters (total iron, ferritin and transferrin), copper status parameters (i.e. copper and ceruloplasmin), inflammatory markers and cellular adhesion molecules. EDTA tubes (Becton, Dickinson and Company, Franklin Lakes, NY, USA) were sampled the end of each period in weeks 3 and 4 and plasma was obtained by low-speed centrifugation at $1300 \mathrm{~g}$ for $15 \mathrm{~min}$ at $4 \stackrel{\circ}{\circ}$. To avoid auto-oxidation, $10 \mathrm{ml}$ butylated hydroxytoluene (BHT; $25 \mathrm{mg} / \mathrm{mL}$ ethanol) was added per $1 \mathrm{~mL}$ of EDTA plasma, immediately after centrifugation and then stored at $-80 \stackrel{\circ}{\circ}$. BHT-enriched plasma was used for analysis of oxyphytosterol, oxycholesterol, oxidized LDL and malondialdehyde (MDA) concentrations. Fresh whole EDTA blood was sampled in week 4 and was used for the isolation of red blood cells (RBCs) as described previously [9]. BHT was added to the RBC and PBMC fraction, stored at -80 ㅇ C and used for the analysis of oxyphytosterol and oxysterol concentrations. Heparin tubes (Becton, Dickinson and Company, Franklin Lakes, NY, USA) were also sampled in week 4 and plasma was obtained by low-speed centrifugation at $1300 \mathrm{~g}$ for $15 \mathrm{~min}$ at $4 \stackrel{\circ}{ } \mathrm{C}$. Heparin plasma was used for the analyses of the trolox equivalent antioxidant capacity (TEAC) assay and uric acid concentrations. For this, 10\% TCA was added to the plasma (1:1) followed by centrifugation ( $13.000 \mathrm{rpm}, 5 \mathrm{~min}$ at $4 \stackrel{\circ}{\circ}$ ). Whole heparin blood was sampled in week 4 and 1.3\% 5-Sulfosalicylic Acid (SSA) in $10 \mathrm{mM} \mathrm{HCL}$ was added for the analysis of GSH/ GSSG. Fresh whole heparin blood was used for the analysis of HbA1c concentrations. An Acid Citrate Dextrose (ACD) tube was sampled at the end of each period and was used for the isolation of blood platelets. BHT was added to the platelets fraction, stored at $-80 \cong \mathrm{C}$ and used for the analysis of oxyphytosterol and oxycholesterol concentrations. A NaF tube was sampled at the end of each period and plasma was obtained by low-speed centrifugation at

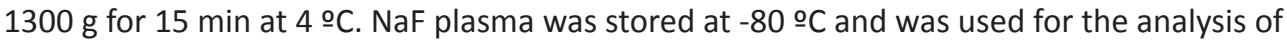
glucose concentrations.

\section{Analyses}

Total cholesterol (CHOD-PAP method; Roche Diagnostic, Mannheim, Germany), highdensity lipoprotein cholesterol (HDL-C) (CHOD-PAP method; Roche Diagnostics, Mannheim, Germany) after precipitation of apoB-containing lipoproteins with phosphotungstic acid and magnesium ions, and triacylglycerol (TAG) concentrations, with correction for free glycerol, were analysed in serum enzymatically (GPO-Trinder; Sigma-Aldrich Corp., St. Louis, MO, 
USA). LDL-C concentrations were calculated according to the Friedewald equation [10]. Apolipoprotein concentrations (apoA1 and apoB100) were analysed using highly sensitive immunoturbidimetric assays (Horiba ABX, Montpellier, France). Serum hs-CRP concentrations (Kamiya Biomedical Company, Seattle, USA) and glucose concentrations (Roche Diagnostics Systems, Hoffmann-La Roche Ltd., Basel, Switzerland) were also analysed enzymatically. All samples from one subject were analysed within one run at the end of the study. Glycated haemoglobin (HbA1c) was measured by high-pressure liquid chromatography (HPLC) (BioRad variant II, Bio-Rad Laboratories, Inc.). Sitosterol and campesterol concentrations were analysed using liquid chromatography-flame ion detection (LC-FID) as described previously [11]. Concentrations are expressed as $\mathrm{mg} / \mathrm{dL}$ and as $10^{2} \mu \mathrm{mol} / \mathrm{mmol}$ total cholesterol. Oxyphytosterol concentrations ( $7 \alpha$-hydroxy $(\mathrm{OH})$-campesterol, $7 \alpha-\mathrm{OH}$-sitosterol, $7 \beta-\mathrm{OH}$ campesterol, $7 \beta-\mathrm{OH}$-sitosterol, 7-keto-campesterol and 7-keto-sitosterol) and oxycholesterol concentrations ( $7 \alpha-\mathrm{OH}$-cholesterol, $7 \beta-\mathrm{OH}$-cholesterol and 7-keto-cholesterol) in plasma as well as in RBC 's, PBMC's and platelets were analysed by gas-liquid chromatography-mass spectroscopy (GC-MS) according to the procedure as described by Husche et al [12] and expressed as $\mathrm{ng} / \mathrm{mL}, \mathrm{ng} / \mathrm{mg}$ or as $\mathrm{pg} / \mathrm{mg}$. Oxycholesterol and oxyphytosterol concentrations in plasma were also standardized for cholesterol concentrations and expressed as nmol/ mmol cholesterol. Oxidized LDL (oxLDL) was measured by chemiluminescent ELISA by determining the content of oxidized phospholipids per particle of apoB100 (oxidized phospholipids:apoB100 ratio) as described elsewhere [13]. Iron and copper status parameters were analysed as previously described [29]. MDA concentrations (oxidative stress marker), trolox equivalent, GSH/GSSG and uric acid concentrations (antioxidative markers) were analysed as previously described [14, 15]. Plasma inflammatory markers (II-6 and TNF $\alpha$ ), cellular adhesion molecules (E-selectin, P-selectin, soluble (s) ICAM-1, sICAM-3 and SVCAM-1), thrombomodulin and serum amyloid A (SAA) were measured with a commercially available Multi Spot ELISA kit (Meso Scale Discovery). Fibroblast Growth Factor 21 (FGF-21) and 19 (FGF-19) concentrations were measured with a single spot ELISA kit (R\&D systems). All analyses were performed in samples from week 4, except for lipid, (apo)lipoprotein and hsCRP concentrations which were measured in weeks 3 and 4 and averaged for data analysis.

\section{Statistics}

Effects of vitamin E and lipoic acid supplementation were evaluated by a univariate analysis of variance (ANOVA) with subject number as a random factor. When dietary effects reached statistical significance $(p<0.05)$, diets were compared pairwise using a Bonferroni's correction. Oxyphytosterol and oxycholesterol levels in RBC, PBMC and blood platelet fraction were not normally distributed and were therefore reported as medians with ranges and differences between treatments were evaluated by a Friedman's test. Oxyphytosterol concentrations in healthy subjects were measured in our previous study using exactly the 
same method [4] and compared to those of subjects with IGT or type II diabetes by an unpaired Student's T-test. All statistical analyses were performed using SPSS 20.0 for Mac Os X (SPSS Inc., Chicago, IL, USA).

\section{Results}

Average daily intakes of energy, fibre, and cholesterol, and the proportions of energy from protein, carbohydrates, total fat, saturated fatty acids, monounsaturated fatty acids, and polyunsaturated fatty acids, and habitual vitamin E intake as calculated from the FFQ's did not differ between the three intervention periods (Table 7.2).

Table 7.2. Daily dietary intake during the study

\begin{tabular}{lccc}
\hline & Control period & Vitamin E period & Lipoic acid period \\
\hline Energy (MJ) & $8.3 \pm 2.8$ & $8.3 \pm 2.3$ & $8.3 \pm 2.3$ \\
\hline Fat (energy\%) & $38.2 \pm 7.4$ & $37.0 \pm 6.5$ & $36.7 \pm 6.7$ \\
SAFA $^{\mathrm{a}}$ & $11.8 \pm 3.1$ & $11.6 \pm 2.3$ & $12.1 \pm 2.9$ \\
MUFA $^{\mathrm{a}}$ & $13.6 \pm 2.9$ & $13.4 \pm 3.2$ & $12.8 \pm 3.2$ \\
PUFA $^{\mathrm{a}}$ & $9.0 \pm 3.8$ & $8.4 \pm 2.6$ & $8.3 \pm 2.9$ \\
\hline Protein (energy\%) & $16.4 \pm 4.1$ & $16.4 \pm 3.4$ & $16.1 \pm 2.9$ \\
\hline CHO $^{\mathrm{a}}$ (energy\%) & $41.0 \pm 5.7$ & $42.3 \pm 6.4$ & $42.8 \pm 6.1$ \\
\hline Alcohol (energy\%) & $1.9 \pm 2.7$ & $1.8 \pm 2.3$ & $1.7 \pm 2.4$ \\
\hline Fibre (g/day) & $23.4 \pm 10.0$ & $24.1 \pm 5.6$ & $24.2 \pm 6.0$ \\
\hline Cholesterol (mg/day) & $204 \pm 66$ & $201 \pm 56$ & $196 \pm 64$ \\
\hline Vitamin E (mg/day) & $13.9 \pm 7.4$ & $13.2 \pm 5.3$ & $13.1 \pm 5.5$ \\
\hline
\end{tabular}

Values are means $\pm S$.D. All subjects $(n=20)$ received the three dietary periods in random order.

a SAFA: saturated fatty acids, MUFA: monounsaturated fatty acids, PUFA: polyunsaturated fatty acids, CHO: carbohydrates

${ }^{\text {b }}$ dietary vitamin E intake without capsule supplementation

Fasting oxyphytosterol concentrations after the control period in subjects with IGT or type II diabetes were compared with those from a previous study with healthy subjects during the control period [4]. Oxyphytosterol concentrations were comparable between subjects with IGT and type II diabetes. Figure 7.1 shows that $7 \alpha-\mathrm{OH}$-campesterol and $7 \alpha-\mathrm{OH}$-sitosterol were significantly higher in subjects with IGT or type II diabetes compared with healthy subjects $(p<0.001)$. 7 $\beta-\mathrm{OH}$-campesterol concentrations were comparable between the 
two populations, while $7 \beta-\mathrm{OH}$-sitosterol concentrations were higher in subjects with IGT or type II diabetes compared with healthy subjects $(p<0.001)$. Concentrations of 7-ketocampesterol and 7-keto-sitosterol were also significantly higher in subjects with IGT or type II diabetes compared with healthy subjects $(p<0.001)$. Thus, these findings suggest that IGT and diabetic patients had increased oxidative stress.
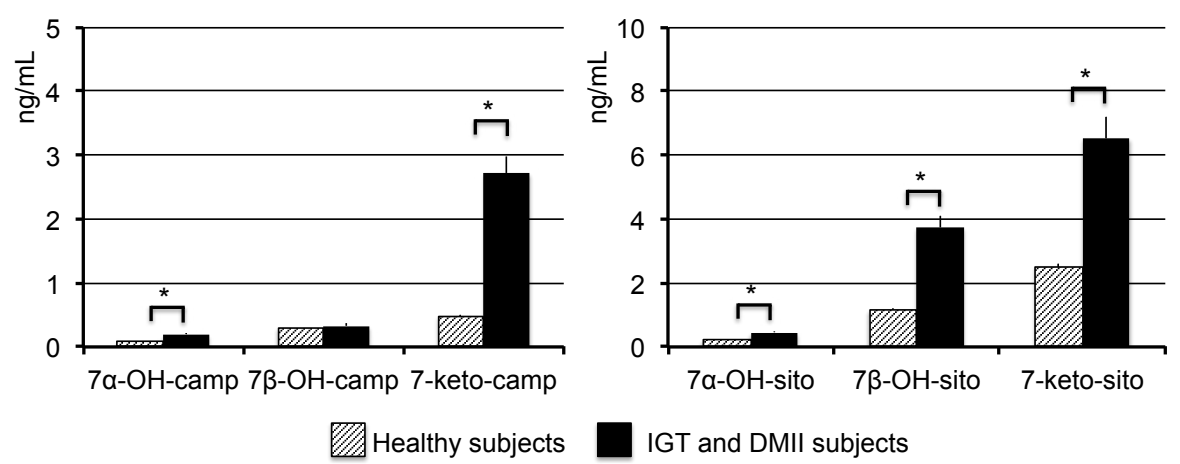

Figure 7.1. Fasting plasma oxyphytosterol concentrations after a control period in healthy subjects and subjects with IGT or type II diabetes $(* p<0.001)$

Fasting oxyphytosterol and oxycholesterol levels in plasma, RBC's, and platelets in subjects with IGT or type II diabetes are shown in Table 7.3. In PBMC's, oxyphytosterol levels were below the detection limit. Plasma $7 \alpha-\mathrm{OH}-, 7 \beta-\mathrm{OH}$ - and 7-keto-cholesterol, -campesterol and -sitosterol concentrations were comparable in the vitamin $\mathrm{E}$, lipoic acid and control periods. Cholesterol-standardized oxyphytosterol and oxycholesterol levels showed similar results. In RBC's, oxycholesterol concentrations were comparable during the vitamin E, lipoic acid and control periods. For the oxyphytosterols, 7-keto-campesterol median levels were lower in the vitamin E period as compared to the control period (37 [23-87] pg/mg and 51 [31-331] $\mathrm{pg} / \mathrm{mg}$ respectively; $\mathrm{p}<0.05)$, while the other oxyphytosterol isoforms were comparable at the end of the three periods. In blood platelets, $7 \alpha-\mathrm{OH}-, 7 \beta-\mathrm{OH}$ - and 7-keto-cholesterol, -campesterol and -sitosterol levels were comparable in the vitamin $\mathrm{E}$, lipoic acid and control periods. In the PBMC fraction, $7 \beta-\mathrm{OH}$-cholesterol median levels were higher in the vitamin E period compared to the control period (223 [2-9925] pg/mg and 174 [22-16997] pg/mg respectively; $p<0.05)$ while the other cholesterol oxidation levels were comparable in the vitamin E, lipoic acid and control periods.

Serum total cholesterol concentrations were $0.26 \pm 0.35 \mathrm{mmol} / \mathrm{L}$ higher at the end of the vitamin $E$ period $(4.9 \% ; p<0.05)$ as compared with the lipoic acid period and $0.23 \pm$ $0.44 \mathrm{mmol} / \mathrm{l}(4.2 \% ; p<0.05)$ higher as compared with the control period. This was also reflected in the total cholesterol/HDL cholesterol ratio, which was increased in the vitamin E period by $0.27 \pm 0.40$ (5.6\%; $p<0.01$ ) compared with the control period, while there was a trend towards reduction in the lipoic acid period $(-4.4 \% ; p=0.06)$. Also serum apoB100 concentrations were higher in the vitamin $E$ period compared with the lipoic acid $0.05 \pm$ 
$0.08 \mathrm{~g} / \mathrm{L} ; p<0.05)$ and control periods $(0.07 \pm 0.10 \mathrm{~g} / \mathrm{L} p<0.01)$. Finally, apoA1 concentrations were also increased in the vitamin E period compared with lipoic acid $(0.06 \pm 0.08 \mathrm{~g} / \mathrm{L}$; $p<0.01)$ and control periods $(0.05 \pm 0.09 \mathrm{~g} / \mathrm{L} ; p<0.05)$. No differences were found in serum TAG and HDL-C concentrations between the three periods.

Table 7.4 shows markers reflecting oxidative stress and antioxidative capacity. Oxidized LDL levels and MDA concentrations, which are both markers of oxidative stress, were comparable at the end of the three intervention periods.

In addition, parameters reflecting antioxidative capacity did not differ between the vitamin E, lipoic acid and control periods. Also plasma cytokines, cellular adhesion molecules, and iron and copper status were comparable between the three periods (Table 7.5).

Plasma glucose, HbA1c, FGF-19, FGF-21, serum plant sterols and lathosterol and cholestanol concentrations were comparable between the vitamin E, lipoic acid and control periods (Table 7.6).

\section{Correlations}

In the control period, positive correlations were found between plasma $7 \alpha-\mathrm{OH}$-campesterol and $7 \alpha-\mathrm{OH}$-sitosterol concentrations $(r=0.845 ; p<0.001)$, between $7 \beta-\mathrm{OH}$-cholesterol and $7 \beta-\mathrm{OH}$-sitosterol concentrations $(r=0.625 ; p<0.01)$, and between 7-keto-campesterol and 7-keto-sitosterol concentrations $(r=0.902 ; p<0.001)$. Although plasma concentrations between the different oxyphytosterol isoforms also correlated significantly, correlations were less strong than between similar isoforms. Also in RBC's and platelets, oxycampesterol and oxysitosterol levels were correlated, although stronger correlations were seen in platelets compared with RBC's (Table 7.7). Plasma and RBC oxyphytosterol levels, plasma and platelet oxyphytosterol levels and RBC and platelets oxyphytosterol levels did not correlate.

In plasma $7 \alpha-\mathrm{OH}$-cholesterol and $7 \alpha-\mathrm{OH}$-campesterol concentrations were significantly correlated $(r=0.535 ; p<0.02)$, whereas plasma $7 \alpha-\mathrm{OH}$-cholesterol and $7 \alpha-\mathrm{OH}$-sitosterol concentrations were not $(r=0.288 ; p=0.232)$. $7 \beta-\mathrm{OH}$-cholesterol and $7 \beta-\mathrm{OH}$-campesterol concentrations correlated significantly $(r=0.502 ; p<0.05)$ and there was a trend towards a correlation between $7 \beta-\mathrm{OH}$-cholesterol and $7 \beta-\mathrm{OH}$-sitosterol $(r=0.407 ; p=0.084)$. There were no correlations between 7-keto-cholesterol concentrations and 7-keto-campesterol or between 7-keto-cholesterol and 7-keto-sitosterol concentrations. Oxidized LDL levels only correlated with 7-keto-cholesterol concentrations. 
Table 7.3. Effect of vitamin $E$ and lipoic acid supplementation on oxyphytosterol and oxycholesterol concentrations in plasma, RBC's and platelets

\begin{tabular}{|c|c|c|c|}
\hline & Control period & Vitamin E period & Lipoic acid period \\
\hline \multicolumn{4}{|l|}{ Plasma (ng/mL) } \\
\hline $7 \alpha-\mathrm{OH}$-cholesterol & $48.83 \pm 32.10$ & $50.33 \pm 31.13$ & $52.97 \pm 33.08$ \\
\hline $7 \alpha-\mathrm{OH}$-campesterol & $0.20 \pm 0.09$ & $0.22 \pm 0.12$ & $0.18 \pm 0.10$ \\
\hline $7 \alpha-\mathrm{OH}$-sitosterol & $0.46 \pm 0.23$ & $0.51 \pm 0.27$ & $0.53 \pm 0.21$ \\
\hline $7 \beta-\mathrm{OH}$-cholesterol & $8.82 \pm 4.03$ & $8.95 \pm 4.07$ & $8.32 \pm 4.03$ \\
\hline $7 \beta$-OH-campesterol & $0.33 \pm 0.17$ & $0.35 \pm 0.27$ & $0.35 \pm 0.26$ \\
\hline $7 \beta$-OH-sitosterol & $3.73 \pm 1.63$ & $4.05 \pm 1.61$ & $4.51 \pm 2.21$ \\
\hline 7-keto-cholesterol & $23.53 \pm 10.36$ & $26.44 \pm 12.90$ & $21.74 \pm 7.76$ \\
\hline 7-keto-campesterol & $2.71 \pm 1.20$ & $2.59 \pm 1.15$ & $2.81 \pm 1.39$ \\
\hline 7-keto-sitosterol & $6.50 \pm 3.07$ & $7.21 \pm 3.82$ & $7.70 \pm 3.23$ \\
\hline Sum oxycholesterol & $80.64 \pm 37.90$ & $88.93 \pm 40.54$ & $83.03 \pm 39.0$ \\
\hline Sum oxyphytosterol & $13.28 \pm 5.22$ & $14.93 \pm 5.65$ & $16.32 \pm 6.61$ \\
\hline \multicolumn{4}{|c|}{ RBC's (oxyphytosterols: pg/mg, oxycholesterol: ng/mg) } \\
\hline $7 \alpha-\mathrm{OH}$-cholesterol & $1.0(0.3-24.8)$ & $0.4(0.2-1.0)$ & $0.4(0.2-19.4)$ \\
\hline $7 \alpha$-OH-campesterol & $2.5(1.6-76.0)$ & $2.3(0.7-3.8)$ & $6.2(0.85-74.6)$ \\
\hline $7 \alpha$-OH-sitosterol & $8.8(4.0-80.1)$ & $7.2(2.1-11.0)$ & $6.8(3.4-81.4)$ \\
\hline $7 \beta-\mathrm{OH}$-cholesterol & $1.4(0.2-35.3)$ & $0.4(0.2-1.3)$ & $0.4(0.1-28.2)$ \\
\hline 7ß-OH-campesterol & $2.6(0-76.8)$ & $1.5(0-3.6)$ & $1.9(0.1-109.0)$ \\
\hline $7 \beta$-OH-sitosterol & $20.7(11.5-122.7)$ & $18.5(4.5-24.8)$ & $18.4(3.7-127.0)$ \\
\hline 7-keto-cholesterol & $3.3(0.8-95.9)$ & $1.3(0.7-3.9)$ & $1.1(0.8-115.7)$ \\
\hline 7-keto-campesterol & $51.0(31.4-330.7)$ & $36.7(23.4-86.6)^{\mathrm{a}}$ & $40.2(23.7-301.7)$ \\
\hline 7-keto-sitosterol & $91.3(65.8-333.0)$ & $89.0(45.5-157.1)$ & $81.7(43.1-282.6)$ \\
\hline
\end{tabular}




\begin{tabular}{|c|c|c|c|}
\hline Sum oxycholesterol & $5.6(1.6-156.0)$ & $2.1(1.1-6.1)$ & $2.0(1.3-161.4)$ \\
\hline Sum oxyphytosterol & $180.3(24.9-992.2)$ & $156.4(76.4-271.3)$ & $153.0(75.3-885.1)$ \\
\hline \multicolumn{4}{|l|}{ Platelets (pg/mg) } \\
\hline $7 \alpha-\mathrm{OH}$-cholesterol & 72.6 (23.1-229.0) & $86.2(31.9-504.7)$ & $107.6(7.0-400.1)$ \\
\hline $7 \alpha$-OH-campesterol & $3.6(0.9-18.2)$ & $5.0(1.8-26.2)$ & $2.6(1.1-13.8)$ \\
\hline $7 \alpha-\mathrm{OH}$-sitosterol & $16.2(5.2-63.4)$ & $19.0(5.2-98.4)$ & $7.0(5.1-65.3)$ \\
\hline $7 \beta-\mathrm{OH}$-cholesterol & $81.3(24.6-328.5)$ & $115.0(33.9-536.4)$ & $104.0(27.7-371.4)$ \\
\hline $7 \beta$-OH-campesterol & $2.6(1.2-15.0)$ & $2.4(0-23.2)$ & $3.0(0.5-15.1)$ \\
\hline $7 \beta$-OH-sitosterol & $30.6(4.1-101.0)$ & $30.8(4.6-145.8)$ & $16.4(2.8-122.5)$ \\
\hline 7-keto-cholesterol & $345.4(19.0-1068.6)$ & 376.5 (36.9-1185.2) & 234.1 (61.8-2110.9) \\
\hline 7-keto-campesterol & $254.0(71.2-757.0)$ & $253.4(63.5-1260.9)$ & $112.0(69.8-884.2)$ \\
\hline 7-keto-sitosterol & $\begin{array}{c}444.9(152.8- \\
1227.8)\end{array}$ & $\begin{array}{c}469.8(156.0- \\
2075.6)\end{array}$ & $233.4(155.2-1618.9)$ \\
\hline Sum oxycholesterol & $560.4(66.7-1472.5)$ & $\begin{array}{c}642.0(102.6- \\
2104.7)\end{array}$ & $465.1(112.7-2833.8)$ \\
\hline Sum oxyphytosterol & $\begin{array}{c}752.5(245.9- \\
2169.4)\end{array}$ & $\begin{array}{c}779.6(234.8- \\
3564.5)\end{array}$ & $357.5(248.6-2670.8)$ \\
\hline \multicolumn{4}{|l|}{ PBMC's (pg/mg) } \\
\hline $7 \alpha-\mathrm{OH}$-cholesterol & $291.5(57.0-6840.1)$ & $462.5(64.6-5201.5)$ & $226.5(63.3-1895.2)$ \\
\hline $7 \beta-\mathrm{OH}$-cholesterol & $173.5(21.6-16997.1)$ & $223.4(1.81-9924.9)^{a}$ & $178.4(18.8-9287.7)$ \\
\hline 7-keto-cholesterol & $184.1(97.3-665.8)$ & $183.3(49.3-1013.6)$ & $191.5(64.7-81761.8)$ \\
\hline Sum oxycholesterol & $\begin{array}{c}999.4 \\
(282.1-24078.0)\end{array}$ & $\begin{array}{c}1146.6 \\
(1.81-15470.9)\end{array}$ & $\begin{array}{c}1116.5 \\
(401.6-82869.8)\end{array}$ \\
\hline
\end{tabular}

Values are means \pm SD or median (ranges) $(n=20)$

a Significantly different compared with control period $(p<0.05)$ 
Table 7.4. Effect of vitamin E and lipoic acid supplementation on oxidative and antioxidative parameters

\begin{tabular}{lccc}
\hline & Control period & Vitamin E period & Lipoic acid period \\
\hline $\begin{array}{l}\text { OxLDL (oxidized } \\
\text { phospholipids:apoB100 ratio) }\end{array}$ & $0.05 \pm 0.07$ & $0.04 \pm 0.06$ & $0.04 \pm 0.06$ \\
\hline MDA ( $\mu \mathrm{mol} / \mathrm{L})$ & $2.2 \pm 0.4$ & $2.1 \pm 0.4$ & $2.0 \pm 0.3$ \\
\hline Trolox equivalent $(\mu \mathrm{mol} / \mathrm{L})$ & $489.5 \pm 73.7$ & $479.3 \pm 77.8$ & $493.6 \pm 90.1$ \\
\hline GSH/GSSG & $49.4 \pm 30.8$ & $44.7 \pm 22.8$ & $50.0 \pm 27.2$ \\
\hline Uric acid $(\mu \mathrm{mol} / \mathrm{L})$ & $312.4 \pm 59.8$ & $313.5 \pm 59.4$ & $321.3 \pm 70.4$ \\
\hline
\end{tabular}

Values are means $\pm S D(n=20)$ 
Table 7.5. Effect of vitamin E and lipoic acid supplementation on plasma inflammatory markers, cellular adhesion molecules and iron and copper status parameters

\begin{tabular}{|c|c|c|c|}
\hline & Control period & Vitamin E period & Lipoic acid period \\
\hline \multicolumn{4}{|l|}{ Inflammation } \\
\hline $\operatorname{CRP}(\mathrm{g} / \mathrm{L})$ & $2.75 \pm 2.49$ & $2.33 \pm 1.60$ & $3.58 \pm 4.78$ \\
\hline IL-6 (ng/mL) & $1.18 \pm 0.45$ & $1.21 \pm 0.52$ & $1.18 \pm 0.47$ \\
\hline TNFa (ng/mL) & $3.65 \pm 1.04$ & $3.67 \pm 1.02$ & $3.79 \pm 0.95$ \\
\hline Thrombomodulin (ng/mL) & $5.11 \pm 1.38$ & $5.04 \pm 1.40$ & $5.05 \pm 1.34$ \\
\hline $\mathrm{SAA}(\mathrm{mg} / \mathrm{L})$ & $8.88 \pm 11.40$ & $6.05 \pm 4.56$ & $8.47 \pm 5.30$ \\
\hline \multicolumn{4}{|l|}{ Cellular adhesion } \\
\hline E-selectin (ng/mL) & $27.00 \pm 9.67$ & $30.01 \pm 12.93$ & $29.74 \pm 13.17$ \\
\hline P-selectin (ng/mL) & $65.54 \pm 18.65$ & $68.30 \pm 22.18$ & $69.79 \pm 24.74$ \\
\hline sICAM-1 (ng/mL) & $267.75 \pm 55.85$ & $269.55 \pm 60.37$ & $277.40 \pm 65.36$ \\
\hline sICAM-3 (ng/mL) & $0.58 \pm 0.15$ & $0.62 \pm 0.17$ & $0.60 \pm 0.17$ \\
\hline VCAM-1 (ng/mL) & $428.45 \pm 117.41$ & $426.00 \pm 119.21$ & $423.55 \pm 98.91$ \\
\hline \multicolumn{4}{|l|}{ Iron and copper status } \\
\hline Total iron $(\mu \mathrm{mol} / \mathrm{l})$ & $14.48 \pm 4.32$ & $15.72 \pm 4.83$ & $15.69 \pm 5.83$ \\
\hline Ferritin $(\mu \mathrm{g} / \mathrm{L})$ & $140.95 \pm 199.80$ & $139.48 \pm 166.61$ & $147.48 \pm 174.53$ \\
\hline Transferrin $(\mathrm{g} / \mathrm{L})$ & $2.74 \pm 0.46$ & $2.70 \pm 0.37$ & $2.68 \pm 0.38$ \\
\hline Transferrin saturation (\%) & $21.96 \pm 8.02$ & $24.08 \pm 9.22$ & $24.10 \pm 10.22$ \\
\hline Copper ( $\mu \mathrm{mol} / \mathrm{L})$ & $12.24 \pm 1.64$ & $11.93 \pm 1.61$ & $12.02 \pm 1.51$ \\
\hline Ceruloplasmin (g/L) & $0.25 \pm 0.05$ & $0.24 \pm 0.02$ & $0.24 \pm 0.03$ \\
\hline
\end{tabular}

Values are means $\pm S D(n=20)$ 
Table 7.6. Effect of vitamin E and lipoic acid supplementation on plasma glucose, serum lipid and lipoprotein concentrations and serum plant sterol, lathosterol and cholestanol concentrations

\begin{tabular}{lccc}
\hline & Control period & Vitamin E period & Lipoic acid period \\
\hline Glucose (mmol/L) & $7.26 \pm 1.64$ & $7.29 \pm 1.68$ & $7.16 \pm 1.47$ \\
\hline HbA1c (\%) & $6.18 \pm 0.86$ & $6.19 \pm 0.84$ & $6.22 \pm 0.85$ \\
\hline FGF-19 (pg/mL) & $46 \pm 45$ & $49 \pm 47$ & $50 \pm 54$ \\
\hline FGF-21 (pg/mL) & $400 \pm 263$ & $486 \pm 278$ & $437 \pm 227$ \\
\hline Total cholesterol (mmol/L) & $5.28 \pm 0.97$ & $5.52 \pm 0.90^{1,3}$ & $5.28 \pm 0.96$ \\
\hline LDL cholesterol (mmol/L) & $3.30 \pm 0.89$ & $3.44 \pm 0.90^{3}$ & $3.21 \pm 0.86$ \\
\hline HDL cholesterol (mmol/L) & $1.34 \pm 0.27$ & $1.30 \pm 0.25$ & $1.30 \pm 0.25$ \\
\hline Total cholesterol/HDL & $4.12 \pm 0.90$ & $4.38 \pm 1.01^{2,5}$ & $4.18 \pm 0.89$ \\
\hline Triacylglycerol (mmol/L) & $1.62 \pm 0.64$ & $1.72 \pm 0.65$ & $1.73 \pm 0.66$ \\
\hline ApoB100 (g/L) & $1.04 \pm 0.19$ & $1.11 \pm 0.20^{2,3}$ & $1.06 \pm 0.19$ \\
\hline ApoA1 (g/L) & $1.41 \pm 0.22$ & $1.45 \pm 0.20^{1,4}$ & $1.40 \pm 0.22$ \\
\hline Sitosterol* & $1.40 \pm 0.83$ & $1.48 \pm 0.84$ & $1.40 \pm 0.72$ \\
\hline Campesterol* & $2.03 \pm 1.11$ & $2.08 \pm 1.17$ & $2.00 \pm 1.12$ \\
\hline Cholestanol* & $2.07 \pm 0.37$ & $2.05 \pm 0.35$ & $1.54 \pm 0.53$ \\
\hline Valhosterol* & & $1.60 \pm 0.49$ & $0.04 \pm 0.34$ \\
\hline
\end{tabular}

Values are means \pm SD and *sterols are expressed as $10^{2} \times \mu \mathrm{mol} / \mathrm{mmol}$ cholesterol.

Significantly different compared with control period: ${ }^{1}(p<0.05),{ }^{2}(p<0.01)$

Significantly different compared with lipoic acid period ${ }^{3}(p<0.05),{ }^{4}(p<0.01),{ }^{5}(p=0.06)$ 
Table 7.7. Oxyphytosterol correlations within plasma and within tissue (RBC's \& platelets) in control period

\begin{tabular}{|c|c|c|c|c|}
\hline Parameter & Parameter & Compartment & Correlation* & p-value \\
\hline $7 \alpha$-OH-campesterol & $7 \alpha-\mathrm{OH}$-sitosterol & Plasma & 0.845 & $<0.001$ \\
\hline $7 \beta$-OH-campesterol & $7 \beta$-OH-sitosterol & Plasma & 0.625 & $<0.01$ \\
\hline 7-keto-campesterol & 7-keto-sitosterol & Plasma & 0.902 & $<0.001$ \\
\hline \multirow[t]{2}{*}{$7 \alpha$-OH-campesterol } & $7 \beta$-OH-campesterol & Plasma & 0.442 & 0.058 \\
\hline & 7-keto-campesterol & Plasma & -0.408 & 0.083 \\
\hline $7 \beta$-OH-campesterol & 7-keto-campesterol & Plasma & -0.071 & 0.773 \\
\hline \multirow[t]{2}{*}{$7 \alpha-\mathrm{OH}$-sitosterol } & $7 \beta$-OH-sitosterol & Plasma & 0.678 & $<0.01$ \\
\hline & 7-keto-sitosterol & Plasma & -0.067 & 0.785 \\
\hline $7 \beta$-OH-sitosterol & 7-keto-sitosterol & Plasma & 0.538 & $<0.015$ \\
\hline \multirow[t]{2}{*}{$7 \alpha-\mathrm{OH}$-campesterol } & $7 \beta$-OH-campesterol & $\mathrm{RBC}$ & 0.922 & $<0.001$ \\
\hline & 7-keto-campesterol & $\mathrm{RBC}$ & 0.390 & 0.110 \\
\hline $7 \beta$-OH-campesterol & 7-keto-campesterol & $\mathrm{RBC}$ & 0.420 & 0.080 \\
\hline \multirow[t]{2}{*}{$7 \alpha-\mathrm{OH}$-sitosterol } & $7 \beta$-OH-sitosterol & $\mathrm{RBC}$ & 0.798 & $<0.001$ \\
\hline & 7-keto-sitosterol & $\mathrm{RBC}$ & 0.440 & 0.07 \\
\hline 7ß-OH-sitosterol & 7-keto-sitosterol & $\mathrm{RBC}$ & 0.340 & 0.152 \\
\hline \multirow[t]{2}{*}{$7 \alpha$-OH-campesterol } & $7 \beta$-OH-campesterol & Platelets & 0.577 & $<0.01$ \\
\hline & 7-keto-campesterol & Platelets & 0.746 & $<0.001$ \\
\hline $7 \beta$-OH-campesterol & 7-keto-campesterol & Platelets & 0.653 & $<0.01$ \\
\hline \multirow[t]{2}{*}{$7 \alpha$-OH-sitosterol } & $7 \beta$-OH-sitosterol & Platelets & 0.809 & $<0.001$ \\
\hline & 7-keto-sitosterol & Platelets & 0.741 & $<0.001$ \\
\hline $7 \beta-O H$-sitosterol & 7-keto-sitosterol & Platelets & 0.794 & $<0.001$ \\
\hline
\end{tabular}

* correlations in plasma concentrations were determined with Pearson's correlation and correlations in RBC and platelet levels were determined with Spearman's rho correlation 


\section{Discussion}

This study demonstrates that circulating oxyphytosterol as well as oxycholesterol concentrations are not lowered by vitamin E or lipoic acid supplementation in metabolically stressed subjects with IGT or type II diabetes.

There is a clear lack of knowledge which factors affect oxyphytosterol concentrations in plasma and tissues. We have earlier shown that consumption of plant sterol enriched products did not increase fasting plasma oxyphytosterol concentrations, despite an increase in fasting serum non-oxidized plant sterol concentrations [4]. Now, we have evaluated whether plasma oxyphytosterol concentrations are reduced after antioxidant supplementation. However, circulating oxyphytosterol concentrations were not reduced after consumption of vitamin $\mathrm{E}$ or lipoic acid for 4 weeks. In addition, none of the other oxidative stress markers were changed and parameters reflecting anti-oxidative capacity did also not change after consuming these antioxidants for 4 weeks. This was rather unexpected and the question is why these antioxidants did not have an effect. Potential factors that could have affected the outcome are the population, the dose and the duration of the intervention period. The present study was performed in a population which consisted of subjects with IGT or type II diabetes, a population that is generally recognized for their increased oxidative stress [16]. This allowed us to compare oxyphytosterol concentrations between healthy subjects from our earlier study and those in our subjects with increased oxidative stress. Oxidative stress plays an important role in the initiation and progression of type II diabetes and these subjects have increased oxidized LDL-C and oxycholesterol concentrations [17]. We here demonstrate for the first time that not only oxycholesterol, but also plasma oxyphytosterol concentrations are higher in subjects with IGT or type II diabetes as compared with healthy subjects. Circulating oxycampesterol concentrations were $122 \%$ higher and oxysitosterol concentrations were $83 \%$ higher, while plant sterol concentrations were comparable between the two populations. Almost all oxyphytosterol isoforms were higher in IGT and diabetic subjects, except $7 \beta-O H$-campesterol concentrations, which were comparable. Regarding the dose and the duration, both vitamin $\mathrm{E}$ and lipoic acid have been shown to reduce oxidative stress markers in various populations in both short-term ( $<6$ weeks) and in longer-term studies $[18,19]$. For example, vitamin E consumption (400 $\mathrm{mg} / \mathrm{d}$ ) for 3 months reduced MDA concentrations in a study with 80 type 2 diabetic patients showed [20]. In patients with carotid atherosclerosis 6 weeks of vitamin E $(900 \mathrm{mg} / \mathrm{d})$ supplementation reduced $7 \beta-\mathrm{OH}$-cholesterol levels [21]. Plasma MDA and oxycholesterol concentrations were also measured in our study, but were not changed after high-dose vitamin E supplementation. As reviewed by Pazdro et al. most studies have demonstrated convincingly that vitamin $\mathrm{E}$ protects against lipid peroxidation in diabetic subjects, while effects on protein and DNA oxidation are less clear [22]. Intravenous lipoic acid therapy $(600 \mathrm{mg} / \mathrm{d})$ reduced MDA and prostaglandin concentrations already after two weeks in 13 obese subjects with impaired glucose tolerance [23], while 8 weeks oral lipoic acid supplementation $(1200 \mathrm{mg} / \mathrm{d}$ ) in obese subjects failed to reduce oxLDL and prostaglandin 
concentrations [24]. This may suggest that intravenous lipoic acid supplementation is more effective than oral supplementation in human subjects [24], which might explain the lack of effect in our study. However, Marangon et al. used a comparable oral dose of lipoic acid, e.g. $600 \mathrm{mg} / \mathrm{d}$ and demonstrated a decrease in urinary isoprostane concentrations and a reduction in LDL oxidative susceptibility in 31 healthy subjects [25]. Their intervention period lasted 2 months and it might be postulated that our intervention period of 4 weeks was too short to induce changes in oxidative stress markers. This overview illustrates that there is no clear explanation for the lack of effect when considering population, dose and study duration.

Besides evaluating effects on oxidative parameters we also measured a panel of markers reflecting antioxidative capacity. Previous studies showed an increase in endogenous antioxidant enzyme activities after vitamin E consumption (400 $\mathrm{mg} / \mathrm{d}$ ) in type II diabetic subjects $[20,26]$. In addition, lipoic acid increased intracellular glutathione concentrations in a variety of cell types and tissues [27, 28]. However, we were not able to demonstrate an improvement in these anti-oxidative markers in plasma concentrations of subjects with IGT or type II diabetes after vitamin E or lipoic acid consumption.

Whether increased oxyphytosterol concentrations are potentially atherogenic remains to be determined. If so, it would be of interest to further characterize oxyphytosterol concentrations in different (diseased) population and assess which dietary interventions might be successful in reducing plant sterol oxidation products. In our earlier study with healthy control subjects we tried to assess whether oxidation of plant sterols might be iron or copper-mediated [29]. In that study, oxLDL concentrations correlated positively with three different iron status markers, while no correlations were observed between any of the three iron status markers and oxyphytosterol concentrations, suggesting that oxidation of plant sterols might not be iron-mediated. Copper status markers did not correlate with oxLDL or with oxyphytosterol concentrations. Iron status markers and copper status markers were again determined in the current study. Serum concentrations in the IGT and diabetic population were lower as compared to healthy subjects. The observation that iron and copper concentrations are lower while oxyphytosterol concentrations are higher in IGT and diabetic patients may suggest that oxidation of plant sterols is not regulated at all via iron or copper-mediated oxidation. However, iron status parameters were also not correlated with oxycholesterol concentrations. This suggest that the relation between oxycholesterol and iron or copper-mediated oxidation is not as straightforward, even though it is generally assumed that cholesterol oxidation is (partly) regulated via iron or copper-mediated oxidation [30].

An important question is not only whether plasma oxyphytosterol concentrations are changed after vitamin E or lipoic acid, but also what happens with oxyphytosterols inside tissues. Schött et al. recently determined oxyphytosterol concentrations in plasma and aortic valve cusps in patients undergoing elective aortic valve replacement due to severe aortic stenosis [31]. Oxyphytosterol isoforms correlated significantly within plasma and 
within tissue [aortic valve cusps], while a correlation between plasma and aortic valve cusp tissue was lacking. These results are (partly) in agreement with our study, since we also observed no relation between plasma and blood cell oxyphytosterol concentrations, while the different oxyphytosterol isoforms within the various cells types did correlate. We therefore suggest that oxidation of plant sterols might occur locally within tissues and does not originate from uptake via plasma, which might explain the lack of correlation between plasma and tissue concentrations. However, vitamin E and lipoic acid failed to reduced oxyphytosterol and oxycholesterol values in RBC's and platelet fractions.

Rather unexpected findings in this study were increased serum lipid and (apo)lipoprotein concentrations in the vitamin E period compared with lipoic acid and control periods. This effect was consistent since cholesterol (total and LDL-C) and its carrier (apoB100) were increased. ApoA1 concentrations were increased in the vitamin $\mathrm{E}$ period, even though HDL-C concentrations were comparable in all three period. This cholesterol-raising effect of vitamin E was unanticipated and has only been described a few times before [19, 32]. Daily intake of vitamin E capsules cannot explain the observed effect, since they only provided minor amounts of linoleic and oleic acid. Changes in dietary intake are also highly unlikely, since food frequency questionnaires showed comparable dietary intake in all three periods. For now, we have no obvious explanation for this highly unexpected effect of vitamin $E$ supplementation.

In conclusion, we here show that circulating oxyphytosterol concentrations are not reduced by vitamin E and lipoic acid supplementation, while we previously demonstrated that oxyphytosterol concentration are not increased after plant sterol consumption. However, oxyphytosterol concentrations clearly differ between healthy subjects and subjects with impaired glucose tolerance or type II diabetes. The possible clinical implications of these differences in oxyphytosterol concentrations and whether these may have an impact on CVD risk in IGT or type II diabetic subjects remains to be determined.

\section{Acknowledgements}

The project was funded by the Netherlands Organisation for Scientific Research (TOP grant No. 91208006). Lipoic acid was kindly provided by Peter J. H. Jones (Richardson Centre for Functional Foods and Nutraceuticals, University of Manitoba, Winnipeg, Manitoba, Canada). There are no conflicts of interest to declare.

\section{References}

1. Ras RT, Hiemstra H, Lin Y, Vermeer MA, Duchateau GS, Trautwein EA. Consumption of plant sterol-enriched foods and effects on plasma plant sterol concentrations--a meta-analysis of randomized controlled studies. Atherosclerosis. 2013 Oct;230(2):336-46. 
2. Escurriol V, Cofan M, Moreno-Iribas C, Larranaga N, Martinez C, Navarro C, et al. Phytosterol plasma concentrations and coronary heart disease in the prospective Spanish EPIC cohort. J Lipid Res. 2010 Mar;51(3):618-24.

3. Matthan NR, Pencina M, LaRocque JM, Jacques PF, D’Agostino RB, Schaefer EJ, et al. Alterations in cholesterol absorption/synthesis markers characterize Framingham offspring study participants with CHD. J Lipid Res. 2009 Sep;50(9):1927-35.

4. Baumgartner S, Mensink RP, Husche C, Lutjohann D, Plat J. Effects of plant sterol- or stanol-enriched margarine on fasting plasma oxyphytosterol concentrations in healthy subjects. Atherosclerosis. $2013 \mathrm{Apr} ; 227(2): 414-9$.

5. Otaegui-Arrazola A, Menendez-Carreno M, Ansorena D, Astiasaran I. Oxysterols: A world to explore. Food Chem Toxicol. 2010 Dec;48(12):3289-303.

6. Yoshida Y, Umeno A, Shichiri M. Lipid peroxidation biomarkers for evaluating oxidative stress and assessing antioxidant capacity in vivo. J Clin Biochem Nutr. 2013 Jan;52(1):9-16.

7. Baumgartner S, Mensink RP, Konings M, Friedrichs S, Schött H-F, Lutjohann D, et al. Postprandial plasma oxyphytosterol concentrations after consumption of plant sterol or stanol enriched mixed meals in healthy subjects. Unpublished.

8. Nathan DM, Davidson MB, DeFronzo RA, Heine RJ, Henry RR, Pratley R, et al. Impaired fasting glucose and impaired glucose tolerance: implications for care. Diabetes Care. 2007 Mar;30(3):753-9.

9. Pieters DJ, Mensink RP. Effects of stearidonic acid on serum triacylglycerol concentrations in overweight and obese subjects: a randomized controlled trial. Eur J Clin Nutr. 2014 Sep 17.

10. Friedewald WT, Levy RI, Fredrickson DS. Estimation of the concentration of low-density lipoprotein cholesterol in plasma, without use of the preparative ultracentrifuge. Clin Chem. 1972 Jun;18(6):499-502.

11. Thelen KM, Laaksonen R, Paiva H, Lehtimaki T, Lutjohann D. High-dose statin treatment does not alter plasma marker for brain cholesterol metabolism in patients with moderately elevated plasma cholesterol levels. J Clin Pharmacol. 2006 Jul;46(7):812-6.

12. Husche $\mathrm{C}$, Weingartner $\mathrm{O}$, Pettersson $\mathrm{H}$, Vanmierlo $\mathrm{T}$, Bohm M, Laufs $\mathrm{U}$, et al. Validation of an isotope dilution gas chromatography-mass spectrometry method for analysis of 7-oxygenated campesterol and sitosterol in human serum. Chem Phys Lipids. 2011 Sep;164(6):425-31.

13. Tsimikas S, Brilakis ES, Miller ER, McConnell JP, Lennon RJ, Kornman KS, et al. Oxidized phospholipids, Lp[a] lipoprotein, and coronary artery disease. N Engl J Med. 2005 Jul 7;353(1):46-57.

14. Boots AW, Drent M, Swennen EL, Moonen HJ, Bast A, Haenen GR. Antioxidant status associated with inflammation in sarcoidosis: a potential role for antioxidants. Respir Med. 2009 Mar;103(3):364-72.

15. Pilz J, Meineke I, Gleiter $\mathrm{CH}$. Measurement of free and bound malondialdehyde in plasma by high-performance liquid chromatography as the 2,4-dinitrophenylhydrazine derivative. J Chromatogr B Biomed Sci Appl. 2000 Jun 9;742(2):315-25.

16. Stephens JW, Khanolkar MP, Bain SC. The biological relevance and measurement of plasma markers of oxidative stress in diabetes and cardiovascular disease. Atherosclerosis. 2009 Feb;202(2):321-9.

17. Ferderbar S, Pereira EC, Apolinario E, Bertolami MC, Faludi A, Monte O, et al. Cholesterol oxides as biomarkers of oxidative stress in type 1 and type 2 diabetes mellitus. Diabetes Metab Res Rev. 2007 Jan;23(1):35-42.

18. Porkkala-Sarataho E, Salonen J, Nyyssönen K, Kaikkonen J, Salonen R, Ristonmaa U, et al. Long-term effects of vitamin $\mathrm{E}$, vitamin $\mathrm{C}$, and combined supplementation on urinary 7-hydro-8-oxo-2'-deoxyguanosine, serum cholesterol oxidation products, and oxidation resistance of lipids in nondepleted men. Arterioscler Thromb Vasc Biol. 2000(9):2087-93.

19. Ble-Castillo JL, Carmona-Diaz E, Mendez JD, Larios-Medina FJ, Medina-Santillan R, Cleva-Villanueva G, et al. Effect of alpha-tocopherol on the metabolic control and oxidative stress in female type 2 diabetics. Biomed Pharmacother. 2005 Jul;59(6):290-5.

20. Shinde SN, Dhadke VN, Suryakar AN. Evaluation of Oxidative Stress in Type 2 Diabetes Mellitus and Follow-up Along with Vitamin E Supplementation. Indian J Clin Biochem. 2011 Jan;26(1):74-7. 


\section{CHAPTER 7}

21. Micheletta F, Natoli S, Misuraca M, Sbarigia E, Diczfalusy U, luliano L. Vitamin E supplementation in patients with carotid atherosclerosis: reversal of altered oxidative stress status in plasma but not in plaque. Arterioscler Thromb Vasc Biol. 2004 Jan;24(1):136-40.

22. Pazdro R, Burgess JR. The role of vitamin E and oxidative stress in diabetes complications. Mech Ageing Dev. 2010 Apr;131(4):276-86.

23. Zhang Y, Han P, Wu N, He B, Lu Y, Li S, et al. Amelioration of lipid abnormalities by alpha-lipoic acid through antioxidative and anti-inflammatory effects. Obesity [Silver Spring]. 2011 Aug;19(8):1647-53.

24. Yan W, Li N, Hu X, Huang Y, Zhang W, Wang Q, et al. Effect of oral ALA supplementation on oxidative stress and insulin sensitivity among overweight/obese adults: a double-blinded, randomized, controlled, cross-over intervention trial. Int J Cardiol. 2013 Jul 31;167(2):602-3.

25. Marangon K, Devaraj S, Tirosh O, Packer L, Jialal I. Comparison of the effect of alpha-lipoic acid and alphatocopherol supplementation on measures of oxidative stress. Free Radic Biol Med. 1999 Nov;27(9-10):111421.

26. Gokkusu C, Palanduz S, Ademoglu E, Tamer S. Oxidant and antioxidant systems in niddm patients: influence of vitamin E supplementation. Endocrine research. 2001 Aug;27(3):377-86.

27. Bast A, Haenen GR. Interplay between lipoic acid and glutathione in the protection against microsomal lipid peroxidation. Biochimica et biophysica acta. 1988 Dec 16;963(3):558-61.

28. Busse E, Zimmer G, Schopohl B, Kornhuber B. Influence of alpha-lipoic acid on intracellular glutathione in vitro and in vivo. Arzneimittel-Forschung. 1992 Jun;42(6):829-31.

29. Baumgartner S, Mensink RP, den Hartog G, Bast A, Bekers O, Husche C, et al. Oxyphytosterol formation in humans: identification of high vs. low oxidizers. Biochem Pharmacol. 2013 Jul 1;86(1):19-25.

30. You S, Wang Q. Ferritin in atherosclerosis. Clin Chim Acta. 2005;357(1):1-16.

31. Schott HF, Luister A, Husche C, Schafers HJ, Bohm M, Plat J, et al. The relationships of phytosterols and oxyphytosterols in plasma and aortic valve cusps in patients with severe aortic stenosis. Biochem Biophys Res Commun. 2014 Apr 11;446(3):805-10.

32. Aldred S, Sozzi T, Mudway I, Grant MM, Neubert H, Kelly FJ, et al. Alpha tocopherol supplementation elevates plasma apolipoprotein A1 isoforms in normal healthy subjects. Proteomics. 2006 Mar;6(5):1695-703. 


\section{Chapter 8}

General Discussion 


\section{Introduction}

Functional foods enriched with plant sterols and plant stanols have been demonstrated to lower LDL-C concentrations in numerous intervention studies. Several meta-analyses have summarized this evidence and described the dose-response LDL-C lowering effect of plant sterols and plant stanols [1-3]. However, guidelines are not unanimous with respect to consumption of plant sterol and stanol enriched foods. A European Atherosclerosis Consensus (EAS) panel recommended the use of functional foods with plant sterols and stanols in patients with high cholesterol levels at intermediate and low global cardiovascular risk that do not qualify for pharmacotherapy. In addition, the panel concluded that plant sterol and stanols could be considered in (very) high-risk patients who do not reach their LDL-C targets on pharmacotherapy or in those with statin intolerance [4]. On the other hand, recently updated guidelines from the National Institute of Health and Clinical Excellence (NICE) advice against the use of plant sterols or stanols for the prevention of CVD in subjects treated for primary and secondary prevention or in subjects with diabetes (type I and II) [5]. This inconsistency in guidelines is partly explained by a lack of endpoint studies for plant sterol and plant stanol consumption and because there are uncertainties regarding health effects of increased plant sterol concentrations after plant sterol consumption, which is a hotly debated topic. In addition, plant sterols are susceptible to oxidation and can form plant sterol oxidation products (oxyphytosterols). Information regarding oxyphytosterol metabolism is very scarce. For example, it is not known 1) which factors affect circulating oxyphytosterol concentrations, 2) if and how these oxidation products are related to metabolic health parameters and 3) whether they are atherogenic as suggested earlier for oxycholesterol concentrations. Information regarding plant sterols and plant stanols in the postprandial phase is also limited and it is not known 1) what the effects are of a mixed meal rich in plant sterols and plant stanols on postprandial lipid and glucose responses and 2) whether postprandial oxyphytosterol concentrations are affected by plant sterol and plant stanol consumption.

Therefore, we aimed to investigate whether fasting oxyphytosterol concentrations are affected by dietary determinants, such as plant sterol and plant stanol consumption and antioxidant supplementation and whether oxyphytosterol concentrations differ between populations. In addition, we also evaluated effects of plant sterol and plant stanol consumption in the postprandial state, by assessing effects on lipid, lipoprotein and glucose responses and effects on postprandial oxyphytosterol concentrations.

\section{Increased plant sterol concentration and CVD risk}

Plant sterols and plant stanols are structurally related to cholesterol and have cellular functions in plants analogous to those of cholesterol in animals. The difference between plant sterols and cholesterol resides in the side-chain, while plant stanols are the saturated derivative of plant sterols. The main sources of plant sterols are vegetable oils, cereals, vegetables, fruits, 
nuts and seeds, with a mean daily intake that ranges between 200 and $300 \mathrm{mg} / \mathrm{d}$, but can be as high as $600 \mathrm{mg} / \mathrm{d}$ in vegetarians. Plant stanols are less abundant in nature, with a mean daily intake of $17-24 \mathrm{mg} / \mathrm{d}$ [6]. Plant sterols and plant sterols (together with cholesterol and other lipophilic substances) are incorporated into mixed micelles that serve as vehicles to deliver these products to the brush border membrane. Here they are taken up into the enterocyte by Niemann-Pick C1-Like1 (NPC1L1), which is a general sterol transporter protein. After uptake into enterocytes, plant sterol and stanols are excreted back from the intestinal mucosa into the intestinal lumen by the ATP-binding cassette (ABC) transporters $A B C G 5 / 8$. Absorption rates are very low, i.e. $0.5-2 \%$ for plant sterols and $0.04-0.2 \%$ for plant stanols [7]. Once present in the circulation, plant sterols and plant stanols are cleared by the liver and rapidly secreted from the liver into bile by hepatic $A B C G 5 / G 8$ transporters. Due to low absorption and high biliary secretion rates, circulating concentrations of plant sterols and plant stanols are low, with plant sterol concentrations ranging from $0.3-1.0 \mathrm{mg} / \mathrm{dL}$ and plant stanol concentrations ranging from $0.002-0.012 \mathrm{mg} / \mathrm{dL}[8,9]$. Consuming plant sterol enriched food products increases circulating plant sterol concentrations. A recent metaanalysis by Ras et al. included 41 studies with 2084 subjects and showed that an average plant sterol intake of $1.6 \mathrm{~g} / \mathrm{d}$ resulted in $31.3 \%$ increase in sitosterol and $37.3 \%$ increase in campesterol concentrations [10]. Plant stanol enriched products increase plant stanol concentrations (increase of $0.012-0.028 \mathrm{mg} / \mathrm{dL}$ at an intake of $0.6 \pm 0.4 \mathrm{~g} / \mathrm{d}$ ) and additionally reduce serum plant sterol concentrations with observed reductions ranging from $16-23 \%$ [11]. The (patho)-physiological relevance of increased plant sterol concentrations after plant sterol consumption has been subject of scientific debate for two different reasons. First, questions were raised regarding the safety of elevated serum plant sterol concentrations after the identification of phytosterolemia, a rare genetic disorder. Subjects suffering from phytosterolemia have a mutation in the $A B C G 5 / 8$ genes, which causes a lower secretion rate of plant sterols and stanols from enterocytes into the intestinal lumen and from hepatocytes into the bile ducts. Subjects have very high plant sterol concentrations and often have an early onset of atherosclerosis, while serum cholesterol concentrations are not always elevated [12]. However, recent evidence reports phytosterolemic patients with high plant sterol concentrations, but without any signs of atherosclerotic disease [13]. This observation suggests that the relation between extremely high plant sterol concentrations and CVD risk is not as straightforward as once thought, but rather more complicated. This might be explained by the presence of an additional second trigger that together with elevated plant sterols results in premature atherosclerosis. A second reason why increased plant sterol concentrations have been implicated as a CVD risk factor relates to epidemiological studies that demonstrated positive associations between plant sterol concentrations and CVD risk $[14,15]$. However, this relation is again not as straightforward, since there are also studies that show negative associations and studies that do not report any association between plant sterol concentrations and CVD risk [16-18]. Although speculations have been raised, 
such as use of different study designs and adjustments for potential confounding variables, the reason for this controversy in epidemiological studies is not known.

\section{Fasting oxycholesterol and oxyphytosterol concentrations}

Due to the presence of a double bond between $\mathrm{C} 5-\mathrm{C} 6$, cholesterol and plant sterols can be oxidized resulting in the formation of oxycholesterols and oxyphytosterols. Since plant stanols lack this double bind in their ring structure, they cannot be oxidized [19]. Cholesterol oxidation products have been studied more intensively than plant sterol oxidation products. This relates to the fact that cholesterol is associated with development of atherosclerosis, is endogenously produced and plasma (oxy)cholesterol concentrations are higher than (oxy) phytosterol concentrations [20]. Brooks et al. first identified cholesterol oxidation products in human atheromatous plaques in 1966 [21], while plant sterol oxidation products were identified in 1983 in plasma of patients with Waldenström's macroglobulaemia [22]. In 1999, Grandgirard et al. measured oxyphytosterols in healthy subjects with a concentration of 0.3 $\mu \mathrm{g} / \mathrm{mL}$ [23]. Hereafter, oxyphytosterols have been determined in plasma of phytosterolemic patients, where a concentration of $4.7 \mu \mathrm{g} / \mathrm{mL}$ (sitosterol oxidation products) was determined, representing $1.4 \%$ of circulating sitosterol concentrations [24]. A few years later, oxyphytosterols were again measured in healthy subjects, but now with a lower limit of detection, in a range of $0.005-0.057 \mu \mathrm{g} / \mathrm{mL}$, which is a 100 times lower than the first measurement in 1999. Since then, oxyphytosterols have been determined by several research groups worldwide and due to the variability in measuring techniques combined with very low circulating concentrations, large variations were present in oxyphytosterol concentrations [25-27]. During recent years, methods for the analysis of oxyphytosterols have improved and oxyphytosterol concentrations between 0.1 and $4.9 \mathrm{ng} / \mathrm{mL}$ are reported in healthy subjects [26-28], which are still 10-100 times lower than plasma concentrations found for oxycholesterol [29]. Figure 8.1 demonstrates cholesterol and oxycholesterol concentrations (A) and plant sterol and oxyphytosterol concentrations (B) in our population of healthy subjects in a control period. In this population, $0.006 \%$ of cholesterol was oxidized, while $0.06 \%$ of plant sterols were present as oxyphytosterols, which is a factor 10 higher. 

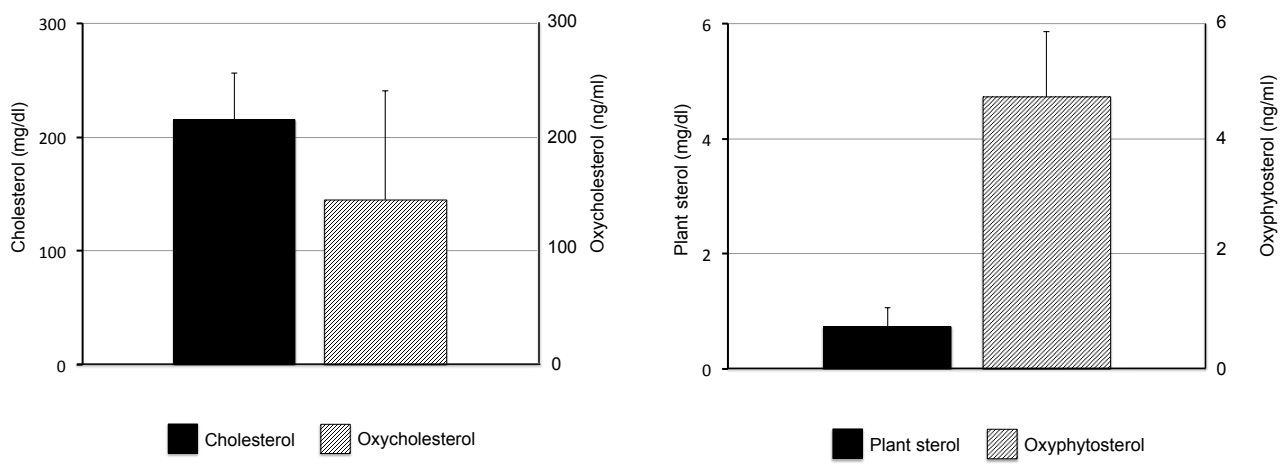

Figure 8.1. (Oxy)cholesterol (panel A) and (oxy)phytosterol concentrations (panel B) in healthy subjects in a control period (means $\pm \mathrm{SD}$ ). Units differ for non-oxidized and oxidized sterols $(\mathrm{mg} / \mathrm{dL} \mathrm{vs} . \mathrm{ng} / \mathrm{mL}$ ), while the scales differ between (oxy)cholesterol $(0-300 \mathrm{mg} / \mathrm{dL}$ and 0-300 ng/mL) and (oxy)phytosterol concentrations $(0-6 \mathrm{mg} / \mathrm{dL}$ and $0-6 \mathrm{ng} / \mathrm{mL})$.

Table 8.1 shows the sum of oxyphytosterol concentrations in healthy subjects, of whom subjects were identified as low or high oxidizers, and in subjects with impaired glucose tolerance or type II diabetes. This data shows a clear distinction between these populations and this is the first time that this comparison is made, since oxyphytosterol concentrations were previously only determined in healthy subjects and in phytosterolemic patients. Importantly, it was also measured with the same method in the same lab, which is important regarding the above-mentioned variation in measuring assays between laboratories.

Table 8.1. Oxyphytosterol concentrations in healthy subjects and subjects with impaired glucose tolerance (IGT) or type II diabetes (DMII)

\begin{tabular}{ll}
\hline & Sum OPS $(\mathrm{ng} / \mathrm{mL})^{\mathrm{a}}$ \\
\hline Low oxidizers $(\mathrm{n}=3)$ & $3.6 \pm 0.01$ \\
\hline Healthy subjects $(\mathrm{n}=37)$ & $4.7 \pm 1.1$ \\
\hline High oxidizers $(\mathrm{n}=3)$ & $6.4 \pm 2.2$ \\
\hline IGT and DMII subjects $(\mathrm{n}=20)$ & $13.9 \pm 5.3$ \\
\hline
\end{tabular}

Values are expressed as means \pm SD

a Sum OPS consists of $7 \alpha-\mathrm{OH}$-campesterol, $7 \alpha-\mathrm{OH}$-sitosterol, $7 \beta-\mathrm{OH}$-campesterol, $7 \beta-\mathrm{OH}$-sitosterol, 7-ketocampesterol and 7-keto-sitosterol

This difference between healthy and diabetic subjects with respect to oxyphytosterol concentrations is also reflected in oxycholesterol concentrations. Arca et al. measured $7 \beta-\mathrm{OH}$-cholesterol and 7-keto-cholesterol in healthy subjects and in familial combined hyperlipidemic (FCHL) patients as a marker of oxidative stress [30]. They already established that these concentrations differ significantly from each other in these two populations. Since we measured oxyphytosterol concentration in our type II diabetic subjects, we were able to compare this data (Table 8.2) demonstrating that $7 \beta-\mathrm{OH}$-cholesterol differed markedly between the populations, while this distinction was less clear for 7-keto-cholesterol 
concentrations. Data shown in Table 8.1 and Table 8.2 suggest that there is a strong shared oxidative component in oxycholesterol and oxyphytosterol concentrations.

Table 8.2. Oxycholesterol concentrations in healthy and subjects with IGT or DMII and in familial combined hyperlipidemic (FCHL) patients

\begin{tabular}{lll}
\hline & $7 \beta-O H$-cholesterol $(\mathrm{ng} / \mathrm{mL})$ & 7-keto-cholesterol $(\mathrm{ng} / \mathrm{mL})$ \\
\hline Healthy subjects $(\mathrm{n}=54)^{\mathrm{a}}$ & $4.7 \pm 1.3$ & $12.2 \pm 7.0$ \\
\hline DMII subjects $(\mathrm{n}=20)$ & $8.3 \pm 4.0$ & $23.5 \pm 10.4$ \\
\hline FCHL patients $(\mathrm{n}=45)$ & $17.7 \pm 13.8$ & $25.5 \pm 15.2$ \\
\hline
\end{tabular}

Values are expressed a means \pm SD

a Data from healthy subjects and FCHL patients were derived from Arca et al. [30] and data from DMII subjects are derived from this thesis.

\section{Dietary interventions and fasting oxyphytosterol concentrations}

We were able to establish that oxyphytosterol concentrations are clearly different between subjects but it would be of interest to investigate whether oxyphytosterol concentrations can be influenced by nutritional interventions. For this reason, we performed our first intervention study as described in chapter 3, to evaluate whether oxyphytosterol concentrations would change after plant sterol and plant stanol consumption. As expected, campesterol concentrations increased by $50 \%$ and sitosterol concentrations increased by $36 \%$ after consumption of plant sterol enriched margarine, while reductions of $38 \%$ and $35 \%$ in campesterol and sitosterol concentrations were found after consumption of plant stanol enriched margarine for 4 weeks. These changes are line with literature, as recently described in a meta-analysis by Ras et al. [10]. However, despite these increases in plant sterol concentrations, circulating oxyphytosterol concentrations did not change after plant sterol consumption, while reductions in $7 \beta-\mathrm{OH}$-campesterol concentrations and - when standardized for cholesterol - also 7-keto-campesterol concentrations were seen after plant stanol consumption. These data suggest that circulating oxyphytosterol concentrations are influenced by additional factors besides the presence of substrate, i.e. non-oxidized plant sterols in plasma. On the other hand, a study by Husche et al. reported a significant $87 \%$ increase in $7 \mathrm{\beta}-\mathrm{OH}$-sitosterol concentrations in healthy subjects after consumption of $3.0 \mathrm{~g} / \mathrm{d}$ plant sterol enriched margarine for 4 week [26]. Both studies used the same margarine and plasma samples were also determined in the same laboratory. While our study was a double blind randomised cross-over trial, Husche's study had a smaller sample-size and lacked a control group, which might explain (part of) this apparent discrepancy. However, both studies demonstrated that increases in serum plant sterol concentrations after plant sterol consumption does not correlate with changes in plasma oxyphytosterol concentrations. In addition, serum plant sterol concentrations and circulating oxyphytosterol concentrations also did not correlate in the control period. 
As discussed previously, controversies exist regarding increased plant sterol concentrations and an increased CVD risk in epidemiological studies. A potential answer explaining this controversy might be found in increased oxyphytosterol concentrations. For now, our data suggests that an increase in serum plant sterol concentrations does not change circulating oxyphytosterol concentrations and might therefore not explain discrepancies in epidemiological studies. However, to definitely answer this question, oxyphytosterol concentrations should be measured in epidemiological studies that report contradictive results on the association between plant sterol concentrations and CVD risk. As mentioned before, serum plant sterol concentrations and circulating oxyphytosterol concentrations do not correlate cross-sectional nor after plant sterol consumption. On the other hand, oxyphytosterol concentrations correlated well between different periods in the same subjects, indicating that plasma oxyphytosterol concentrations seem to be consistent within subjects under different dietary circumstances. This resulted in the identification of 'low and high oxidizers' as described in chapter 4 , who differed with respect to their oxyphytosterol concentrations. To assess whether these differences also extend to other oxidized compounds, oxycholesterol and oxidized LDL (oxLDL) concentrations were determined and these oxidative stress markers also differed between low and high oxidizers, highlighting that there is an oxidative component that determines circulating oxyphytosterol concentrations in healthy human subjects. In vivo oxidation is often catalysed by iron ions, which can generate hydroxyl radicals from hydrogen peroxide. We demonstrated a positive correlation between iron stores and oxLDL concentrations, while plasma oxyphytosterol concentration were not correlated with iron status markers. This suggests that different pathways are responsible for oxidation of plant sterols and LDL particles. On the other hand, oxycholesterol concentrations were positively associated with serum ferritin concentrations in a large cohort of Finnish men [31], while we were not able to show correlations with iron status markers and oxycholesterol concentrations in 20 subjects with impaired glucose tolerance or type II diabetes (chapter 7). To investigate the role of oxidative stress on plasma oxyphytosterol concentrations, we investigated whether plasma oxyphytosterol concentrations might be changed after antioxidant supplementation. For cholesterol oxidation products, antioxidant supplementation has been shown to reduce cholesterol oxidation products in previous studies. Szuchman et al. showed that patients with diabetes and hypercholesterolemia have higher oxycholesterol concentrations than control subjects [32]. In addition, consumption of pomegranate juice (high in antioxidants) suppressed the capacity of diabetic blood to oxidize an exogenous oxidative stress marker and the ratio oxycholesterol/total cholesterol was reduced by $93 \%$. A study performed in patients with carotid atherosclerosis showed reductions in $7 \beta-O H$-cholesterol after 6 weeks of vitamin $E(900 \mathrm{mg} / \mathrm{d})$ supplementation [33]. In chapter 7, we described the first study that evaluated potential changes in oxyphytosterol concentrations after antioxidant supplementation. The study was performed with 20 subjects with impaired glucose tolerance of type 2 diabetes who received daily vitamin $\mathrm{E}$ (804 mg) and lipoic acid (600 mg) capsules for 4 weeks in a randomised cross-over trial. 
We showed that oxyphytosterol concentrations were not changed after 4 weeks high-dose antioxidant supplementation. Besides comparable oxyphytosterol concentrations in the vitamin E, lipoic acid and control period, other oxidation parameters such as oxycholesterol, oxLDL and MDA levels were also not changed after vitamin E or lipoic acid supplementation. To summarize the two described intervention studies: we attempted to change plasma oxyphytosterol concentrations by providing more substrate, e.g. increased plant sterol concentrations and enabling a greater anti-oxidative capacity, e.g. by supplementing of vitamin $\mathrm{E}$ and lipoic acid. Except for small reductions in $7 \beta-\mathrm{OH}$-campesterol and 7-ketocampesterol after plant stanol consumption, fasting oxyphytosterol concentrations were not changed, at least not by the nutritional means described in this thesis.

\section{Oxyphytosterol concentrations in serum versus tissue}

Oxyphytosterol concentrations are mainly determined in plasma, while information regarding tissue concentrations is scarcer. Oxycholesterols have been analysed into more detail since certain oxycholesterols (mainly side-chain oxidation products) carry out important functions within the body such as ligands for the nuclear receptors liver $X$ receptor (LXR) $\alpha$ and LXR $\beta$ and as intermediates in bile acid biosynthesis [34]. ROSmediated oxycholesterols are suggested to be associated with initiation and progression of atherosclerosis $7 \beta-\mathrm{OH}$-cholesterol and 7-keto-cholesterol concentrations have been found in atherosclerotic plaques [35]. Staprans et al. showed that dietary $\alpha$-epoxy cholesterol is incorporated into chylomicrons (CM) and CM-remnants and then transferred to LDL and HDL implying that transportation of oxycholesterols to different tissues within the body occurs through lipoproteins [36]. The addition of oxyphytosterols to the diet on tissue level has also been investigated. Oxyphytosterols were fed to hamsters at different concentrations and the same oxyphytosterols isoforms were measured in heart, kidney, liver and aortic tissue. A higher oxyphytosterol content in the diet resulting in a dose-dependent oxyphytosterol increase in the different tissues, while very low dietary oxyphytosterols resulted in hardly detectable plasma and tissue levels, implying that small amounts of oxyphytosterols can probably be eliminated fast by the animals. Oxyphytosterol concentrations were lower in liver tissue compared to kidney en heart tissue, which might reflect a higher metabolic rate in this organ [37]. The provided diets contained more oxysitosterols than oxycampesterols and sitosterol oxidation products were consistently higher in plasma and tissue than campesterol oxidation products. To assess the effect of oxysterol or oxyphytosterol consumption on atherosclerotic lesion formation, female LDL receptor ${ }^{+/-}$mice were fed a control diet, a high-fat oxycholesterol diet or a high-fat oxyphytosterol diet. The addition of oxycholesterol and oxyphytosterols to an atherogenic high-fat diet resulted in a higher proportion of severe lesions and in addition, oxyphytosterol levels were the highest in the groups receiving the oxyphytosterol diet, indicating that diet-derived oxyphytosterols are incorporated into lesions. Unfortunately, plasma and tissue oxyphytosterol concentrations 
could not be compared, since plasma oxyphytosterol concentrations were not measured in this study [38]. In patients undergoing elective aortic valve replacement due to severe aortic stenosis, oxyphytosterol concentrations were measured in plasma and in tissue (aortic valve cusps). While there was a strong correlation between different oxyphytosterol isoforms within plasma and within issue, a correlation between plasma and aortic tissue was lacking [39]. This data is in agreement with our study in type II diabetic subjects, where we measured oxyphytosterol concentrations in red blood cells and in platelets and also did not report a correlation between plasma and tissue concentrations. However, a study performed in male apoE$^{-/}$mice did report significant correlations between oxyphytosterol concentrations in plasma and aortic tissue [40]. In this study, mice received daily intraperitoneal injections over 4 weeks with cholesterol, sitosterol, $7 \beta-\mathrm{OH}$-cholesterol, $7 \beta-\mathrm{OH}$-sitosterol or a control vehicle. Compared to the control period, daily injections of cholesterol did not result in increased serum or aortic cholesterol concentrations, while injections of $7 \beta-\mathrm{OH}$-cholesterol increased $7 \beta-\mathrm{OH}$-cholesterol concentrations in serum but not in aortic tissue. On the other hand, sitosterol and $7 \beta-\mathrm{OH}$-sitosterol concentrations both increased in serum and in the arterial wall after injection of sitosterol and $7 \beta-\mathrm{OH}$-sitosterol, respectively. An explanation why this study reports a correlation between plasma and tissue concentrations, whereas previous studies were not able to show this correlation, might be explained by the method of intraperitoneal injections. Injecting a substance results in high plasma concentrations, which probably will lead to an incorporation of the injected substance into tissues, causing plasma and tissue concentrations to correlate, which might explain the lack of correlation in the patients that underwent elective aortic valve replacement and in our type II diabetic subjects.

\section{Postprandial oxyphytosterol responses after plant sterol and plant stanol consumption}

Besides fasting oxyphytosterol concentrations, we were also able to measure postprandial oxyphytosterol concentrations after consumption of a mixed meal enriched with plant sterol and plant stanol esters. We already established that fasting oxyphytosterol concentrations did not change after plant sterol consumption. In chapter 5, we assessed postprandial oxyphytosterol concentrations and demonstrated that postprandial oxyphytosterol concentrations are increased after plant sterol consumption. Serum (nonoxidized) campesterol and sitosterol concentrations increased in parallel with $7 \beta-\mathrm{OH}-$ campesterol and $7 \beta-\mathrm{OH}$-sitosterol after plant sterol consumption, while 7-keto-phytosterol concentrations only changed over time without a plant sterol effect. The question whether postprandial plant sterol oxidation products are formed endogenously or absorbed from the diet is difficult to answer, since the consumed margarine contained plant sterols as well as oxyphytosterols. Therefore, we can only speculate on the origin of postprandial oxyphytosterol concentrations. Linseisen et al. measured postprandial oxycholesterol concentrations in five healthy subjects, which consumed a meal rich in cholesterol and in 
cholesterol oxidation products [41]. Analogue to our observation regarding postprandial oxyphytosterol concentrations, oxycholesterol concentrations increased in parallel with nonoxidized cholesterol concentrations and the authors concluded that absorption patterns of non-oxidized and oxidized cholesterol are comparable with differences in the bioavailability of single oxycholesterol isoforms. Another indication that circulating oxyphytosterol concentration predominantly origin from dietary absorption is presented in the study by Weingärtner et al, who reported that mice injected with non-oxidized cholesterol or sitosterol did not show an increase in plasma oxycholesterols or oxyphytosterols concentrations, suggesting that there was no endogenous formation, at least not in the circulation [40]. Tomoyori et al. suggested that campesterol oxidation products have a higher absorption rate than sitosterol oxidation products in rats [42]. If this holds also true in the human situation, then these higher absorption rates are reflected in postprandial concentrations but not in fasting oxyphytosterol concentrations, since fasting oxysitosterol concentrations are higher than oxycampesterol concentrations. For non-oxidized plant sterols, it has been shown that campesterol is better absorbed than sitosterol and this is reflected in both fasting as well as postprandial concentrations [7]. In addition, the postprandial pattern of plant sterols and oxyphytosterols resembles the second meal effect as described for cholesterol, which states that cholesterol from a first meal is secreted during subsequent meal consumptions [4345]. Based on our postprandial data and this possible second meal effect, we suggest that plasma oxyphytosterol concentrations predominantly originate form dietary absorption. The question remains how to explain the difference between fasting oxycampesterol and oxysitosterol concentrations. If indeed absorption rates of campesterol oxidation products are higher as suggested from animal data, than clearance rates probably differ between campesterol and sitosterol oxidation products. To provide a definite answer to the question whether plasma plant sterol oxidation products result from endogenous formation or dietary absorption, future studies should be performed where labelled non-oxidized plant sterols are consumed and subsequent enrichment in labelled plasma oxyphytosterols are measured in plasma.

\section{Postprandial metabolic responses after plant sterol and plant stanol consumption}

The LDL-lowering effect of plant sterols and plant stanols has been demonstrated in numerous studies. However, recent studies have suggested that plant sterols and plant stanols also lower fasting triacylglycerol (TAG) concentrations, especially in individuals with elevated baseline TAG concentrations [46, 47]. Although high fasting TAG concentrations are independent risk marker for CVD [48], non-fasting serum TAG concentrations are emerging as an important CVD risk marker due to the postprandial atherogenicity of TAG-rich (remnant) lipoprotein particles $[49,50]$. Most people are in the non-fasting state or postprandial state for most part of the day and in chapter 6 , we examined the 8-hour postprandial response after consuming plant sterol or plant stanol ester enriched margarines as part of a shake. 
We demonstrated a similar response in TAG and apolipoprotein (apo) B48 concentrations after the first meal, while these responses were increased after consumption of the second meal in the plant stanol period. This effect was stronger with increasing age and more evident compared to the sterol period than to the control period. Previous studies suggest that chronic or acute plant stanol consumption does not affect postprandial lipid and lipoprotein concentrations [51-53]. Although these studies have some limitations, they also differ from our study design since we used a sequential meal protocol with regular blood sampling. As described by Jackson, a sequential two-meal protocol provides a more physiological challenge to detect subtle changes in TAG metabolism, especially after the second meal consumption when the clearance cascade is stressed [54]. Since the observed plant stanol effect was only evident after consumption of the second meal, this suggests that the activity of enzymes involved in processing of TAG-rich lipoproteins (TRLs) or the rate of clearance of TRL remnants by receptor-mediated processed was affected. In general, the increase of the postprandial TAG concentrations correlates positively with age and our observed effect was more prominent with an increase in age [55]. The most important determinant of postprandial TRL accumulation is the capacity of lipoprotein lipase (LPL) to hydrolyse TAG, thus to convert very low-density lipoproteins (VLDL) and chylomicrons into remnants. A decrease in LPL activity would probably be the most likely explanation for the observed plant stanol effect. Possibilities might be found in modulators of LPL activity; such as changed local peroxisome proliferator activated receptor (PPAR)- $\alpha$ and $-\gamma$ expression in adipose and/or skeletal muscle or increased serum apoCIII concentrations after plant stanol consumption. Increased levels of apoCIII are associated with an impaired catabolism of TRLs and reducing apoCIII concentrations has gained much attention as a potential target to correct hypertriglyceridemia in subjects with type II diabetes of insulin resistance [56]. As mentioned before, recent studies reported reduced fasting TAG concentrations after plant stanol consumption, while we report an increase in postprandial TAG concentrations after consumption of a second meal. However, reductions in fasting TAG concentrations were only observed in subjects with elevated fasting TAG concentrations while our population consisted of healthy subjects and as expected, we were not able to demonstrate a reduction in fasting TAG concentrations in this population. There are no studies available that investigated postprandial responses after plant sterol and plant stanol consumption in subjects with higher baseline TAG concentrations. However, Bozetto et al. investigated whether ezetimibe, a cholesterol-lowering drug that acts through a reduction in cholesterol absorption - analogue to plant sterols and plant stanol - affects postprandial TRL's in subjects with type II diabetes. They reported that a 6-week treatment with ezetimibe and simvastatin, compared to simvastatin alone, reduced fasting and postprandial TAG and apoB48 concentrations [57]. The reduced postprandial responses mainly reflected the chronic action of ezetimibe to reduce cholesterol absorption, since fasting TAG and apoB48 concentrations were also reduced. Plant sterols and plant stanols also reduce cholesterol absorption - although to a lesser extent than ezetimibe - but this was not reflected in the 
postprandial responses. However, as indicated, our population consisted of healthy subjects while the ezetimibe study was performed in type II diabetic subjects. It remains to be determined how postprandial responses are changed after consumption of plant sterols and plant stanols in subjects with elevated TAG concentrations or in subjects with type II diabetes.

\section{Conclusion and future directions}

This thesis describes that fasting oxyphytosterol concentrations differ between low and high oxidizers and between healthy and diabetic subjects. Whether these differences in oxyphytosterol concentrations have an impact on CVD risk remains to be determined in future studies. Fasting oxyphytosterol concentrations were not increased after daily consumption of a plant sterol enriched margarine for a period of 4 weeks, while plant stanol consumption reduced $7 \beta-\mathrm{OH}$-campesterol concentrations and - when standardized for cholesterol also 7-keto-campesterol levels. In addition, high-dose antioxidant supplementation (804 $\mathrm{mg} / \mathrm{d}$ vitamin $\mathrm{E}$ and $600 \mathrm{mg} / \mathrm{d}$ lipoic acid) for a period of 4 weeks did not change plasma or blood cell oxyphytosterol concentrations in type II diabetic subjects. In contrast to fasting oxyphytosterol concentrations, postprandial oxyphytosterol concentrations did increase after plant sterol consumption. Against our expectations, postprandial TAG and apoB48 responses were increased after consumption of a mixed meal rich in plant stanols, which might be explained by a reduced postprandial LPL activity although underlying mechanisms remain to be elucidated.

\section{Future directions regarding oxyphytosterols}

Future studies should be carried out to assess whether oxyphytosterols causes metabolic disturbances and if they are atherogenic as suggested earlier for oxycholesterol concentrations. In addition, relationships between plasma vs. tissue concentrations of oxyphytosterols should be further evaluated, which may also provide insight into the site of oxidation. Furthermore, oxyphytosterol concentrations have only been determined in healthy subjects, in subjects with impaired glucose tolerance or type II diabetes and in phytosterolemic patients. Characterization of oxyphytosterols in other populations, such as patients with atherosclerotic disease or neurodegenerative diseases would expand our knowledge on the role of oxyphytosterol concentrations in the metabolism of (diseased) populations. In addition, measurement of oxyphytosterols in phytosterolemic patients with and without atherosclerotic disease could provide more information on the potential atherogenicity of oxidized plant sterols. Whether oxyphytosterols are derived from endogenous formation of absorption from the diet can only be answered by a study in which labelled non-oxidized plant sterols are consumed and subsequent enrichment in labelled plasma oxyphytosterols is measured. 


\section{Future directions regarding postprandial lipid metabolism}

Postprandial lipid responses were increased after consumption of a mixed meal rich in plant stanols. To provide more insight into postprandial responses after plant sterol and plant stanol consumption, kinetic studies should be performed in which lipoprotein production and clearance can be further evaluated. An increased postprandial lipid response was in contrast to our expectations since fasting TAG may be reduced after plant sterol and stanol consumption. However, this TAG-lowering effect was seen in subjects with elevated baseline TAG concentrations and it would be interesting to assess whether postprandial lipid responses are different in diabetic subjects or in subjects with high baseline TAG concentration compared with healthy subjects.

\section{References}

1. Abumweis SS, Barake R, Jones PJ. Plant sterols/stanols as cholesterol lowering agents: A meta-analysis of randomized controlled trials. Food Nutr Res. 2008;52

2. Demonty I, Ras RT, van der Knaap HC, Duchateau GS, Meijer L, Zock PL, et al. Continuous dose-response relationship of the LDL-cholesterol-lowering effect of phytosterol intake. J Nutr. 2009 Feb;139:271-84.

3. Ras RT, Geleijnse JM, Trautwein EA. LDL-cholesterol-lowering effect of plant sterols and stanols across different dose ranges: a meta-analysis of randomised controlled studies. Br J Nutr. 2014 Jul;112:214-9.

4. Gylling H, Plat J, Turley S, Ginsberg HN, Ellegard L, Jessup W, et al. Plant sterols and plant stanols in the management of dyslipidaemia and prevention of cardiovascular disease. Atherosclerosis. 2014 Feb;232:34660.

5. Robson J. Lipid modification: cardiovascular risk assessment and the modification of blood lipids for the primary and secondary prevention of cardiovascular disease. Heart. 2008 Oct;94:1331-2.

6. Ostlund RE, Jr. Phytosterols in human nutrition. Annu Rev Nutr. 2002;22:533-49.

7. Ostlund RE, Jr., McGill JB, Zeng CM, Covey DF, Stearns J, Stenson WF, et al. Gastrointestinal absorption and plasma kinetics of soy Delta(5)-phytosterols and phytostanols in humans. Am J Physiol Endocrinol Metab. 2002 Apr;282:E911-6.

8. Chan YM, Varady KA, Lin Y, Trautwein E, Mensink RP, Plat J, et al. Plasma concentrations of plant sterols: physiology and relationship with coronary heart disease. Nutr Rev. 2006 Sep;64:385-402.

9. Gylling H, Miettinen TA. The effects of plant stanol ester in different subject groups. Eur Cardiol. 2010;6:18-21.

10. Ras RT, Hiemstra H, Lin Y, Vermeer MA, Duchateau GS, Trautwein EA. Consumption of plant sterol-enriched foods and effects on plasma plant sterol concentrations--a meta-analysis of randomized controlled studies. Atherosclerosis. 2013 Oct;230:336-46.

11. Fransen HP, de Jong N, Wolfs M, Verhagen H, Verschuren WM, Lutjohann D, et al. Customary use of plant sterol and plant stanol enriched margarine is associated with changes in serum plant sterol and stanol concentrations in humans. J Nutr. 2007 May;137:1301-6.

12. Sudhop T, von Bergmann K. Sitosterolemia--a rare disease. Are elevated plant sterols an additional risk factor? Z Kardiol. 2004 Dec;93:921-8.

13. Hansel B, Carrie A, Brun-Druc N, Leclert G, Chantepie S, Coiffard AS, et al. Premature atherosclerosis is not systematic in phytosterolemic patients: severe hypercholesterolemia as a confounding factor in five subjects. Atherosclerosis. 2014 May;234:162-8. 
14. Assmann G, Cullen P, Erbey J, Ramey DR, Kannenberg F, Schulte H. Plasma sitosterol elevations are associated with an increased incidence of coronary events in men: results of a nested case-control analysis of the Prospective Cardiovascular Munster (PROCAM) study. Nutr Metab Cardiovasc Dis. 2006 Jan;16:13-21.

15. Sudhop T, Gottwald BM, von Bergmann K. Serum plant sterols as a potential risk factor for coronary heart disease. Metabolism. 2002 Dec;51:1519-21.

16. Escurriol V, Cofan M, Moreno-Iribas C, Larranaga N, Martinez C, Navarro C, et al. Phytosterol plasma concentrations and coronary heart disease in the prospective Spanish EPIC cohort. J Lipid Res. 2010 Mar;51:618-24.

17. Pinedo S, Vissers MN, von Bergmann K, Elharchaoui K, Lutjohann D, Luben R, et al. Plasma levels of plant sterols and the risk of coronary artery disease: the prospective EPIC-Norfolk Population Study. J Lipid Res. 2007 Jan;48:139-44.

18. Windler E, Zyriax BC, Kuipers F, Linseisen J, Boeing H. Association of plasma phytosterol concentrations with incident coronary heart disease Data from the CORA study, a case-control study of coronary artery disease in women. Atherosclerosis. 2009 Mar;203:284-90.

19. Otaegui-Arrazola A, Menendez-Carreno M, Ansorena D, Astiasaran I. Oxysterols: A world to explore. Food Chem Toxicol. 2010 Dec;48:3289-303.

20. Brown AJ, Jessup W. Oxysterols: Sources, cellular storage and metabolism, and new insights into their roles in cholesterol homeostasis. Mol Aspects Med. 2009 Jun;30:111-22.

21. Brooks CJ, Harland WA, Steel G. Squalene, 26-hydroxycholesterol and 7-ketocholesterol in human atheromatous plaques. Biochim Biophys Acta. 1966 Dec 7;125:620-2.

22. Brooks CJW, R.M. M, W.J. C, J. M, T.D.V. L. 'Profile' analysis of oxygenated sterols in plasma and serum. Biochem Soc Trans. 1983;11:700-1.

23. Grandgirard A, Sergiel JP, Nour M, Demaison-Meloche J, Ginies C. Lymphatic absorption of phytosterol oxides in rats. Lipids. 1999 Jun;34:563-70.

24. Plat J, Brzezinka H, Lutjohann D, Mensink RP, von Bergmann K. Oxidized plant sterols in human serum and lipid infusions as measured by combined gas-liquid chromatography-mass spectrometry. J Lipid Res. 2001 Dec;42:2030-8.

25. Grandgirard A, Martine L, Demaison L, Cordelet C, Joffre C, Berdeaux O, et al. Oxyphytosterols are present in plasma of healthy human subjects. Br J Nutr. 2004 Jan;91:101-6.

26. Husche $\mathrm{C}$, Weingartner $\mathrm{O}$, Pettersson $\mathrm{H}$, Vanmierlo $\mathrm{T}$, Bohm M, Laufs $\mathrm{U}$, et al. Validation of an isotope dilution gas chromatography-mass spectrometry method for analysis of 7-oxygenated campesterol and sitosterol in human serum. Chem Phys Lipids. 2011 Sep;164:425-31.

27. Menendez-Carreno M, Steenbergen H, Janssen HG. Development and validation of a comprehensive twodimensional gas chromatography-mass spectrometry method for the analysis of phytosterol oxidation products in human plasma. Anal Bioanal Chem. 2012 Feb;402:2023-32.

28. Baumgartner S, Mensink RP, Husche C, Lutjohann D, Plat J. Effects of plant sterol- or stanol-enriched margarine on fasting plasma oxyphytosterol concentrations in healthy subjects. Atherosclerosis. 2013 Apr;227:414-9.

29. Schroepfer GJ, Jr. Oxysterols: modulators of cholesterol metabolism and other processes. Physiol Rev. 2000 Jan;80:361-554.

30 Arca M, Natoli S, Micheletta F, Riggi S, Di Angelantonio E, Montali A, et al. Increased plasma levels of oxysterols, in vivo markers of oxidative stress, in patients with familial combined hyperlipidemia: reduction during atorvastatin and fenofibrate therapy. Free Radic Biol Med. 2007 Mar 1;42:698-705.

31. Tuomainen TP, Diczfalusy U, Kaikkonen J, Nyyssonen K, Salonen JT. Serum ferritin concentration is associated with plasma levels of cholesterol oxidation products in man. Free Radic Biol Med. 2003 Oct 15;35:922-8.

32. Szuchman A, Aviram M, Musa R, Khatib S, Vaya J. Characterization of oxidative stress in blood from diabetic vs. hypercholesterolaemic patients, using a novel synthesized marker. Biomarkers. 2008 Feb;13:119-31. 
33. Micheletta F, Natoli S, Misuraca M, Sbarigia E, Diczfalusy U, luliano L. Vitamin E supplementation in patients with carotid atherosclerosis: reversal of altered oxidative stress status in plasma but not in plaque. Arterioscler Thromb Vasc Biol. 2004 Jan;24:136-40.

34. Russell DW. Oxysterol biosynthetic enzymes. Biochim Biophys Acta. 2000 Dec 15;1529:126-35.

35. Garcia-Cruset S, Carpenter KL, Guardiola F, Stein BK, Mitchinson MJ. Oxysterol profiles of normal human arteries, fatty streaks and advanced lesions. Free Radic Res. 2001 Jul;35:31-41.

36. Staprans I, Pan XM, Rapp JH, Feingold KR. Oxidized cholesterol in the diet is a source of oxidized lipoproteins in human serum. J Lipid Res. 2003 Apr;44:705-15.

37. Grandgirard A, Demaison-Meloche J, Cordelet C, Demaison L. Incorporation of oxyphytosterols in tissues of hamster. Reprod Nutr Dev. 2004 Nov-Dec;44:599-608.

38. Plat J, Theuwissen E, Husche C, Lutjohann D, Gijbels MJ, Jeurissen M, et al. Oxidised plant sterols as well as oxycholesterol increase the proportion of severe atherosclerotic lesions in female LDL receptor+/ - mice. Br J Nutr. 2014 Jan 14;111:64-70.

39. Schott HF, Luister A, Husche C, Schafers HJ, Bohm M, Plat J, et al. The relationships of phytosterols and oxyphytosterols in plasma and aortic valve cusps in patients with severe aortic stenosis. Biochem Biophys Res Commun. 2014 Apr 11;446:805-10.

40. Weingartner O, Husche C, Schott HF, Speer T, Boehm BO, miller M, et al. Vascular effects of intraperitoneal applicated sterols, phytosterols and oxyphytosterols in apoE-/-mice. Abstract - Presented at 4th ENOR Symposium. 2014

41. Linseisen J, Wolfram G. Absorption of cholesterol oxidation products from ordinary foodstuff in humans. Ann Nutr Metab. 1998;42:221-30.

42. Tomoyori H, Kawata $\mathrm{Y}$, Higuchi T, Ichi I, Sato H, Sato M, et al. Phytosterol oxidation products are absorbed in the intestinal lymphatics in rats but do not accelerate atherosclerosis in apolipoprotein E-deficient mice. J Nutr. 2004 Jul;134:1690-6.

43. Beaumier-Gallon G, Dubois C, Portugal H, Lairon D. Postprandial studies on dietary cholesterol in human subjects using stable isotopes and gas chromatography-mass spectrometry analysis. Atherosclerosis. 1998 Dec;141 Suppl 1:S81-5.

44. Fielding B. Tracing the fate of dietary fatty acids: metabolic studies of postprandial lipaemia in human subjects. Proc Nutr Soc. 2011 Aug;70:342-50.

45. Silva KD, Wright JW, Williams CM, Lovegrove JA. Meal ingestion provokes entry of lipoproteins containing fat from the previous meal: possible metabolic implications. Eur J Nutr. 2005 Sep;44:377-83.

46. Demonty I, Ras RT, van der Knaap HC, Meijer L, Zock PL, Geleijnse JM, et al. The effect of plant sterols on serum triglyceride concentrations is dependent on baseline concentrations: a pooled analysis of 12 randomised controlled trials. Eur J Nutr. 2013 Feb;52:153-60.

47. Naumann E, Plat J, Kester AD, Mensink RP. The baseline serum lipoprotein profile is related to plant stanol induced changes in serum lipoprotein cholesterol and triacylglycerol concentrations. J Am Coll Nutr. 2008 Feb;27:117-26.

48. Hegele RA, Ginsberg HN, Chapman MJ, Nordestgaard BG, Kuivenhoven JA, Averna M, et al. The polygenic nature of hypertriglyceridaemia: implications for definition, diagnosis, and management. Lancet Diabetes Endocrinol. 2014 Aug;2:655-66.

49. Bansal S, Buring JE, Rifai N, Mora S, Sacks FM, Ridker PM. Fasting compared with nonfasting triglycerides and risk of cardiovascular events in women. Jama. 2007 Jul 18;298:309-16.

50. Nordestgaard BG, Benn M, Schnohr P, Tybjaerg-Hansen A. Nonfasting triglycerides and risk of myocardial infarction, ischemic heart disease, and death in men and women. Jama. 2007 Jul 18;298:299-308.

51. Gylling H, Hallikainen M, Simonen P, Miettinen HE, Nissinen MJ, Miettinen TA. Serum and lipoprotein sitostanol and non-cholesterol sterols after an acute dose of plant stanol ester on its long-term consumption. Eur J Nutr. 2012 Aug;51:615-22. 


\section{CHAPTER 8}

52. Relas H, Gylling H, Miettinen TA. Effect of stanol ester on postabsorptive squalene and retinyl palmitate. Metabolism. 2000 Apr;49:473-8.

53. Relas H, Gylling H, Miettinen TA. Acute effect of dietary stanyl ester dose on post-absorptive alpha-tocopherol, beta-carotene, retinol and retinyl palmitate concentrations. Br J Nutr. 2001 Feb;85:141-7.

54. Jackson KG, Walden CM, Murray P, Smith AM, Lovegrove JA, Minihane AM, et al. A sequential two meal challenge reveals abnormalities in postprandial TAG but not glucose in men with increasing numbers of metabolic syndrome components. Atherosclerosis. 2012 Jan;220:237-43.

55. Jackson KG, Abraham EC, Smith AM, Murray P, O'Malley B, Williams CM, et al. Impact of age and menopausal status on the postprandial triacylglycerol response in healthy women. Atherosclerosis. 2010 Jan;208:246-52.

56. Matikainen N, Adiels M, Soderlund S, Stennabb S, Ahola T, Hakkarainen A, et al. Hepatic lipogenesis and a marker of hepatic lipid oxidation, predict postprandial responses of triglyceride-rich lipoproteins. Obesity (Silver Spring). 2014 Aug;22:1854-9.

57. Bozzetto L, Annuzzi G, Corte GD, Patti L, Cipriano P, Mangione A, et al. Ezetimibe beneficially influences fasting and postprandial triglyceride-rich lipoproteins in type 2 diabetes. Atherosclerosis. 2011 Jul;217:142-8. 
Summary 


\section{Summary}

Cardiovascular disease (CVD) is the leading cause of morbidity and mortality in many parts of the world. Risk factors to develop CVD include cigarette smoking, high blood pressure, diabetes mellitus, obesity and an unfavourable serum lipoprotein profile, such as elevated low-density lipoprotein cholesterol (LDL-C) concentrations. Dietary lifestyle changes are important to reduce CVD risk and in this context the development of functional foods that lower serum LDL-C concentrations has been groundbreaking. Plant sterols and plant stanols are lipid-like compounds that share structural similarities with cholesterol. They consist of a steroid nucleus with a double bond present at C5-C6. There are various plant sterols that differ only in the side-chain configuration. Plant stanols are the saturated derivative of plant sterols. Plant sterols and plant stanols have been incorporated in a variety of functional foods and consumption of approximately $2.5-3.0 \mathrm{~g} / \mathrm{d}$ of plant sterols or plant stanols can lower serum LDL-C concentrations up to $12 \%$. In addition, consuming plant sterol enriched products will increase serum plant sterol concentrations, while the consumption of plant stanols will decrease plant sterol concentrations. Plant sterols are susceptible to oxidation and can form oxyphytosterols, while plant stanols cannot be oxidized since they lack a double bond in their ring structure.

The aim of the studies described in this thesis was to investigate the effects of plant sterol and plant stanol consumption on lipoprotein metabolism and oxyphytosterol concentrations in the fasting and postprandial state and to evaluate the effects of antioxidant supplementation on plasma oxyphytosterol concentrations.

Chapter $\mathbf{2}$ is an overview of the available literature regarding various aspects of using plant sterols and plant stanols in the treatment of dyslipidaemia. Besides the well-known LDL-C lowering effect of plant sterols and plant stanols, this chapter also describes their beneficial effects on triacylglycerol (TAG) concentrations and provides an overview of arguments used in the ongoing debate whether increased plant sterol concentrations are associated with an increased CVD risk. In chapter 3, we investigated the effects of plant sterol and plant stanol consumption on fasting plasma oxyphytosterol concentrations in healthy human subjects. For this, 43 healthy subjects (18-70 years) participated in a randomised, double-blind, cross-over study and consumed for 4 weeks a plant sterol enriched $(3.0 \mathrm{~g} / \mathrm{d}$ of plant sterols), a plant stanol enriched $(3.0 \mathrm{~g} / \mathrm{d}$ of plant stanols), and a control margarine separated by wash-out periods of 4 weeks. Compared with control, LDL-C concentrations were reduced after plant sterol $(-8.1 \%)$ and after plant stanol consumption $(-7.8 \%)$, but oxyphytosterol concentrations were not changed after plant sterol consumption. However, $7 \beta-\mathrm{OH}$-campesterol concentrations were reduced after plant stanol consumption by 0.07 $\mathrm{ng} / \mathrm{mL}(\sim 14 \%)$ and by $0.07 \mathrm{ng} / \mathrm{mL}(\sim 15 \%)$ compared with the control and sterol margarines. We concluded from this study that a daily consumption of a plant sterol enriched margarine for a period of 4 weeks does not increase fasting plasma oxyphytosterol concentrations, 
while minor reductions were seen after plant stanol consumption. This study showed large but consistent differences in oxyphytosterol concentrations between individuals. In chapter 4, we tried to identify factors that might explain these inter-individual differences in plasma oxyphytosterol concentrations. This study demonstrated that plasma oxyphytosterol concentrations do not correlate with serum non-oxidized plant sterol concentrations and that plasma oxyphytosterol concentrations remained relatively stable over time. We identified six subjects with consistently low or high plasma oxyphytosterol concentrations during all three dietary interventions, which were also reflected in oxidized LDL (oxLDL) concentrations. Oxidative and anti-oxidative capacity markers, such as iron/copper status, $\alpha$-tocopherol concentrations and TEAC values were measured but could not explain differences between the high and low plasma oxyphytosterol concentrations. Besides the effect of plant sterol and plant stanol consumption on fasting oxyphytosterol concentrations, we also evaluated postprandial plasma oxyphytosterol concentrations after consumption of a plant sterol or stanol enriched mixed meal (chapter 5). Humans are in a non-fasting state for most part of the day and to investigate effects on oxyphytosterol concentrations during the postprandial state, 10 healthy subjects consumed a shake ( $50 \mathrm{~g}$ of fat, $12 \mathrm{~g}$ of protein, 67 $\mathrm{g}$ of carbohydrates), containing no, or $3.0 \mathrm{~g}$ of plant sterols or plant stanols. Blood samples were taken up to 8 hours and after 4 hours subjects received a second shake (without plant sterols or plant stanols). This postprandial meal test was performed at the end of each of the three intervention periods in which subjects consumed 20 gram of margarine on a daily basis, providing them with no, or 3.0 gram of plant sterols or stanols per day. $7 \beta-\mathrm{OH}$-campesterol and $7 \beta-\mathrm{OH}$-sitosterol concentrations increased after consumption of a mixed meal enriched with plant sterol esters compared with a mixed meal or a mixed meal enriched with plant stanol esters. These higher oxyphytosterol concentrations were particularly present after consumption of a second meal. A comparable postprandial pattern was seen for non-oxidized campesterol and sitosterol concentrations, which also increased after a mixed meal enriched with plant sterol esters compared with a control or plant stanol meal. We speculated whether plasma oxyphytosterols originate from dietary absorption or endogenous formation and suggested that plasma oxyphytosterol concentrations most likely are derived form dietary absorption. However, a definite answer to this question can only be provided by a study in which labelled non-oxidized plant sterols are consumed and enrichment in labelled plasma oxyphytosterols is measured. Recent studies have suggested that consumption of plant sterol and plant stanol enriched products not only lower LDL-C concentration, but also reduce fasting TAG concentrations, especially in subjects with higher TAG concentrations. Since humans are in a non-fasting state for most part of the day and non-fasting serum TAG concentrations are emerging as an important CVD risk marker, we investigated the effects of plant sterol or plant stanol consumption on postprandial lipid and glucose and metabolism (chapter 6). For this, 42 healthy subjects underwent a meal test at the end of each intervention period, in which they consumed a shake containing no, or $3.0 \mathrm{~g}$ of plant sterols or plant stanols. Blood sampling was performed up to 8 hours and 
subjects received a second shake without plant sterols or stanols after 4 hours. Incremental areas under the curves (iAUC) were calculated to evaluate the total (0-8 hours), first meal (0-4 hours) and second meal (4-8 hours) postprandial responses. TAG and apolipoprotein (apo) B48 of the total and first meal response were comparable between the three meals, while TAG and apoB48 responses after the second meal were higher after consumption op the plant stanol enriched shake compared with the control shake and the plant sterol enriched shake. This increased TAG and apoB48 response after the second meal was more pronounced with increasing age and statistically higher compared with the sterol shake than with the control shake. We suggested that consumption of plant stanols might have affected the clearance rate of TAG-rich lipoproteins (TRLs), but to provide more insight into postprandial responses, future studies should assess lipoprotein production and clearance after plant sterol and stanol consumption. As mentioned, we were not able to demonstrate a change in fasting oxyphytosterol concentrations in healthy subjects after consumption of a plant sterol or a plant stanol enriched margarine. In chapter 7, we describe the results of a human intervention study in subjects with impaired glucose tolerance (IGT) or type II diabetes, in which the effects of vitamin E or lipoic acid supplementation on fasting plasma oxyphytosterol concentrations are studied. Twenty subjects with IGT or type II diabetes consumed for 4 weeks placebo capsules, vitamin E capsules (804 mg/d) or lipoic acid capsules $(600 \mathrm{mg} / \mathrm{d})$ and oxyphytosterol concentrations were higher in subjects with IGT or type II diabetes as compared to concentrations in healthy subjects. However, fasting plasma oxyphytosterol were not reduced after consumption of vitamin E or lipoic acid for 4 weeks. In addition, other markers reflecting oxidative stress (oxycholesterol, MDA concentrations and oxidized LDL levels) and antioxidant capacity (TEAC assay, uric acid concentrations and GSH/GSSG) were also not changed after 4 weeks high-dose antioxidant supplementation.

In conclusion, fasting oxyphytosterol concentrations differ between healthy subjects and subjects with impaired glucose tolerance or type II diabetes. In healthy subjects, fasting oxyphytosterol concentrations are not increased after consumption of a plant sterol enriched margarine for 4 weeks, while a plant stanol enriched reduced $7 \beta-\mathrm{OH}$-campesterol concentrations. In addition, vitamin E or lipoic acid consumption did not change fasting oxyphytosterol concentrations in subjects with IGT or type II diabetes. Furthermore, postprandial plant sterol and oxyphytosterol concentrations increased after consumption of a mixed meal enriched with plant sterols compared to a mixed meal alone, or enriched with plant stanols. This increase was particularly evident after the second meal, which is indicative for a second meal response, which has also been described for cholesterol. Finally, postprandial TAG and apoB48 concentrations increased age-dependently after plant stanol consumption as part of a mixed meal, compared to a control meal and a meal rich in plant sterols. 
Samenvatting 


\section{Samenvatting}

Hart- en vaatziekten (HVZ) zijn wereldwijd de belangrijkste oorzaak van ziekte en sterfte. Risicofactoren om HVZ te ontwikkelen zijn roken, een hoge bloeddruk, suikerziekte, overgewicht en een ongunstig serum lipidenprofiel, zoals een verhoogd cholesterolgehalte in de laag-dichtheid lipoproteïnen (LDL-C). Het risico om HVZ te ontwikkelen kan verlaagd worden door het voedingspatroon te veranderen en functionele voedingsmiddelen, die het LDL-C gehalte verlagen, spelen hierbij een belangrijke rol. Plantensterolen en plantenstanolen zijn vetachtige stoffen, die lijken op cholesterol. Zowel plantensterolen als plantenstanolen worden verwerkt in functionele voedingsmiddelen en het LDL-C gehalte kan tot $12 \%$ worden verlaagd als er dagelijks 2.5-3.0 g/d plantensterolen of plantenstanolen worden gegeten. Daarnaast stijgt het gehalte plantensterolen in het bloed na het eten van plantensterolen, terwijl het gehalte plantensterolen in het bloed daalt na het eten van plantenstanolen. Omdat plantenstanolen een iets andere structuur hebben dan plantensterolen, kunnen de plantenstanolen niet oxideren.

Het doel van de studies die beschreven staan in dit proefschrift, was om het effect te onderzoeken van de consumptie van plantensterolen en plantenstanolen op de stofwisseling van lipoproteïnen en oxyphytosterolconcentraties in de gevaste staat en na de maaltijd. Daarnaast zijn de effecten van antioxidant suppletie op plasma oxyphytosterolconcentraties onderzocht.

In hoofdstuk 2 wordt een overzicht weergegeven van de beschikbare literatuur over de verschillende aspecten van het gebruik van plantensterolen en plantenstanolen bij de behandeling van een ongunstig lipidenprofiel. Naast het bekende LDL-C- verlagend effect van plantensterolen en plantenstanolen, worden in dit hoofdstuk ook de gunstige effecten op het triacylglycerol(TAG)-gehaltebeschrevenenerwordteenoverzichtgegevenvan deargumenten die gebruikt worden in de discussie rondom verhoogde plantensterolconcentraties en een verhoogd risico op HVZ. In hoofdstuk 3 onderzochten we de effecten van de consumptie van plantensterolen en plantenstanolen op de gevaste oxyphytosterolconcentraties in gezonde proefpersonen. Aan deze studie hebben 43 gezonde personen (18-70 jaar) deelgenomen en zij hebben gedurende 4 weken een plantensterol-verrijkte $(3.0 \mathrm{~g} / \mathrm{d})$, een plantenstanolverrijkte $(3.0 \mathrm{~g} / \mathrm{d})$ en een controle margarine gegeten, gescheiden door een rustperiode van 4 weken. Ten opzichte van de controle margarine, was het LDL-C gehalte verlaagd na het eten van de plantensterol-verrijkte margarine (-8.1\%) en na het eten van de plantenstanolverrijkte margarine (-7.8\%), maar de oxyphytosterolconcentraties waren niet veranderd na het eten van de plantensterol-verrijkte margarine. Daarentegen waren de $7 \beta$-hydroxy $(\mathrm{OH})$ campesterolconcentraties verlaagd na het eten van de plantenstanol-verrijkte margarine; er was namelijk een verlaging van $0.07 \mathrm{ng} / \mathrm{mL}$ ( 14\%) vergeleken met de controle margarine en een verlaging van $0.07 \mathrm{ng} / \mathrm{mL}(15 \%)$ vergeleken met de plantensterol-verrijkte margarine. Uit deze studie konden we concluderen dat na een dagelijkse consumptie van plantensterol- 
verrijkte margarine gedurende 4 weken, gevaste oxyphytosterolconcentraties niet toenemen, maar dat plasma oxyphytosterolconcentraties enigszins dalen na het eten van plantenstanol-verrijkte margarine. Deze studie toonde aan dat er grote, maar consistente verschillen bestaan in oxyphytosterolconcentraties tussen verschillende mensen. In hoofdstuk 4 hebben we geprobeerd om factoren te vinden die deze verschillen tussen mensen in plasma oxyphytosterolconcentraties zouden kunnen verklaren. Deze studie toonde aan dat plasma oxyphytosterolconcentraties niet correleren met niet-geoxideerde plantensterolconcentraties en dat plasma oxyphytosterolconcentraties relatief stabiel zijn gedurende een langere periode. We identificeerden zes personen met consistente lage of hoge plasma oxyphytosterolconcentraties gedurende alle drie voedingsinterventies. Deze lage of hoge oxyphytosterolconcentraties waren ook terug te zien in de geoxideerde LDL (oxLDL) concentraties. Oxidatieve en antioxidative capaciteit markers, zoals ijzer/ koperstatus, vitamine E-concentraties en TEAC waardes werden gemeten maar deze konden de verschillen tussen de hoge en lage plasma oxyphytosterolconcentraties niet verklaren. Naast het effect van de consumptie van plantensterolen en plantenstanolen op gevaste oxyphytosterolconcentraties, hebben wij ook de plasma oxyphytosterolconcentraties na de maaltijd gemeten na de consumptie van een gemengde maaltijd rijk aan plantensterolen of plantenstanolen (hoofdstuk 5). Tijdens het grootste gedeelte van de dag zijn mensen in een niet-gevaste staat en om het effect op de oxyphytosterolconcentraties na de maaltijd te onderzoeken, hebben 10 gezonden proefpersonen een shake gegeten $(50 \mathrm{~g}$ vet, $12 \mathrm{~g}$ eiwit, $67 \mathrm{~g}$ koolhydraten), met of zonder $3.0 \mathrm{~g}$ plantensterolen of plantenstanolen. Gedurende deze 8-uur durende testdag werden bloedmonsters afgenomen en na 4 uur werd weer een shake gegeten, maar nu zonder toegevoegde plantensterolen of plantenstanolen. Deze testdag werd uitgevoerd aan het einde van elk van de drie interventieperioden waarbij proefpersonen dagelijks 20 gram margarine hebben gegeten (met of zonder $3.0 \mathrm{~g}$ plantensterolen of plantenstanolen). $7 \beta-\mathrm{OH}$-campesterol- en $7 \beta-\mathrm{OH}$-sitosterolconcentraties waren verhoogd na het eten van de plant sterol-verrijkte shake vergeleken met de plant stanol-verrijkte shake en de controle shake. Oxyphytosterolconcentraties waren vooral hoger na het eten van de tweede shake. De niet-geoxideerde campesterol- en sitosterolconcentraties vertoonden een vergelijkbaar patroon na de maaltijd, aangezien deze ook toenamen na het eten van de plant sterol-verrijkte shake vergeleken met de plant stanol-verrijkte shake en de controle shake. De vraag of plasma oxyphytosterolconcentraties afkomstig zijn uit de voeding of dat deze gevormd worden in het lichaam, kan alleen worden beantwoord door gelabelde niet-geoxideerde plantensterolen te eten en vervolgens een verrijking in gelabelde plasma oxyphytosterolen te meten in het bloed. Recente studies hebben gesuggereerd dat de het eten van producten verrijkt met plantensterolen en plantenstanolen niet alleen het LDL-C gehalte verlagen maar ook het TAG gehalte in het bloed kunnen verlagen, vooral bij personen met verhoogde TAG-concentraties. Aangezien mensen het grootste gedeelte van de dag in een niet-gevaste staat zijn en niet-gevaste TAGconcentraties een belangrijke risicofactor zijn om HVZ te ontwikkelen, onderzochten wij het 
effect van het eten van plantensterolen en plantenstanolen op de vet- en glucosestofwisseling na de maaltijd (hoofdstuk 6). Om dit te onderzoeken, hebben 42 gezonden proefpersonen aan het einde van elk van de drie interventieperioden een shake gegeten (met of zonder $3.0 \mathrm{~g}$ plantensterolen of plantenstanolen). Bloedafnames werden afgenomen tot 8 uur na het eten van de shake en na 4 uur werd weer een shake gegeten, maar nu zonder toegevoegde plantensterolen of plantenstanolen. De oppervlakte onder de curves (iAUC) werden berekend om de responsen na de maaltijd te vergelijken tussen de interventies en dit werd gedaan voor de totale periode (0-8 uur), de periode na de eerste maaltijd (0-4 uur) en de periode na de tweede maaltijd (4-8 uur). De TAG en apolipoproteine (apo)B48concentraties na de totale en de eerste maaltijd responsen waren vergelijkbaar tussen de drie interventies, waarbij TAG en apoB48 responsen na de tweede maaltijd hoger waren na het eten van een plant stanol-verrijkte shake vergeleken met de plant sterol-verrijkte shake en de controle shake. Deze verhoogde TAG en apoB48 responsen na de tweede maaltijd waren meer uitgesproken met toenemende leeftijd en hoger in vergelijking met de plant sterol verrijkte-shake dan met de controle shake. We suggereerden dat de consumptie van plantenstanolen een effect zou kunnen gehad op de klaring van TAG-rijke lipoproteïnen (TRL), maar om meer inzicht te krijgen in de responsen na het eten van producten rijk aan plantensterolen en plantenstanolen, zal de productie en de klaring van lipoproteïnen verder moeten worden bestudeerd in toekomstige studies. Zoals al eerder hier beschreven, hebben wij geen verandering gevonden in gevaste oxyphytosterolconcentraties na het eten van een margarine rijk aan plantensterolen of plantenstanolen. In hoofdstuk 7 beschrijven we de resultaten van een studie in personen met een verminderde glucosetolerantie (IGT) of met type II diabetes, waarbij de effecten van vitamine $E$ of liponzuur suppletie op gevaste oxyphytosterolconcentraties worden bestudeerd. Twintig proefpersonen met IGT of diabetes type II hebben gedurende 4 weken elke dag placebo capsules, vitamine E capsules (804 mg/d) of liponzuur capsules $(600 \mathrm{mg} / \mathrm{d}$ ) ingenomen en oxyphytosterolconcentraties waren hoger bij proefpersonen met IGT of diabetes type II in vergelijking met gezonde proefpersonen. Echter, na de inname van vitamine $\mathrm{E}$ of liponzuur gedurende 4 weken was er geen verlaging in de gevaste oxyphytosterolconcentraties. Daarnaast waren andere markers die oxidatieve stress weergeven (oxycholesterol, MDA-concentraties en oxLDL) en antioxidant weergeven in het lichaam (TEAC assay, urinezuur en GSH/GSSG) ook niet veranderd na een hoge dosis antioxidant inname gedurende 4 weken.

In conclusie, gevaste oxyphytosterolconcentraties verschillen tussen gezonde proefpersonen en proefpersonen met een verminderde glucosetolerantie of diabetes type II. Het eten van een plant sterol-verrijkte margarine gedurende 4 weken zorgt niet voor een toename in gevaste oxyphytosterolconcentraties in gezonde proefpersonen, terwijl $7 \beta-\mathrm{OH}$-campesterolconcentraties verlaagd waren na het eten van een plant stanol-verrijkte margarine. Bovendien heeft de inname van vitamine $E$ of liponzuur geen effect op gevaste oxyphytosterolconcentraties bij personen met IGT of diabetes type II. Daarnaast waren 
plantensterol en oxyphytosterolconcentraties na de maaltijd verhoogd na het eten van een gemengde maaltijd verrijkt met plantensterolen in vergelijking met een gemengde maaltijd alleen, of een maaltijd verrijkt met plantenstanolen. Deze toename was vooral duidelijk te zien na het eten van een tweede maaltijd, wat duidt op een tweede maaltijd response zoals al eerder werd beschreven voor cholesterol. Tenslotte stijgen postprandiale TAG- en apoB48-concentraties na het eten van een plant stanol-verrijkte shake vergeleken met een plant sterol-verrijkte shake en een controle shake, een effect wat meer uitgesproken is met toenemende leeftijd. 

Dankwoord 


\section{Dankwoord}

Jeej, eindelijk is mijn proefschrift oftewel 'het boekje' dan af! Ik heb er de afgelopen jaren met veel plezier aan gewerkt en ik wil graag iedereen bedanken die op welke manier dan ook hieraan heeft bijgedragen.

Allereerst wil ik mijn promotoren bedanken voor alle steun en begeleiding die ik heb mogen ontvangen tijdens mijn promotietraject. Beste Jogchum, bedankt voor de kans die je me gegeven hebt en voor het overbrengen van je enthousiasme voor voedingsonderzoek. Je had altijd tijd voor vragen, ik heb veel van je geleerd en heb met veel plezier met je samengewerkt. Samen hebben we veel congressen bezocht, wat naast de gezelligheid ook heel leerzaam was, bedankt voor alles.

Beste Ronald, bedankt voor je betrokkenheid, het delen van je uitgebreide kennis en je kritische blik op mijn manuscripten. Bedankt ook voor de fijne samenwerking, dat ik altijd bij je terecht kon met vragen en het geduld wat je nam om deze samen met mij te beantwoorden. Ik heb ontzettend veel van je geleerd en wil je daar graag voor bedanken. Daarnaast, vond ik het erg leuk om op maandagochtend de stand van zaken in het amateurvoetbal of tennis samen door te nemen!

I would like to thank the members of my assessment committee; Prof. dr. A.A.M. Masclee, Prof. dr. E.E Blaak, Prof. dr. F-J. van Schooten, Prof. dr. E.A. Trautwein and Dr. O. Weingärtner for their time to review my thesis.

I would also like to thank Prof. dr. D. Lütjohann and his team in Bonn for the countless plant sterols and oxyphytosterol measurements and I hope we can continue our nice collaboration in the future.

Het uitvoeren van voedingsonderzoek zou niet mogelijk zijn zonder de medewerking van proefpersonen, dus ik wil graag alle proefpersonen bedanken voor hun interesse en deelname aan mijn studies!

Ik heb een ontzettende leuke tijd gehad bij Human Biologie en dit komt mede door de samenwerking met vele fijne collega's. Zowel op het werk als daarbuiten heb ik genoten van de gezelligheid en ik had alle dagjes uit, weekendjes weg, carnavals in de Perroen en kerstdiners niet willen missen! In de afgelopen jaren heb ik veel hulp gehad en ik wil dan ook graag de dames van het secretariaat, alle analisten, technische ondersteuning en prikhelpers bedanken voor alle werk en hulp in de afgelopen jaren! Martine, Maud en Maurice, bedankt voor alle lipiden, glucose, oxyphyto-metingen en ELISA's, zonder jullie had ik dit nooit allemaal kunnen opschrijven! Onze diëtistes, Yvonne, Nina en Daisy, bedankt voor alle hulp tijdens de testdagen en het klaarmaken van alle milkshakes en ontbijtjes. 
Leonie en Chris, jullie zijn mijn eerste kamergenootjes geweest, samen hebben we een leuke tijd gehad en ik vond het een grote eer om paranimf bij jullie te zijn. Leonie, als snel nadat we kamergenootjes werden, zijn wij ook vriendinnen geworden. Je bent een van de liefste mensen die ik ken en ik hoop dat we nog vaak op meiden-date gaan met Sanne en Tineke in Mestreech. Chris, wij konden het meteen goed met elkaar vinden en tijdens ons promotietraject samen hebben we dan ook een leuke vriendschap ontwikkeld. Ik verheug me om nog vaker met jou, Kelly en Ron samen gezellig te eten of ons eentje te drinken! Mijn andere kamergenootjes, Daisy, Nina, Peter en Sophie, bedankt voor alle gezelligheid, koffie/thee pauzes en (niet)-wetenschappelijke discussies. Dorien, ik vind het heel leuk om samen met zo'n lieve vriendin een kamer te delen, bedankt voor de gezelligheid en de leuke gesprekken tussen het werken door. Andere collega's en oud-collega's, Florence, Noud, Carla, Ioanna, Herman, Els, Nadine, Lotte en Charlotte, bedankt voor alle hulp en gezelligheid de afgelopen jaren. Jos, bedankt voor je eeuwige inzet voor de vakgroep. Dorien R., bedankt voor je positieve invloed op de vakgroep. Tineke, ik bewonder je om je werklust en je enthousiasme en ik hoop dat we nog vaak leuke tripjes gaan maken. ledereen bij $\mathrm{HB}$, bedankt voor de leuke tijd!

Ik wil ook graag mijn paranimfen bedanken. Sanne, wij leerden elkaar kennen tijdens onze studie en na ons avontuur in Spanje, zijn we samen aan ons promotietraject kunnen beginnen. Je bent een van de meest oprechte mensen die ik ken en ik vond het heel leuk om dit traject samen met je te doorlopen. Ik wil je graag bedanken voor alle hulp, advies en leuke gesprekken tijdens deze jaren en ik ben blij dat je vandaag naast me staat! Jill, we kennen elkaar al sinds de middelbare school en na onze tijd in de Wyckergrachtstraat zijn we echt goede vriendinnen geworden. Sinds die tijd hebben we samen veel meegemaakt en ik geniet van onze gesprekken, etentjes en avondjes uit. Ik verheug me om samen nog veel leuke dingen mee te maken. Ik vond het bijzonder om jouw paranimf te zijn en ik vind het fijn dat jij er vandaag voor mij bent!

Mijn lieve vriendinnetjes, Dorien, Femke, Florieke, Peggy en Renee wil ik ook graag bedanken. Ook al zien we ons niet meer zo vaak als dat we zouden willen, vind ik het fijn om weten dat ik zo'n lieve vriendinnetjes om mij heen heb waar ik altijd op kan rekenen! Bedankt voor jullie interesse in mijn werk en voor de welkome afwisseling van mijn proefschrift tijdens weekendjes samen. We hebben lief en leed gedeeld in de afgelopen jaren en ik kijk ernaar uit om dit nog heel veel jaren samen te blijven doen, ik hou van jullie sjatjes!

Marcel, Tiny, Eva en Jaap, bedankt voor jullie steun en interesse in mijn werk de afgelopen jaren. Vanaf dag 1 voel ik me ontzettend welkom in jullie gezin en ik wil jullie graag bedanken voor alles wat jullie doen voor Ron en mij. Ik had me geen betere schoonfamilie kunnen wensen! 
Thomas en Milou, wat ben ik blij met zo'n lieve broer en schoonzus om de hoek. Bedankt voor alle interesse in mijn onderzoek en ook zeker voor alle hulp in de afgelopen jaren (op welk vlak dan ook). Thomas, ik kan altijd op je rekenen en ik ben trots dat jij mijn broer bent!

Lieve papa en mama, ik kan jullie niet genoeg bedanken voor alles wat jullie voor mij gedaan hebben. Bedankt voor jullie onvoorwaardelijke steun, jullie liefde en voor alle kansen die jullie mij gegeven hebben, dankzij jullie ben ik de persoon geworden die ik nu ben. Ik hou van jullie!

Lieve Ron, ik wil je graag bedanken voor je steun en je geduld tijdens mijn promotietraject en voor het aanhoren van (soms lastige) oxyphyto-praatjes. Wij zijn al heel wat jaartjes samen en ik verheug me om nog heel veel mooie jaren samen mee te maken. Ik kijk ernaar uit om samen een gezin met jou te stichten. Bedankt voor je liefde lieve schat, ik hou heel veel van je! 
Curriculum Vitae 


\section{Curriculum Vitae}

Sabine Baumgartner was born on December 25th 1985 in Heerlen, the Netherlands. She completed secondary school at the Sintermeerten College in Heerlen in 2004 and she started her study Health Sciences at Maastricht University in the same year. She performed internships at the department of Human Biology with an additional internship of 6 months at the Universidad de Navarra in Pamplona, Spain and she obtained her Master's degree for the European master of Metabolism and Nutrition in January 2009. After graduation, she worked as a research assistant at the department of Human Biology of Maastricht University under the supervision of prof. dr. ir. R.P. Mensink, where she conducted a human intervention trial investigating the effects of interesterified dietary fats in collaboration with King's College London. In September 2009, she was appointed as a PhD-student under supervision of prof. dr. ir. R.P. Mensink and prof. dr. J. Plat at the department of Human Biology of Maastricht University. She conducted several nutritional human intervention trials to investigate the effects of plant sterol and plant stanol consumption on fasting and postprandial oxyphytosterol concentrations and their effects on postprandial glucose and lipoprotein concentrations. In 2011, she was awarded with a best poster award at the European Atherosclerosis Congres (EAS) in Göteborg, Sweden and in 2014 she was awarded with the Foppe ten Hoor Young Investigator Award at the Nutritional Science Days (NSD) in Deurne, the Netherlands. 


\section{List of publications}




\section{List of publications}

Baumgartner S, Mensink RP, Konings M, Schött H-F, Friedrichs S, Husche C, Lütjohann D, and Plat J. Postprandial plasma oxyphytosterol concentrations after consumption of a plant sterol- or stanolenriched high-fat meal in healthy subjects. Conditionally accepted

Filippou A, Berry SE, Baumgartner S, Mensink RP, Sanders TA. Palmitic acid in the sn-2 position decreases glucose-dependent insulinotropic polypeptide secretion in healthy adults. Eur J Clin Nutr. 2014; May;68(5):549-54

Baumgartner S, Mensink RP, den Hartog G, Bast A, Bekers O, Husche C, Lütjohann D, Plat J. Oxyphytosterol formation in humans; identification of high vs. low oxidizers. Biochem Pharmacol 2013 Jul 1;86(1):19-25

Baumgartner S, Mensink RP, Husche C, Lütjohann D, Plat J. Effects of plant sterol- or stanol-enriched margarine on fasting oxyphytosterol concentrations in healthy subjects. Atherosclerosis. 2013 Apr;227(2):414-9

Baumgartner S, Kelly ER, van der Made S, Berendschot TTJM, Husche C, Lütjohann D, Plat J. The influence of consuming an egg or an egg-yolk drink for 12 weeks on serum lipids, inflammation and liver function in human volunteers. Nutrition 2013 Oct;29(10):1237-44

Plat J, McKay D, Baumgartner S, Clifton PM, Gylling H, Jones PJH. Progress and prospective of plant sterol and stanol research; Report of the Maastricht meeting. Atherosclerosis. 2012 Dec;225(2):521-33

Baumgartner S, Mensink RP, Plat J. Plant sterols and stanols in the treatment of dyslipidemia: new insights into targets and mechanisms related to cardiovascular risk. Curr Pharm Des. 2011; 17(9): 92232

Sanders TAB, Filippou A, Berry SE, Baumgartner S, Mensink RP. Palmitic acid in the sn-2 position of triacylglycerols acutely influences postprandial lipid metabolism. Am J Clin Nutr. 2011; Dec;94(6):143341

\section{Submitted manuscripts}

Baumgartner S, Mensink RP, Plat J. Effects of a plant sterol or stanol enriched mixed meal on postprandial lipid and glucose metabolism in healthy subjects. Submitted

Baumgartner S, Mensink RP, Haenen G, Bast A, Binder CJ, Bekers O, Husche C, Lütjohann D, Plat J. Effects of vitamin E or lipoic acid supplementation on fasting oxyphytosterol concentrations in subjects with impaired glucose tolerance or type II diabetes. Submitted 


\section{Presentations}

Baumgartner S, Mensink RP, Plat J. Effect of plant sterol and plant stanols on CVD risk: do oxyphytosterols play a role? Presented at The Dutch Nutritional Science Days (NSD) 2014 in Deurne, The Netherlands. Oral presentation

Awarded with the Foppe ten Hoor young investigator award

Baumgartner S, Mensink RP, Konings M, Schött H-F, Friedrichs S, Husche C, Lütjohann D, Plat J. Fasting vs. postprandial plasma oxyphytosterol concentrations: endogenous formation or uptake? Presented at the 4th ENOR symposium in Coimbra, Portugal, 2014. Oral presentation

Baumgartner S, Mensink RP, Plat J. Effects of a plant sterol- or stanol-enriched high-fat meal on postprandial lipid and glucose metabolism in healthy subjects. Presented at the European Atherosclerosis Society (EAS) Congress 2014 in Madrid, Spain. Poster presentation

Baumgartner S, Mensink RP, Plat J. Effects of a plant sterol- or stanol-enriched high-fat meal on postprandial lipid and glucose metabolism in healthy subjects. Presented at 43 . Jahrestagung des arbeitskreises "Klinischer Lipidstoffwechsel", Maikammer, Germany, 2013. Oral presentation

Baumgartner S, Mensink RP, Plat J. Effects of a plant sterol- or stanol-enriched high-fat meal on postprandial lipid and glucose metabolism in healthy subjects. Presented at The Dutch Nutritional Science Days (NSD) 2013 in Deurne, The Netherlands. Oral presentation

Baumgartner S, Mensink RP, den Hartog G, Lütjohann D, Plat J. Oxyphytosterol formation in humans; how to identify high vs. low oxidizers. Presented at the European Atherosclerosis Society (EAS) Congress 2013 in Lyon, France. Poster presentation

Baumgartner S, Mensink RP, den Hartog G, Lütjohann D, Plat J. Oxyphytosterol formation in humans; how to identify high vs. low oxidizers. Presented at the $2^{\text {nd }}$ ENOR symposium in Dijon, France, 2012. Oral presentation

Baumgartner S, Mensink RP, Husche C, Lütjohann D, Plat J. Effects of plant sterol- or stanol-enriched margarine on serum oxyphytosterol concentrations in healthy subjects. The Dutch Nutritional Science Days (NSD) 2011 in Deurne, The Netherlands. Oral presentation

Baumgartner S, Mensink RP, Husche C, Lütjohann D, Plat J. Effects of plant sterol- or stanol-enriched margarine on serum oxyphytosterol concentrations in healthy subjects. Presented at the European Atherosclerosis Society (EAS) Congress 2011 in Gothenburg, Sweden. Poster presentation

This poster presentation was awarded with a best poster award.

Baumgartner $\mathbf{S}$ and Mensink RP. The acute effects of triacylglycerol structure of palmitic acid-rich fats on postprandial metabolism. Presented at The Dutch Nutritional Science Days (NSD) 2010 in Deurne, The Netherlands. Oral presentation

Baumgartner S, Mensink RP, Plat J. The influence of daily egg consumption on serum lipid concentrations and cardiovascular risk markers in humans. Presented at The Dutch Nutritional Science Days (NSD) 2009 in Deurne, The Netherlands. Oral presentation 